\title{
A equiidade como princípio norteador da identificação de necessidades relativas ao controle dos agravos respiratórios na infância
}

ANNA MARIA CHIESA

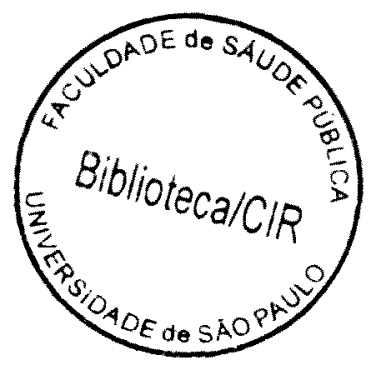

Tese de Doutorado apresentada ao Departamento de Prática de Saúde da Faculdade de Saúde Pública da Universidade de São Paulo para obtençào do título de Doutor

Area de concentraçào

Serviços de Saude Pública

ORIENTADORA: PROFA. DRA. MARCIA

FARIA WESTPHAL

CO-ORIENTADOR: DR. MARCO AKERMAN

Sào Paulo

1999 
Autorizo, exclusivamente para fins acadèmicos e cientificos, a reprodução total ou parcial desta tese. por processos totocopiadores.

Assinatura

Data

38511199 doc 
Dedicatória

A minha mãe, pela ajuda incondicional.

Aos meus filhos, Mariana, Bruno e (justavo pela convivencia carinhosa e tolerante no cotidiano.

Ao Roberto, pelo estimulo e incentivo afetuosos sempre presentes. 


\section{Agradecimentos}

Muitas pessoas participaram de forma decisiva para a realização deste trabalho. É com o intuito de agradecer sinceramente pela colaboração de todas que passo a mencioná-las.

A Prof. Tit. Marcia Faria Westphal, orientadora e parceira na realização deste trabalho, pelo estímulo constante, pela compartilha de conhecimentos e principalmente, pela confiança e carinho que sempre dedicou-me nestes anos de orientação.

Ao Dr Marco Akerman, co-orientador, pela valiosa contribuição na realização deste trabalho, marcada pela seriedade e compromisso na avaliação e disponibilização de conhecimentos fundamentais para a transformação do projeto inicial no atual trabalho.

A Prof Tit. Nelly Martins F. Candeias, pelas contribuições apresentadas e pela dedicação e cuidado ao apreciar o trabalho

A Prof Tit Rosa Maria Godoy Serpa da Fonseca. colega do Departamento de Enfermagem em Saude Coletiva, pela confiança que sempre manifestou, fundamental para o meu aprimoramento profissional.

A Prof. Dra. Maria Rita Bertolozzi, colega do Departamento ENS, pela compartilha nos momentos dificeis em que valorizou e incentivou a realização deste trabalho, além das contribuições apresentadas.

A Prof. Dra. Maria Amélia de Campos Oliveira, colega do Departamento ENS, pela colaboração em diversos momentos do desenvolvimento da pesquisa e pela atenção cuidadosa no cotidiano do trabalho.

A todas as colegas do Departamento ENS. pela convivència cotidiana e pelo incentivo nos dificeis momentos de sobreposiçào do trabalho.

Aos colegas da Escola de Enfermagem da USP, especialmente Luciana Sanches Silva. Andréia Roma da Costa. Ricardo Matos Castellani, Ana Maria Sanches Garcia. Terezinha Amaro dos Reis Alves, Neusa da Silva Oliveira, funcionários do Departamento ENS. e aos demais funciionarios do Centro de Informática, do Serviço de Biblioteca. do Setor de Reprografia e do Setor de Transportes, pelo apoio indispensavel.

A Maria Aparecida Mendes do Serviço de Aprimoramento da Faculdade de Saúde Pública, pela cordialidade e atenção sempre dispensados

As colegas que constituem o Grupo de Trabalho do Projeto Respira e às que integram o Grupo de Estudos de Promoçào à Saúde, pelas inúmeras e proficuas discussões que auxiliaram o delineamento deste trabalho. 
Aos profissionais e funcionários do Centro de Saude Escola Prof. Samuel B. Pessoa. especialmente Sra. Ivete P. Andrade, Enf. Diane Cohen e Dr. Rubens Kon, pela participação nas discussões e pelo atendimento sempre cordial e atencioso em todos os momentos.

Aos profissionais do IBGE, PROAIM, CETESB, CET, Laboratório de Geoprocessamento da Escola Politécnica da USP, pela disponibilização das informações necessárias para o desenvolvimento deste trabalho e pela atenção.

Ao Rodrigo Andrade Tavares, pela valiosa contribuição na assessoria estatística.

Ás alunas da EEUSP, Bolsistas de Iniciação Cientifica, Nea Miwa Kashiwagi e Karla de Freitas, pela responsabilidade demonstrada e sobretudo pelos desafios compartilhados com seriedade e competência,

A todas as pessoas que participaram voluntariamente das discussões desencadeadas, pela contribuição especial.

A população da região estudada. pela gentileza com que nos atendeu.

A Fundação de Amparo à Pesquisa do Estado de São Paulo. FAPESP. pelo apoio financeiro disponibilizado ao projeto. 


\section{Resumo}

\section{Chiesa AM. A eqüidade como princípio norteador da identificação de necessidades relativas ao controle dos agravos respiratórios na infância. São Paulo; 1999. [ Tese de Doutorado - Faculdade de Saúde Pública da USP]}

Objetivo. A presente pesquisa centra-se na perspectiva de identificar as desigualdades sociais que se configuram em condições de risco para as doenças respiratórias na infância. presentes no território de abrangència de uma determinada Unidade Básica de Saúde conhecer as necessidades sentidas pelas familias residentes na referida área, relativas ao cuidado das crianças na vigência de agravos, bem como identificar as iniquiidades a partir da análise das necessidades e enfrentamentos propostos pelos diferentes grupos. Para tal, realizou-se um estudo analitico associando-se técnicas quanti-qualtitativas em duas etapas distintas. Método. A primeira etapa centrou-se na caracterização do território de abrangência do Centro de Saúde Escola Samuel B. Pessoa, delimitando-se os setores censitários componentes da área e utilizando-se indicadores compostos de inserção social e de qualidade dos domicílios para identificar as diferentes condições de exposição ambiental para as doenças respiratórias no território. A construção dos indicadores utilizou dados secundários fornecidos pelo IBGE. após tratamento estatístico, para a caracterização da população residente nos 49 setores censitários. Com isso, pôde-se identificar quatro grupos homogèneos em termos de potencial de exposição às condições de risco para doenças respiratórias. Numa segunda etapa, foram entrevistadas 64 famílias residentes na área para conhecer as dificuldades relatadas pelas mesmas na vigència de agravos respiratórios nas crianças menores de cinco anos de idade e os enfrentamentos apontados para a diminuição dos referidos problemas. Resultados. Foram identificados quatro grupos homogèneos em termos de exposição às condições de risco no território estudado e diferentes necessidades que subsidiam açōes de cunho intersetorial para a diminuição das mesmas. As iniquidades constatadas relacionam-se à capacidade das familias de controlar o processo doentio e a superação se dá a partir de reformulações nos serviços de saúde, no atendimento das creches e na maior divulgaçào de mecanismos de controle da poluição do ar

Descritores: Iniqüidades em saude. Controle das IRA no nivel local Promoção à Saúde. Indicadores Compostos. 


\section{Summary}

Chiesa AM. A equiidade como principio norteador da identificaça de necessidades relativas ao controle dos agravos respiratórios na infância [Equity as a guiding principle to the identification of needs in respiratory disease control in childhood]. São Paulo (BR), 1999. [Tese de DoutoradoFaculdade de Saude Pública da Lniversidade de São Paulo]

Objective. The present research is centered in the perspective of: to identify social inequalities which configure risk conditions for respiratory diseases in the childhood in the territory of inclusion of a certain Basic Health Care Unit, to know the needs mentioned by resident families in referred area. related to their children care during the disease, as well as, to identify inequities from the analysis of these needs and changes proposed by different social groups. For such. an analytic study took place associating quantiqualitative technics that involved two different stages. Method. The first stage was centered in the characterization of the territory of inclusion of the Health Care Unit, and the census tracts that composed the area were identified throught composed indicators of social insertion and of quality of the homes to identify the different conditions of environmental exposition to respiratory diseases in the territory. To the construction of these indicators secondary data were used by the IBGE. after statistical analyses. for the characterization of the resident population in the 49 census tracts. With that. four homogeneous groups were identified in terms of potential exposition to risk conditions for respiratory diseases. In a second stage, 64 resident families were interviewed in the area. in order to know the difficulties identified by them during the episodes of respiratory diseases in children less than five years old and the changes pointed for the decrease of the referred problems. Results It was possible to identify four homogeneous groups in terms of exposition to risk conditions in the studied territory and their different needs that subsidize intersectorial actions for the decrease of these diseases. The observed inequities are linked to empower families in controlling the illness process and its overcoming. starting trom changes in health services, in nurseries and in amplifying the diffusion of mechanisms to control air pollution.

Descriptors: Iniquities in health. ARI control in local level Health Promotion. Composed indicators 


\section{INDICE}

I INTRODUÇÃO |

1.1 Epidemiologia dos Agravos respiratorios na população infảntil 2

1.2 Os Fatores de risco associados as IRA

1.3 As possibilidades de controle das IRA no contexto das politicas de saude no Brasil

2 A CONCEPCÃO DA PESQUISA 20

2.1 Delimitação do problema $\quad 32$

2.2 Objetivo Geral 36

2.3 Objetivos Especificos 36

; CAMINHO METODOLOGICO 37

3.1 Descrição do cenario de estudo

3.2 A população de estudo $\quad 40$

3.3 Referencial de Analise 40

3.3.1 O processo de territorialização em saúde no contexto da globalização 43

$\begin{array}{ll}3.4 \text { As etapas do processo } & 48\end{array}$

3.5 Fundamentação das categorias analíticas $\quad 50$

3.5.1 Dimensão objetiva $\quad 50$

352 Dimensào Subjetiva

4 CARACTERIZAC İO DO CENARIO DO ESTLDO 64

+ 1 Historico do Poroamento da Região do Butantã 04

42 Qualidade do $\mathrm{Ar}$

4.3 Caracterização das micro regiòes do estudo $\quad 70$

4.40 Processo de construção do Indice de Potencial de Exposição

as Condiçòes de Risco para as doenças respiratorias na infầncia 76

4.50 territorio a partir das desigualdades nas condiçōes de vida $\quad 108$

氵AS PERCEPCÕES DOS GRUPOS SOBRE A VIVÉNCIA E O

CONTROLE DAS DOENC AS RESPIRATORIAS NAINFȦNCIA 118

$\begin{array}{ll}5.1 \text { Caracterizaçào das tamilias entrevistadas } & 118\end{array}$

$\begin{array}{ll}5.2 \text { Os problemas de saude mencionados } & 120\end{array}$

$\begin{array}{ll}5.3 \text { As dificuldades no adoecimento da criança } & 127\end{array}$ 
5.4 As percepções dos entrevistados sobre possiveis causas

relacionadas às IRA

5.5 Os enfrentamentos apontados

6. A PROMOC̃̃O Ȧ SAÚDE E AS INIQÜIDADES : PROPOSTAS PARA SUPERAÇÃO

6.1 A Identificação das iniqüidades 163

6.2 A determinação das iniqüidades 176

6.3 Encaminhamentos para a superação das iniqüidades 184

7. CONCLUSÃO 191

REFERÊNCIAS BIBLIOGRÁFICAS 194 ANEXOS 
Introaução 


\section{Introdução}

O interesse pelo desenvolvimento deste estudo veio se consolidando nos últimos quatro anos a partir do trabalho realizado junto ao Projeto RESPIRA, vinculado ao Núcleo de Apoio às Atividades de Cultura e Extensão: Assistência de Enfermagem em Saúde Coletiva (NACE:AENSC), através do qual pude participar de reuniões técnicas e cursos de capacitação para profissionais de saúde na temática de controle das Infecções Respiratórias Agudas (IRA); além da possibilidade de promover oficinas de capacitação e divulgação da estratégia de controle das IRA, em âmbito regional e nacional.

Espero que as questões aqui abordadas possam contribuir para a construção de uma proposta metodológica de identificação da realidade local. onde a atenção primária à saúde acontece, buscando o fortalecimento do Sistema Único de Saúde. Trata-se de um exercício de aproximação ao conhecimento de determinada área geográfica que constitui território de assistência de um Centro de Saúde da Universidade de São Paulo. o Centro de Saúde Samuel Barnsley Pessoa. Nesta aproximação. foram utilizados métodos quantitativos e qualitativos, tendo em vista a captação da realidade de forma mais abrangente, seguindo-se as atuais proposições do campo da Promoção e Educação em Saúde, através da ação intersetorial nos setores públicos de atuação. A finalidade é intervir na origem dos problemas e não somente nos seus resultados, que constituem. via de regra, problemas de saúde observados.

Optei por realizar a investigação a partir da perspectiva do controle das doenças respiratórias na população infantil, que constitui uma demanda concreta e relevante em termos de morbidade na região estudada. Vale destacar que encontra-se em fase de desenvolvimento um projeto de pesquisa interinstitucional. intitulado Projeto de Identificação de Fatores Associados às Doenças Prevalentes na Infầncia que integra docentes da Escola de Enfermagem da USP, docentes da disciplina de Pediatria Social da Faculdade de Medicina da USP e profissionais do Centro de Saúde Escola Samuel B. Pessoa. Tal projeto foi elaborado com apoio da Organização Panamericana da Saúde e do Ministério da Saúde e visa. principalmente, caracterizar 
a população usuária do referido Centro de Saúde. identificando os fatores associados ao processo de adoecimento entre as crianças menores de cinco anos atendidas pelo referido Centro de Saúde. Pretende-se com isso, reconhecer características que serviriam como "marcadores" de risco, hierarquizando os problemas existentes, para adequar a assistência oferecida, atendendo ao princípio da eqüidade, aprimorando a qualidade da assistência à criança com IRA.(BERTOLOZZI, et al. 1998). A escolha do Centro de Saúde Escola Samuel B. Pessoa para o desenvolvimento da presente pesquisa também se deu em função da aproximação em trabalhos na área de extensão universitária, através do Núcleo de Apoio às Atividades de Cultura e Extensão Universitária: Assistência de Enfermagem em Saúde Coletiva (NACE:AENSC).

\subsection{Epidemiologia dos agravos respiratórios na população infantil}

As doenças respiratórias na infầncia têm constituído a cada dia motivo de preocupação para os profissionais de saúde, dada a sua elevada morbidade, observada em termos mundiais, bem como a alta mortalidade que incide principalmente nos países do terceiro mundo. Segundo dados divulgados pela Organização Mundial da Saúde (OMS), cerca de 13 milhões de crianças menores de cinco anos morrem anualmente no mundo por doenças do aparelho respiratório, sendo que $95 \%$ das mortes ocorrem nos paises em desenvolvimento. (ORGANIZAÇÃO PANAMERICANA DA SAÚDE. 1993)

São considerados problemas respiratórios das vias superiores os resfriados, as otites. as sinusites, as amigdalites; e problemas das vias inferiores, as epiglotites. bronquites e pneumonias. As definições sumárias dos agravos mencionados baseadas em documentos do Ministério da Saúde, encontram-se no anexo 1.

Apesar da maior ocorrência de agravos das vias aéreas superiores. os problemas que acometem o trato respiratório inferior causam maior pre:)cupação devido à maior probabilidade de complicação. A falta de assistência adequada pode 
contribuir para a evolução para o óbito. Neste trabalho será utilizada a denominação de Infecções Respiratórias Agudas (IRA) para o conjunto destas patologias.

Existem poucos dados disponíveis relativos à exata morbidade por infecções respiratórias agudas, já que não se trata de agravo passível de controle através de um sistema de informações como o de notificação compulsória. Apesar disso, vários estudos realizados internacionalmente revelam que a sua incidência é alta na população de menores de cinco anos de idade, constituindo o principal motivo das consultas pediátricas dos serviços de saúde (MONTO e ULLMAN, 1993; LEOWSKI, 1993; BORRERO e FAJARDO. 1993.)

Outros estudos sobre morbidade das IRA reaiizados em comunidade apontam para uma prevalência bastante elevada, de aproximadamente $30 \%$, sendo os agravos das vias altas, três vezes mais comuns do que os das vias baixas (MONTEIRO e BENICIO. 1987).

Algumas investigações evidenciam que $o$ aumento da incidência desses agravos respiratórios em âmbito mundial encontra-se relacionado a fatores de ordem ambiental. Para isso, contribuem o processo de urbanização crescente que altera a qualidade do ar em decorrência da deterioração do meio ambiente. assim como o processo de sociabilização precoce das crianças que. principalmente em decorrência do trabalho materno. permanece desde tenra idade em ambientes coletivos por períodos prolongados (OPAS, 1993: COSTA e CAMPOS, 1993).

Estima-se que uma criança residente em área urbana tenha anualmente entre 5 e 8 episódios de problemas respiratórios, tanto de vias superiores como inferiores, nos cinco primeiros anos de vida. Nos grandes centros urbanos, a incidência das IRA tende a elevar-se muito. como foi observado por Barata e colaboradores que encontraram 11,8 episódios em 100 crianças/ano, com duração média de 6,8 dias (BARATA et al, 1996). 
As infecções respiratórias agudas incidem mais na faixa etária de 6 a 18 meses de idade e, mesmo quando se trata de um quadro benigno, isto é. sem risco de letalidade, causam desconforto à criança, pois podem provocar: febre, inapetência, tosse. sono irregular, entre outros sinais e sintomas. Dada a alta incidência nesta faixa etária, o conjunto destes agravos constitui motivo de preocupação para os responsáveis pelas crianças, na medida em que exige cuidados específicos (COSTA e CAMPOS, 1993).

Apesar dos indicadores de morbidade apresentarem uma certa homogeneidade na distribuição em diferentes regiões do mundo, excetuando-se as diferenças percebidas entre as zonas rural e urbana. o mesmo não ocorre com a incidência da mortalidade onde as diferenças são marcantes no tocante à sua magnitude. Nos páises economicamente mais pobres as crianças morrem mais por pneumonias de origem bacteriana, passiveis de controle através da antibioticoterapia apropriada (BENGUIGUI, 1995).

EJZENBERG (1995) contesta o fato de se encontrar maior número de pneumonias de origem viral nos países sócio-economicamente mais desenvolvidos, enquanto nos países mais pobres predominam as pneumonias de etiologia bacteriana. $\mathrm{O}$ autor considera que algumas diferenças verificadas podem ocorrer em função da utilização de diferentes métodos de pesquisa. No entanto, uma questão fundamental quando se analisam os fatores que contribuem para as diferenças mundiais em termos de mortalidade, centra-se nas condições de vida e no acesso da população a serviços de saúde capazes de detectar precocemente os agravos e tratá-los adequadamente.

No Brasil, as doenças respiratórias são responsáveis por aproximadamente $10 \%$ das mortes entre os menores de um ano, predominando neste grupo as pneumonias de origem bacteriana. As doenças respiratórias constituem a segunda causa de óbito na população de zero a um ano de idade e a primeira causa entre as crianças de um a quatro anos, no território nacional (SILVA. 1996). 
Até 1988 verificou-se que, em termos nacionais, os problemas respiratórios constituíram a segunda causa dos óbitos das regiões Sul e Sudeste e a terceira causa nas demais regiões. Em São Paulo, a mortalidade pelas infecções respiratórias agudas também é significativa, ocupando o terceiro lugar na população infantil, apesar de ser o Estado que conta com os melhores índices de sobrevivência para a população de zero até 6 anos de idade, segundo estudo realizado pelo Instituto Brasileiro de Geografia e Estatística (IBGE) e pelo Fundo das Nações Unidas para a Infância, UNICEF (UNICEF/IBGE, 1994).

Ao estudar a mortalidade por IRA em menores de 5 anos, durante 1970 e 1991 no Estado do Rio Grande do Sul, CHATKIN e MOLINARI (1997) encontraram uma tendência decrescente da ordem de $-7,79 \%$. No entanto, os autores consideram tais taxas de declínio ainda pequenas se comparadas às médias anuais de países como o Canadá que teve uma redução de - 14,7\% entre os anos de 1969 a 1977 e os Estados Unidos que observaram uma redução de mortalidade de - 15,3 \% entre 1968 a 1977.

MONTEIRO e BENÍCIO (1987), em estudo realizado no Município de São Paulo, observaram a incidência de 6.5 internações por 100 crianças-ano, sendo de 3,5 a 2.8, respectivamente, para internações por pneumonias e afecções respiratórias com componente obstrutivo, índices muito altos em relação a outros países do terceiro mundo.

No estudo de BARATA, et al. (1996), realizado no Município de São Paulo nos anos de 1986 e 1987 foi encontrada uma incidência de 11,08 episódios por 100 crianças/mês, com uma duração média de 6,8 dias. O grupo etário mais atingido foi o dos menores de 1 ano e em $36,1 \%$ dos casos de IRA identificados verificaram-se eventos semelhantes no mesmo domicilio.

Em estudo de morbidade, realizado no Município de São Paulo, com amostra do total de atendimentos médicos na rede municipal de saúde, no período de abril de 
1991 a março de 1992, as doenças respiratórias constituíram $42.8 \%$ dos atendimentos a menores de 1 ano (19.095 consultas) e $47 \%$ no grupo de 1 a 4 anos (32.235 atendimentos). Houve predominância das IRA de trato superior que representaram cerca de $20 \%$ das consultas. Já a pneumonia foi diagnosticada em 3,5\% dos atendimentos em menores de 1 ano e apresentaram-se em 3,8\% das crianças de 1 a 4 anos atendidas nas unidades de saúde (BERTOLOZZI, 1998).

\subsection{Os Fatores de risco associados às IRA}

A maioria dos estudos relativos à incidência das IRA ressalta a contribuição de fatores de risco relacionados ao adoecimento. VICTORA (1998) apresenta uma síntese dos estudos relacionados aos fatores de risco. destacando que muitos dos resultados dificultam a generalização em função de incoerências nas definições conceituais dos casos. Vale ressaltar que na perspectiva adotada no presente estudo que será apresentada de forma mais detalhada no capítulo referente ao Marco Conceitual. é necessário elucidar a incidência de tais fatores segundo a inserção social dos indivíduos acometidos pelas doenças citadas. Alguns estudos contemplam essa perspectiva sem, no entanto, constituírem maioria. Mesmo assim. o cenário epidemiológico das IRA. conhecido a partir da produção científica disponível, pode ser de grande utilidade para subsidiar politicas para o enfrentamento das iniqüidades.

$\mathrm{Na}$ literatura encontram-se descritos os seguintes fatores de risco associados às doenças respiratórias citadas: o baixo peso ao nascer. a desnutrição. o desmame precoce, a poluição ambiental. a maior concentração de pessoas no mesmo cômodo que a criança utiliza para dormir e a presença de fumantes na familia.

No estudo de NIOBEY, et al. (1992) as variáveis mais importantes para a ocorrência de morte por pneumonia em crianças na região metropolitana do Rio de Janeiro, região Sudeste. foram o baixo peso ao nascer, o desmame precoce, a ordem de nascimento da criança, o grau de instrução dos pais. o número de moradores, a 
renda familiar per capita, a presença de moradores fumantes, a vacinação $B C G$, a história prévia de internação, além da história prévia de asma e/ou pneumonia.

FONSECA, et al. (1997) ao estudarem os fatores de risco para pneumonia nos menores de 2 anos, na cidade de Fortaleza, região Nordeste, encontraram como mais importantes: a desnutrição, o baixo peso ao nascer, a ausência de aleitamento materno, a freqüência à creche, a mãe que trabalha fora, a história de doenças anteriores. a aglomeração e a história reprodutiva da mãe.

Em estudo realizado na cidade de Pelotas, região Sul do país, por AMARAL et al. (1997), houve associação significativa das IRA com a baixa escolaridade materna. a baixa renda familiar, a maior aglomeração no quarto da criança, a ausência de sanitário e água encanada no domicílio, ao fumo passivo, a freqüência da criança em creche.

Os indicadores nacionais que compõem o panorama de saúde da criança revelam um cenário desfavorável no tocante a estes indicadores. favorecendo a manutenção dos agravos respiratórios em patamares elevados.

Na Região Metropolitana de São Paulo, segundo dados da Fundação SEADE (1992). o baixo peso ao nascer. inferior a 2.500 gramas. apresenta-se em torno de $9.04 \%$ dos nascidos vivos. Especificamente com relação a este fator, VICTORA et al. citados por NIOBEY et al. (1992), identificaram que o risco de morrer por IRA antes de completar um ano de idade é 6.7 vezes maior para os recém-nascidos cujo peso é inferior a $2.500 \mathrm{~g}$. Ainda com relação a este aspecto é importante destacar que no cenário nacional a maior preocupação está centrada nos lactentes pequenos para a idade gestacional (PIG), ou seja, aqueles que apesar do parto ter ocorrido próximo da data prevista. ainda assim nascem com peso inferior, denotando comprometimento do crescimento intrauterino. Tais crianças podem apresentar problemas na resposta imunológica ao longo do crescimento. 
A desnutrição infantil, ou seja. crianças com peso abaixo do percentil 10 . utilizando-se os critérios do Centro Nacional para Estatísticas sobre Saúde dos Estados Unidos, relaciona-se ao agravamento dos processos patológicos respiratórios e não propriamente com a maior ou menor freqüência dos episódios. VICTORA (1998) relata uma série de estudos de caso-controle que evidenciaram que crianças com peso inferior a $-2 \mathrm{Z}$ score do padrão de referência para o indicador peso para a idade tiveram um risco cinco vezes maior de adoecer por pneumonia do que aquelas classificadas com $-1 \mathrm{Z}$ score. Segundo dados apresentados pela UNICEF/IBGE (1998), sobre a situação mundial da infância, o Brasil apresenta uma taxa de 16,3\% crianças desnutridas entre os menores de cinco anos de idade. Em São Paulo. MONTEIRO (1987) encontrou uma prevalência de $23 \%$ das formas leves deste agravo, ou seja. em crianças com déficit ponderal na faixa entre 76 a $90 \%$ do peso esperado para a idade.

Quanto à questão relativa ao desmame precoce, é fato que o aleitamento materno exclusivo confere proteção à criança através da ação de fatores imunoalergênicos, que não são passiveis de reposição artificial. VICTORA (1998) destaca que os estudos existentes indicam que há risco de adoecer por pneumonia que pode ser de 1,5 a 4 vezes maior para os lactentes não amamentados.

Apesar da precariedade de dados existentes sobre o período de aleitamento materno, sabe-se que esta prática é insatisfatória no município de São Paulo, sendo este mais um aspecto a ser considerado na análise da problemática em pauta que em muito contribui para a maior suscetibilidade das crianças no desenvolvimento de episódios respiratórios do trato inferior em idades bastante precoces, aumentando o risco de letalidade. MONTEIRO e REA, (1988) verificaram que $25 \%$ das crianças do Município de São Paulo deixaram de receber o leite materno exclusivo já nos primeiros quinze dias de vida, sendo que tal tendência continua de forma acelerada até os 4 meses, época em que cerca de $75 \%$ das crianças já recebiam outro tipo de leite de forma complementar. 
Outros fatores de ordem mais genérica relacionam-se ao problema, destacando-se a poluição do ar, que se caracteriza pela presença de um ou mais contaminantes no ar, em quantidades capazes de torná-lo nocivo, impróprio ou inconveniente ao bem-estar da população (MOTTA e MENDES, 1995). Segundo os mesmos autores, a poluição configura-se a partir da emissão de poluentes primários, por causas naturais (erupções vulcânicas, queima de florestas) ou decorrentes da atividade humana, como os escapamentos de veículos e as emissões industriais. A combinação dos poluentes na massa de ar pode levar à formação de poluentes secundários a partir de reações quimicas. Tal processo pode ser controlado a partir da ação natural de depuração do ar pelas chuvas e ventos que dispersam os poluentes atmosféricos. No entanto, este mecanismo tem sido dificultado nas últimas décadas, pela urbanização vertical crescente e pelas próprias características geográficas do Município de São Paulo, circundado por montanhas que dificultam a circulação dos ventos.

Apesar de recente, este problema causa grande preocupação, pelo comprometimento da qualidade de vida e pelas conseqüências relacionadas à saúde, principalmente aos idosos e aos menores de cinco anos. Foi um dos temas discutidos na Conferência das Nações Unidas sobre Meio Ambiente e Desenvolvimento - Rio 92, realizada em junho de 1992, na cidade do Rio de Janeiro e integra o conjunto de ações e compromissos da Agenda 21, assinada por 170 paises, que constitui um Plano de Ação voltado para o alcance de desenvolvimento sustentável nos diferentes países. No referido Plano recomenda-se a criação de uma Agenda 21 Local, específica para a realidade de cada município e, sobretudo, para envolver diversos setores na discussão e enfrentamento dos complexos problemas ambientais. A Agenda 21 Local, de São Paulo, formulada a partir de 1995, propõe as seguintes alternativas para controlar a poluição do ar na cidade: reduzir a emissão de poluentes, implantar corredores exclusivos para transporte coletivo, criar frota de veículos movidos a gás natural, estimular a proximidade entre áreas de moradia e de emprego reduzindo a demanda de transportes e destinar mais verbas para os sistemas de transporte coletivo grande porte, como trens e metrôs (São Paulo, 1996). 
Sabe-se que este tem sido um problema que vem preocupando há muito a população como um todo. tendo sido recentemente instituido o rodízio de veículos na cidade de São Paulo (SÃO PAULO, 1996), na tentativa de minimizar os efeitos deletérios à saúde, principalmente durante os meses de inverno. Apesar de se tratar de um projeto muito polêmico, dada a sua insuficiência no controle permanente da poluição e pelo fato de restringir-se somente ao controle dos veículos individuais, a aprovação deste decreto revela uma situação crítica de ordem ambiental, diretamente relacionada ao agravamento das doenças respiratórias.

O relatório elaborado pelo Engine, Fuel and Emissions Engineering Incorporated em janeiro de 1994. sobre o Projeto de Integração dos Transportes Urbanos e seus beneficios para a qualidade do ar no Estado de São Paulo, aponta que a redução da circulação de veículos e ônibus, através da sua substituição por metrô e trens. além do uso de ônibus com combustíveis de baixa poluição trariam beneficios diretos para a melhoria da qualidade do ar na região metropolitana de São Paulo. Outros beneficios seriam obtidos a partir da regulamentação da emissão de gases dos veículos, a exemplo do que é feito com o rodizio, bem como através da instituição do controle permanente da emissão de poluentes dos veículos em circulação.

Segundo a Companhia de Tecnologia de Saneamento Ambiental (CETESB) entidade ligada à Secretaria do Meio Ambiente do Governo do Estado de São Paulo, os maiores problemas verificados no Estado de São Paulo, na atualidade, são devidos à alta concentração de material particulado, ou poeira (PM10) e a poluentes como o ozônio (O3) e monóxido de carbono (CO). Em 1991, observou-se uma incidência acima da média aceitável de $50 \mu \mathrm{g} / \mathrm{m}^{3}$ de PM10, em 18 das 20 estações de controle do ar da RMSP. Em regiões de tráfego intenso esses índices chegaram a atingir 120 $\mu \mathrm{g} / \mathrm{m}^{3}$. Tais niveis de PM10 podem levar ao aumento da morbi-mortalidade por doenças respiratórias, pois seus efeitos sobre a saúde estão associados à dificuldade na remoção das particulas inaladas pelo sistema respiratório, à presença de substâncias minerais com propriedades tóxicas, à presença de substâncias 
carcinogênicas associadas às partículas e à capacidade das partículas finas em aumentar os efeitos fisiológicos de resposta ao contato com os gases irritantes (CETESB. 1996).

Com relação ao $\mathrm{CO}$, as concentrações desse gás têm excedido com freqüência o padrão de 9 partes por milhão (ppm) em um período de 8 horas, chegando a atingir $20 \mathrm{ppm}$. Os efeitos do monóxido de carbono estão relacionados a processos mais gerais do organismo na medida em que as moléculas deste gás associam-se à hemoglobina, comprometendo o trarısporte de oxigênio pelo organismo. (CETESB, 1996)

SALDIVA et al. (1994), em estudo realizado na cidade de São Paulo, encontraram uma associação positiva entre os níveis elevados de poluição do ar e o aumento da mortalidade por problemas respiratórios em crianças identificando, inclusive, que os efeitos da poluição sobre a mortalidade ocorrem em patamares inferiores aos índices de referência.

VICTORA (1998) destaca que há evidências de que partículas suspensas de dióxido sulfúrico provocam tosse e IRA de vias baixas e que a admissão hospitalar por tais agravos também se relaciona à concentração de partículas finas.

CARDOSO (1997) relata que a poluição do ar pode aumentar a incidência de agravos respiratórios do trato inferior através do comprometimento do sistema de defesa pulmonar, diminuindo a resposta tanto dos mecanismos específicos de produção de linfócitos $\mathrm{B}$ e $\mathrm{T}$, como dos mecanismos não específicos de filtragem aerodinâmica, sistema de transporte mucociliar e fagocitose. FENNELLY citado por CARDOSO (1997) relata que $30 \%$ das partículas menores que $1 \mu \mathrm{m}$ são capazes de penetrar o trato respiratório e depositarem-se nos alvéolos, sendo necessário muito tempo até que o organismo consiga removê-las. 
A poluição do ar é. sem sombra de dúvida. um problema de alta complexidade a ser enfrentado sendo necessário pensar de maneira abrangente o processo de urbanização, através de programas que garantam transportes coletivos menos poluidores, em alternativas para a circulação de mercadorias que passem a utilizar mais outros tipos de via de circulação como as ferrovias e as hidrovias; além de colocar em prática, de fato. os mecanismos de controle de emissão de poluentes já conhecidos.

VICTORA (1998) também destaca. enquanto fatores ambientais relacionados à morbidade por IRA, a exposição à fumaça, a aglomeração de pessoas em espaços fechados e a exposição ao frio decorrentes de moradias insatisfatórias. Com relação a este último aspecto. sabe-se que o aumento ou diminuição abrupta da temperatura do corpo modifica a perda relativa de calor e tem um efeito desfavorável no estado geral do indivíduo. Assim. a moradia deve minimizar os efeitos das mudanças de temperatura externa, contribuindo para isso o tipo de material de construção, o acabamento, o tipo de forração, assim como o tipo de piso para garantir vedação adequada. (WESTPHAL, 1982).

No estudo de CARDOSO (1997), sobre a poluição intradomiciliar em uma população de crianças atendidas em hospitais do Município de São Paulo, os fatores mais importantes relacionados às IRA foram a exposição das crianças à grande concentração de pessoas nos dormitórios e à umidade excessiva no interior dos domicílios, assim como as mudanças bruscas de temperatura. Quanto a estas últimas, a autora relata que uma variação semanal média de $1^{\circ} \mathrm{C}$ esteve associada a um aumento de $6 \%$ na incidência das doenças respiratórias. Verificou-se ainda que a concentração de ácaros aumenta cerca de 3 vezes a ocorrência de doença do trato inferior (CARDOSO, 1997).

Outro fator de risco para as IRA apontado na literatura diz respeito à concentração de pessoas por dormitório. Segundo WESTPHAL (1982), a American Public Health Association recomenda que a concentração de pessoas por dormitório 
não ultrapasse a relação de 1.5 por cômodo. CARDOSO (1997) verificou no município de São Paulo, em estudo já citado, que a alta concentração de pessoas no dormitório esteve associada 2 vezes e meia no aumento da incidência das IRA de trato inferior e como fator de redução de $60 \%$ na incidência de asma.

Quanto a este aspecto, a cidade de São Paulo apresenta um cenário crítico em algumas regiões, dado o déficit habitacional em função do crescimento populacional. Como outros aspectos de ordem social, este problema não se apresenta de maneira uniforme em toda a cidade, escondendo enormes diferenças em função da ocupação desigual do espaço territorial. Tanto nos bairros mais centrais como nos periféricos da cidade, as residências têm diminuido de tamanho, quer seja pelo custo elevado do terreno ou pelo alto custo da construção. Nos locais onde predomina a prática da auto-construção, na qual o período de consecução da obra se estende, a falta de acabamento adequado constitui problema, sendo comum a presença de umidade, evidenciada como fator de risco para os agravos em pauta. Estudos já realizados em São Paulo detectaram a associação direta destes aspectos ambientais ao aparecimento e permanência de agravos respiratórios, sobretudo os de origem alérgica (RIBEIRO, et al. 1971; WANDALSEN, et al. 1976; WESTPHAL e CARNEIRO-SAMPAIO, 1984; CARNEIRO-SAMPAIO, et al. 1984).

Dentre os fatores anteriormente descritos, talvez o que acometa a população de forma mais ampliada seja a poluição ambiental, sendo necessárias medidas de alcance coletivo para a minimização dos seus efeitos sobre a saúde. É importante destacar que os dados apresentados sob a forma de médias escondem enormes diferenças segundo a inserção social das famílias, o que determina o acesso diverso à moradia, aos serviços de saúde de qualidade capazes de monitorar os agravos em uma fase em que seja possível diagnosticá-los e tratá-los sem conseqüências; assim como o acesso das crianças a instituições onde possam desenvolver-se plenamente.

Tais problemas, inerentes aos agravos respiratórios, só serão passíveis de controle a partir de uma atuação governamental mais contundente e definida a partir 
de políticas públicas que interfiram sobre as condições que causam ou perpetuam os agravos respiratórios. Por outro lado, o controle das IRA também se relaciona à forma de organização da assistência no setor saúde. identificando-se possíveis ações voltadas para a diminuição do problema. Nesta esfera. é imprescindível recuperar ações que tenham impacto sobre uma determinada realidade epidemiológica através da intervenção sistematizada dos trabalhadores da saúde, destacando-se o papel das ações de educação em saúde.

\subsection{As possibilidades de controle das IRA no contexto das políticas de saúde no Brasil}

Uma análise global desta problemática deve estar articulada à compreensão da estruturação do sistema de saúde do país, bem como ao reconhecimento de que as diferenças regionais nas taxas de mortalidade mencionadas anteriormente não podem ser discutidas se descontextualizadas do processo de formação das sociedades e de seus respectivos modos de produção.

A rede pública de saúde brasileira, nos seus diferentes graus de complexidade, apresenta-se com sérios problemas de ordem financeira, gerencial e de adequação da assistência, em função da política econômica adotada, o que contribui ainda mais para a manutenção dos índices de morbi-mortalidade em patamares elevados.

Concomitantemente a esta situação, vive-se a tarefa de implementação do Sistema Único de Saúde (SUS), criado a partir da Lei 8080 de 1990 que no tocante à organização da atenção à saúde, entre outras diretrizes, preconiza o fortalecimento do nível local como porta de entrada do sistema e responsável pela vigilância à saúde da população sob sua responsabilidade.

O Ministério da Saúde adotou como estratégia de enfrentamento dos problemas respiratórios na infầncia, a proposta da Organização Mundial da Saúde (OMS) e da Organização Panamericana da Saúde (OPAS), que enfatiza a detecção 
precoce das pneumonias, a fim de assegurar o tratamento adequado das crianças e impedir a ocorrência de mortes evitáveis. Trata-se de uma proposta estruturada que visa facilitar a identificação dos casos graves, dentre as crianças que compõem a demanda dos serviços, através da padronização da intervenção. Em síntese, a proposta apresenta um quadro resumo de sinais de gravidade em geral e específicas para as doenças respiratórias que permitem ao profissional capacitado identificar problemas, facilitar a decisão sobre a conduta e estabelecer um contato com o acompanhante voltado para a orientação dos cuidados domiciliares e sobre a necessidade de retorno ao serviço. Tal estratégia envolve a participação do maior número de profissionais e/ou ocupacionais dos serviços de saúde e visa ampliar a resolutividade do nível local contribuindo assim para a redução da mortalidade por tais doenças (BRASIL. 1994).

Mais recentemente, as ações de controle das IRA deixaram de constituir uma das ações do Programa de Atenção Integral à Saúde da Criança (PAISC) e passaram a integrar a estratégia de Atenção Integrada às Doenças Prevalentes da Infầncia (AIDPI). A AIDPI combina a atenção aos problemas de saúde da infância com a avaliação nutricional e o incentivo à vacinação, além de outros aspectos que também influem sobre a saúde das crianças. Desta maneira, desloca-se o foco da atenção do aspecto eminentemente curativo centrado na queixa para a avaliação integral da criança no momento do atendimento, quer seja numa situação de consulta agendada ou eventual. A finalidade principal da estratégia é a melhoria das práticas de atenção nos serviços de saúde, sobretudo no nível local, através do reconhecimento e intervenção precoce sobre os problemas de saúde, reduzindo a perda de oportunidades de prevenção, detecção precoce e tratamento dos agravos. A estratégia enfatiza ainda a importância das ações educativas e apoio às familias com relação ao cuidado da criança no domicílio (OPAS, 1997).

Dada a estratégia de descentralização dos serviços que subjaz à proposta do SUS, compete ao Ministério da Saúde delinear os programas em termos de subsídio técnico para a atuação em nível local. Entretanto, nesta última instância, há que se 
reconhecer os diferentes perfis epidemiológicos para priorizar as ações necessárias; entendendo-se perfis epidemiológicos no sentido amplo que não se restringe ao panorama dos indicadores de saúde mas incorporando as condições de vida para a análise da problemática de saúde. Não se trata, portanto, da simples reprodução de propostas programáticas elaboradas tanto em âmbito nacional como internacional. Tal situação coloca aos profissionais de saúde atuantes no nível local, o desafio de buscar instrumentos que permitam o reconhecimento das condições potenciais de risco para a população e a formulação de ações de alcance coletivo que consigam ter impacto sobre os mesmos.

Nesse contexto. há que se destacar a importância que assume o Sistema Único de Saúde. que constitui fundamentalmente um projeto político, uma conquista dos setores progressistas e que contempla o direito à saúde, a participação da população na gestão dos serviços e a eqüidade. como princípios norteadores. O SUS, como uma esfera de atuação do poder público, tem como uma das tarefas a utilização dos escassos recursos da verba pública, a partir da definição de prioridades para sua utilização. Dessa forma, o nível local de atenção à saúde se destaca na medida em que permite a visualização das necessidades de saúde de forma mais apropriada, semelhantemente à proposta de Sistemas Locais de Saúde (SILOS), apesar de sua terminologia não ter sido incorporada no Brasil da mesma forma em que ocorreu nos países da América Latina. Aqui o conceito de Distrito Sanitário foi mais difundido, principalmente a partir da década de 80 .

A concepção de Sistemas Locais de Saúde (SILOS) constitui uma importante estratégia para viabilizar a Vigilância à Saúde, tomando-se esta como um processo muito mais amplo e complexo que se coloca atualmente para o enfrentamento dos inúmeros problemas e agravos que comprometem a qualidade de vida dos diferentes segmentos da população (SOUZA e KALICHMAN, 1992). Segundo esses autores, o foco central das ações de Vigilância à Saúde deve ser a busca da eqüidade das condições de vida da população, para que se possa agir no sentido de promover saúde na sociedade. A qualidade de vida é entendida como a condição de existência relativa 
ao modo de viver em sociedade, articulando o momento histórico e a estruturação no cotidiano que está estreitamente relacionada ao grau de liberdade social e à capacidade de usufruto das conquistas técno-científicas.

A Vigilância à Saúde é, portanto, a nova atribuição dos serviços de saúde a partir do SUS. De acordo com PAGANINI e CAPOTE MIR (1990), os SILOS surgem como uma tática operacional que visa fortalecer a atenção primária, dado que fomentam a participação social. a ação intersetorial. a descentralização das decisões, a utilização de métodos de planejamento ascendente e a formulação de políticas voltadas para a realidade local.

O SILOS como política de saúde visa atender aos seguintes objetivos: a eficiência social. no que se refere à otimização dos recursos materiais e humanos existentes; a eficácia social, relativa ao cumprimento das metas delineadas; a eqüidade, no que diz respeito ao direito de todos os cidadãos manterem-se saudáveis e terem acesso aos serviços de saúde e a democratização, no sentido de promover a participação da população na gestão e planejamento das ações (MENDES, 1990).

No contexto sócio-político da América Latina, observam-se as conseqüências de um modelo de desenvolvimento econômico concentrador de riquezas. com uma crescente divida social, um grande contingente de trabalhadores desempregados que aumentam os setores informais da economia, tornando-se marginalizados no acesso aos serviços de saúde (PAGANINI e CAPOTE MIR, 1990)

No quadro de morbimortalidade das nações latino-americanas, sobretudo nos centros urbanos, coexistem os agravos de origem infecciosa, parasitária e carenciais, juntamente com os problemas cardiovasculares, os acidentes, os transtornos mentais, os agravos de origem degenerativa e de contaminação ambiental. No entanto, para o enfrentamento destes problemas, continuam sendo estruturadas ações de caráter normativo e vinculadas ao modelo de assistência individual. 
Na medida em que a exposição aos riscos não se dá de forma equânime entre os diferentes segmentos populacionais. torna-se fundamental conhecer as necessidades de saúde específicas dos grupos que compõem a população de determinado SILOS para ampliar a forma de abordagem dos problemas, enfatizando as ações coletivas além das individuais e o trabalho intersetorial para atuar sobre as causas que levam aos problemas de saúde e não somente sobre as doenças (PAGANINI e CAPOTE MIR, 1990).

MENDES (1990) destaca a importância de se considerar a heterogeneidade da população em termos de suas necessidades e do acesso aos serviços de saúde. postulando o conceito de eqüidade como fundamental para a priorização das açôes, visando a gradual diminuição das desigualdades observadas. $O$ conceito de eqüidade pode assumir diferentes significados e será desenvolvido com maior profundidade no capítulo 3 em que se descreverá o referencial de análise. Para este mesmo autor, os SILOS constituem espaços privilegiados para viabilizar uma política de saúde que além de respaldada em um arcabouço jurídico e em planos operativos, para obtenção de melhores resultados, configura-se também num espaço que permite a produção e difusão de conhecimentos, imprescindiveis para a sua consolidação.

Para KADT e TASCA (1993), a operacionalização do conceito de eqüidade no setor saúde se faz a partir do reconhecimento das "chances de vida" de determinada população ao invés de trabalhar com o conceito de risco, já que este último se restringe a aspectos biológicos e é mais voltado a ações individuais do que coletivas.

Ressaltando-se a gênese social do processo saúde-doença, coloca-se a necessidade de organizar o setor com vistas a melhorar o acesso e a qualidade da atenção à saúde a partir de atividades locais dirigidas aos grupos com menores chances de vida, destacando-se ainda a importância das ações intersetoriais. 
UNGLERT (1995) destaca que é fundamental conhecer a acessibilidade dos serviços de saúde em termos geográficos (topografia, vias públicas), funcionais (oferta de serviços, horários), culturais (confronto entre a normatização técnica e o ideário popular) e econômicos. Na proposta de territorialização, a autora destaca como questões norteadoras para o planejamento das ações, o conceito de comunidade, porque é objetivo do sistema atender às necessidades da população à que se destinam. e eqüidade tendo em vista que é necessário garantir a justa distribuição dos recursos que, dada a forma como o setor saúde é estruturado no Brasil são, em si, escassos.

O presente estudo tem como base o conceito de eqüidade, que se centra no desafio de identificar diferentes problemas de saúde passiveis de intervenções diferenciadas, para que possa ser cumprida a finalidade do trabalho em saúde, qual seja, o de modificar os perfis de morbi-mortalidade. $O$ enfoque centra-se nas possibilidades de controle das IRA no território constituído pela área de abrangência de um Centro de Saúde destacando-se as ações no campo da Promoção e Educação em Saúde. A seguir, serão apresentados os conceitos fundamentais utilizados para embasar a presente investigação. 
$\mathcal{Q}$ concepção da $\mathcal{P}_{\text {esquisa }}$ 


\section{A concepção da pesquisa}

A participação voluntária da população nos programas educativos é fundamental para que não se reproduzam os modelos paternalistas, coercitivos e normatizadores de condutas historicamente presentes na prática educativa em saúde, os quais, têm sido alvo de severas críticas (OSHIRO, 1988; COCCO, 1991; WESTPHAL, 1992). Apesar das contribuições especificas do campo da educação na atuação em saúde, várias Conferências de Saúde vêm ressaltando a importância de se adotar uma concepção mais moderna e inovadora para expandir as propostas de intervenção, para além dos processos educativos que enfocavam prioritariamente os estilos de vida dos indivíduos. enquanto objeto de intervenção (BUSS e IGNARA. 1996).

Segundo GREEN e KREUTER (1991) o escopo da Promoção à Saúde é um conceito muito mais ampliado, na medida em que incorpora a combinação de apoios educacionais e ambientais para as ações e modificações nas condições de vida, para que propiciem condições necessárias para a saúde da população. Desde 1986, o movimento da Promoção à Saúde vem concretizando este ideário ao enfatizar fatores sociais, econômicos e ambientais como determinantes da saúde.

A I Conferência Internacional de Promoção à Saúde, realizada em Ottawa, Canadá, em 1986, pode ser considerada como marco para ampliar as discussões sobre os determinantes da saúde e o objeto de ação de suas práticas. Na ocasião, a Promoção à Saúde foi conceituada como "processo de capacitação da comunidade para atuar na melhoria da sua qualidade de vida e saúde, incluindo uma maior participação no controle deste processo" (MINISTÉRIO DA SAÚ́DE, 1996). Tal conceituação recoloca a população em uma posição bastante distinta da anterior, na medida em que deixa de ser somente o alvo dos programas e passa a assumir uma posição na definição dos problemas a serem enfrentados. Amplia-se a concepção de saúde referindo-a a seus determinantes e também a possibilidade de intervenções, que extrapolam o setor saúde. Os campos de ação definidos na Carta de Ottawa incluem a 
elaboração e implementação de políticas públicas saudáveis, a criação de ambientes favoráveis à saúde, o reforço para a ação comunitária. bem como o desenvolvimento de habilidades pessoais e a reorientação dos sistemas e serviços de saúde.

Em 1988, na Conferência realizada em Adelaide, Austrália, as discussões centraram-se no tema das Políticas Públicas Saudáveis, reforçando o entendimento da saúde como um direito humano fundamental e um sólido investimento social. Para o fortalecimento das políticas públicas saudáveis, foi evidenciada a necessidade de ampliar o interesse e a preocupação de diferentes setores no sentido de criar ambientes favoráveis para a vida. Nestas discussões, ainda, foi destacado o conceito de eqüidade, como meta para que a superação das desigualdades decorrentes da inserção social desigual. Já naquele momento foi destacada a importância do desenvolvimento de parcerias com vistas a ações intersetoriais capazes de causar impacto sobre as condições geradoras de saúde.

Em 1991. foi realizada a III Conferência Internacional de Promoção à Saúde, em Sundsvall, na Suécia, que contribuiu para a melhor caracterização do campo de ação relacionado aos ambientes saudáveis. As discussões realizadas vieram incorporar as dimensões sociais, econômicas, políticas e culturais, além dos aspectos físicos e naturais ao conceito de ambiente.

No contexto da América Latina foi realizada, em 1992, uma Conferência Internacional de Promoção à Saúde, em Santafé de Bogotá, Colômbia, com a participação de representantes de vários países latinoamericanos, onde foi discutida principalmente a adequação da incorporação dos conceitos do novo paradigma da Promoção à Saúde no contexto do continente latinoamericano. Nesta reunião foi destacada a importância dos determinantes sociais sobre a saúde dos povos propondo que o conceito de Promoção à saúde incorporasse a tarefa de "transformar as relações excludentes, conciliando interesses econômicos e propósitos sociais de bem estar social" (PROMOÇÃO DA SAÚDE, 1996). A realização da Conferência no contexto latinoamericano contribuiu para destacar o contingente de pessoas vivendo em 
condições de miséria, decorrentes de um modelo econômico excludente que constitui uma séria barreira aos propósitos das ações de Promoção à Saúde. Recupera-se. assim. a importância da eqüidade social e da solidariedade para o alcance do objetivo maior de atuar sobre os determinantes de saúde.

Em 1997, em Jacarta, Indonésia ocorreu a IV Conferência Internacional de Promoção à Saúde. Foi a primeira vez que um país asiático e em desenvolvimento, com problemas estruturais extremamente sérios, sediou este tipo de evento o que acabou por reforçar os propósitos anteriormente delineados para a Promoção à Saúde. Foi destacada a importância de formular ações concretas para alcançar os propósitos e de estabelecer uma articulação mundial para efetivá-las, dadas as condiçôes desiguais vivenciadas pelos diferentes países. A “Aliança Global” proposta implica em um compromisso de reforçar as ações necessárias, dadas as especificidades de cada país, sem que isso signifique que os países sejam responsáveis únicos na concretização das metas.

A partir desta breve recuperação histórica acerca das Conferências Internacionais sobre a Promoção à Saúde, é possivel visualizar importantes conceitos, definidos num curto período de 12 anos. Entretanto, os avanços conceituais não tiveram a repercussão esperada em termos concretos de ações. GREEN e KREUTER (1991), destacam que, apesar de serem encontrados muitos textos que propõem a capacitação da população no controle e/ou melhoria das condições de saúde, esse é um tema ainda pouco pesquisado. Os mesmos autores propõem que a Promoção à Saúde incorpore os âmbitos das políticas regulatórias e ambientais na superação da problemática em questão. Às intervenções educativas, incorporar-se-iam as ações gerenciais e econômicas necessárias para a construção de sistemas sociais e políticas saudáveis.

Vários autores (GREEN e KREUTER, 1991; ROBERTSON e MINKLER, 1994; MENDES, 1996), identificam o conhecimento das necessidades sentidas pela população-alvo como o ponto de partida fundamental para a 
estruturação de programas. Dado que estas configuram um aspecto subjetivo da realidade são necessários métodos específicos de abordagem dessa realidade, para que seja obtido êxito nos programas. Caso contrário. as políticas tornar-se-ão estéreis, com soluções tecnocráticas e voltadas para problemas inexistentes ou pouco importantes para a população a quem se destinam as ações.

A ampliação da concepção de "diagnóstico social" de GREEN e KREUTER (1991), assume uma importância muito grande na atualidade, sobretudo se enfocarmos a situação das políticas públicas de saúde no âmbito nacional e dada a necessidade de se construir modelos assistenciais voltados para as distintas realidades locais. Neste processo de produção de conhecimentos, o intercâmbio entre o conhecimento técnico-científico e o conhecimento popular assume grande importância para a definição de políticas locais. A história da atuação dos serviços na área da saúde pública, no entanto, revela práticas pautadas em programas estruturados de maneira vertical, desarticulados da realidade local e pautado na oferta de ações de impacto reconhecidamente pequeno.

Hegemonicamente, a resposta aos problemas de saúde-doença das populações tem se voltado para o atendimento das demandas individuais pautadas no modelo clínico de intervenção, atribuindo ao agravo uma ou diversas causas não hierarquizadas (CAMPOS et al., 1994; MENDES-GONÇALVES 1994; PAIM.1995)

Segundo MENDES(1996), o maior problema vivenciado hoje pelos serviços de saúde refere-se à sua forma de estruturação que se caracteriza por ser independente das necessidades de saúde da população. Os profissionais de saúde têm privilegiado intervenções "a priori”, antes mesmo de realizarem um diagnóstico pormenorizado do problema em questão. Os que o têm feito relacionado à prática educativa, não têm se detido, com a profundidade necessária, na análise das determinações dos problemas de saúde. Segundo o próprio autor, a superação dessa realidade dar-se-á a partir dá incorporação, pelos atores da saúde, do conteúdo presente na Carta de Ottawa. Nesta, a saúde tem que ser entendida de forma 
ampliada, tomando-se o social como determinante da incidência dos problemas e incorporando-a ao conceito de qualidade de vida. Para atuar nesta perspectiva, os serviços deverão pautar-se no Modelo de Vigilância à Saúde ao invés de no Modelo da Atenção Médica.

Apesar de reconhecer em tese a importância das condições de vida na configuração dos perfis de morbi-mortalidade, a assistência às demandas coletivas, em geral. não utiliza instrumentos adequados para discriminar as necessidades específicas de diferentes grupos. Quando essa preocupação está presente, relaciona-se à doença ou à gravidade do processo patológico vivenciado que, segundo a concepção mencionada, já constitui a conseqüência da inserção social dos individuos.

Segundo ROBERTSON e MINKLER (1994), a área da Promoção à Saúde passou por mudanças importantes na última década, na medida em que incorporou os conceitos de "empowerment", entendida como ampliação de poder ou fortalecimento" e participação comunitária. Para estes autores, no entanto. incorporar estes conceitos como centrais para atuação no campo da Promoção à Saúde, significa superar a ênfase anteriormente dada aos estilos de vida e aprofundar na compreensão dos determinantes sociais que incidem sobre a saúde. O conceito de "empowerment", segundo estes autores, origina-se na psicologia social, no feminismo, na teologia da libertação e no ativismo social e pode ser considerado como um processo de desenvolvimento pessoal, interpessoal ou de ampliação do poder político. Nessa perspectiva ROBERTSON e MINKLER (1994) definem o poder como "um recurso não material distribuído diferentemente na sociedade"

No âmbito da Saúde Pública, no entanto, o entendimento de "empowerment" ficou mais restrito ao processo de mudança na auto-percepção do indivíduo, negligenciando o aspecto social da vivência. Dessa forma, foi utilizado até mesmo para culpabilizar as pessoas pela falta de habilidades em modificar suas condições de

\footnotetext{
"Utiliza-se o termo " fortalecimento" para representar o processo de aquisição de maior poder para o enfrentamento dos problemas, que é inerente à perspectiva de "empowerment".
} 
vida. Assim. WALLERSTEIN (1994) propõe uma dimensão mais abrangente desse conceito na prática das ações em saúde, na qual os indivíduos possam ampliar o controle sobre suas vidas através da participação em grupos, visando transformações da realidade social e política.

"The goals of an empowerment social action process, therefore, are individual and community capacity building, control over life decisions, equity of resources, and improved quality of life" (WALLERSTEIN, 1994, p. 154)

Com isso, há uma profunda distinção da abordagem tradicional centrada na mudança de comportamento individual, já que tais processos destacam a necessidade de contemplar a dimensão singular (relativa à subjetividade); a particular (relativa ao grupo social ao qual se insere) e a estrutural (relativa à estrutura política, jurídica e ideológica). Nesta concepção, a prevenção dos agravos à saúde não é tratada isoladamente e sim como uma meta a ser atingida juntamente com o desenvolvimento sustentado, a melhoria da qualidade de vida e a justiça social.

Essa concepção tem por base o entendimento de que os perfis epidemiológicos se diferenciam em função das condições de vida da população. assumindo também importância, a falta de controle que os indivíduos têm sobre suas vidas. A Promoção à Saúde se configura como o instrumento para capacitação dos individuos para aumentar o controle sobre os determinantes da saúde (WALLERSTEIN e BERNSTEIN, 1994).

Assim. a participação comunitária também tem sido repensada, substituindo o caráter integrador atribuído por muitos técnicos por outro transformador, reconhecendo no coletivo um espaço onde se dá a reprodução social através das mediações entre o micro-sistema (do cotidiano dos indivíduos) e o macro-sistema (de ordem política, jurídica e econômica) e que agrega familias e outras instituições sociais como igrejas, organizações comunitárias, escolas e outros. Um aspecto importante desta nova conceituação é a de que a própria comunidade já dispõe de elementos que constituem forças sociais transformadoras, colocando para os 
profissionais que atuam na área da Promoção à Saúde a tarefa de estimular e fortalecer a participação da população na definição dos problemas vividos e ajudar na proposição das ações necessárias para a superação. Trata-se, portanto, de um novo papel a ser desempenhado, diferente daquele em que contava somente com a leitura dos problemas de forma unilateral pelos técnicos.

Outro autor, TONES (1994), nos remete aos desafios atuais no campo da Promoção à Saúde no sentido de buscar as reais necessidades da população. Segundo este autor, a atuação deve pautar-se, prioritariamente, na diminuição das iniqüidades e no fortalecimento da população. Esta ação, denominada "competente" pelo referido autor. compreende quatro dimensões, quais sejam: ampliar as oportunidades de escolha. alertar sobre as suas possiveis conseqüências, desenvolver trabalhos educativos que incorporem a reflexão sobre a realidade vivida estimulando a discussão sobre quais seriam as mudanças possiveis e, finalmente, instrumentalizar com habilidades necessárias para a realização das mudanças desejadas.

CASTELLANOS (1991) recupera historicamente os Acordos Internacionais que ocorreram desde 1961 até 1990, destacando a XXIII Conferência Sanitária Panamericana, onde fica clara a necessidade de desenvolvimento da capacidade do setor saúde para aplicar o enfoque epidemiológico no reconhecimento do estado de saúde da população. Já naquela época destacava como marco conceitual o entendimento do processo saúde-doença como expressão dos "modos de andar a vida" e que as condições de vida dos diferentes grupos refletem as especificidades de sua inserção social, determinadas no processo de reprodução social.

"As condições de vida de um grupo populacional expressam a forma em que tal grupo se insere no processo mais geral de reprodução social" (CASTELLANOS, 91 p.21)

O mesmo autor esclarece ainda que o processo de reprodução social abrange uma dimensão ecológica, relativa à moradia e ao trabalho; uma dimensão biológica, 
relativa ao potencial genético e à capacidade imunológica dos indivíduos; uma dimensão que incorpora as formas de consciência e conduta relativa aos estilos de vida individuais e coletivos e também uma dimensão econômica, relativa às formas de articulação com a produção, distribuição e consumo de bens e serviços.

CASTELLANOS (1991) ainda destaca que a dinâmica interna de cada processo resulta do conflito entre o seu impacto e as respostas compensatórias dadas pelas políticas públicas, sendo que o balanço se expressa em problemas de saúde e bem-estar. Assim, o estudo do momento da reprodução social deve incluir variáveis correlatas a cada uma dessas dimensões:

"As condições de vida determinam necessidades de saúde e estas são socialmente representadas como problemas de saúde." (CASTELLANOS, 1991 p.23)

Portanto, necessidades de saúde resultam também de falhas ou dificuldades geradas nos processos de reprodução social e a oferta das ações de saúde e atenção primária para resolvê-las. SCHRAIBER e MENDES-GONÇALVES (1996) alertam para a inversão de prioridades na elaboração das políticas públicas e que se refletem na prática cotidiana, na medida em que propõem a satisfação das necessidades de saúde e estruturam a oferta dos serviços, sem que as intervenções propostas estejam voltadas para a resolução das causas primeiras relacionadas às condições de vida. Neste sentido, os autores propõem que os serviços constituam espaços que permitam a emergência de necessidades relativas à vida cotidiana da população-alvo dos programas e que, até o presente momento, ainda não têm sido contempladas na oferta dos serviços.

Outro aspecto fundamental a ser considerado ao pensar a proposição de ações voltadas para a Vigilância à Saúde é a necessidade de articulação dos diversos setores que atuam na formulação e execução de políticas públicas, potencializando as ações e construindo de fato a Promoção à Saúde. 
Na constituição do novo paradigma da Promoção à Saúde, sobretudo a partir da Conferência de Bogotá que se pautou na realidade latinoamericana, foi ressaltada a importância da eqüidade na produção social da saúde e doença. Torna-se necessário aprofundar o conhecimento dos entendimentos sobre o termo na área da saúde.

Segundo GOLDBAUM (1997), a eqüidade manteve sempre estreita relação com o objeto da epidemiologia na sua tarefa precípua de reconhecer as condições que favorecem a expansão das doenças. No entanto, foi nas últimas décadas que se pode observar de forma mais evidente, a preocupação dos profissionais de saúde em analisar a distribuição das doenças a partir do reconhecimento das iniqüidades sociais. Isso tem assumido maior importância nos debates dado o aumento dos processos excludentes da sociedade em decorrência da globalização da economia onde as repercussões desses processos de exclusão evidenciam-se no aumento das diferenças entre os grupos sociais, que se traduzem na extrema desigualdade na distribuição dos recursos, bem como nos indicadores de saúde.

No âmbito da Organização Mundial de Saúde, principalmente na Europa, já no inicio da década de 90 , foram feitas diversas reuniões técnicas sobre o tema das iniqüidades em saúde, com a perspectiva de aprofundar o tema tanto no aspecto conceitual, como no operacional, encaminhando para a proposição de instrumentos capazes de identificar e monitorar as iniqüidades. com vistas a superá-las.

WHITEHEAD (1990) esclarece que tal preocupação passou a ser pauta dessas reuniões, dada a magnitude dos diferentes perfis epidemiológicos entre as regiões da Europa e entre os diferentes grupos sociais num mesmo país. Ressalta a autora que as iniqüidades podem ser mensuradas através de grandes diferenças, por exemplo, quanto à expectativa de vida e causas de mortalidade, evidenciando a estreita relação entre a pobreza e a redução das chances de vida. Os dados de morbidade também revelam diferenças associáveis à inserção social dos indivíduos, na medida em que podem ser identificadas diferentes vivências do processo saúde/doença bem como a maior incidência de processos crônicos nas camadas economicamente 
mais pobres da população. A perspectiva de atuação em saúde que busque a resolução de problemas e a interferência nos indicadores de saúde deve focalizar, prioritariamente, a identificação das iniqüidades com vistas a reduzir a sua influência, buscando com isso, transformar os perfis epidemiológicos, no sentido de aprimorálos, sendo dificil atuar nessa perspectiva se não forem conhecidos os grupos prioritários para a atuação.

O compromisso para a consecução da eqüidade foi assumido como consenso da reunião de epidemiólogos realizada durante o I Congresso Latinoamericano de Epidemiologia, no qual assumem enquanto compromisso dos trabalhadores na área a intensificação de mecanismos para atuar no sentido de promover a eqüidade, na defesa da vida com dignidade e na consolidação dos avanços alcançados.

Ao abordar a temática da eqüidade é necessário explicitar os diferentes conceitos existentes que nos remetem a duas perspectivas distintas, quais sejam: as iniqüidades relativas ao nível de saúde de diferentes grupos e aquelas relativas ao dimensionamento e distribuição dos serviços de saúde.

Com relação à primeira perspectiva, WHITEHEAD (1990) destaca o fato de que o termo iniqüidade contempla o sentido de injustiça, não podendo ser aplicado a todas as diferenças observadas entre os grupos, no aspecto matemático da distribuição das doenças. As diferenças existentes relativas às características biológicas e de caráter individual não devem ser consideradas como iniqüidades. Por sua vez, o conceito de iniqüidade é aplicado aos problemas de saúde cujas causas são consideradas injustas em relação ao conjunto da sociedade, decorrentes da inserção social dos indivíduos e do limitado poder de controle individual sobre as mesmas.

O conceito formulado pela Organização Mundial de Saúde em 1986 já apontava para essa distinção: 
"Equity in health implies that ideally everyone should have a fair opportunity to attain their full health potential and, more pragmatically, that no one should be disadvantaged from achieving this potential, if it can be avoided" (WHITEHEAD, 90, p.9)

Baseada nesta definição, a autora destaca que o foco central de uma política de ação em eqüidade e saúde deveria ser a redução ou eliminação dos problemas cujas causas são consideradas evitáveis e que se referem à injustiça social. Neste sentido, a perspectiva norteadora é a de ampliar as condições para tornar iguais as oportunidades, reduzindo ao máximo as influências da desigualdade decorrente da inserção social. É nessa perspectiva que HANSEN (s/d) destaca a relevância da inserção social nas análises sobre os problemas a serem estudados nos grupos populacionais.

A segunda perspectiva relativa à eqüidade relaciona-se mais à assistência à saúde e tem como tática maior a meta de Saúde para Todos no ano 2000. Tal abordagem destaca a importância da reestruturação do modelo de atenção, disponibilizando os serviços de saúde de forma a ampliar o acesso da população aos mesmos, permitindo que todos possam usufruir da tecnologia e do conhecimento em saúde.

MUSGROVE (1986) aborda essa perspectiva de eqüidade a partir do acesso aos serviços de saúde e apresenta instrumentos de diagnóstico e monitoramento do alcance da eqüidade, de grande importância para os profissionais que atuam no setor saúde. Entretanto, consideramos que tal perspectiva restringe o âmbito de atuação do setor saúde, sendo necessário a ampliação do conceito para a ação intersetorial, fundamental para atuar sobre os determinantes das condições de vida que geram os problemas de saúde.

Apesar deste último conceito ter contribuído sobremaneira para os processos de descentralização dos serviços de saúde de alguns países, constitui uma meta irreal, 
principalmente pelo fato de considerar as melhorias almejadas como decorrentes da atenção à saúde. $\mathrm{Na}$ verdade são necessárias mudanças nas condições de vida dos grupos mais vulneráveis, para que sejam obtidos impactos na transformação dos perfis epidemiológicos.

CASTELlanOS (1997a) também destaca a importância da Saúde Pública para assumir as iniquidades sociais como objeto tanto para as intervenções como para a investigação sendo que, nesta última, o problema que se delineia é relativo ao recorte do objeto que na maioria das vezes fica circunscrito ao nivel individual. $\mathrm{O}$ conceito de iniqüidade diz respeito às brechas passiveis de redução nos perfis epidemilógicos.

CASTELLANOS (1997b) apresenta os avanços realizados na construção de indicadores que evidenciam as iniqüidades sociais, com o intuito de possibilitar a comparação entre os diversos países de uma dada região, destacando o Indicador Geral de Acessibilidade ao Desenvolvimento Social Acumulado - IGADSA. Tal indicador foi construido a partir de cinco variáveis, a saber: acessibilidade acumulada aos serviços básicos de saúde, acessibilidade relativa a recursos econômicos, acessibilidade acumulada aos nutrientes, acessibilidade acumulada ao sistema educativo e acessibilidade acumulada ao saneamento básico. A utilização desse indicador contribui para clarificar a relação entre desenvolvimento social e impacto sobre a mortalidade, aprimorando a discussão sobre a eficácia social além da simples relação custo/beneficio das ações propostas.

Tendo em vista a perspectiva da presente investigação, os conceitos aqui apresentados, constituem marco referencial para subsidiar o desenvolvimento do estudo. Pretende-se enfatizar os aspectos relacionados à identificação de iniqüidades num dado território de atuação de uma Unidade Básica de Saúde e propor ações de âmbito intersetorial, baseadas na perspectiva do "empowerment". O delineamento metodológico foi estruturado tendo em vista os aspectos conceituais e recuperando-se algumas experiências metodológicas já realizadas em diferentes estudos e 
incorporando-se novos elementos capazes de dar uma amplitude maior ao estudo, visando contribuir para a melhor compreensão da Promoção à Saúde no contexto do SUS.

\subsection{Delimitação do problema}

O controle das doenças respiratórias da população infantil está permeado pelos seguintes aspectos:

- a ampliação do acesso da população infantil aos serviços de saúde, capazes de reconhecer os diferentes graus de comprometimento da criança acometida pelo problema respiratório e oferecer tratamento precoce e adequado, incluindo as orientações e disponibilidade para a reavaliação;

- a existência e garantia de tratamento em serviços especializados, caso seja necessário, em função de agravamento do quadro;

- a estruturação de ações intersetoriais visando a minimização dos fatores nocivos relativos ao ambiente, incluindo-se o controle da poluição ambiental, a manutenção de locais onde permanecem as crianças em condições apropriadas de ventilação, iluminação e ausência de umidade, bem como a restrição do fumo;

- a divulgação junto à população de informações sobre os sinais de gravidade das doenças respiratórias na infância, restringindo o uso de antibióticos para os casos em que haja indicação e o uso indiscriminado de medicamentos antitussigenos e descongestionantes.

Entretanto, não há clareza suficiente sobre a maneira como a população enfrenta tais agravos. Tampouco pode-se dizer que é conhecida a concepção que tem do enfrentamento das condições ambientais inadequadas, cuja mudança extrapola o âmbito individual de atuação.

Em pesquisa realizada junto aos moradores de diferentes tipos de habitações na periferia de São Paulo, JACOBI (1990) evidencia dois aspectos importantes: o primeiro diz respeito ao fato de que a população identifica com clareza as deficiências 
existentes na moradia e relaciona tais problemas ao aparecimento de agravos respiratórios:

"As correntes de ar frio, os buracos na construção, o chão frio, as infiltrações de água e a falta de ventilação foram apontados como as principais causas de bronquites, resfriados, gripes e pneumonias" (JACOBI, 1990 p. 125).

Em segundo lugar, a população citou os problemas existentes no bairro, associando-os à incidência das doenças, englobando inclusive os problemas decorrentes da violência percebida e, muitas vezes, vivenciada. No entanto, os profissionais das instituições públicas de saúde situadas nos bairros em que foi realizada esta pesquisa, apesar de relacionarem a ocorrência de doenças às condições ambientais, não mencionavam nada a esse respeito nas orientações acerca do tratamento e prevenção de novos casos para os clientes atendidos.

Mais uma vez evidencia-se que, apesar de se reconhecer uma parcela da gênese social dos perfis epidemiológicos, a atuação em saúde se dá de forma desvinculada de outros setores, reforçando a idéia de que a resolução dos problemas centra-se nas ações curativas e individuais.

Segundo COHN et al. (1991) a dicotomia instaurada na prestação de serviços em saúde origina-se na história da estruturação dos serviços, que impunha uma divisão de responsabilidades, na qual, ao Estado competia o controle das endemias e epidemias com ações de alcance coletivo e a assistência individual curativa ficava sob a responsabilidade do seguro social. Propõe como processo de superação desta prática de reprodução de programas verticais e calcados na assistência médicacurativa, a necessidade de "debruçar-se não só sobre a carência diagnosticada, mas à sentida pela população e, da mesma forma, não só sobre as necessidades de saúde tecnicamente diagnosticadas, mas também sobre o processo através do qual essas necessidades se transformam em demandas."(p. 26). Destaca-se a ênfase dada às 
mediações simbólicas da população-alvo das ações de saúde a respeito da vivência do processo doentio, bem como sobre as percepções e explicações atribuídas ao mesmo.

Mais recentemente, a mesma autora refere que o atual desafio para a Saúde Coletiva deve ser o de superar os enfoques de atuação sobre a pobreza, entendida somente do ponto de vista material, incorporando o conceito de "emancipação", recuperando as carências observadas na esfera da participação. Baseia tal proposição no conceito de desenvolvimento humano, ampliando o entendimento de desenvolvimento social, incorporando a extensão e maior distribuição dos beneficios advindos do crescimento econômico, a recuperação do ambiente e a necessidade do fortalecimento da participação das camadas mais pobres da população em termos de resguardar oportunidades e condições de escolha. Os processos emancipatórios enfocam a identificação e a superação dos problemas relacionados à liberdade das pessoas e visam, em última instância, a promoção da democratização da sociedade, através do fortalecimento das instituições/organizações representativas da população no âmbito da sociedade civil. Segundo Sen citado por COHN (1997) ao Estado democrático compete a "capacidade de gestão e de captação de necessidades e demandas sociais", entendidas não somente enquanto carências materiais. Trata-se de assumir a perspectiva intersetorial para formular políticas públicas voltadas para a qualidade de vida, definidas a partir das dimensões socioculturais e pela maior participação comunitária.

Apesar de não se referir diretamente ao gerenciamento das ações de saúde, o interesse deste projeto volta-se para reconhecer, numa determinada localidade, as necessidades sentidas pelos diferentes grupos sociais, reportando-se ao conceito de "chances de vida" apresentado por KADT e TASCA (1993), no cuidado da criança acometida por agravos respiratórios e na sua prevenção.

Esta pesquisa pretendeu conhecer as necessidades percebidas pelas familias que tenham crianças menores de 5 anos, no tocante ao cuidado das mesmas na vigência de agravos respiratórios. Dado o entendimento de que a saúde-doença 
constitui manifestações de um mesmo processo, que é resultante da forma como a sociedade se estrutura e que define diferentes formas de trabalhar e de viver, buscouse analisar as diferentes chances de adoecer por agravos respiratórios na região, utilizando técnicas de estudo baseadas na territorialização em saúde.

Para tanto, foi delimitada a base geo-social na área de abrangência do Centro de Saúde Escola Samuel B. Pessoa, pertencente ao Distrito Sanitário do Butantã, identificando-se diferentes necessidades da população residente em áreas homogêneas do ponto de vista sócio-econômico e ambiental, isto é com diferentes "chances de vida" e de adoecer por IRA. Buscou-se ainda identificar as diferentes percepções acerca das dificuldades e dos problemas enfrentados pela população pertencente a tais áreas homogêneas. As iniqüidades emergiram assim, a partir da análise da exposiçâo às condições de risco e das potencialidades de enfrentamento da situação.

Os resultados obtidos foram de grande valia para a identificação de diferentes necessidades de atenção dos diferentes grupos que compõem a população da área de abrangência do Centro de Saúde Escola Samuel B. Pessoa O conceito de área homogênea utilizado neste trabalho foi construído a partir de indicadores sócioeconómicos e ambientais associados à doença respiratória (RIBEIRO, et al. 1971; WANDALSEN, et al. 1976; WESTPHAL e CARNEIRO-SAMPAIO, 1984; CARNEIRO-SAMPAIO, et al. 1984; AMARAL, et al. 1997; FONSECA, et al. 1997; VICTORA, 1998). 


\subsection{Objetivo Geral}

O presente estudo visou o conhecimento das necessidades da população residente na área de abrangência do Centro de Saúde Escola Samuel B. Pessoa relativas ao controle dos agravos respiratórios na infância, buscando obter elementos para o planejamento das ações de Promoção e Educação à Saủde em nível local.

\subsection{Objetivos Específicos}

1. Criar instrumentos para caracterizar a área de abrangência do Centro de Saúde Escola Samuel B. Pessoa do ponto de vista sócio-econômico e ambiental identificando os potenciais exposição às condições de risco para os agravos respiratórios na infầncia

2. Identificar as mediações simbólicas dos diferentes grupos residentes na área com relação à vivência do adoecimento das crianças por IRA no cotidiano.

3. Identificar as iniqüidades a partir da análise das necessidades e encaminhamentos possíveis dos diferentes grupos homogêneos em relação ao controle das IRA das crianças. 
Caminho OKetadológico 


\section{Caminho Metodológico}

\subsection{Descrição do cenário de estudo}

A aproximação com a região do Butantã vem sendo efetivada desde o ano de 1995 quando docentes da Disciplina Enfermagem Preventiva e Comunitária do curso de graduação em Enfermagem da Escola de Enfermagem da Universidade de São Paulo implementaram o ensino de campo da referida disciplina em unidades de saúde da região. Naquela ocasião, a partir de contatos com os técnicos do Núcleo de Epidemiologia do Distrito de Saúde do Butantã da Secretaria de Saúde da Prefeitura do Município de São Paulo, atuamos em quatro das 14 Unidades Básicas de Saúde, que compunham o referido Distrito. Um dos estudos desenvolvidos permitiu a caracterização das familias em que haviam ocorrido óbitos por causas respiratórias em crianças menores de cinco anos (CHIESA e BERTOLOZZI, 1997). Foi realizado um estudo epidemiológico para localizar a ocorrência de mortalidade por doenças respiratórias, bem como caracterizar a realidade sócio-econômica das familias acometidas pelo problema, além das suas formas de enfrentamento.

No ano seguinte foi feita uma nova abordagem para a aproximação dos problemas de saúde da população, não mais a partir de agravos ocorridos, mas sim buscando identificar as familias a partir de suas condições de trabalho e de vida. Formaram-se assim grupos considerados homogêneos segundo as formas de vida e de trabalho adequadas ou inadequadas. Com isso pretendeu-se caminhar na construção de um modelo que subsidiasse o planejamento de intervenções em saúde coletiva tendo como referência a concepção de SILOS. Assim, a disciplina Enfermagem Preventiva e Comunitária, em 1996, estruturou-se a partir de uma investigação que tinha como finalidade o reconhecimento da heterogeneidade do coletivo, relativa às formas de trabalho e de vida, bem como as configurações dos perfis epidemiológicos desses grupos homogêneos (QUEIROZ e SALUM, 1997). 
Para a operacionalização dessa proposta foram fundamentais as informações da Fundação SEADE que. em publicação datada de 1992, propôs a hierarquização de variáveis para reconhecer as desigualdades existentes na Região Metropolitana de São Paulo. No referido estudo foi feita uma articulação entre as diferentes situações encontradas relativas, às condições de moradia. instrução, emprego e renda, considerando-se diferentes carências, para conhecer de forma mais detalhada as condições em que vivem as famílias. O trabalho mencionado acima indicou que a utilização simultânea de diferentes indicadores auxilia a orientação de políticas sociais, uma vez que define mais precisamente o conjunto das necessidades da populaçãoalvo.

$O$ delineamento desse estudo teve grande influência das discussões travadas no cotidiano do ensino da disciplina Enfermagem Preventiva e Comunitária, bem como das inquietações decorrentes da necessidade de construir um referencial metodológico capaz de reconhecer as iniqüidades presentes no território do SILOS. Vale ainda destacar, como contribuição definitiva no delineamento desta pesquisa, o curso sobre territorialização em saúde realizado na mesma ocasião num momento em que pairava no campo da saúde coletiva a mesma preocupação na ampliação de instrumentos que permitissem embasar a atuação em saúde para assumir novas responsabilidades decorrentes da operacionalização do SUS. Na esfera da organização dos serviços, tais desafios diziam respeito à articulação dos diferentes setores formuladores das políticas sociais, visando a construção de um novo modelo de Vigilância à Saúde capaz de atuar sobre os determinantes do processo saúdedoença.

O Centro de Saúde Escola Samuel B. Pessoa foi escolhido como unidade básica de saúde de referência do SILOS em parte porque tem assumido um papel de vanguarda na área da Saúde Coletiva, pela implementação de alternativas inovadoras no campo da assistência, ensino e pesquisa. Foi inaugurado em 1977, respondendo à necessidade da época de ampliar a cobertura de serviços de saúde junto à população local. Na sua trajetória de 20 anos, tem registrado a constante busca de inovar e criar 
alternativas tecnológicas no campo da Saúde Coletiva. O C.S.E. é o resultado de um convênio entre a Secretaria Estadual de Saúde de São Paulo e a Faculdade de Medicina da Universidade de São Paulo (SCHRAIBER, MENDES-GONÇALVES, 1996)

Situa-se na região oeste do Município de São Paulo, próximo ao Instituto Butantan e do campus da Cidade Universitária Armando Salles de Oliveira e constitui uma das 14 Unidades Básicas de Saúde que compõem o Distrito Sanitário do Butantã.Segundo dados do Núcleo de Epidemiologia e Informações da Saúde (NEPI) do Distrito de Saúde do Butantã, a população estimada para 1994 no referido Distrito era de 386.609 habitantes sendo que havia 33.947 habitantes com idade inferior a 5 anos. Segundo dados do Programa de Aprimoramento de Informações sobre a Mortalidade do Município de São Paulo (PROAIM), também no mesmo ano de 1994, as doenças respiratórias ocupavam o segundo lugar como causa de óbito dos menores de um ano e primeiro lugar, juntamente com as doenças infecciosas e parasitárias, como causa de óbito entre as crianças de 1 a 4 anos.

Nessa região, as doenças agudas do aparelho respiratório apresentam-se no grupo etário de menores de um ano, como a segunda causa de óbitos e a primeira causa de morbidade, sendo nas de 1 a 5 anos, a primeira causa de mortalidade e de morbidade.

Segundo estudo realizado no Centro de Saúde Escola do Butantã, no ano de 1995 (GOMES, et al. 1997), a prevalência das IRA como motivo de consulta foi de aproximadamente $40 \%$ a $50 \%$ do total de atendimentos em menores de 5 anos. Este mesmo estudo revela que os fatores de risco mais freqüentes nas crianças atendidas, foram: antecedentes de IRA no primeiro ano de vida (63,1\%), tabagismo passivo $(58,1 \%)$ e permanência da criança em creches $(46,9 \%)$. 


\subsection{A população do estudo}

A população estudada foi aquela que habitava os domicílios que integravam os setores censitários da área de abrangência do Centro de Saúde Escola Samuel B. Pessoa. Dada a alta incidência dos agravos respiratórios no perfil de morbidade da população infantil e tendo-se por base o referencial da Vigilância à Saúde e Promoção à Saúde. bem como a abordagem centrada no coletivo, o enfoque da presente investigação voltou-se para a totalidade das familias residentes na área delimitada, para a qual deve voltar-se o trabalho de vigilância à saúde. Nesta perspectiva, torna-se fundamental o conhecimento das iniqüidades presentes na população em tela, para obter subsídios para a implementação de propostas de intervenção. Por isso, partiu-se da comunidade e da população total como referência para a caracterização e posterior identificação de necessidades.

\subsection{Referencial de Análise}

A abordagem dialética foi escolhida para subsidiar a análise, pois possibilita enfatizar as relações entre indivíduo e sociedade. entre base material e as idéias, a realidade e a sua compreensão, destacando-se a atuação do sujeito histórico no processo de transformação social.

No campo da Promoção à Saúde e da Educação em Saúde, como instrumento da primeira. foram buscados os fundamentos da Teoria Crítica em Educação, destacando-se a contribuição de GIROUX (1983). Essa corrente de pensamento focaliza a subjetividade, enquanto força essencial para a emancipação humana e para a mudança social e, portanto, para o "empowerment", possibilitando o fortalecimento da participação popular nos programas de Promoção à Saúde. A análise crítica, nesta perspectiva, contribui para a explicitação das relações de dominação subjacentes à realidade objetiva, tendo como foco de pesquisa a subjetividade e as esferas da cultura da vida cotidiana. 
A Teoria Crítica surgiu com o propósito de repensar e reconstruir radicalmente o significado de emancipação humana, projeto esse que diferia da bagagem teórica do marxismo ortodoxo. Adota como um de seus valores centrais o compromisso de penetrar o mundo das aparências objetivas para expor as relações sociais subjacentes. A análise parte das condições objetivas de vida e volta-se para as relações sociais subjacentes a ela e que lhes dão sustentação, destacando-se as relações de dominação e subordinação, utilizando o quadro de referência dialético para entender as mediações que ligam as instituições e atividades da vida diária com a lógica e as forças dominantes que moldam a totalidade social maior (GIROUX, 1983).

Segundo GIROUX (1983), a Teoria Crítica origina-se a partir do legado do trabalho teórico desenvolvido por alguns membros da Escola de Frankfurt, centrada na crítica ao positivismo e ao marxismo ortodoxo. Com relação à racionalidade positivista, a crítica principal reside no questionamento da estrutura normativa da produção de conhecimento, na medida em que, os fatos aparecem separados dos valores e significados, a objetividade sobrepõe-se à crítica possibilitando que a aparência oculte a essência.

Segundo FLECHA (1996) a prática crítica em educação centra-se na superação das desigualdades criadas por determinado modelo de sociedade, ao recuperar o diálogo como elemento essencial para chegar ao consenso igualitário. $\mathrm{O}$ autor ressalta, no entanto, que dada a inserção social desigual, os sujeitos encontramse com poderes também desiguais.

Essa preocupação respalda-se na Teoria da Ação Comunicativa de HABERMAS, citado por FREITAG (1993) na qual a superação dos problemas da modernidade passa por dois processos:

- A subordinação do mundo sistêmico ao mundo vivido, ou seja "a fixação de objetivos políticos, a organização da economia devem, em última instância, respeitar a volonté générale formada e validada nas instituições do cotidiano do 
mundo vivido. O caráter sistêmico, auto-regulador da reprodução material da sociedade, deve ser respeitado na medida em que assegure o bem-estar de todos" (FREITAG, 1993, p. 43). Esta perspectiva é análoga ao conceito de comunidade descrito anteriormente por ROBERTSON e MINKLER (1994), ao destacarem a relação dialética entre os micro-sistemas e os macro-sistemas.

- O desenvolvimento de processos emancipatórios que fortaleçam os sujeitos. "Prioritária sempre será a liberdade, a autodeterminação, a auto-realização de todos os membros da sociedade. E isso significa a sua participação permanente na política mediante a articulação de seus interesses e vontades no interior do mundo vivido, via ação comunicativa e discursos (teóricos e práticos)"(FREITAG. 1993, p. 43).

$\mathrm{Na}$ perspectiva acima apresentada a autora destaca o resgate da intersubjetividade e o desenvolvimento de processos emancipatórios para o encaminhamento dos problemas atualmente presentes. $O$ trabalho, na perspectiva da educação crítica, tem potencial para subsidiar o campo conceitual da Promoção à Saúde, na medida em que são destacados como eixos centrais o fortalecimento dos grupos que têm menor acesso às decisões e o estímulo à participação comunitária. Neste sentido, também aproxima-se das proposições de $\mathrm{COHN}$ (1997), ao definir a necessidade de fortalecer o Estado democrático, através da formulação de políticas públicas de caráter intersetorial, que atendam melhor às necessidades da população. Oliveira, citado por COHN (1997), diz que é necessário reorientar o Estado no sentido de que este contemple mais as expectativas da sociedade civil nas suas ações. 


\subsubsection{O processo de territorialização em saúde no contexto da globalização}

No delineamento deste estudo foram fundamentais as proposições de SANTOS (1994) e UNGLERT (1995), para os quais o território assume uma dimensão diferenciada na formulação de políticas públicas, dentre as quais as políticas de saúde. Para SANTOS (1994), a nova ordem mundial impõe a lógica do mercado a todas as instâncias da vida, baseada na supremacia da competitividade que assume proporções assustadoras, na medida em que, para seus defensores, não deve ser regulada. A globalização tem sido um processo muito mais voltado para unificar do que para unir, não respeitando as condições históricas e reais de todos os envolvidos.

"Hoje, o que é federativo no nível mundial não é uma vontade de liberdade. mas de dominação. não é o desejo de cooperação mas de competição, tudo isso exigindo um rígido esquema de organização que atravessa a vida humana. Com tais desígnios. o que globaliza falsifica, corrompe, desequilibra, destrói." (SANTOS, 1994 p. 36)

Um dos núcleos de resistência às conseqüências destrutivas desse processo é o espaço local que pode contribuir com o fortalecimento dos segmentos sociais que detém menor poder, pelo fato de constituir cenário do "acontecer solidário". O aspecto central do espaço-local reside na diversidade de objetos presentes na sua constituição e nas relações estabelecidas entre os seus atores. Milton Santos classifica o cotidiano como uma "Quinta Dimensão" de interesse para a análise, com vistas ao enfrentamento dos problemas emergentes.

"Em qualquer momento, o ponto de partida é a sociedade humana realizando-se. Essa realização dá-se sobre uma base material: o espaço e seu uso, o tempo e seu uso; a materialidade e suas formas, as ações e suas diversas feições. "( SANTOS, 1994, p. 42).

$O$ interesse pelo espaço local é intensificado sobretudo pelo conflito estabelecido entre este, que representa o espaço vivido por todos, e o espaço global, enquanto um processo racionalizador e um conteúdo ideológico originado 
externamente. O território engloba as dimensões do mercado e da sociedade civil, tornando-se uma peça fundamental para a análise na perspectiva do conhecimento da realidade (SANTOS, 1994; SANTOS, et al. 1994).

Conceber o território como espaço-local e como pólo distinto da globalização, leva à descoberta de aspectos relevantes na reprodução social dos atores nele envolvidos. Em se tratando da relação estabelecida entre os indivíduos e a sociedade num dado território, compartilhamos da proposição de ARROYO (1995), de que a conquista da cidadania pode ter início na redistribuição eqüitativa de instituições promotoras de serviços vinculados ao direitos inalienáveis do ser humano como a educação, a saúde, a moradia e o lazer. Os espaços que constituem os locais de moradia que deveriam contemplar tais serviços escondem imensas desigualdades, sobretudo nas grandes metrópoles, onde evidenciam-se grandes extensões territoriais carentes desses serviços.

Segundo DOWBOR (1996), o processo de globalização da sociedade cria situações complexas e que se modificam rapidamente, exigindo ainda mais a participação dos atores sociais, sobretudo no que diz respeito aos problemas específicos, cujo enfrentamento é possivel em instâncias mais próximas do cidadão. Se, por um lado, a cidade torna as relações humanas mais impessoais por outro, é onde se encontram grandes contingentes de pessoas vivendo sob condições mais homogêneas, o que possibilitaria o desenvolvimento de processos de organização capazes de reagir frente aos interesses de grupos específicos. Outro aspecto levantado pelo autor de extrema importância para trabalhos no âmbito do fortalecimento da participação comunitária, é a noção da solidariedade:

“A própria recuperação dos valores e a reconstituição da dimensão ética do desenvolvimento exige que para o ser humano o outro volte a ser um ser humano, um indivíduo, uma pessoa com os seus sorrisos e suas lágrimas. Este processo de reconhecimento do outro não se dá no anonimato. E o anonimato se ultrapassa no circuito de conhecidos, na comunidade". (DOWBOR, 1996, p.71) 
Não se trata de uma recuperação idealista do conceito de comunidade traçando uma perspectiva utópica no sentido de inatingível, de que seria uma solução para todos os males atuais. Tampouco trata-se de uma nova aproximação junto ao espaço comunitário nos moldes do que ocorreu na década de 50 sob a política de "desenvolvimento da comunidade", conforma descreve AMMANN (1985), através da qual estabelecia-se uma relação de dominação cultural dos países centrais sobre os povos economicamente dependentes.

O desafio atual para subsidiar as ações comunitárias seria a aproximação com vistas ao desenvolvimento de trabalhos centrados na perspectiva da valorização do local. explorando as potencialidades da vivência solidária como base para o fortalecimento da identidade da cidadania.

$\mathrm{Na}$ área da saúde, vários autores (MENDES 1995; TEIXEIRA. 1995; UNGLERT 1995) relatam a utilização desse quadro conceitual como elemento fundamental para a construção de uma nova abordagem dos serviços em relação ao território que ocupam. No trabalho de UNGLERT (1995), são destacadas as contribuições da Geografia Humana no embasamento deste conceito e descrito o processo de Oficinas de Territorialização, como forma de operacionalização da intervenção em saúde no âmbito do SUS.

“A territorialização em saúde é um processo de apropriação do espaço local por parte da equipe de saúde. É a delimitação do espaço estabelecida pelos atores sociais que habitam esse espaço, respeitando seus valores, crenças, enfim, sua visão peculiar do espaço e, basicamente, sua história. Trata-se de um processo dinâmico, de um território em permanente construção " (UNGLERT, 95, p.120).

Dentro dessa ótica, o Projeto "Cidades Saudáveis" foi proposto pela OPAS, na década de 90, como uma perspectiva de fortalecimento do âmbito local para enfrentar o modelo de globalização nas esferas econômica, cultural e nos processos de 
informatização. Assim, os âmbitos local e regional passaram a assumir um papel de destaque, sobretudo para o enfrentamento dos resultados dos processos de exclusão social e minimização da responsabilidade do Estado que se observa. No Município de Campinas, São Paulo, por exemplo, o grupo de trabalho que implementou o referido projeto, traduziu esta perspectiva na seguinte citação:

“A eclosão do 'local,' que transcende a mera definição geográfica, não constitui uma situação conjuntural, mas que expressa mudanças morfológicas. Os espaços locais vêm adquirindo nos últimos anos uma significativa importância política e social, que se manifesta na aparição e desenvolvimento de problemáticas e movimentos sociais locais, capazes de construir suas próprias agendas e com possível disposição para resolver suas necessidades e demandas particulares." (AKERMAN et al. 1997)

A perspectiva apontada anteriormente apresenta uma identidade com o conceito de empowerment descrito no capítulo de Marco Conceitual, principalmente por incorporar a dimensão do coletivo na superação dos problemas, rompendo com o enfoque centrado nas mudanças individuais. Pode-se dizer que a base teórica que subsidia os projetos denominados de Cidades Saudáveis, concretiza o empowerment coletivo.

PAIM (1997) descreve diferentes abordagens que têm sido utilizadas na compreensão da relação entre a estrutura social e as condições de saúde. Destaca as contribuições de POSSAS (1989), que refere-se à inserção no mercado de trabalho como condição básica na definição das distintas condições de vida e estilos de vida. Salienta ainda a importância do reconhecimento da intervenção do Estado, por intermédio das políticas públicas, no atendimento das necessidades de reprodução social dos diferentes grupos.

"O estudo das condições de vida de determinados grupos sociais deve levar em conta não só a distribuição da renda e o poder aquisitivo na esfera do poder individual, mas também certas ações estatais que buscam garantir o atendimento de necessidades consideradas básicas para a sobrevivência, como, por exemplo, 
saúde, saneamento, educação. alimentação e nutrição, lazer, segurança, entre outras” (PAIM. 1997 p. 11).

$O$ referido autor destaca ainda a propriedade da base territorial para a realização de investigações epidemiológicas voltadas para as condições de vida e inserção espacial dos grupos humanos, utilizando o território não somente na perspectiva física ou natural, mas como processo histórico e social, podendo constituir uma alternativa teórico-metodológica para a análise das necessidades e desigualdades sociais. Considerando-se que o espaço é socialmente construido, ele pode constituir uma possibilidade para a estratificação da população, segundo condições de vida e para indicar relações entre a saúde e a estrutura social. Tais estudos serviriam para orientar politicas públicas norteadas pela eqüidade e formular intervenções capazes de aprimorar as condições de vida e saúde (PAIM, 1997). 


\subsection{As etapas do processo}

Partindo do foco central do presente estudo, relativo à operacionalização do conceito de eqüidade para subsidiar a formulação de propostas de intervenção no campo da Promoção à Saúde, bem como as indicações de que o pesquisador deve utilizar o maior número de dados disponíveis da realidade local, esse estudo foi estruturado em duas etapas. Num primeiro momento foram utilizadas técnicas quantitativas de geo-processamento lançando-se mão dos resultados de pesquisas quantitativas anteriormente realizadas associadas a processos de discussão junto à população local. Na segunda etapa foi estruturada uma pesquisa qualitativa que permitiu conhecer mais profundamente o sistema de valores existentes numa determinada localidade bem como as mediações simbólicas que a população faz entre causalidade das IRA e as condições de vida decorrentes das diferenças de inserção social.

Conforme destacado anteriormente, a opção metodológica é ancorada na concepção de eqüidade e no fortalecimento da participação da população para a superação da problemática da saúde/doença, identificando-se claramente a interdependência entre saúde e desenvolvimento social. Reconhece-se assim, como fulcro das ações de Promoção à Saúde a identificação de fatores que geram as iniqüidades, assim como a atuação no sentido da transformação das atitudes e condutas da população (MINISTÉRIO DA SAÚDE, 1996).

Para isso, recuperou-se a experiência de estudos que evidenciam as iniqüidades decorrentes da inserção desigual dos indivíduos na sociedade, visando uma atuação conseqüente tendo em vista a minimização das mesmas através da formulação das políticas públicas. Neste sentido, destaca-se o trabalho coordenado por SPOSATI (1996), no qual foram utilizados indicadores compostos para evidenciar as desigualdades sociais existentes na cidade de São Paulo. O presente estudo também contemplou o delineamento metodológico dos estudos ecológicos que utilizam a área geográfica como unidade de análise, permitindo a comparação de 
indicadores de saúde e sócio-econômicos a partir de dados obtidos no Censo. Para BORRELL (1997), tais estudos oferecem um produto diverso daqueles que partem dos dados relativos aos indivíduos, pois medem outro fenômeno relativo ao ambiente social onde os indivíduos vivem além do fato de considerarem as causas sociais das doenças, podendo auxiliar na formulação de políticas voltadas para os problemas sócio-sanitários. CASTAIRS (1981), citado por BORREL (1997), por exemplo, que trabalhou com variáveis censitárias e CASTAIRS e MORRIS (1988), citado por BORREL (1997), constituem exemplos de estudos ecológicos baseados nos índices de privação, de grande contribuição para a identificação de problemas e formulação de políticas específicas.

CASTELLANOS (1997a) também destaca a contribuição de estudos que utilizam a dimensão ecológica para a Saúde Pública, principalmente, no caso da formulação de ações específicas para os diferentes perfis de saúde dos diferentes grupos sociais e para produzir impacto sobre as iniqüidades sociais em saúde.

Por reconhecer a relevância da inserção social dos indivíduos nos seus perfis de morbi-mortalidade, optou-se por analisar as condições de risco para as doenças respiratórias na região de abrangência do C.S. E. Samuel B. Pessoa, levando-se em conta as categorias das condições objetivas de vida, da população alvo das ações de vigilância à saúde e suas mediações simbólicas no que diz respeito à vivência dos problemas respiratórios e os encaminhamentos possiveis apontados. Trata-se, portanto, de um estudo analítico com base na relação dialética entre as dimensões objetivas e subjetivas acerca do controle das IRA na região, buscando evidenciar as contradições entre as mesmas nos diferentes grupos da população estudada. Ao descrever o entendimento subjacente às mesmas enquanto categorias analíticas do processo investigativo, serão descritas as etapas componentes da pesquisa. 


\subsection{Fundamentação das categorias analíticas}

Tendo em vista o referencial teórico e a finalidade desse estudo foram utilizadas técnicas quantitativas e qualitativas para captar as dimensões objetivas de exposição às condições de risco ambiental para as IRA aliadas à dimensão subjetiva, para captar as medições simbólicas dos sujeitos acerca das suas condições objetivas de vida.

3.5.1 Dimensão objetiva constituiu a caracterização das condições materiais de vida das familias envolvidas na investigação, que podem levar ao conhecimento das diferentes condições geradoras de saúde (KADT e TASCA, 1993).

Tendo em vista a caracterização da base territorial que conforma a área de abrangência do Centro de Saúde, primeiramente foram identificados os setores censitários componentes da mesma. Para tal, foi fundamental a colaboração dos técnicos da Vigilância Epidemiológica do Centro de Saúde que nos forneceram dados relativos à atual composição dos setores, visto que houve mudança de delimitação dos mesmos no Censo de 1991.

A partir daí, o Instituto Brasileiro de Geografia e Estatística, IBGE, forneceu dados sobre o conjunto de 49 setores censitários componentes da área de abrangência em estudo disponibilizando um conjunto de 294 variáveis referentes aos domicílios particulares permanentes pertencentes à área. Essa classificação é apoiada nas seguintes definições do UNICEF/IBGE (1994):

Domicílio: local de moradia estruturalmente separado e independente, constituído por um ou mais cômodos. A separação fica caracterizada quando o local de moradia é limitado por paredes, muros, cercas, etc. coberto por um teto e permite que seus moradores se isolem, arcando com parte ou todas as suas despesas de alimentação ou moradia. 
Particular: quando o domicílio é destinado à habitação de uma pessoa ou de um grupo de pessoas cujo relacionamento é ditado por laços de parentesco, dependência doméstica ou ainda, normas de convivência.

Permanente: o domicílio localizado em casa. apartamento ou cômodo e destinado à moradia.

Para atender aos objetivos descritos anteriormente, foram selecionadas algumas variáveis que permitissem a caracterização da inserção social da população residente na área. Com isso, buscou-se identificar situações de exposição a diferentes gradientes de condições favoráveis à vida (chances de vida) e de risco para o adoecimento por agravos respiratórios, tomando como foco o coletivo como um todo, incorporando o conceito de eqüidade em relação à saúde, distinguindo-se assim do conceito muitas vezes utilizado relativo ao consumo dos serviços de saúde. Partiuse da identificação das iniqüidades existentes para poder contemplar a eqüidade no processo de formulação da intervenção no âmbito da Promoção à Saúde.

Tal caracterização foi baseada na construção de indicadores compostos que constituem "medida que associa diferentes variáveis sócio-economicas e de ambiente num indicador sintético para analisar as características de grupos populacionais vivendo em determinadas áreas geográficas" (AKERMAN et al. 1996“).

Dentre as variáveis disponíveis no banco de dados fornecido pelo IBGE, foi identificado, primeiramente, um conjunto que pudesse retratar os aspectos de inserção social dos sujeitos e outro conjunto mais voltado para as condições do domicílio, dada a importância dessas no desencadeamento dos agravos respiratórios. Os conjuntos de variáveis foram denominados indicadores de inserção social e de qualidade do domicílio e ao final, compuseram o índice de potencial de exposição às condições de risco ambiental para o adoecimento por IRA. Apresenta-se a seguir o esquema utilizado para a construção dos indicadores compostos que formaram a base 
instrumental para a comparação dos setores censitários com vistas à identificação das desigualdades sociais potencialmente geradoras de iniqüidades para a saúde.

- Indicador de Inserção Social (IIS): Renda do Chefe do Domicílio, Escolaridade do Chefe. Situação de Ocupação do Domicílio

- Indicador de Qualidade do Domicílio (IQD): Acesso à água, Condições Sanitárias, Aglomeração, Coleta de lixo, Tipo de construção.

A seleção das variáveis levou em conta tanto os fatores descritos na literatura, relativos ao adoecimento e morte por IRA em crianças, como também resultados de um processo de discussão através da estratégia de grupos focais junto a lideranças locais para a definição conjunta do peso de cada variável na composição do índice em tela seguindo as recomendações de AKERMAN et al (1996) que postulam como de fundamental importância, que não se defina a priori quais as variáveis que deverão compor os indicadores, propondo que estas sejam definidas a partir de processos participativos a fim de que contemplem as percepções de outros sujeitos, além dos técnicos.

Conforme foi dito anteriormente, diversos estudos apontam como fatores sociais associados às IRA: a baixa escolaridade dos pais; o maior número de pessoas no domicílio, a baixa idade materna, a permanência em período integral em creches ou instituições congêneres, precárias condições sócio-econômicas e habitacionais da familia. (VICTORA et al. 1994; BARATA et al. 1996; MONTEIRO e BENÍCIO, 1987; CARDOSO, 1997). Em função disso, foram identificadas no banco de dados disponíveis as variáveis correspondiam aos fatores associados já conhecidos.

Houve uma grande limitação na conformação do Indicador de Inserção Social no que diz respeito às informações sobre o trabalho dos chefes de família. Acredito que, dado o valor que o trabalho assume atualmente na sociedade que vem prescindindo a cada dia de mão-de-obra e sofrendo um processo rápido e intenso de fragilização das relações de trabalho, com significativas perdas de conquistas 
indiscutíveis para toda a população o ideal seria utilizar dados relativos à inserção no modo de produção dos chefes das familias do estudo. No entanto, não foi possível encontrar dados desse âmbito em termos dos setores censitários, inviabilizando a incorporação dessa categoria na composição do Indicador de Inserção Social, apesar de considerá-la importante. Aśsim, o indicador incluiu a escolaridade do chefe, a renda per capita, que foi calculada, e a situação de ocupação do domicílio por entender, que esta última, seria uma possibilidade de retratar uma condição de maior ou menor estabilidade no vínculo com a moradia e, possivelmente, a fixação no território, permanente ou temporária.

Com relação ao Indicador Qualidade do Domicílio, foram selecionadas cinco variáveis para retratar as condições de conforto em termos de exposição da criança às friagens ou a outro fator deletério à sua saúde, que pudesse atuar como um facilitador do adoecimento por IRA. Incluiu as variáveis: acesso à água; condições sanitárias; aglomeração (calculada a partir do número médio de dormitórios e número de pessoas dos domicílios); coleta de lixo e tipo de construção.

De acordo com o referencial teórico da Promoção à Saúde, que preconiza a aproximação entre técnicos e população através de processos de discussão conjunta dos problemas e encaminhamentos possíveis para sua superação e, tendo em vista a finalidade deste estudo de não reproduzir uma prática de diagnóstico da situação apenas unilateralmente, por parte dos técnicos de um setor de prática de políticas públicas, buscou-se contemplar este aspecto através da discussão sistematizada junto aos setores representativos da população local, utilizando-se a técnica de Grupo Focal. Foram realizados dois encontros com representantes da comunidade para apresentar esta proposta de conjunto de variáveis e incorporar as sugestões. As discussões foram realizadas em duas datas diferentes, reunindo representantes do Conselho Tutelar da Criança e do Adolescente do Butantã, técnicos do Centro de Educação Ambiental, representantes do Parque da Previdência e membros da Pastoral da Saúde e Criança, envolvendo um total de 21 pessoas, sendo 8 participantes no primeiro grupo e 13 no segundo grupo. 
Os participantes foram convidados a participar em função do seu maior conhecimento da realidade local, seja pelo fato de serem moradores com alguma atividade distinta do conjunto, ou pelo fato de trabalharem em instituições públicas ligadas à preservação do meio ambiente ou de proteção à criança. $\mathrm{Na}$ ocasião, foram também convidados representantes de outras entidades representativas de moradores, mas não foi possível contar com a presença destes últimos nas reuniões.

A escolha da técnica de grupo focal para o desenvolvimento das reuniões respaldou-se nas considerações de WESTPHAL; BÓGUS; FARIA (1996) de que os grupos focais constituem estratégia que facilita a obtenção de dados com profundidade e abreviação do tempo quando se trata de temática relativa à vida, sobretudo quando o aspecto a ser estudado diz respeito à relação entre pessoas que não têm um relacionamento habitual.

Para BASCH (1987) "a entrevista de grupo focal constitui-se numa técnica de pesquisa qualitativa utilizada para obter-se dados sobre sentimentos e opiniões de pequenos grupos de participantes acerca de determinado problema, experiência, serviço ou outro fenômeno" (1987, p.414). Sua operacionalização requer que o trabalho seja desenvolvido junto a um número pequeno de participantes e, por isso, os dados obtidos através dessa estratégia não são generalizáveis.

Segundo WESTPHAL; BÓGUS; FARIA (1996) os grupos focais surgem como técnica de pesquisa no campo das ciências sociais na época da II Guerra Mundial, ressurgindo mais recentemente, sobretudo no campo da psicologia social, nas pesquisas de mercado e no campo da saúde. Neste último, vem se consolidando enquanto uma opção metodológica ligada às pesquisas qualitativas.

Todos os trabalhos citados destacam que o êxito da aplicação da técnica de grupo focal depende fundamentalmente da atuação do coordenador que deve garantir um ambiente de troca de opiniões e não de disputa, facilitando a interação entre os 
participantes. Outra habilidade necessária é a de manter a discussão no tema central, fazendo sumarizações da discussão sempre que necessário, para auxiliar o grupo na reflexão conjunta, ou ainda, aproveitando as oportunidades para colocar novas questões que possam aprofundar a discussão revelando outras facetas do tema. Outro aspecto também destacado por diversos autores é a necessidade de conduzir o processo de discussão mantendo-se atento à comunicação não verbal do grupo, para que possa ser evidenciada a maior diversidade de opiniões ou sentimentos relacionados ao tema. Este aspecto é de fundamental importância em se tratando de uma técnica que explora a subjetividade dos atores envolvidos. (BASCH, 1987)

Ainda enquanto habilidade do coordenador. é destacada a clareza para expor a finalidade da discussão e o que se espera dos participantes. Caso fique obscuro este aspecto, a reunião poderá gerar insegurança e se configurar num encontro improdutivo e sem sentido, ou pior ainda, num clima de hostilidade. Vale lembrar que não se trata de evitar explicitar os conflitos e divergências presentes no grupo e sim abordá-los esclarecendo as diferentes opiniões, sem encaminhar para a polarização em que uma posição possa prevalecer sobre a outra, ou ainda, em que seja necessário chegar ao consenso. É, portanto, fundamental que o coordenador tenha experiência no desenvolvimento deste tipo de técnica, já que a maioria das situações surgem no desenvolvimento da discussão, sem que possam ser preparados a priori os encaminhamentos mais apropriados. (BASCH, 1987)

Por se tratar de uma entrevista grupal, tem como vantagem o alcance do maior número de pessoas num menor tempo e a possibilidade do aprofundamento das discussões em função da troca que ocorre no grupo. (GLIK et al. 1987-1988)

Durante as reuniões, num primeiro momento foi feita pela pesquisadora a apresentação dos participantes e uma breve exposição da temática central da pesquisa. Foi destacada a necessidade de incorporar à metodologia um peso distinto para cada variável, a partir da recuperação do conhecimento da realidade local. Nos dois grupos houve grande participação dos presentes que se mostraram muito interessados em 
acompanhar todo o restante do processo de investigação. Um aspecto muito interessante a ser ressaltado é o fato de que as pessoas têm sempre muito a dizer a respeito da realidade vivida, carecendo muitas vezes de espaços oportunos para manifestar suas reflexões.

As discussões com a população confirmaram a proposta inicial no tocante à indicação das variáveis e tiveram como resultado a ponderação destas para a construção dos indicadores, bem como o peso dos indicadores na construção do indice. Ou seja. diante dos dados disponíveis pelo IBGE, houve consenso em utilizar as variáveis propostas, não tendo sido acrescentada nem retirada nenhuma delas. $\mathrm{O}$ resultado final dos grupos focais foi o esquema de hierarquização das variáveis. Com relação ao IIS foi sugerido que o peso maior recaísse sobre a escolaridade e com relação ao IQD foi indicado que o peso maior deveria ser dado ao número de pessoas por dormitório. denominado no estudo por condições de aglomeração (peso 3) seguido de condições sanitárias e tipo de construção (peso 2) e finalmente, acesso à água e coleta de lixo (peso 1).

Quanto à conformação do Índice de Potencial de Exposição às Condições de Risco Ambiental para os Agravos Respiratórios que representa a síntese dos dois indicadores, foi sugerido que o IIS tivesse peso 2 sobre o IQD.

Os dados sobre os setores censitários receberam tratamento estatístico, tendo sido calculada a média ponderada de cada setor em cada variável selecionada, que representa a situação típica da mesma em cada setor. Em seguida, as variáveis componentes dos indicadores receberam os diferentes pesos para o cálculo dos mesmos. O peso de cada variável também sofreu modificações a partir do esquema básico proposto, levando-se em conta a determinação social do processo saúde/doença, os fatores predisponentes ou facilitadores dos agravos respiratórios em crianças descritos na literatura e, também, as sugestões apresentadas pela população que participou dos grupos focais. Chegou-se então, ao seguinte esquema para compor os indicadores: 


\section{Indicador de Inserção Social:}

$\underline{\text { Renda }+2 \times \text { Escolaridade }+ \text { Ocupação do Domicílio }}$

4

\section{Indicador de Qualidade do Domicílio: \\ Água $+2 \times$ Cond. Sanit. $+3 \times$ Aglomeração $+2 \times$ Tipo de const. + Lixo}

A partir dos conjuntos de indicadores buscou-se estabelecer a relação entre ambos para se chegar ao Índice de Exposição Ambiental para os Agravos Respiratórios através da expressão:

\section{Índice de Potencial de Exposição Ambiental: 2 x IIS + IQD}

Os setores censitários foram comparados e chegou-se a um "ranking" dos mesmos estabelecendo-se os diferentes potenciais de adoecimento por IRA. Não foram utilizados dados relativos à incidência dos agravos respiratórios porque $o$ objeto da pesquisa centrou-se nos potenciais para o adoecimento tendo em vista um trabalho de Promoção à Saúde, ou seja, uma situação anterior ao adoecimento.

Depois de conhecer a realidade local em termos das desigualdades existentes, procedeu-se à Segunda parte da pesquisa relativa ao conhecimento do cotidiano das famílias residentes nas diferentes situações, visando reconhecer as necessidades sentidas no enfrentamento dos agravos respiratórios.

\subsubsection{Dimensão Subjetiva:}

Segundo TRIVIÑOS (1995) "a grande propriedade da consciência é a de refletir a realidade objetiva. Assim surgem as sensações, as percepções, 
representações. conceitos e juizos. Todos eles são imagens. Reflexões adequadas. verdadeiras da realidade objetiva. Estas imagens são produtos ideais.”(p.62)

A identificação das mediações simbólicas entre a realidade objetiva e ocorrência de agravos por IRA permite conhecer as necessidades sentidas do ponto de vista da população moradora na área de abrangência do serviço para que sejam contempladas ao se formularem as proposições de intervenção no âmbito da educação e promoção à saúde. Tal afirmativa baseia-se na premissa da atuação junto aos grupos sociais inseridos num mesmo espaço homogêneo e que partilham condições sócioeconômicas e ambientais semelhantes.

O conceito de necessidades utilizado no presente trabalho segue a proposição de MENDES-GONÇALVES (1992), de que o ser humano caracteriza-se por ser naturalmente dotado de necessidades e poderes. As necessidades estariam relacionadas à qualidade de pertencer à natureza, ou seja, todo ser vivo tem determinadas necessidades. Por sua vez os poderes dizem respeito às habilidades para atender a tais necessidades na luta pela sobrevivência. Exercer a humanidade seria o contínuo reconhecimento de suas necessidades, aprimorando as formas de superação das mesmas. O autor esclarece ainda que as necessidades estão intimamente vinculadas ao modo como a sociedade produz e distribui os bens de consumo. subordinando as necessidades de reprodução ao modo de produção social.

“As necessidades 'sentidas' são portanto, históricas: constituem o conjunto de necessidades de toda ordem que devem estar presentes para a reprodução do homem em um certo período e em uma certa sociedade. e eventualmente, em cada grupo particular de homens nessa sociedade" (MENDES-GONÇALVES, 92, p. 20)

Segundo HELLER, citada por MENDES-GONÇALVES (1992), as necessidades são certamente conscientes e dizem respeito aos indivíduos apesar da sua gênese social, ou seja, decorrem do fato de que a sociedade se estrutura de determinada forma, mas sempre se tratará de necessidades de indivíduos. 
A leitura que os indivíduos fazem da realidade vivida está pautada em determinados códigos de valores, que irão orientar sua conduta. DI NICOLA (1994) ressalta a importância de ampliar mais estudos para conhecer o que os individuos alvos de programas acreditam sobre o que os mantêm saudáveis ou consideram ser prejudicial à sua saúde, ao invés de avaliar apenas a sua conduta frente às imposições dos serviços e profissionais de saúde.

CASTELLANOS (1997a) também destaca a importância de serem adotados procedimentos metodológicos que recuperem a subjetividade coletiva das populações ou a forma como esta se manifesta em cada grupo populacional. $\mathrm{O}$ autor estabelece a distinção existente entre necessidades e problemas. considerando estes mais complexos, relativos a processos que interelacionam o plano material das necessidades e a subjetividade dos sujeitos.

Para estabelecer uma aproximação proficua junto à população no campo da saúde coletiva, seria necessário descortinar a inter-relação existente entre necessidades e identificação de problemas anteriormente à proposição de ações.

Buscando superar tais lacunas de conhecimentos, foi estruturada uma segunda fase da pesquisa, na qual, a partir de uma amostra representativa da população infantil componente dos grupos homogêneos de setores identificados anteriormente, foram feitas entrevistas domiciliares.

\section{A pesquisa qualitativa}

O desenvolvimento desta fase foi pautado em métodos qualitativos. A técnica utilizada foi a entrevista semi estruturada junto aos familiares das crianças, em visitas nos domicílios dos setores censitários, com posterior análise temática e identificação das necessidades apontadas pela população. Para tanto foi elaborado um roteiro de entrevista estruturado para atender ao segundo objetivo deste trabalho qual seja identificar as mediações simbólicas dos diferentes grupos residentes nessa área com 
relação à vivência do adoecimento por IRA no cotidiano. Este instrumento foi testado e encontra-se no anexo 2.

\section{Definição da amostra}

Para a realização das entrevistas, partiu-se da conformação dos referidos grupos. em termos da concentração da população infantil. para contemplar minimamente o critério de representatividade para a realização das entrevistas domiciliares. Vale destacar que para esta etapa de cunho qualitativo não havia necessidade fixar a priori o número de entrevistas, já que o critério que embasa os estudos qualitativos é realizar tantas entrevistas até que os temas presentes se repitam Partiu-se de uma primeiro parâmetro para estabelecer a amostra desta etapa qualitativa. que foi o maior número de entrevistas de campo possiveis de serem realizadas num periodo de 15 dias com uma equipe de 4 entrevistadores. O número obtido a partir desse critério foi de 64 entrevistas, distribuidas percentualmente segundo a concentração de crianças menores de 5 anos nos diferentes grupos homogêneos, analisando-se conjuntamente a questão do esgotamento dos temas. Foram realizadas 14 entrevistas no Grupo I; 8 entrevistas no Grupo II; 19 entrevistas no Grupo III e 23 entrevistas no Grupo IV.

O critério de aleatoriedade da amostra foi contemplado. através de sorteio de um ponto no mapa de cada setor censitário componente dos grupos. O ponto delimitado servia como referência para o pesquisador de campo iniciar a localização de domicílios nos quais houvesse pelo menos uma criança de até cinco anos de idade residindo. As pesquisadoras percorriam a área e ao encontrar uma família residente que atendia aos critérios, expunham o trabalho e indagavam sobre a disponibilidade de participarem da pesquisa.

\section{Preparo do campo}

Vale mencionar que próximo à data da fase de campo, foi divulgada uma matéria sobre a pesquisa em questão, em jornal de distribuição gratuita, relatando a finalidade do trabalho, inclusive com fotos das entrevistadoras, visando divulgar o trabalho e 
ampliar a adesão da população. diminuindo as possiveis recusas. A equipe de pesquisadoras recebeu um treinamento para a realização da atividade que incluiu reuniōes com discussão e leitura de textos sobre metodologia qualitativa, com ênfase nas habilidades da entrevista não diretiva.

\section{Coleta de dados}

O trabalho de campo contou. também. com a participação direta de uma visitadora sanitária do Centro de Saúde Escola que tem um conhecimento grande da área geográfica. o que facilitou a localização dos pontos sorteados para percorrer os setores censitários.

As entrevistas domiciliares foram realizadas junto aos responsáveis por familias que atendiam ao critério descrito. após consentimento. com a finalidade de conhecer a ocorrência de morbidade atual dos agravos, os aspectos significativos relacionados à vivência dos familiares, a sua opiniâo em relaçâo às causas presumiveis do adoecimento e indicações e sugestões para um possível para o maior controle das IRA. numa perspectiva de atuação na Promoção à Saúde. As entrevistas seguiram o roteiro constante no anexo 2 e foram feitas em diferentes dias da semana, inclusive aos sábados. entre às 9:00 e as 18:00hs, nos meses de março e abril de 1998 .

\section{Análise dos dados}

Segundo MINAYO (1993), existe uma dificuldade operacional no tratamento dos dados qualitativos. A denominação Análise de Conteúdo é genérica e abarca diferentes métodos quantitativos para decifrar o material qualitativo, neglicenciandose muitas vezes, o conhecimento da significação dos sujeitos porta-vozes dos enunciados. Segundo a mesma autora, o momento atual das discussões acerca dos caminhos para o tratamento de dados qualitativos tem à frente o desafio de superar o nivel do senso comum que emerge dos discursos e o subjetivismo do pesquisador na interpretação dos dados, com vistas a estabelecer uma vigilância crítica para o tratamento de dados provenientes de textos, entrevistas e documentos. Dentre as diferentes técnicas que compõem a Análise de Conteúdo, destaca-se a Análise 
Temática, que se configura como mais rápida. na medida em que se limita à identificação de temas ou núcleos de significação dos enunciados, suprimindo-se a inferência da perspectiva analítica. Permite descobrir os núcleos de sentido constitutivos de determinada comunicação, sendo apropriada no estudo de motivações, opiniões, crenças, atitudes, valores ou tendências, seja no discurso individual ou no grupal (BARDIN, 1988).

A operacionalização da Análise Temática enquanto recurso metodológico implica no desenvolvimento de três etapas:

1. Pré-Analítica: o pesquisador deve ler o material inúmeras vezes e ao final estabelecer os temas ou categorias emergentes do discurso, quer pela freqüência com que surgem ou pelo fato de denotarem valores ou comportamentos relativos aos discursos.

2. Exploração do Material: processo no qual o material é codificado e os dados são sistematizados. recortando trechos de discurso que irão compor os temas.

3. Interpretação dos Resultados: tradicionalmente é utilizada a freqüência estatística como parâmetro para a interpretação. No entanto, é possível enfatizar a diversidade de significados ao invés do aspecto estatístico. A partir da sistematização anterior o pesquisador passa para a análise e interpretação dos dados, tendo como referência o quadro teórico no qual o estudo foi delimitado.

Segundo MINAYO (1993), na abordagem dialética a interpretação exige a elaboração de categorias analíticas para desvendar as relações essenciais alicerçadas em categorias empíricas e operacionais.

No presente estudo, os dados da fase qualitativa foram trabalhados seguindose as etapas da Análise Temática proposta por BARDIN (1988). Para a interpretação buscou-se explicitar as contradições dos discursos confrontando-se com a inserção social dos sujeitos, incorporando-se com isso elementos da hermenêutica-dialética e compatibilizando-se com o referencial teórico descrito anteriormente. Tendo por base elementos de aproximação do fenômeno, buscou-se identificar as contradições existentes entre a realidade objetiva dos grupos estudados, as mediações simbólicas 
que fazem das mesmas e as proposições programáticas de enfrentamento do agravo, no sentido de incorporar as necessidades percebidas pelos distintos grupos homogêneos que compõem o coletivo para o planejamento das ações de Promoção de Saúde e Controle das IRA. em crianças menores de cinco anos, no nível local. As categorias empíricas eleitas foram as variáveis sócio-econômicas e ambientais, bem como as percepçôes sobre o adoecimento por IRA do coletivo. Como categoria analítica principal. destacou-se a contradição entre o conceito e a prática vigente, a fim de possibilitar a proposição da superação dialética. 
Caracterização do cenário do estudo 


\section{Caracterização do Cenário do Estudo}

\subsection{Histórico do Povoamento da Região do Butantã}

A região do Butantã, cuịo símbolo é uma Paineira. é um dos bairros do Municipio de São Paulo que manteve uma ocupação predominantemente rural. com fazendas de grande extensão territorial. até o final do século XIX. A denominação é de origem indígena, Boi Netã. passando para Boitatã até o atual Butantan ou Butantã. que significa "taipa de terra roçada". As terras pertenceram primeiramente ao Sr. Afonso Sardinha e depois foram doadas ao jesuitas. Com o confisco dos bens dessa ordem religiosa. tiveram diversos proprietários até que. em 1889. o Sr. Arnaldo de Oliveira Barreto vendeu suas terras à fazenda do Estado. Durante o século XVII. há relatos de que o maior problema vivido pelos moradores da vila era transpor o Rio Jurubatuba. atual Rio Pinheiros. Houve muita dificuldade para a construção de uma ponte que permitisse a comunicação com o bairro de Pinheiros.

Em 1899, por iniciativa do cientista Adolfo Lutz, foi fundado o Instituto Soroterápico numa área da Fazenda Butantan, pelo Dr. Vital Brazil, em função do surto de peste bubônica que. naquela época acometia os moradores da capital (MARTINS. 1995-1996).

Em 1915, após a inauguraçâo do Jockey Club nas proximidades da área do Butantã, a Companhia City comprou uma grande extensão territorial e deu início ao loteamento urbano da área. Em seu trabalho sobre o processo de urbanização da cidade de São Paulo. ROLNIK (1997) descreve a forma como atuava a referida Companhia. no período em questão:

"Para o suprimento de água. esgotos, iluminação e eletricidade, a City financiava o custo de instalações e depois era ressarcida pelas concessionárias através da receita proveniente do consumo" ..."Graças, portanto, aos laços com a Light e com figuras-chave na política local a City pode usufruir do acesso, em condições privilegiadas, a serviços básicos de infra-estrutura, contando com serviços priorizados pela Prefeitura e pela repartição de Águas e Esgotos, que 
era estadual. além de isenções de impostos. em detrimento dos cofres públicos e das áreas mais populosas e carentes da cidade. onde a necessidade de infraestrutura era urgente" (ROLNIK, 1997, p. 135)

Por volta de 1912 a companhia era proprietária de $37 \%$ da área urbana da cidade de S. Paulo. O Conselho Diretor era composto por representantes dos poderes executivo e legislativo, além de acionistas ligados a incorporadoras estrangeiras. A política da companhia. em função dos interesses desses grupos acionistas, priorizava a extensão de serviços de infra-estrutura urbana a locais rentáveis do ponto de vista do investimento imobiliário. desconsiderando a prioridade em relação à concentração habitacional. por exemplo de bairros operários da época. O processo de urbanização da região teve como ponto de partida esse processo de loteamento que buscava atrair para este local setores diferenciados da população.

Na publicação que relata a história do bairro, apoiado pela Casa da Cultura do Butantã. encontramos um relato de 1958, que descreve a região como um subúrbio em processo de urbanização como prolongamento de Pinheiros e com a construção da Cidade Universitária em curso. Destaca-se também. como patrimônio cultural local. a Casa do Bandeirante. preservando o que havia restado da sede da velha fazenda de Afonso Marinho. seu primeiro proprietário (MARTINS, 1995-1996).

A Cidade Universitária Armando de Salles Oliveira, fundada para sediar os estabelecimentos de ensino da Universidade de São Paulo situados na capital, teve início em 1935. mas foi na década de 60 que recebeu maior incentivo para conclusão das obras. pois os atletas dos IV Jogos Panamericanos seriam hospedados no conjunto residencial (UNIVERSIDADE, 1997). A construção da Cidade Universitária foi mais um fator que contribuiu para que a região mantivesse uma grande área verde e se constituísse num pólo residencial para o conjunto de trabalhadores, estudantes e professores da Universidade de São Paulo.

Atualmente. a região do Butantã como um todo. tem $56,4 \mathrm{~km}^{2}$, englobando 
as micro regiões do Butantã, Rio Pequeno, Morumbi, Raposo Tavares e Vila Sônia. Caracteriza-se como predominantemente residencial, com grande especulação imobiliária. sendo comum a construção de conjuntos habitacionais e grande número de edifícios de apartamentos, sem que no entanto. tenha havido a adequada ampliação da infra-estrutura de equipamentos sociais e de serviços (SÃO PAULO, 1992).

Segundo relatos obtidos dos técnicos do Centro de Educação Ambiental nas reuniões de Grupo Focal. na década de trinta deu-se a ocupação do território através de bairros planejados e na década de 60 iniciou-se a ocupação do território de forma mais indiscriminada. dando início ao surgimento de favelas da região.

\subsection{Qualidade do Ar}

Os sistemas viários e de transporte constituem problemas para a região na medida em que esta é cortada por avenidas e duas rodovias com alta concentração de veículos, principalmente ônibus e caminhões (Vide Mapa 1). Segundo dados fornecidos pela Companhia de Engenharia de Tráfego (CET 1996), a Av. Francisco Morato apresenta um volume diário médio de 50100 veículos no sentido bairrocentro e de 38100 veículos no sentido centro-bairro: a Av. Eng. Heitor Antonio Eiras Garcia. apresenta um volume diário médio que varia entre 6800 e 8200 veículos nos dois sentidos e a Av. Waldemar Ferreira apresenta um volume diário médio entre 27 500 e 24400 veículos nos dois sentidos. Tais vias possibilitam o acesso para os municípios vizinhos de Taboão da Serra, Embu e Osasco, bem como constituem a única via de acesso para a região Sul do país. A ligação inter-regional fica prejudicada pela limitação de pontos de acesso, freqüentemente ocasionando congestionamentos. Com isso, as condições atmosféricas ficam bastante comprometidas, sobretudo nas proximidades às vias de maior fluxo de veículos, em decorrência da elevada concentração de poluentes resultantes da combustão do diesel. 


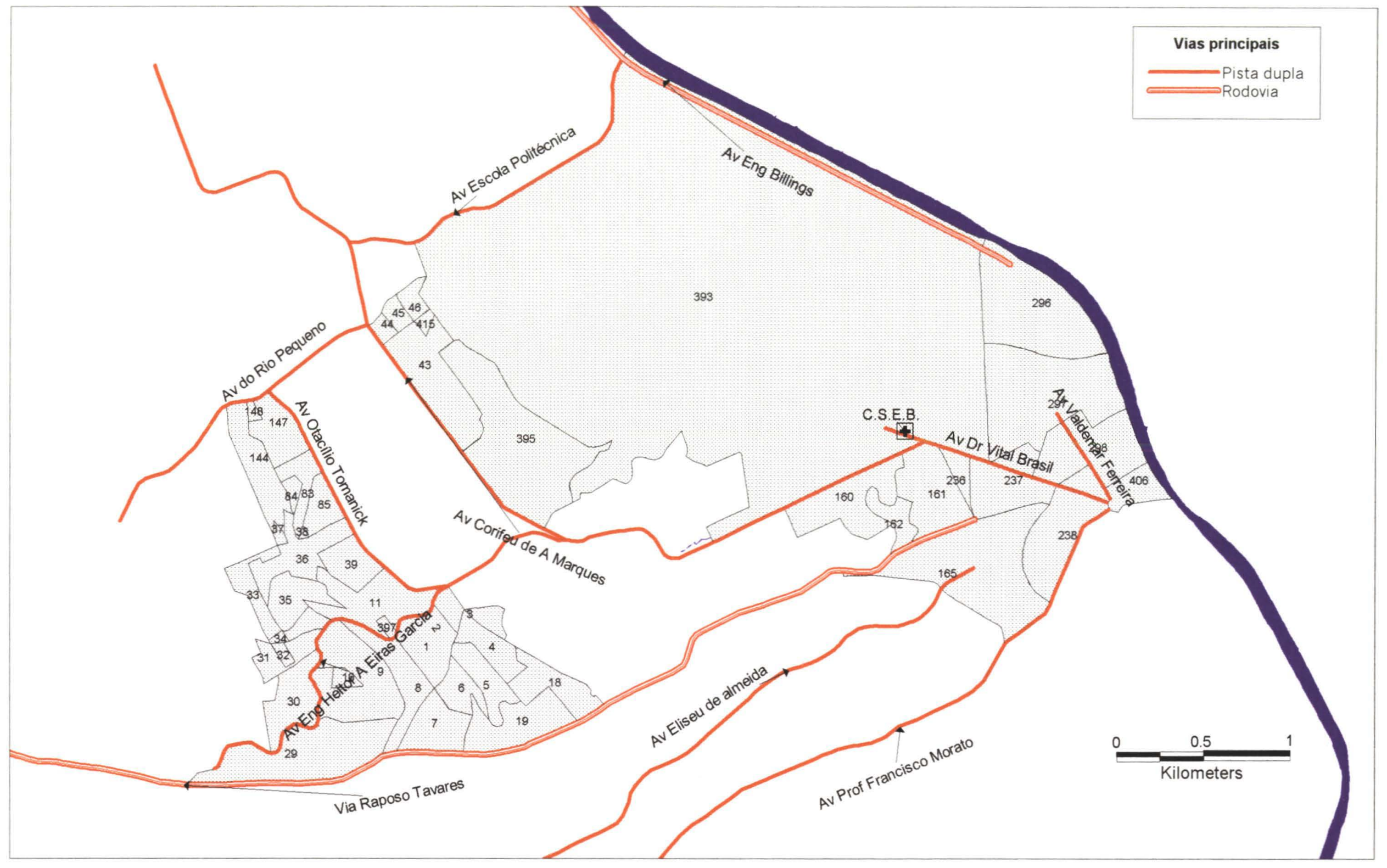

Mapa 1 - Principais vias de acesso da área de abrangência do Centro de Saúde Escola " Samuel Barnsley Pessoa", Butantã, 1999. 
Para melhor caracterização do problema da poluição atmosférica na regiâo estudada foram solicitados à CETESB dados relativos à concentração de partículas inaláveis identificados pela estação fixa de controle da qualidade do ar. mais próxima da micro região em estudo. situada no Município de Taboão da Serra no periodo compreendido entre maio de 1997 e maio de 1998. Vale destacar que a referida estação não efetua medição de outros poluentes de interesse para os agravos respiratórios, como monóxido de carbono ou dióxido de enxofre limitando portanto, o conhecimento de parâmetros ambientais somente em decorrência da concentração das partículas inaláveis (PI). Os dados fornecidos indicam que no período daquele ano. a concentração de PI ultrapassou o limite de $150 \mu \mathrm{g} / \mathrm{m}^{3}$ em 24 horas. conforme o quadro 1. 
Quadro 1: Datas em que a concentração de partículas inaláveis foi superior a $150 \mu \mathrm{g} / \mathrm{m}^{3}$ em 24 horas na estação de Taboão da Serra entre maio de 1997 e maio de 1998

\begin{tabular}{cc}
\hline Data & Concentração de particulas inaláveis $\left(\mu \mathrm{g} / \mathrm{m}^{3}\right)$ \\
\hline $20 / 05 / 97$ & 183,69 \\
$21 / 05 / 97$ & 170.37 \\
$11 / 06 / 97$ & 164,93 \\
$13 / 06 / 97$ & 151,46 \\
$10 / 07 / 97$ & 163,87 \\
$15 / 07 / 97$ & 188,00 \\
$16 / 07 / 97$ & 174,89 \\
$17 / 07 / 97$ & 172,69 \\
$28 / 07 / 97$ & 159,43 \\
$29 / 07 / 97$ & 169,73 \\
$30 / 07 / 97$ & 178,59 \\
$31 / 07 / 97$ & 155,73 \\
$01 / 08 / 97$ & 184,62 \\
$15 / 08 / 97$ & 155,00 \\
$16 / 08 / 97$ & 152,52 \\
$18 / 08 / 97$ & 166,68 \\
$20 / 08 / 97$ & 157,14 \\
$03 / 09 / 97$ & 181,39 \\
$04 / 09 / 97$ & 165,33 \\
$13 / 09 / 97$ & 153,52 \\
\hline Fonte:CETESB
\end{tabular}

Segundo os parâmetros nacionais de qualidade do ar, a concentração de PI não deveria exceder o limite de $150 \mu \mathrm{g} / \mathrm{m}^{3}$ mais do que uma vez ao ano, no entanto, pode-se verificar que. na região do estudo, houve a superação do limite por 20 vezes.

KISHI e SALDIVA (1998) encontraram um aumento de cerca de $20 \%$ no número de internações por causas respiratórias quando a concentração de material particulado excedia o nível de $76,93 \mathrm{mg} / \mathrm{m}^{3}$. Se considerarmos este último valor para análise dos dados fornecidos pela CETESB, enquanto parâmetro acima do qual o ar seria nocivo para a população infantil, (aumentando as possibilidades de ocorrência de morbidade mais grave) esta condição seria encontrada em 87 dias no período de um ano. Este aspecto, portanto, é de grande relevância na região, principalmente em função do grande número de veículos que circulam nas vias públicas. 


\subsection{Caracterização das micro regiões do estudo}

A área de estudo englobou parte das micro regiões do Rio Pequeno e Butantã, apresentadas no mapa 2 que ilustra a localização destas regiões no Município de São Paulo. A região do Rio Pequeno apresenta um número regularmente satisfatório de equipamentos sociais e infra-estrutura, resultantes de conquistas populares, mas ainda com graves problemas em função do grande número de córregos não canalizados, de extensos pontos de enchentes e de grande número de favelas.

Os Distritos ou micro regiões do Butantã e Rio Pequeno integram a Região Oeste 1 da cidade de São Paulo que apresenta indicadores característicos de uma situação intermediária em termos do Município. Ou seja. os distritos que a compõem ocupam posições no "ranking" de exclusão/inclusão social, constituindo-se na terceira região com menor exclusão social na cidade. Num mesmo trabalho comparativo das disparidades existentes no interior de cada Distrito de Paz. o Distrito do Butantã ocupa a $9^{\text {a }}$ melhor posição e o Rio Pequeno a $64^{\text {a }}$ evidenciando uma grande disparidade entre ambos, apesar da proximidade geográfica. A densidade demográfica do Distrito do Butantã é de 46,22 hab $/ \mathrm{km}^{2}$ enquanto que a do Rio Pequeno é de 105.86 hab/ $\mathrm{km}^{2}$ (SPOSATI, 1996).

Durante a gestão Municipal de 1989 a 1993. houve preocupação em ampliar a atuação intersetorial e a participação popular em toda a cidade de São Paulo. Para tanto, na região do Butantã foi criado um Grupo Intersetorial de Planejamento que definiu o meio ambiente como eixo central aglutinador das ações integradas. (SÃO PAULO, 1992) 
Mapa 2 - Município de São Paulo

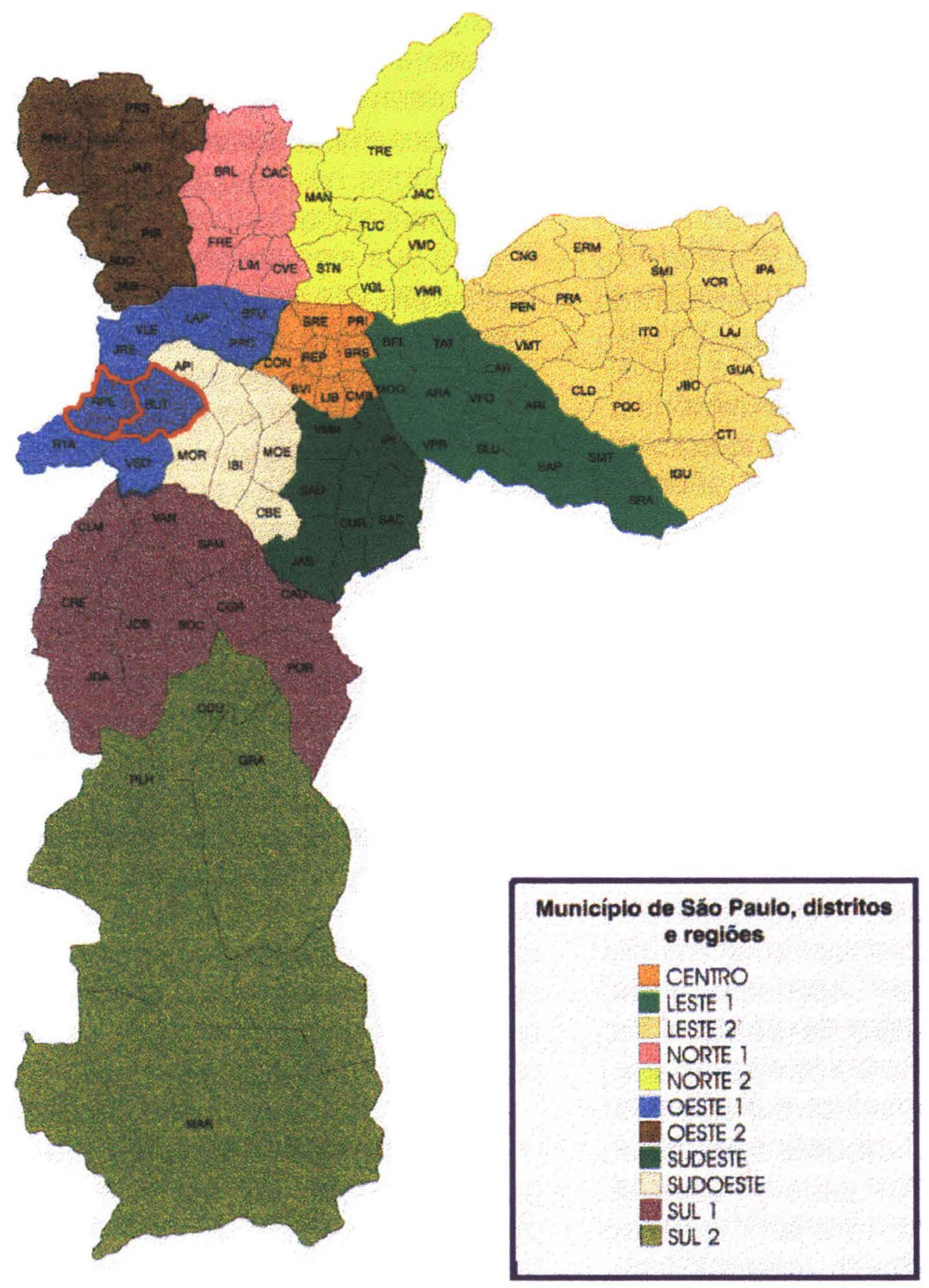

Fonte: SPOSATI, 1996 (Destaque em vermelho na Zona Oeste 1 nosso) 
O Centro de Saúde Escola Samuel Barnsley Pessoa situa-se próximo ao Instituto Butantã e à Cidade Universitária Armando Sales de Oliveira. Foi inaugurado em 1977 a partir de um convênio entre o Departamento de Medicina Preventiva da Faculdade de Medicina da USP e a Secretaria de Estado da Saúde de São Paulo. Na ocasião já existia outra Unidade Básica de Saúde nas imediaçôes e. com isso. a área de abrangência definida para sua atuação nào é contígua. incluindo parcialmente os Distritos de Paz do Butantã e do Rio Pequeno. O critério fundamental utilizado para delimitar a área de abrangencia. na época da sua implantaçào. foi a facilidade de acesso por ónibus. O objetivo era ampliar a demanda do Centro de Saúde já que nas imediações concentravam-se estabelecimentos comerciais e familias de maior poder aquisitivo. Lm 1987. a área de abrangência foi redesenhada. a partir de um estudo realizado sobre a demanda das diversas Unidades Básicas de Saúde que atuavam na regiào. considerando o acesso potencial e o acesso efetivo. (DALMASO: SALA: SENNA: 1996)

Conforme descrito no Capitulo de Metodologia. o conhecimento da realidade do território, foi feito a partir da identificação dos setores censitários componentes da área de abrangência do Centro de Saúde que inclui 50 setores censitários. com uma população total de 47511 habitantes. segundo dados do Censo de 1991. Entre os 50) setores censitarios identificados. optou-se pela exclusão de um deles (o de ${ }^{\circ} 95$ ) por se tratar de moradia estudantil. de caráter temporário. distinguindo-se dos demais. que reuniam predominantemente. domicilios permanentes particulares.

Foram solicitados dados ao IBGE foram relativos aos setores censitários classificados no Censo de 1991: 1. 2. 3. 4. 5. 6. . . 8. 9. 10, 11, 18, 19, 29, 30, 31.32. $33.34 .35 .36 .37,38.39 .43 .44 .45 .46 .83,84,85.144 .147 .148 .160 .161 .162$. 165.236. 237. 238. 296. 297.298. 393.395.397. 406 e 415.

A partir da delimitação geográfica dos setores fornecida pelo IBGE utilizando-se o programa MAP Info, chegou-se ao seguinte mapa da área de abrangência do Centro de Saúde Escola Samuel B. Pessoa: 


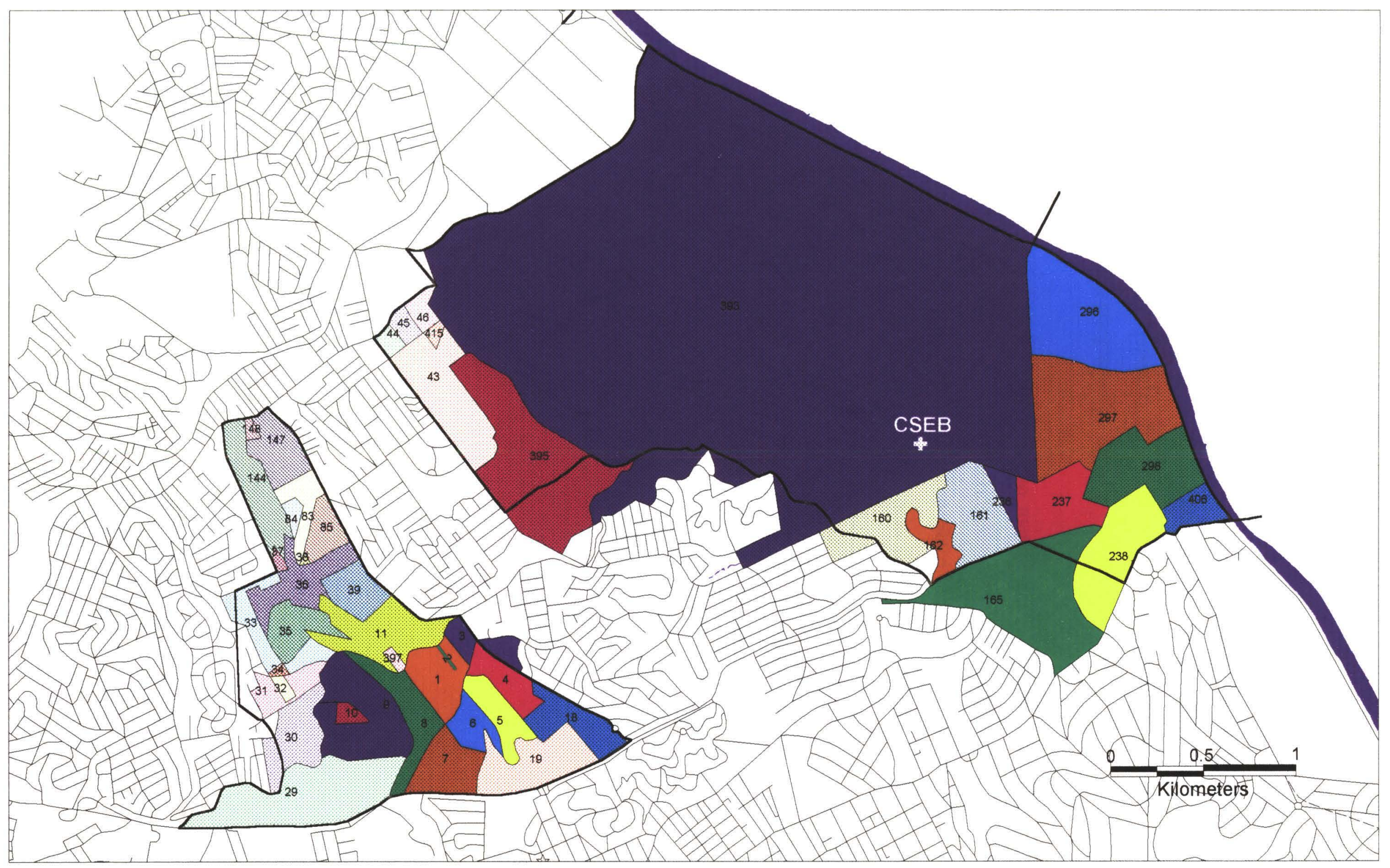

Mapa 3 - Distribuição dos Setores Censitários da área de abrangência do Centro de Saúde Escola " Samuel B. Pessoa", Butantã, 1999. 
No mapa 3. as cores foram utilizadas para distinguir os setores censitários e facilitar sua localização geográfica na área em estudo. Cabe ressaltar que, em alguns casos. os limites do setor extrapolavam a área de abrangência do Centro de Saúde. $\mathrm{Na}$ medida em que isso ocorreu somente com relação aos setores 238, 165, 393 e 395. optou-se por considerá-los na totalidade, diante da impossibilidade operacional de limitar o estudo aos domicílios integrantes da área de Vigilância à Saúde.

Outro aspecto. que pode ser observado no mapa, é a característica de não contigüidade da área. conforme foi descrito anteriormente. A área onde se situa o Centro de Saúde integra o Distrito do Butantã e a outra, mais distante, integra o Distrito do Rio Pequeno. A grande área delimitada pelo setor 393 refere-se à Cidade Universitária Armando Salles de Oliveira.

A tabela 1 apresenta a distribuição de domicílios, o número de total de habitantes e a população de crianças de menores de 5 anos de idade, nos diferentes setores que compõem a área de abrangência do referido Centro de Saúde Escola, segundo dados do Censo Demográfico de 1991. 
Tabela 1:Distribuição dos domicilios, da população total e da população de menores de cinco anos nos setores censitários que compõem a área de abrangência do Centro de Saúde Escola Samuel B. Pessoa,

São Paulo, 1998

\begin{tabular}{|c|c|c|c|}
\hline Setores Censitários & Total de Domicilios & População Total & População de 0 a 4 \\
\hline 1 & 254 & 914 & 69 \\
\hline 2 & 438 & 1532 & 139 \\
\hline 3 & 128 & 474 & 22 \\
\hline 4 & 193 & 728 & 42 \\
\hline 5 & 236 & 876 & 48 \\
\hline 6 & 168 & 634 & 29 \\
\hline 7 & 180 & 708 & 57 \\
\hline 8 & 384 & 1405 & 138 \\
\hline 9 & 548 & 2203 & 196 \\
\hline 10 & 254 & 1184 & 170 \\
\hline 11 & 406 & 1639 & 157 \\
\hline 18 & 256 & 979 & 47 \\
\hline 19 & 272 & 1031 & 74 \\
\hline 29 & 245 & 899 & 74 \\
\hline 30 & 183 & 595 & 84 \\
\hline 31 & 241 & 939 & 93 \\
\hline 32 & 85 & 396 & 56 \\
\hline 33 & 342 & 1373 & 127 \\
\hline 34 & 75 & 334 & 31 \\
\hline 35 & 350 & 1281 & 94 \\
\hline 36 & 247 & 903 & 73 \\
\hline 37 & 160 & 718 & 119 \\
\hline 38 & 143 & 688 & 100 \\
\hline 39 & 245 & 893 & 58 \\
\hline 43 & 217 & 848 & 68 \\
\hline 44 & 238 & 1001 & 111 \\
\hline 45 & 298 & 1376 & 191 \\
\hline 46 & 363 & 1627 & 248 \\
\hline 83 & 295 & 1119 & 97 \\
\hline 84 & 138 & 667 & 92 \\
\hline 85 & 191 & 735 & 55 \\
\hline 144 & 490 & 1936 & 151 \\
\hline 147 & 367 & 1342 & 110 \\
\hline 148 & 102 & 491 & 63 \\
\hline 160 & 369 & 1373 & 100 \\
\hline 161 & 232 & 961 & 56 \\
\hline 162 & 174 & 592 & 49 \\
\hline 165 & 367 & 1372 & 63 \\
\hline 236 & 303 & 959 & 58 \\
\hline 237 & 366 & 1028 & 75 \\
\hline 238 & 234 & 784 & 59 \\
\hline 296 & 200 & 909 & 32 \\
\hline 297 & 255 & 1173 & 33 \\
\hline 298 & 226 & 765 & 44 \\
\hline 393 & 446 & 1519 & 158 \\
\hline 395 & 32 & 112 & 7 \\
\hline 397 & 49 & 177 & 10 \\
\hline 406 & 81 & 241 & 18 \\
\hline 415 & 229 & 1078 & 125 \\
\hline TOTAL & 12295 & 47511 & 4170 \\
\hline
\end{tabular}

Fonte : IBGE, Censo de 1991 


\subsection{O Processo de construção do Índice de Potencial de Exposição às Condições de Risco para as doenças respiratórias na infância}

A construção do indicador composto de Inserção Social e de Qualidade do Domicilio, conforme descrito no capítulo 2. constou de três fases. A primeira referese à caracterização da região do estudo a partir de variáveis relacionadas pela literatura, como de interesse para o estudo da causalidade ou risco para as IRA.

A segunda fase foi realizada com a participação de representantes de segmentos da população envolvidos com o problema ou com a sua solução. A avaliação da importância atribuída por esses grupos populacionais a estas variáveis. como condições de risco para as IRA orientou a pontuação e o agrupamento destas variáveis.

A terceira fase constituiu o tratamento estatístico e o mapeamento das variáveis.

\section{Fase: Caracterização do território}

Os dados de interesse para a caracterização do território foram selecionados e agrupados. tendo em vista as categorias empiricas indicadoras de Inserção Social e de Qualidade de Vida. O processo de seleção e organização destas categorias foi peculiar a cada uma delas. o que permitiu a caracterização e o mapeamento do território sob vários pontos de vista conforme apresentado a seguir.

\section{Condição de Ocupação do Domicílio}

A categoria empírica condição de ocupação do domicílio foi utilizada como indicador social da moradia, entendendo-se que este aspecto pode ser considerado um bem de grande valor. sobretudo no cenário urbano da cidade de São Paulo. Retrata a fixação das famílias no território estudado, revelando diferentes graus estabilidade a 
esse respeito. Reflete a garantia da família de manter-se abrigada num espaço extremamente disputado. em decorrência da especulação imobiliária. As diferentes condições de estabilidade neste aspecto poderão influenciar de forma positiva ou negativa na vida das familias. No presente estudo, isso foi considerado parte integrante do indicador de inserção social, porque a propriedade da casa constitui fator de indiscutível importância na qualidade de vida das familias. "ser proprietário do imóvel ou pagar aluguel. morar em casa cedida ou na situação ilegal de invasor correspondem a diferentes situações em termos de segurança e estabilidade, que modificam substancialmente as condições de vida" (SEADE, 1992, p. 16). Este aspecto de estabilidade da moradia também é considerado na pesquisa de condições de vida desenvolvida pela Fundação SEADE que abarca quatro possibilidades de classificação dos domicílios: próprio. incluindo o terreno e a construção ou somente a construção: alugado: cedido e outro.

Para o tratamento estatístico foi considerada como condição estável de moradia somente a construção própria em terreno próprio, sendo que a condição de construção própria em terreno não próprio e aluguel foram consideradas regulares e, finalmente, domicílio cedido e outro foram considerados instáveis. A condição estável recebeu nota 3,0, a condição regular nota 2,0 e condição instável recebeu nota 1,0 . Feita a classificação foi verificado o que predominava em cada setor, a partir da média ponderada desta variável, incorporando-se as frações de contribuição de cada condição. Com isso, chegou-se a uma nota final por setor e ao seguinte quadro de valores apresentados na Tabela 2 , representativos da condição de estabilidade de moradia nos setores da área de abrangência do Centro de Saúde Escola Samuel B. Pessoa: 
Tabela 2:Distribuição Percentual dos Domicilios Particulares Permanentes nos Setores Censitários segundo a Condição de Ocupação, no Distrito do Butantã, São Paulo, 1998.

\begin{tabular}{|c|c|c|c|c|}
\hline \multirow{2}{*}{$\begin{array}{c}\text { Setor } \\
\text { Censitário }\end{array}$} & \multicolumn{3}{|c|}{ Condicão de ocupação (\%) } & \multirow[t]{2}{*}{ Nota } \\
\hline & Instável & Regular & Estável & \\
\hline 1 & 1,57 & 20,08 & 78.35 & 2,77 \\
\hline 2 & 2,28 & 21,00 & 76,71 & 2,74 \\
\hline 3 & 0.00 & 5,47 & 94,53 & 2.95 \\
\hline 4 & 7,77 & 12,44 & 79,79 & 2,72 \\
\hline 5 & 7,63 & 13,98 & 78,39 & 2,71 \\
\hline 6 & 6,55 & 21,43 & 72,02 & 2.65 \\
\hline 7 & 3,89 & 26,67 & 69,44 & 2,66 \\
\hline 8 & 2,08 & 35,16 & 62,76 & 2,61 \\
\hline 9 & 4,38 & 32,12 & 63.50 & 2.59 \\
\hline 10 & 0,39 & 98,82 & 0,79 & 2,00 \\
\hline 11 & 9,36 & 39,90 & 50,74 & 2,41 \\
\hline 18 & 4,69 & 13,67 & 81,64 & 2,77 \\
\hline 19 & 6,25 & 25,37 & 68,38 & 2,62 \\
\hline 29 & 13,88 & 22,04 & 64,08 & 2,50 \\
\hline 30 & 8,74 & 28,96 & 62,30 & 2,54 \\
\hline 31 & 16.60 & 30,29 & 53,11 & 2,37 \\
\hline 32 & 0,00 & 100,00 & 0,00 & 2.00 \\
\hline 33 & 12,87 & 34,21 & 52.92 & 2,40 \\
\hline 34 & 0.00 & 100,00 & 0,00 & 2,00 \\
\hline 35 & 8,86 & 36,86 & 54,29 & 2,45 \\
\hline 36 & 5,26 & 46,56 & 48,18 & 2.43 \\
\hline 37 & 0,63 & 98,75 & 0.63 & 2,00 \\
\hline 38 & 0,70 & 95,80 & 3,50 & 2,03 \\
\hline 39 & 2,86 & 31,02 & 66,12 & 2,63 \\
\hline 43 & 3,23 & 10,60 & 86,18 & 2,83 \\
\hline 44 & 1,68 & 95,80 & 2,52 & 2,01 \\
\hline 45 & 0,67 & 97,32 & 2,01 & 2,01 \\
\hline 46 & 2,75 & 91,46 & 5,79 & 2,03 \\
\hline 83 & 2,37 & 39,32 & 58,31 & 2.56 \\
\hline 84 & 0,00 & 99,28 & 0,72 & 2,01 \\
\hline 85 & 8,90 & 20,42 & 70,68 & 2,62 \\
\hline 144 & 16,12 & 32,65 & 51,22 & 2.35 \\
\hline 147 & 6,27 & 26,16 & 67,57 & 2,61 \\
\hline 148 & 0.00 & 93,14 & 6,86 & 2.07 \\
\hline 160 & 9.21 & 39,57 & 51,22 & 2,42 \\
\hline 161 & 6,47 & 24,57 & 68,97 & 2,63 \\
\hline 162 & 10,92 & 40,23 & 48,85 & 2,38 \\
\hline 165 & 9,81 & 25,34 & 64,85 & 2,55 \\
\hline 236 & 5,28 & 31,02 & 63,70 & 2,58 \\
\hline 237 & 9.02 & 33.33 & 57,65 & 2,49 \\
\hline 238 & 9,83 & 25,21 & 64,96 & 2,55 \\
\hline 296 & 1,00 & 5.50 & 93.50 & 2.93 \\
\hline 297 & 1.96 & 7,84 & 90,20 & 2,88 \\
\hline 298 & 14,16 & 31,86 & 53,98 & 2,40 \\
\hline 393 & 15.92 & 20,18 & 63,90 & 2,48 \\
\hline 395 & 15,63 & 15,63 & 68,75 & 2,53 \\
\hline 397 & 8,16 & 26,53 & 65,31 & 2,57 \\
\hline 406 & 14.81 & 64,20 & 20,99 & 2,06 \\
\hline 415 & 1,31 & 97,38 & 1,31 & 2,00 \\
\hline
\end{tabular}

Fonte: IBGE, Censo de 1991. 
Comparando com outros Distritos do Município de São Paulo. a região do Butantã tem uma situação relativamente favorável em termos de moradia. Contudo. os dados encontrados revelam que em 12 setores. nos quais há uma concentração de $20.6 \%$ da população total. ainda predomina uma condição regular em termos de estabilidade na moradia.

Na pesquisa anteriormente citada da Fundação SEADE (1992), a média da cidade de São Paulo para habitações consideradas satisfatórias é de $49.8 \%$ no tocante à apropriação da moradia.

\section{Renda "per capita"}

Na pesquisa de Condições de Vida da Região Metropolitana de São Paulo. realizada pela Fundação SEADE. a variável renda não foi a única a ser considerada para classificação da pobreza. Naquele trabalho. foi construído um modelo de investigação capaz de captar as múltiplas facetas que compõem o quadro da pobreza numa região de grande desenvolvimento econômico. A renda é considerada uma variável necessária. porém não suficiente. Nas familias estudadas a contribuição da renda do chefe na renda familiar representava em média. $70.7 \%$ dos rendimentos e a renda "per capita". em média 3.5 salários minimos.

KAWACHI et al. (1997), ao estudarem a relação existente entre o potencial de organização social, a baixa renda e a mortalidade nos diferentes estados do território americano. consideraram baixa uma renda anual menor do que US\$13,359. para uma familia de quatro pessoas. Em rendimentos mensais essa cifra corresponde a US\$ 278 "per capita”. Para a definição dos critérios de classificação da linha de pobreza. existem várias propostas (SEADE. 1992). No presente estudo, optou-se pelo critério de análise a partir do salário mínimo vigente, pela facilidade operacional.

Utilizando-se o critério mencionado acima. as famílias com renda "per capita" 
inferior a $0.5 \mathrm{SM}$ foram consideradas miseráveis; as familias entre 0.5 a $<1.0 \mathrm{SMPC}$ indigentes: entre $1.0 \mathrm{a}<2.0 \mathrm{SMPC}$ pobres e maior ou igual a 2.0 SMPC acima da linha da pobreza. A classificação adotada no presente estudo baseia-se nesse critério, acrescentando-se ainda uma classificação por se tratar de uma área que concentra algumas famílias com elevado poder aquisitivo. A seguir descreve-se a classificação adotada:

$$
\begin{aligned}
& \text { Zero até }<0.5 \mathrm{SMPC} \text { : péssima } \\
& 0.5 \text { até }<1.0 \mathrm{SMPC} \text { : ruim } \\
& 1.0 \text { até }<2.0 \mathrm{SMPC} \text { : regular } \\
& 2.0 \text { até }<3.0 \mathrm{SMPC} \text { : bom } \\
& 3 \text { ou mais SMPC: muito bom }
\end{aligned}
$$

Os dados fornecidos estavam subdivididos em 11 agrupamentos de renda do chefe do domicílio, a saber: meio salário mínimo; de meio até $1 \mathrm{SM}$; de 1 até $2 \mathrm{SM}$ : de 2 a 3 SM; de 3 a 5 SM; de 5 a 10 SM; de 10 a 15 SM; de 15 a 20 SM; 20 SM ou mais: sem rendimento e sem declaração de rendimento.

Para poder utilizá-los foi necessário submeter o banco de dados a um tratamento estatístico. sendo que o primeiro procedimento foi o cálculo da média ponderada em cada setor. utilizando-se as porcentagens dos domicílios em cada faixa de renda e os pontos médios dos intervalos das mesmas. Os pontos médios considerados foram: $0.75 ; 1,5 ; 2,5 ; 4,0 ; 7,5 ; 12.5$ e 17.5 . Os limites foram considerados na íntegra, 0,5 e 2,0; e a condição sem rendimento foi consideradas como 0. A porcentagem de renda não declarada foi excluída do cálculo. Em seguida, para a obtenção da renda "per capita". foi feita a divisão da renda média predominante no setor pelo número médio de pessoas por domicílios do setor. Chegou-se assim a um valor estimado de renda "per capita" por Salário Mínimo, denominado Salário Minimo Per Capita (SMPC). 
A Tabela 3 apresenta as faixas de rendimento dos chefes de domicílios da região estudada. os valores calculados em termos de média ponderada da renda característica dos setores e a renda "per capita" estimada por setor censitário: 
Tabela 3: Distribuição percentual dos niveis de renda dos chefes de domicílios, média ponderada da renda dos setores censitários e Renda "per capita" estimada dos setores censitários do Butantã, São Paulo, 1998.

\begin{tabular}{|c|c|c|c|c|c|c|c|c|c|c|c|c|c|}
\hline \multirow{2}{*}{$\begin{array}{l}\text { Setores } \\
\text { cens:- } \\
\text { tarios }\end{array}$} & \multicolumn{11}{|c|}{ Renda dos chefes de domicilios (\% em salarios minimos) } & \multirow{2}{*}{$\begin{array}{l}\text { Media } \\
\text { ponde- } \\
\text { rada }\end{array}$} & \multirow{2}{*}{$\begin{array}{l}\text { Renda } \\
\text { per capita } \\
\text { em SM }\end{array}$} \\
\hline & 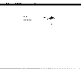 & $\because A$ & $1 \mathrm{~A} 2$ & $2 \mathrm{~A} 3$ & $3 A^{5} 5$ & $5 A^{\circ} 10$ & $10 A \cdot 15$ & $15 A^{\prime} 20$ & $20 A+$ & $\begin{array}{l}\text { Sem } \\
\text { renda }\end{array}$ & $\begin{array}{l}\text { Sem de } \\
\text { claraçăo }\end{array}$ & & \\
\hline 1 & 1,18 & 1.97 & 4.33 & 4.33 & 7.87 & 23.62 & 13.78 & 15,35 & 24,80 & 2,76 & 0.00 & 10.03 & 3,34 \\
\hline 2 & 0,00 & 0,91 & 1,60 & 3,42 & 5,48 & 17,58 & 21,92 & 16,21 & 30,59 & 0.68 & 1,60 & 12,38 & 4,13 \\
\hline 3 & 1.56 & 2.34 & 9.38 & 10,16 & 13.28 & 26.56 & 15.63 & 8.59 & 8,59 & 0.00 & 3.91 & 6.53 & 2,18 \\
\hline 4 & 0.52 & 1.55 & 4.66 & 9.33 & 5,18 & 21.24 & 21.24 & 10.88 & 22,80 & 2.07 & 0.52 & 9.84 & 3,28 \\
\hline 5 & 3,39 & 3.39 & 11.86 & 10,17 & 13,14 & 19,07 & 13.14 & 8.47 & 17,37 & 0.00 & 0.00 & 7.74 & 2.58 \\
\hline 6 & 0.00 & 0.00 & 5.95 & 5.36 & 9.52 & 19.05 & 12.50 & 10,12 & 22,62 & 1.19 & 13,69 & 9,98 & 3,33 \\
\hline 7 & 0.56 & 0.56 & 6.67 & 13,33 & 12,22 & 22.22 & 14.44 & 6,67 & 10,56 & 7.78 & 5,00 & 6,49 & 2,16 \\
\hline 8 & 1,82 & 4.17 & 16,93 & 10.16 & 17,19 & 18.75 & 9.38 & 4.69 & 7,29 & 5.99 & 3.65 & 5,01 & 1.67 \\
\hline 9 & 0.00 & 1.64 & 9.67 & 6,93 & 10.04 & 23.18 & 17.52 & 8.76 & 12,41 & 4.93 & 4,93 & 7,45 & 1.86 \\
\hline 10 & 0,39 & 1,57 & 40,94 & 25,20 & 17,72 & 5,51 & 0,79 & 0,00 & 0,00 & 7,87 & 0,00 & 2,21 & 0,55 \\
\hline 11 & 1,23 & 2.22 & 18,23 & 14,53 & 20,20 & 22,41 & 7,88 & 3,45 & 3,69 & 6.16 & 0,00 & 3,94 & 1,31 \\
\hline 18 & 0.00 & 1,17 & 4.30 & 4.69 & 14.06 & 27.73 & 16.41 & 11.33 & 19,92 & 0.39 & 0.00 & 8.92 & 2,97 \\
\hline 19 & 1.47 & 2.57 & 6.99 & 5,88 & 12,50 & 17.65 & 8.09 & 2.94 & 10,29 & 8.09 & 23,53 & 5.90 & 1.97 \\
\hline 29 & 2.86 & 2.04 & 9.39 & 7.35 & 10.61 & 16.33 & 11.02 & 4.08 & 6.94 & 13.47 & 15.92 & 5.23 & 1.74 \\
\hline 30 & 0.00 & 1,64 & 3.28 & 4.37 & 12.57 & 29.51 & 20.77 & 7.65 & 14,75 & 3.28 & 2,19 & 7.88 & 2.63 \\
\hline 31 & 0.41 & 1.24 & 12,86 & 19.50 & 26,14 & 18.67 & 5,81 & 0,00 & 0.41 & 9,13 & 5,81 & 2,86 & 0.95 \\
\hline 32 & 0.00 & 4.71 & 49.41 & 15.29 & 18.82 & 3.53 & 0,00 & 0.00 & 0,00 & 8.24 & 0.00 & 2,06 & 0.52 \\
\hline 33 & 0,58 & 2,34 & 17,84 & 13,45 & 18,42 & 25,15 & 7,89 & 1,46 & 1,17 & 5.56 & 6,14 & 3,18 & 0,80 \\
\hline 34 & 4,00 & 9,33 & 48,00 & 18,67 & 10,67 & 1,33 & 0,00 & 0.00 & 0,00 & 8.00 & 0,00 & 1,84 & 0,46 \\
\hline 35 & 2.57 & 7.14 & 17,71 & 14,57 & 15.14 & 22.29 & 8.00 & 3.14 & 2.86 & 4.86 & 1.71 & 3,63 & 1,21 \\
\hline 36 & 1.62 & 2.02 & 10,12 & 27,13 & 26.32 & 19.03 & 3,24 & 1,62 & 1,62 & 7.29 & 0,00 & 3,06 & 1.02 \\
\hline 37 & 3,75 & 5.00 & 40,63 & 25,63 & 19,38 & 2,50 & 0,63 & 0,00 & 0,00 & 2,50 & 0,00 & 2,30 & 0.58 \\
\hline 38 & 0,70 & 2,10 & 23,08 & 27,97 & 22,38 & 6,29 & 0.00 & 0.00 & 0,00 & 11,89 & 5.59 & 2,23 & 0,56 \\
\hline 39 & 0.00 & 1,63 & 17.96 & 12,24 & 18.78 & 27,35 & 8.57 & 4,08 & 4,49 & 3.27 & 1.63 & 4,24 & 1.41 \\
\hline 43 & 0,00 & 1,38 & 8.29 & 9,22 & 16,13 & 24,42 & 13,82 & 7,83 & 9,68 & 2.30 & 6,91 & 6.65 & 2,22 \\
\hline 44 & 0,00 & 2,10 & 32.35 & 29,83 & 25,63 & 7,98 & 0,00 & 0.42 & 0,00 & 0.00 & 1,68 & 2,54 & 0,63 \\
\hline 45 & 0,00 & 2.35 & 22,48 & 27,85 & 27,85 & 10,40 & 1,01 & 0,34 & 0,00 & 6,38 & 1,34 & 2,53 & 0,63 \\
\hline 46 & 0.28 & 1,93 & 12,95 & 16.25 & 27,00 & 12.95 & 3,58 & 0.55 & 1,10 & 1.65 & 21,76 & 3,34 & 0.83 \\
\hline 83 & 3.05 & 4.75 & 13.90 & 16.95 & 22,37 & 19.66 & 6.44 & 4,07 & 2,37 & 6,44 & 0,00 & 3.71 & 1,24 \\
\hline 84 & 2.17 & 5.80 & 49.28 & 21,01 & 14.49 & 5.07 & 0.00 & 0,00 & 0,00 & 1.45 & 0.72 & 2,06 & 0.51 \\
\hline 85 & 0,00 & 2.62 & 3,14 & 6.28 & 9,95 & 27,75 & 20,94 & 14.66 & 14,66 & 0.00 & 0.00 & 8,89 & 2.96 \\
\hline 144 & 4.08 & 3.67 & 15.92 & 12,04 & 21,63 & 17,14 & 5.71 & 2,45 & 1.63 & 14.69 & 1.02 & 3,09 & 1,03 \\
\hline 147 & 1,91 & 3,81 & 12.81 & 11,99 & 18.26 & 25,61 & 11,72 & 4,36 & 4,63 & 3.54 & 1,36 & 4,62 & 1,54 \\
\hline 148 & 1,96 & 11,76 & 49,02 & 14,71 & 10.78 & 3,92 & 0.00 & 0,00 & 0,00 & 7.84 & 0,00 & 1,78 & 0,44 \\
\hline 160 & 1,63 & 3.79 & 17,07 & 14,09 & 18,16 & 20,05 & 10,57 & 5,42 & 4,34 & 4.88 & 0,00 & 4,65 & 1,55 \\
\hline 161 & 0.43 & 3,02 & 8,62 & 9,91 & 10,34 & 16,38 & 12,07 & 9,48 & 23,28 & 5,17 & 1,29 & 8.90 & 2,23 \\
\hline 162 & 4,02 & 8.62 & 16,67 & 13,22 & 17,24 & 23,56 & 6.32 & 3,45 & 3,45 & 3.45 & 0,00 & 3,58 & 1.19 \\
\hline 165 & 0,82 & 2,45 & 7.08 & 9,54 & 8,45 & 20,71 & 11.44 & 11.44 & 24,25 & 3.54 & 0.27 & 10.57 & 3.52 \\
\hline 236 & 0.00 & 0.00 & 1,32 & 2.31 & 4,29 & 16,17 & 22,11 & 11,88 & 36.30 & 2.97 & 2,64 & 12,84 & 4,28 \\
\hline 237 & 0.55 & 0.82 & 5.74 & 6.01 & 11.20 & 19.95 & 16.39 & 9,84 & 25.68 & 2.73 & 1.09 & 9.86 & 4.93 \\
\hline 238 & 0,43 & 1,28 & 8.12 & 6,84 & 7,69 & 16,67 & 12,82 & 9.40 & 23,08 & 3,42 & 10,26 & 9,61 & 3.20 \\
\hline 296 & 0,00 & 0.00 & 2,50 & 1,00 & 2,50 & 5,00 & 11,00 & 7,00 & 52,00 & 4.50 & 14,50 & 15,57 & 3,89 \\
\hline 297 & 0.00 & 1,18 & 1.57 & 3,14 & 2,35 & 9.02 & 14.12 & 9.41 & 58,04 & 0,00 & 1,18 & 15,56 & 3,89 \\
\hline 298 & 0,88 & 2,65 & 7.52 & 7.08 & 11,06 & 15,49 & 15,04 & 11,06 & 26,55 & 0.88 & 1,77 & 10.21 & 3,40 \\
\hline 393 & 0.67 & 1.35 & 11,21 & 7.17 & 7,62 & 14.80 & 8.52 & 4,71 & 24,66 & 4.48 & 14,80 & 8.96 & 2.99 \\
\hline 395 & 0.00 & 6.25 & 28,13 & 3.13 & 12.50 & 25.00 & 9.38 & 3.13 & 6,25 & 6.25 & 0,00 & 4.17 & 1,39 \\
\hline 397 & 0,00 & 2,04 & 12.24 & 20,41 & 14,29 & 22,45 & 14,29 & 8,16 & 6,12 & 0.00 & 0,00 & 5,87 & 1,96 \\
\hline 406 & 0.00 & 1.23 & 2.47 & 11.11 & 8.64 & 22.22 & 11.11 & 12.35 & 23,46 & 2.47 & 4.94 & 9,53 & 4,77 \\
\hline 415 & 0.44 & 2.18 & 27.95 & 31,44 & 27,51 & 3.06 & 0.87 & 0.00 & 0,00 & 5.24 & 1.31 & 2,62 & 0.65 \\
\hline
\end{tabular}

Fonte: IBGE, Censo de 1991 
Gráfico 1 - Renda per capita

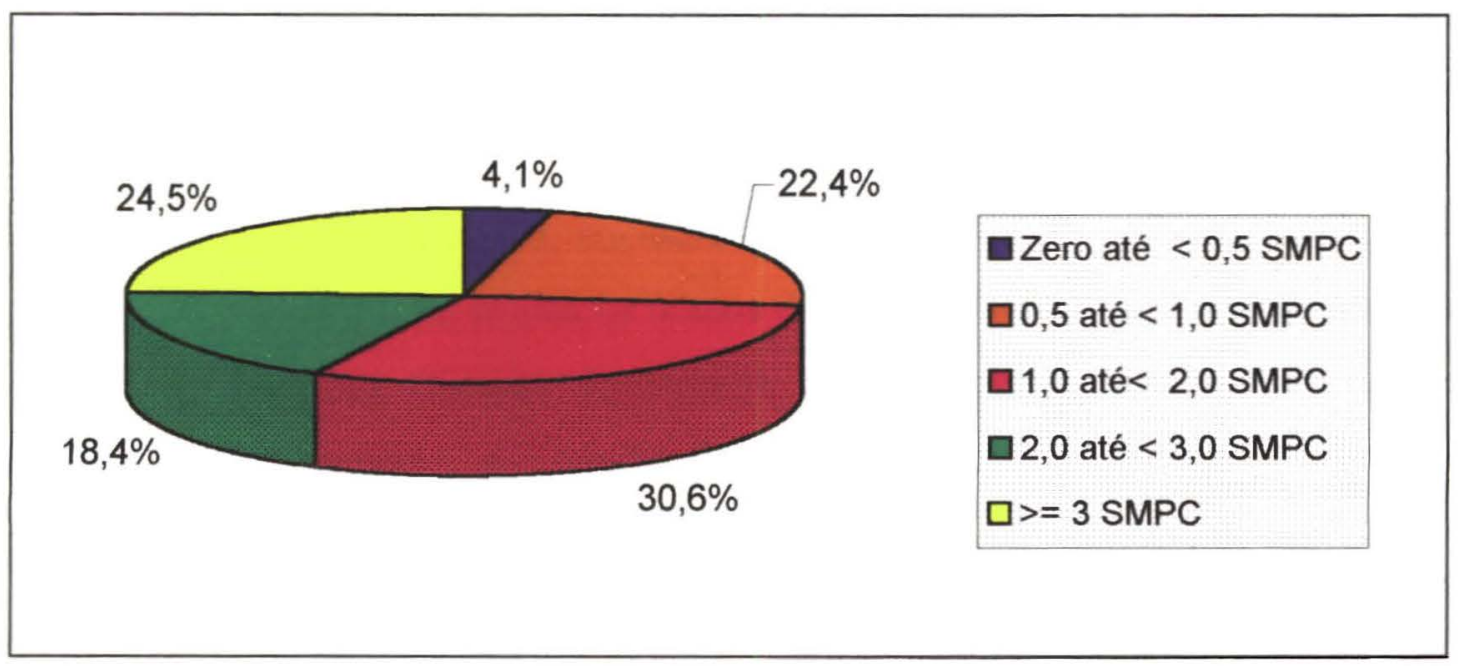

No gráfico 1 acima pode-se verificar que 30,6\% dos setores pertencentes à área de estudo apresentam condição regular em termos da renda "per capita" percebendo entre 1,0 e $<2,0$ salários mínimos; seguidos de $24,5 \%$ em condição muito boa; $22,4 \%$ na condição ruim; $18,4 \%$ na condição boa e $4,1 \%$ na condição péssima. Ou seja, $57,0 \%$ da população residente nos setores censitários que compõem a área estudada encontravam-se em uma situação representativa de diferentes graus de pobreza, considerando-se somente o aspecto renda. Recuperando-se os dados apresentados na Tabela 1 da pg 74, em termos numéricos de habitantes, significa que 28.777 pessoas vivem em situação de pobreza, eqüivalendo $60,56 \%$ da população total da área de abrangência estudada. Apesar das limitações de considerar-se apenas o critério renda, trata-se de um dado significativo, para a formulação de políticas públicas. Outro aspecto a destacar diz respeito à importância de se caracterizar as micro-regiões, com vistas a evidenciar as diversidades componentes de uma dada realidade. A região estudada pode ser considerada relativamente boa, se comparada a outras áreas mais periféricas do Município, porém concentra um elevado número de habitantes com baixo rendimento. 


\section{Escolaridade do Chefe}

Diversos estudos brasileiros ressaltam a importância da escolaridade dos pais na ocorrência das IRA. tanto no que diz respeito à morbidade (VICTORA et al. 1994; MONTEIRO e BENICIO, 1987) como em relação à mortalidade (NIOBEY et al. 1992: AMARAL et al. 1997). No estudo sobre saúde e nutrição das crianças de São Paulo. realizado em 1984-1985. coordenado por Monteiro, foram encontrados 25\% dos chefes de familia com menos de 4 anos de estudo. No trabalho coordenado por SPOSATI (1996) os Distritos do Butantã e Rio Pequeno apresentavam 6.58 e $13.20 \%$ respectivamente. de familias cujos chefes apresentavam escolaridade precária.

No presente estudo. os dados sobre escolaridade encontravam-se subdivididos em seis faixas e eram relativos aos anos de instruçào do chefe do domicilio, como segue: Sem instrução; de 1 a 3; 4 a 7; 8 a 10;11 a 14; 15 ou mais. De forma análoga ao que foi apresentado no item renda. foi calculada a média ponderada da escolaridade em cada setor, utilizando-se as porcentagens de domicílios em cada faixa e os pontos médios dos intervalos no interior das mesmas. Foram obtidos os seguintes pontos: $2 ; 5.5 ; 9 ; 12.5$; e 0 e 15 anos que retratam a escolaridade típica de cada setor. A seguir. foram atribuídos os valores para as faixas de escolaridade considerando-se sem instrução como péssimo: de 1 a 3 como ruim: de 4 a 7 anos de estudo como regular: de 8 a 14 anos como bom e 15 anos ou mais como muito bom. A Tabela 4 retrata a situação de escolaridade dos chefes de domicílios dos setores censitários da região estudada. 
Tabela 4: Distribuição percentual dos Níveis de Escolaridade dos chefes de domicílios e média ponderada da escolaridade dos setores censitários da região do Butantã, São Paulo, 1998.

\begin{tabular}{|c|c|c|c|c|c|c|c|}
\hline \multirow{2}{*}{$\begin{array}{c}\text { Setor } \\
\text { Censitario }\end{array}$} & \multicolumn{6}{|c|}{ Anos e estudo dos Chefos de domicílio } & \multirow{2}{*}{$\begin{array}{c}\text { Média } \\
\text { ponderada de } \\
\text { escolaridade }\end{array}$} \\
\hline & Sem instrução & 1 a 3 & 4 a 7 & 8 a 10 & 11 a 14 & 15 out & \\
\hline 1 & 1,18 & 3,15 & 14,96 & 7,87 & 31,89 & 40,94 & 11,72 \\
\hline 2 & 1.14 & 2,05 & 8.90 & 6.16 & 30,59 & 51,14 & 12.58 \\
\hline 3 & 2.34 & 3,13 & 43,75 & 16.41 & 11,72 & 22,66 & 8,81 \\
\hline 4 & 2.59 & 4.15 & 17,10 & 10.88 & 27,46 & 37,82 & 11,11 \\
\hline 5 & 4.24 & 9,75 & 25,42 & 11,86 & 22,88 & 25,85 & 9,40 \\
\hline 6 & 2,38 & 7.74 & 26,19 & 18,45 & 25,00 & 20,24 & 9.42 \\
\hline 7 & 5.56 & 10.56 & 28,33 & 12.22 & 25.56 & 17,78 & 8,73 \\
\hline 8 & 5,21 & 15,63 & 31,25 & 13.80 & 16,41 & 17.71 & 7,98 \\
\hline 9 & 9,31 & 6,20 & 27,01 & 13,32 & 22.45 & 21,72 & 8,87 \\
\hline 10 & 30.31 & 31.89 & 32.28 & 3.54 & 1.57 & 0.39 & 2.99 \\
\hline 11 & 14.53 & 12,56 & 38,18 & 16.26 & 13.55 & 4.93 & 6,25 \\
\hline 18 & 2,34 & 1,56 & 18,36 & 12,89 & 35,16 & 29,69 & 11.05 \\
\hline 19 & 5,88 & 7.35 & 36,40 & 13.97 & 19.49 & 16,91 & 8,38 \\
\hline 29 & 6.53 & 11.43 & 34,69 & 11.02 & 16.33 & 20.00 & 8.17 \\
\hline 30 & 5.46 & 3.83 & 15,85 & 11,48 & 31.15 & 32,24 & 10.71 \\
\hline 31 & 16.60 & 10.79 & 44.40 & 16.18 & 9.54 & 2,49 & 5,68 \\
\hline 32 & 48,24 & 12.94 & 31.76 & 5.88 & 0.00 & 1,18 & 2.71 \\
\hline 33 & 19,88 & 8,77 & 38,89 & 23,39 & 4.97 & 4,09 & 5,65 \\
\hline 34 & 34.67 & 34,67 & 24,00 & 6,67 & 0.00 & 0,00 & 2,61 \\
\hline 35 & 12,29 & 13,71 & 39,71 & 13.71 & 15,71 & 4,86 & 6,39 \\
\hline 36 & 8.91 & 15,38 & 29,15 & 29.15 & 13,77 & 3,64 & 6,80 \\
\hline 37 & 18.13 & 20,63 & 45.63 & 13,13 & 1.25 & 1.25 & 4,45 \\
\hline 38 & 37.06 & 23,08 & 31,47 & 4,20 & 3,50 & 0,70 & 3,11 \\
\hline 39 & 6.12 & 13,06 & 40,82 & 22,04 & 13,47 & 4,49 & 6,85 \\
\hline 43 & 4,15 & 6.91 & 26.73 & 17,05 & 17,05 & 28,11 & 9,49 \\
\hline 44 & 26,05 & 23,53 & 41,60 & 5,46 & 2,10 & 1,26 & 3,70 \\
\hline 45 & 25,84 & 19,46 & 46,98 & 5,37 & 0,67 & 1,68 & 3,79 \\
\hline 46 & 34.44 & 14.88 & 37.47 & 7.16 & 2.48 & 3,58 & 3,85 \\
\hline 83 & 10,85 & 10,85 & 34,92 & 14,24 & 18.31 & 10.85 & 7.33 \\
\hline 84 & 29,71 & 26,09 & 37,68 & 5,80 & 0,72 & 0,00 & 3,21 \\
\hline 85 & 4.71 & 5.24 & 32.98 & 13.61 & 20.94 & 22,51 & 9,14 \\
\hline 144 & 12.65 & 15,10 & 41,63 & 12.65 & 13.47 & 4,49 & 6.09 \\
\hline 147 & 7.90 & 12,81 & 32,15 & 14.71 & 19,89 & 12,53 & 7,72 \\
\hline 148 & 27.45 & 25.49 & 44,12 & 2,94 & 0,00 & 0,00 & 3,20 \\
\hline 160 & 8.13 & 8,94 & 30,89 & 17,34 & 18,16 & 16,53 & 8.19 \\
\hline 161 & 5,17 & 6,47 & 23,28 & 8,19 & 18,53 & 38,36 & 10,22 \\
\hline 162 & 5,75 & 10.92 & 36,21 & 18.97 & 19,54 & 8,62 & 7,65 \\
\hline 165 & 1,91 & 5,72 & 16,89 & 9,54 & 24,25 & 41,69 & 11,19 \\
\hline 236 & 1.98 & 1.32 & 6,93 & 5.94 & 24,09 & 59,74 & 12,91 \\
\hline 237 & 2,73 & 6.01 & 14,21 & 4.37 & 21,31 & 51,37 & 11,66 \\
\hline 238 & 7.69 & 5,56 & 20,51 & 11,54 & 23,08 & 31,62 & 9,91 \\
\hline 296 & 1.00 & 2,00 & 4,00 & $1, \infty$ & 14,50 & 77,50 & 13,79 \\
\hline 297 & 1.57 & 1,57 & 3,14 & 2,75 & 20.39 & 70,59 & 13.59 \\
\hline 298 & 5.75 & 3,98 & 10,18 & 7,52 & 23,45 & 49,12 & 11,62 \\
\hline 393 & 4,26 & 6.05 & 22,65 & 8.97 & 20,63 & 37,44 & 10,37 \\
\hline 395 & 6.25 & 15,63 & 37,50 & 21,88 & 18.75 & 0.00 & 6,69 \\
\hline 397 & 4.08 & 12.24 & 46.94 & 12.24 & 16,33 & 8,16 & 7,19 \\
\hline 406 & 1,23 & 4,94 & 13,58 & 7.41 & 29,63 & 43,21 & 11,70 \\
\hline 415 & 46,29 & 20.09 & 26,64 & 3.93 & 2,62 & 0,44 & 2,61 \\
\hline
\end{tabular}

Fonte: IBGE, Censo de 1991. 


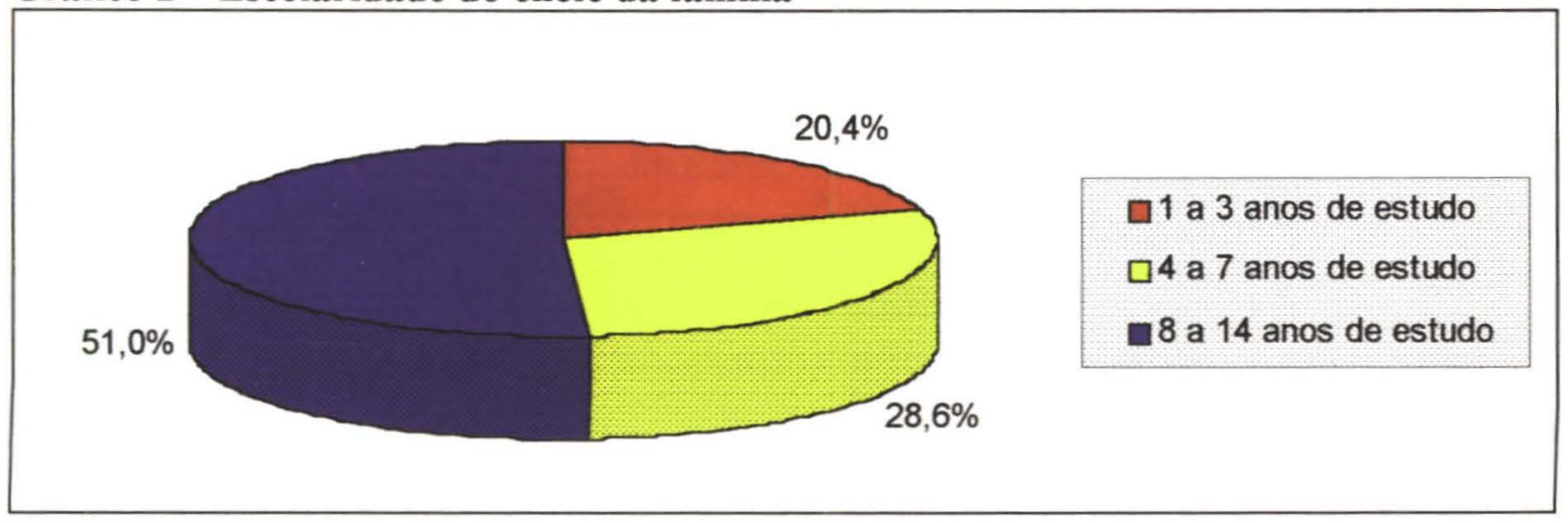

A partir do gráfico 2 que agrupa as média ponderadas encontradas nos setores pode-se verificar que a maioria, $51 \%$, pertence à faixa de escolaridade considerada boa, ou seja, de 8 a 14 anos de estudo; seguida de $28,6 \%$ na condição regular e $20,4 \%$ na condição ruim.

Acesso à Água: AMARAL et al. (1997) encontraram uma associação positiva entre presença de água encanada nos domicílios e morbidade por IRA entre os menores de seis meses. Com relação a este aspecto, os dados fornecidos pelo Censo encontravam-se subdivididos da seguintes maneira: canalização interna proveniente da rede direta (SABESP) e indireta (poço, mina, outro), canalização externa proveniente da rede direta e indireta. A melhor condição foi considerada a canalização interna de água proveniente da rede direta. A canalização interna de água proveniente de outra fonte foi considerada regular e a canalização externa foi considerada ruim. A Tabela 5 retrata a condição de acesso à água dos domicílios pertencentes à região estudada. 
Tabela 5: Distribuição Percentual dos Domicílios Particulares Permanentes em termos das

Condiçóes de Acesso à Ảgua na região do Butantã. São Paulo. 1998.

\begin{tabular}{|c|c|c|c|c|}
\hline \multirow{2}{*}{$\begin{array}{c}\text { Setor } \\
\text { Censitário }\end{array}$} & \multicolumn{3}{|c|}{ Condicões de acesso à água (\%) } & \multirow[t]{2}{*}{ Nota } \\
\hline & Ruins & Regulares & Boas & \\
\hline 1 & 0,00 & 0.00 & 100,00 & 3.00 \\
\hline 2 & 0,00 & 0.00 & 100,00 & 3,00 \\
\hline 3 & 0,00 & 0,00 & 100,00 & 3,00 \\
\hline 4 & 0,00 & 0,00 & 100,00 & 3,00 \\
\hline 5 & 0,00 & 0.00 & 100,00 & 3,00 \\
\hline 6 & 0,00 & 0.00 & 100,00 & 3,00 \\
\hline 7 & 0.00 & 0.56 & 99,44 & 2.99 \\
\hline 8 & 0,26 & 0.00 & 99,74 & 2.99 \\
\hline 9 & 0,36 & 0.00 & 99,64 & 2,99 \\
\hline 10 & 10.24 & 0.00 & 89,76 & 2.80 \\
\hline 11 & 0.74 & 0.00 & 99,26 & 2,99 \\
\hline 18 & 0,00 & 0,00 & 100,00 & 3,00 \\
\hline 19 & 0,00 & 0.00 & 100,00 & 3,00 \\
\hline 29 & 0.41 & 0.00 & 99,59 & 2,99 \\
\hline 30 & 0.55 & 0.00 & 99,45 & 2,99 \\
\hline 31 & 0,00 & 0.00 & 100,00 & 3.00 \\
\hline 32 & 12.94 & 0.00 & 87.06 & 2.74 \\
\hline 33 & 0,00 & 0.29 & 99,71 & 3,00 \\
\hline 34 & 0,00 & 0.00 & 100,00 & 3,00 \\
\hline 35 & 0,00 & 0,00 & 100,00 & 3,00 \\
\hline 36 & 0,00 & 0,00 & 100,00 & 3,00 \\
\hline 37 & 0,63 & 1,88 & 97,50 & 2.97 \\
\hline 38 & 6,29 & 0,00 & 93,71 & 2,87 \\
\hline 39 & 0,00 & 0.00 & 100,00 & 3,00 \\
\hline 43 & 0.00 & 0,00 & 100,00 & 3,00 \\
\hline 44 & 3,36 & 0.00 & 96,64 & 2,93 \\
\hline 45 & 89,60 & 3,36 & 7,05 & 1,17 \\
\hline 46 & 51,24 & 0,28 & 48,48 & 1,97 \\
\hline 83 & 0,34 & 0.00 & 99,66 & 2.99 \\
\hline 84 & 18,84 & 5,07 & 76,09 & 2,57 \\
\hline 85 & 0,00 & 0,00 & 100,00 & 3,00 \\
\hline 144 & 1,63 & 0,00 & 98,37 & 2,97 \\
\hline 147 & 0,27 & 0.00 & 99,73 & 2.99 \\
\hline 148 & 83,33 & 0,00 & 16,67 & 1,33 \\
\hline 160 & 0,81 & 0,00 & 99,19 & 2,98 \\
\hline 161 & 0,43 & 0,00 & 99,57 & 2,99 \\
\hline 162 & 0,00 & 0,00 & 100,00 & 3,00 \\
\hline 165 & 0.27 & 0,00 & 99,73 & 2,99 \\
\hline 236 & 1,32 & 0,00 & 98,68 & 2,97 \\
\hline 237 & 0,27 & 0,00 & 99,73 & 2,99 \\
\hline 238 & 0,43 & 0,00 & 99,57 & 2.99 \\
\hline 296 & 0.00 & 0,00 & 100,00 & 3,00 \\
\hline 297 & 0,00 & 0,00 & 100,00 & 3,00 \\
\hline 298 & 1,33 & 0,00 & 98,67 & 2,97 \\
\hline 393 & 0.45 & 0,22 & 99,33 & 2,99 \\
\hline 395 & 0,00 & 0,00 & 100,00 & 3,00 \\
\hline 397 & 0,00 & 0.00 & 100,00 & 3,00 \\
\hline 406 & 1,23 & 0,00 & 98,77 & 2.98 \\
\hline 415 & 0.87 & 1,31 & 97,82 & 2,97 \\
\hline
\end{tabular}

Fonte IBGE. Censo 1991 
Conforme se observa na Tabela 5 o acesso à rede de distribuição de água não representa problema para a maioria dos moradores pertencentes aos setores censitarios estudados. Um maior detalhamento deste aspecto seria conhecer as condiçòes de fornecimento de ag̣ua ja que há falta de agua de forma constante. em diversos bairros da cidade de São Paulo, provocando problemas à população em termos de higiene e conforto. Reconhecemos, portanto, que em se tratando de um problema operacional para captação do dado. pode parecer uma condição favorável que nào necessariamente retrata de forma completa a realidade vivida.

Na Pesquisa de Condiçōes de Vida, realizada na Região Metropolitana de São Paulo. $83.1^{\circ}$ o dos barracos. $90.4 \%$ dos cortiços e $97.8 \%$ das casas de alvenaria possuiam abastecimento de ag̣ua com canalização interna Chama a atenção a situação dos setores 45. 46 e 148. nos quais o abastecimento de água se dava sem canalização interna para mais do que $50 \%$ dos domicilios neles situados. Sabe-se que foram realizadas ações de urbanização de favelas nos setores 45 e 46 e que, atualmente, o abastecimento de água apresenta melhores condições

\section{Condicões Sanitárias}

Para construir a categoria empirica "condiçōes sanitárias" foram considerados dois aspectos relativos a mesma. o uso privativo ou coletivo do sanitario pelas famílias e a conexão dos mesmos à rede de esgoto. $O$ primeiro diz respeito mais diretamente ao adoecimento por IRA, na medida em que, quando o sanitário é de uso coletivo, alem da maior probabilidade de contaminação, em geral, este fica situado em area externa comum a varios domicilios, expondo seus moradores às correntes de ar frio. A conexão à rede de esgoto contribui de forma mais indireta para os agravos respiratórios, mas também pode prejudicar o crescimento e desenvolvimento das crianças, expondo-as mais às doenças diarreicas

Para a caracterização das condições sanitárias dos domicílios foram consideradas as seguintes variáveis: sanitário de uso exclusivo da familia conectado a 
rede de esgoto. conectado à fossa ou despejado em vala; sanitário de uso coletivo por mais de uma familia conectado à rede de esgoto, conectado à fossa ou despejado em vala: ausência de sanitario. Foi considerada boa a condição em que o domicilio contava com sanitario de uso exclusivo da familia e conectado a rede de esgoto; foram consideradas regulares as condições em que o uso era privativo da familia, porem sem conexão à rede de coleta de esgotos e quando o uso era coletivo com conexão à rede de esgoto: foi considerada ruim a situação de uso coletivo do sanitário sem conexão à rede de esgotos e péssima a ausência do sanitário. A Tabela 6 retrata as condições sanitárias típicas de cada setor censitário 
Tabela 6: Distribuicão Percentual dos Domicilios Particulares Permanentes em termos das

Condiçoes Sanitárias na região do Butantã. São Paulo, 1998

\begin{tabular}{|c|c|c|c|c|c|}
\hline \multirow{2}{*}{$\begin{array}{c}\text { Setor } \\
\text { Censitário }\end{array}$} & \multicolumn{4}{|c|}{ Condições sanitarias (\%) } & \multirow[t]{2}{*}{ Nota } \\
\hline & Pessimas & Ruins & Regulares & Boas & \\
\hline 1 & 0.00 & 2,76 & 0.00 & 97,24 & 3,94 \\
\hline 2 & 0.00 & 0,00 & 0.23 & 99,77 & 4,00 \\
\hline 3 & 0,00 & 0,78 & 0.00 & 99,22 & 3,98 \\
\hline 4 & 0.00 & 0,00 & 0.00 & 100,00 & 4.00 \\
\hline 5 & 0.00 & 0,00 & 0,00 & 100,00 & 4,00 \\
\hline 6 & 0.00 & 1,79 & 0.00 & 98,21 & 3,96 \\
\hline 7 & 0.00 & 1.11 & 0.00 & 98,89 & 3,98 \\
\hline 8 & 0.00 & 3,39 & 6.25 & 90,63 & 3,88 \\
\hline 9 & 0.00 & 2,55 & 2,74 & 94,71 & 3,92 \\
\hline 10 & 0.79 & 0.79 & 89,76 & 8,66 & 3.06 \\
\hline 11 & 0.00 & 2.96 & 12.56 & 84.48 & 3,82 \\
\hline 18 & 0.00 & 0,39 & 0.00 & 99,61 & 3,99 \\
\hline 19 & 0.00 & 9.93 & 0.00 & 90,07 & 3.80 \\
\hline 29 & 0.00 & 5.31 & 3.27 & 91.43 & 3,86 \\
\hline 30 & 0.00 & 2.73 & 9.29 & 89.07 & 3,90 \\
\hline 31 & 2,07 & 6,64 & 1.66 & 90,04 & 3,80 \\
\hline 32 & 5.88 & 7.06 & 87.06 & 0,00 & 2,81 \\
\hline 33 & 1,75 & 16,08 & 11.40 & 70,76 & 3.51 \\
\hline 34 & 0,00 & 13.33 & 0,00 & 86,67 & 3,73 \\
\hline 35 & 0.86 & 16.86 & 1.43 & 80,86 & 3,62 \\
\hline 36 & 0.00 & 9,31 & 0.00 & 90,69 & 3,81 \\
\hline 37 & 5.00 & 11.25 & 83,13 & 0,63 & 2,79 \\
\hline 38 & 4,90 & 4,20 & 18,18 & 72,73 & 3,59 \\
\hline 39 & 0.00 & 6.12 & 0.41 & 93,47 & 3,87 \\
\hline 43 & 0.00 & 0.00 & 5.07 & 94,93 & 3,95 \\
\hline 44 & 0,00 & 94,12 & 2.94 & 2,94 & 2,09 \\
\hline 45 & 0,00 & 85,91 & 11,07 & 3,36 & 2,18 \\
\hline 46 & 0.55 & 4,96 & 76,03 & 18,46 & 3,12 \\
\hline 83 & 0,00 & 0,68 & 0.00 & 99,32 & 3,99 \\
\hline 84 & 7,97 & 21,74 & 80.43 & 0,72 & 2,96 \\
\hline 85 & 0.00 & 0,00 & 0,00 & 100,00 & 4,00 \\
\hline 144 & 0.00 & 9.18 & 3,06 & 88,57 & 3,82 \\
\hline 147 & 0,00 & 1,36 & 0.27 & 98,37 & 3,97 \\
\hline 148 & 9.80 & 1,96 & 83.33 & 4,90 & 2,83 \\
\hline 160 & 0.00 & 3.25 & 1,90 & 94,85 & 3,92 \\
\hline 161 & 0.00 & 3.02 & 0.00 & 96,98 & 3,94 \\
\hline 162 & 0,00 & 17,24 & 0,57 & 82,18 & 3,65 \\
\hline 165 & 0,27 & 4.63 & 1,63 & 93,46 & 3,88 \\
\hline 236 & 0.00 & 0,00 & 0.33 & 99,67 & 4,00 \\
\hline 237 & 0,00 & 2.46 & 0,00 & 97,54 & 3,95 \\
\hline 238 & 0,43 & 2,56 & 1,28 & 95,73 & 3,92 \\
\hline 296 & 0,00 & 0,50 & 0.50 & 99,00 & 3,99 \\
\hline 297 & 0,00 & 0,00 & 0,00 & 100,00 & 4,00 \\
\hline 298 & 0.00 & 9,29 & 0,00 & 91,59 & 3,85 \\
\hline 393 & 0,00 & 1.12 & 1,12 & 97,76 & 3,97 \\
\hline 395 & 0,00 & 0.00 & 0,00 & 100,00 & 4,00 \\
\hline 397 & 0,00 & 0,00 & 0,00 & 100,00 & 4,00 \\
\hline 406 & 0,00 & 2.47 & 0.00 & 97,53 & 3,95 \\
\hline 415 & 0,00 & 0.00 & 97.82 & 2,18 & 3.02 \\
\hline
\end{tabular}

Fonte: IBGE, Censo de 1991. 
Os dados da Tabela 6 revelam que, apesar de se tratar de uma regiào relativamente central e com boas condições de infra-estrutura urbana. somente 0 setores $(12.2 \%)$ contemplam as condições adequadas na sua totalidade. Em 7 setores $(14.2 \%)$ predominam as condições regulares e em 2 setores $(4.08 \%)$ predominam as ruins. Vale destacar que. o conjunto de setores nos quais predominam as condições regulares e ruins, engloba 8142 habitantes. representando $17.13 \%$ da população total da àrea de abrangência

\section{Aglomeração}

A aglomeração de pessoas num mesmo ambiente, por periodos prolongados. constitui importante fator associado ao adoecimento por IRA. Este indicador de fundamental importância na propagação das doenças respiratórias foi obtido calculando-se a relação existente entre o número médio de pessoas por domicilio e o número médio de dormitórios característico dos setores em estudo. Foi obtido de um valor aproximado a partir dos dados secundários fornecidos pelo Censo e, portanto, não há dados percentuais de distribuição de domicilios nessa variável. $\mathrm{Na}$ análise desses dados, foi considerada boa a condição de até duas pessoas por dormitório. a qual foi atribuida nota 3 ; regular, de duas até três pessoas, à qual foi atribuida nota 2 e ruim. mais do que très pessoas, equivalendo à nota 1

O critério que subsidiou o agrupamento descrito acima, pautou-se fundamentalmente no estudo de CARDOSO (1997), no qual foi encontrada associação positiva de morbidade respiratória grave em crianças que dormiam em casas com uma concentração maior do que 3 pessoas por dormitório. O quadro 1 retrata as condições de aglomeração a que está submetida a população residente nos domicílios dos setores estudados, bem como a nota representativa da condição típica dos setores 
Quadro 2: Classificação dos Domicílios Particulares Permanentes dos setores censitários segundo Condições de Aglomeração na região do Butantã, São Paulo, 1998.

\begin{tabular}{|c|c|c|}
\hline $\begin{array}{c}\text { Setor } \\
\text { Censitário }\end{array}$ & $\begin{array}{c}\text { Número de } \\
\text { Pessoas por dormitorio }\end{array}$ & Nota de Aglomeração \\
\hline 1 & 1.50 & 3 \\
\hline 2 & 1,50 & 3 \\
\hline 3 & 1.50 & 3 \\
\hline 4 & 1.50 & 3 \\
\hline 5 & 1.50 & 3 \\
\hline 6 & 1,50 & 3 \\
\hline 7 & 1,50 & 3 \\
\hline 8 & $3, \infty$ & 2 \\
\hline 9 & 2.00 & 3 \\
\hline 10 & 4.00 & 1 \\
\hline 11 & 3.00 & 2 \\
\hline 18 & 1.50 & 3 \\
\hline 19 & 1.50 & 3 \\
\hline 29 & 3.00 & 2 \\
\hline 30 & 3.00 & 2 \\
\hline 31 & 3.00 & 2 \\
\hline 32 & 4,00 & 1 \\
\hline 33 & 4,00 & 1 \\
\hline 34 & 4,00 & 1 \\
\hline 35 & $3, \infty$ & 2 \\
\hline 36 & 3.00 & 2 \\
\hline 37 & $4, \infty$ & 1 \\
\hline 38 & $4, \infty 0$ & 1 \\
\hline 39 & $3, \infty 0$ & 2 \\
\hline 43 & 3,00 & 2 \\
\hline 44 & 4,00 & 1 \\
\hline 45 & 4.00 & 1 \\
\hline 46 & 4.00 & 1 \\
\hline 83 & 3,00 & 2 \\
\hline 84 & 4,00 & 1 \\
\hline 85 & 1,50 & 3 \\
\hline 144 & 3.00 & 2 \\
\hline 147 & 3,00 & 2 \\
\hline 148 & 4,00 & 1 \\
\hline 160 & 3.00 & 2 \\
\hline 161 & $2, \infty$ & 3 \\
\hline 162 & 3,00 & 2 \\
\hline 165 & 1.50 & 3 \\
\hline 236 & 1.50 & 3 \\
\hline 237 & 2,00 & 3 \\
\hline 238 & 1.50 & 3 \\
\hline 296 & 1,33 & 3 \\
\hline 297 & 1,33 & 3 \\
\hline 298 & 1.50 & 3 \\
\hline 393 & 1,50 & 3 \\
\hline 395 & 3,00 & 2 \\
\hline 397 & 3,00 & 2 \\
\hline 406 & 2,00 & 3 \\
\hline 415 & 4.00 & 1 \\
\hline
\end{tabular}

Fonte: IBGE, Censo de 1991. 
Em 20 setores $(43,0 \%)$ as condições encontradas eram boas. com até duas pessoas por dormitório; em 13 setores $(33,0 \%)$ regular e, em $11(24,0 \%)$, ruins. excedendo 3 pessoas por dormitorio como média.

\section{Coleta de Lixo}

A questão da coleta do lixo tem maior relevância para as IRA quando se trata da pratica de queimar o lixo. As outras situaçòes deficientes com relação a este aspecto têm interferência de forma indireta. compondo um ambiente de maior ou menor insalubridade do domicilio

Com relaçào a esta variavel. os dados disponiveis encontravam-se subdivididos nas seguintes categorias: lixo coletado diretamente ou indiretamente: lixo queimado, lixo enterrado ou jogado em terreno baldio, em rio, lago, ou corrego. Foi considerada boa somente a situação de coleta direta: regular, quando a mesma se dava de forma indireta. ou seja. em via proxima aquela em que se encontra o domicilio e nas situaçòes em que o lixo é enterrado, e ruim, para os domicílios em que o lixo é jogado, ou queimado. A Tabela 7 apresenta as condições de coleta de lixo nos setores em estudo 
Tabela 7: Distribuição Percentual dos domicilios dos setores censitários da regiāo do Butantã quanto às Condições de Coleta do Lixo. São Paulo. 1998.

\begin{tabular}{|c|c|c|c|c|}
\hline \multirow{2}{*}{$\begin{array}{c}\text { Setor } \\
\text { censitário }\end{array}$} & \multicolumn{3}{|c|}{ Condições de coleta de lixo } & \multirow[t]{2}{*}{ Nota } \\
\hline & Ruins & Regulares & Boas & \\
\hline 1 & 0.00 & 0,00 & 100,00 & 3,00 \\
\hline 2 & 0.00 & 0.23 & 99.77 & 3.00 \\
\hline 3 & 0.78 & 0.78 & 98,44 & 2,98 \\
\hline 4 & 0.00 & 0.00 & 100.00 & 3,00 \\
\hline 5 & 0.00 & 0,00 & 100.00 & 3.00 \\
\hline 6 & 0.00 & 0.00 & 100.00 & 3,00 \\
\hline 7 & 0.00 & 0.56 & 99.44 & 2,99 \\
\hline 8 & 0.00 & 0,52 & 99.48 & 2,99 \\
\hline 9 & 0.00 & 2,92 & 97.08 & 2,97 \\
\hline 10 & 0.39 & 93,31 & 6.30 & 2,06 \\
\hline$i 1$ & 0.00 & 0,00 & 100.00 & 3,00 \\
\hline 18 & 0.00 & 0.00 & 100,00 & 3,00 \\
\hline 19 & 0.00 & 0.00 & 100.00 & 3.00 \\
\hline 29 & 3.67 & 0.82 & 95.51 & 2.92 \\
\hline 30 & 0.55 & 0.00 & 99.45 & 2.99 \\
\hline 31 & 0.00 & 0,00 & 100.00 & 3.00 \\
\hline 32 & 0.00 & 0,00 & 100,00 & 3,00 \\
\hline 33 & 3.51 & 1.17 & 95,32 & 2,92 \\
\hline 34 & 0.00 & 0,00 & 100,00 & 3,00 \\
\hline 35 & 0.00 & 0.00 & 100,00 & 3,00 \\
\hline 36 & 0.00 & 0,00 & 100.00 & 3,00 \\
\hline 37 & 0.00 & 91,88 & 8.13 & 2,08 \\
\hline 38 & 0.70 & 93,01 & 6.29 & 2.06 \\
\hline 39 & 0,00 & 0,00 & 100,00 & 3,00 \\
\hline 43 & 0.00 & 0,92 & 99.08 & 2,99 \\
\hline 44 & 0.00 & 93,70 & 6.30 & 2,06 \\
\hline 45 & 0.00 & 24,16 & 75,84 & 2,76 \\
\hline 46 & 1,65 & 4,96 & 93,39 & 2,92 \\
\hline 83 & 0.00 & 11.19 & 88,81 & 2.89 \\
\hline 84 & 0.00 & $69,5 i$ & 30.43 & 2,30 \\
\hline 85 & 0,00 & 0.00 & 100,00 & 3.00 \\
\hline 144 & 0.00 & 0.20 & 99.80 & 3,00 \\
\hline 147 & 0.00 & 0.00 & 100,00 & 3,00 \\
\hline 148 & 0,00 & 0,00 & 100,00 & 3,00 \\
\hline 160 & 0,00 & 0,00 & 100,00 & 3,00 \\
\hline 161 & 0.00 & 0,00 & 100,00 & 3,00 \\
\hline 162 & 0.00 & 0,00 & 100,00 & 3,00 \\
\hline 165 & 0,00 & 0,00 & 100,00 & 3,00 \\
\hline 236 & 0,00 & 0,33 & 99,67 & 300 \\
\hline 237 & 0.00 & 77,32 & 22,68 & 2,23 \\
\hline 238 & 0.00 & 1,28 & 98,72 & 2,99 \\
\hline 296 & 0,00 & 0,00 & 100,00 & 3,00 \\
\hline 297 & 0,00 & 0,00 & 100,00 & 3,00 \\
\hline 298 & 1,33 & 0,44 & 98,23 & 2,97 \\
\hline 393 & 0.00 & 1.79 & 98,21 & 2,98 \\
\hline 395 & 9.38 & 0.00 & 90,63 & 2,81 \\
\hline 397 & 0.00 & 0,00 & 100,00 & 3,00 \\
\hline 406 & 0,00 & 1.23 & 98,77 & 2,99 \\
\hline 415 & 0.00 & 0,44 & 99.56 & 3,00 \\
\hline
\end{tabular}

Fonte IBGE, Censo de 1991 
Ao analisarmos os dados apresentados, podemos verificar que. em 23 setores $(46,93 \%)$. a condiçào adequada estava contemplada na totalidade dos domicilios Destaca-se ainda a situação encontrada em 6 setores $(12.24 \%)$ em que predominou a condição regular. Tais dados revelam uma pior condição no acesso a coleta de lixo superior aquele relatada no trabalho de SPOSATI (1996). segundo o qual os Distritos do Butantã e Rio Pequeno tinham somente 0.15 e $0.46 \%$ do total de domicilios. respectivamente. nesta condição. Apesar de se tratar de uma região da cidade de São Paulo com boas condiçòes de infra-estrutura urbana se comparada a outras mai periféricas, ainda há um contingente significativo de cidadâos expostos a um tipo de problema tào antigo quanto a propria formação das cidades

\section{Tipo de Construção}

A opção pelo uso desse aspecto como indicador das condições de risco de doenças respiratórias, deu-se devido a grande influência que este exerce sobre a morbidade respiratória. Domicilios sem acabamento adequado expõem os seus moradores às mudanças bruscas de temperatura ocorridas em curtos periodos de tempo. Os dados fornecidos não especificavam o tipo de acabamento das moradias. comprometendo assim o melhor conhecimento da realidade em estudo

Em relação a esta última variavel, os dados fornecidos pelo Censo apresentavam-se subdivididos nas seguintes condições: casa/apartamento isolado. casa/ apartamento construido em conjunto residencial popular e casa/apartamento em aglomerado subnormal. Os domicilios isolados foram considerados bons; os construidos em conjunto residencial popular foram considerados regulares; e aqueles. classificados como aglomerados subnormal (favela) ou cortiço, foram considerados ruins Nas favelas o tipo de material utilizado para a construção é improvisado, não atendendo ao critério de isolamento térmico de forma adequada. Nos conjuntos populares, é muito comum também que o revestimento não garanta totalmente o isolamento necessário. A condição de casa/apartamento isolados, em si, também não 
garante que estejam contemplados os requisitos necessários de tipo de construção. porem optou-se por considerar-se como boa. na falta de dados complementares. A Tabela 8 apresenta os dados relativos ao tipo de construção encontrado nos domicilios. predominante nos setores censitarios estudados 
Tabela 8: Distribuição percentual dos domicílios segundo o Tịo de Construção caracteristica dos setores censitários da região do Butantã. São Paulo. 1998.

\begin{tabular}{|c|c|c|c|c|}
\hline \multirow{2}{*}{$\begin{array}{c}\text { Setores } \\
\text { censitários }\end{array}$} & \multicolumn{3}{|c|}{ Tipo de construção (\%) } & \multirow[t]{2}{*}{ Nota } \\
\hline & Ruim & Regular & Bom & \\
\hline 1 & 0,79 & 0.00 & 99.21 & 2,98 \\
\hline 2 & 0,23 & 0.00 & 99,77 & 3,00 \\
\hline 3 & 0.00 & 0.00 & 100,00 & 3,00 \\
\hline 4 & 0,00 & 0.00 & 100,00 & 3,00 \\
\hline 5 & 0.00 & 0,00 & 100,00 & 3,00 \\
\hline 6 & 0.00 & 0.60 & 99,40 & 2,99 \\
\hline 7 & 0.56 & 0.00 & 99,44 & 2,99 \\
\hline 8 & 0,52 & 0,00 & 98.96 & 2,97 \\
\hline 9 & 2.37 & 0.36 & 96,90 & 2,94 \\
\hline 10 & 98.03 & 0.00 & 1,97 & 1.04 \\
\hline 11 & 0.00 & 0,00 & 100,00 & 3.00 \\
\hline 18 & 0,00 & 0,00 & 100.00 & 3,00 \\
\hline 19 & 0.00 & 0,00 & 100,00 & 3.00 \\
\hline 29 & 0.00 & 0.00 & 100,00 & 3,00 \\
\hline 30 & 0.00 & 0.00 & 100,00 & 3,00 \\
\hline 31 & 0.00 & 0.00 & 100.00 & 3.00 \\
\hline 32 & 100.00 & 0.00 & 0.00 & 1.00 \\
\hline 33 & 0.88 & 0.00 & 98.25 & 2,96 \\
\hline 34 & 100,00 & 0,00 & 0,00 & 1,00 \\
\hline 35 & 0.29 & 6.57 & 93,14 & 2,93 \\
\hline 36 & 0,00 & 0,00 & 100,00 & 3,00 \\
\hline 37 & 99,38 & 0.00 & 0,63 & 1,01 \\
\hline 38 & 100,00 & 0.00 & 0,00 & 1,00 \\
\hline 39 & 0.00 & 0,00 & 100,00 & 3,00 \\
\hline 43 & 0,92 & 0,00 & 99,08 & 2,98 \\
\hline 44 & 100,00 & 0,00 & 0,00 & 1,00 \\
\hline 45 & 99,66 & 0,00 & 0,00 & 1,00 \\
\hline 46 & 93.66 & 0.00 & 5.79 & 1,11 \\
\hline 83 & 0.00 & 0,00 & 100,00 & 3,00 \\
\hline 84 & 100,00 & 0.00 & 0,00 & 1,00 \\
\hline 85 & 0,00 & 0.00 & 100,00 & 3,00 \\
\hline 144 & 3,67 & 0.20 & 96,12 & 2,92 \\
\hline 147 & 0,00 & 0,00 & 99.46 & 2,98 \\
\hline 148 & 100,00 & 0.00 & 0,00 & 1,00 \\
\hline 160 & 0,00 & 0.00 & 97,29 & 2,92 \\
\hline 161 & 0.00 & 0,00 & 100.00 & 3,00 \\
\hline 162 & 0.00 & 0.00 & 100,00 & 3,00 \\
\hline 165 & 0.00 & 0,00 & 100,00 & 3,00 \\
\hline 236 & 0,66 & 0,00 & 99,34 & 2,99 \\
\hline 237 & 0,00 & 0,00 & 100,00 & 3,00 \\
\hline 238 & 1,71 & 0.43 & 97,86 & 2,96 \\
\hline 296 & 0.00 & 0,00 & 100,00 & 3,00 \\
\hline 297 & 0,00 & 0,00 & 100,00 & 3,00 \\
\hline 298 & 0,00 & 044 & 99,56 & 3,00 \\
\hline 393 & 0,22 & 8.52 & 89,69 & 2,86 \\
\hline 395 & 0,00 & 0,00 & 100,00 & 3,00 \\
\hline 397 & 0.00 & 0,00 & 100,00 & 3,00 \\
\hline 406 & 0.00 & 0.00 & 100,00 & 3,00 \\
\hline 415 & 99,56 & 0,00 & 0,44 & 1,01 \\
\hline
\end{tabular}

Fonte IBGE, Censo de 1991 
Com relação a este aspecto da moradia, a tabela 8 revela que a maioria dos setores apresenta condições favoráveis. Porém em 11 setores $(22,4 \%)$ a totalidade equivale a condições ruins. Trata-se de uma condição pior do que a encontrada pelo SEADE na Pesquisa de Condições de Vida realizada na região metropolitana de São Paulo, na qual $11,0 \%$ das familias estudadas encontravam-se em situação precária, reunindo as situações de favelas e cortiços. Na região do Butantã, este aspecto da moradia revela o predomínio da polarização seja na melhor ou na pior condição.

\section{$2^{*}$ Fase: Priorização das variáveis para a construção dos indicadores}

Conforme descrito no Capitulo 2; após ter sido caracterizada a região em estudo, através das variáveis de interesse, passou-se a agrupá-las com vistas à construção dos indicadores de inserção social e de qualidade do domicílio, a fim de obter o indice de potencial de exposição às condições de risco para as doenças respiratórias na infância. Para o desenvolvimento desta etapa da investigação foram realizadas reuniões com a população local, bem como junto aos representantes de entidades que atuam na região, para discussão sobre a importância das variáveis disponiveis na compreensão do fenômeno em estudo. As reuniões foram realizadas utilizando-se a técnica de Grupo Focal, tendo como tarefa primordial a hierarquização das variáveis para a formulação dos indicadores compostos e do índice de potencial de exposição às condições de risco para os agravos respiratórios.

A primeira reunião envolveu 8 pessoas, foi realizada na auditório do Parque da Previdência, envolvendo técnicos do Centro de Educação Ambiental, vinculados à Secretaria do Verde do Municipio de São Paulo, representantes do Conselho Tutelar da Criança e do Adolescente do Butantã e a Diretora do Parque da Previdência. Houve primeiramente, uma exposição acerca da finalidade e objetivos do trabalho que estava sendo desenvolvido, esclarecendo a contribuição dos participantes com relação à priorização das variáveis. Dado o grande conhecimento da região por parte dos participantes, foi possivel desencadear discussões muito interessantes para 
subsidiar a proposta. Um primeiro item que merece ser destacado foi a concepção de saúde manifesta por uma das integ̣rantes no grupo acerca da gênese social da saúde. " saúde não é só responsabilidade de quem trabalha na área. quer dizer é um produto social"(M.G.)

Desde o inicio do grupo houve preocupaçào em destacar a relevância da educação na qualidade de vida

"Então ai estaria uma resposta às variàveis que vocè coloca que é de habitaçào. Ag̣ora não da prá dizer que só porque mora em favela .... Mas havendo alg̣uma educação o problema não se resolveria mas se amenazaria bastante".(E.B.,

"Se ele nào tem essa questão da formação que ele colocou, da escolaridade do chefe dessa familia. mesmo que ele tenha um pouquinho a sua casa propria o seu banheiro, muitas vezes a origem dele leva a algumas atitudes assim mais arraigadas que levam a um comportamento ruim para a saude". ( L.H.P.)

"Também é a questão da escolaridade. O indice de escolaridade eu acho que tem muito a ver com estas coisas, e realmente tem importância" (M.A.S.F.)

"Então, educação em primeiro lugar....eu coloco a educação como ponto principal que a gente tem que listar também ai'"(E.B.)

Outro item destacado pelo grupo de participantes foi o grande numero de pessoas numa mesma casa como fator importante para indicar a qualidade de vida a partir do domicilio

“...e a parte da habitação também que é três por três e lá moram vinte e três pessoas e uma questão muito ruim...eu acho que as autoridades mesmo devem se preocupar com isso" (E. B )

O tipo de construção também foi mencionado como condição importante pra determinar a qualidade do domicilio

“...porque às vezes vocè entra num barraco que está tudo limpinho, tudo bonitinho mas tem a parede muito fina" 
Neste primeiro grupo houve um debate bastante intenso sobre a diferenciação entre as variáveis, pois alguns participantes defendiam que não deveria haver diferenciação enquanto outros argumentavam pela atribuição de peso diferenciado.

"Eu acho que na primeira fase da sua pesquisa, eles têm que ter peso idêntico, porque é uma questão mais de tratamento estatistico" (M.L.S.)

"Eu acho que a escolaridade deveria ter um peso maior e o social deveria ser maior que o do domicilio" (V.M.F.P.)

"Na doença respiratória eu não concordo. Nós estamos falando em doença respiratória. Quer dizer, na doença respiratória as condições de domicilio pesam muito mais que a renda"(M.G.)

Durante a reunião houve um momento de impasse em relação à indicação sobre os pesos das variảveis, pois alguns participantes defendiam a mesma ponderação para todas, enquanto outros defendiam pesos diferenciados. Foi esclarecido que todas opiniões eram válidas e que seriam contempladas, já que outros grupos ainda se reuniriam para discutir a mesma temática. As indicações foram registradas em papel pelos próprios participantes para facilitar a sistematização dos dados

A segunda reunião foi realizada no salão da Paróquia São Patrício contando com a participação de 13 representantes da Pastoral da Saúde e da Pastoral da Criança que residem na área e desenvolvem ações comunitárias na região. Da mesma forma que no primeiro grupo, houve primeiramente uma apresentação do trabalho, esclarecendo-se a finalidade e os objetivos do mesmo. Durante esta apresentação as participantes fizeram vários relatos sobre situações de adoecimento por IRA em suas próprias familias ou em relação a outros moradores, reiterando a validade da realização do trabalho a fim de ampliar o conhecimento a respeito de um problema muito freqüente.

As opiniōes expressas pelo grupo destacavam a questão do tamanho reduzido da moradia para um grande número de residentes e a escolaridade, como pontos 
distintos para a qualidade de vida e a inserção social, como pode ser observado nas falas a seguir:

"Eu visito uma familia que tem 8 filhos e tem um só cômodo, onde cozinha, onde come, onde dorme, é horrivel" (B.J.)

"Isso é falta de cultura....A partir do momento que o povo tiver cultura ele vai agir, de uma ou de outra maneira. Não importa a condição, acho que seria por ai"'( R.J.L.)

"Pessoa que não tem informação nenhuma, não tem condição" (M.A.F.)

Os comportamentos prejudiciais à saúde foram enfatizados, destacando-se a auto-medicação. O grupo convive com este problema já que a Paróquia mantém a distribuição gratuita de medicamentos para a população carente e há pessoas que procuram o serviço sem receita médica, esperando receber a medicação. Foi esclarecido que na primeira fase de caracterização do território, infelizmente, esse aspecto não poderia ser monitorado a partir dos dados disponiveis. Retomando a discussão para a importância das variáveis na construção dos indicadores, foram destacados principalmente que o indicador de inserção social deveria pesar mais do que a qualidade da moradia e, dentro da inserção social, a variável escolaridade, também deveria ser destacada na ponderação. Os trechos de discurso apresentados a seguir ilustram a discussão relatada.

"E inserção social" (R.J.L.)

“Acho que é inserção social, né ?"(M.J.V.)

"A escolaridade também é necessário" (I.B.B.A.)

"Eu digo a mesma coisa, assim, na parte educativa e na parte financeira"(M.P.V.)

"Porque vamos supor, a gente tem uma casa pequena, dorme cinco ou seis pessoas, às vezes o casal fuma, né? Isso prejudica a criança, não faz bem.”(F. F.)

"Você tendo conhecimento das coisas, você vai trabalhar, vai correr. Você indo atrás você tem condições de morar bem, comer bem" (M.Z.M.F.)

"Eu fico com a inserção social, especialmente escolaridade"(B. J.)

"Baixa escolaridade, acho que está faltando escolaridade"(Z.B.C.) 
Mais especificamente com relação às condições do domicilio, foram destacados a aglomeração, o tipo de construção e as condições sanitárias.

"E o banheiro comunitário que você falou ai. Não é fácil a gente ter uma criança e saber que vai usar um banheiro que todo mundo usa"(F. F.)

"É um todo. E tambèm se não fizer a construção da casa num ambiente adequado, não adianta nada” (M.A.F.J.)

Conforme mencionado no Capitulo 4, os encontros foram gravados e as fitas transcritas para possibilitar a sistematização dos dados. Reunindo-se as contribuições de todos os participantes, houve uma clara predominância das variáveis relativas à inserção social sobre as variáveis que qualificavam a residência. No interior do indicador de inserção social, a variável mais destacada foi a escolaridade, à qual foi atribuido peso 2 na composição do indicador. Com relação à moradia, considerandose as manifestações dos participantes nos grupos, destacou-se a maior quantidade de pessoas por domicilio, aqui denominada aglomeração. Optou-se por atribuir peso maior para aglomeração (peso 3), seguido das duas outras mencionadas que foram tipo de construção e condições sanitárias (peso 2), deixando as variáveis relativas ao abastecimento de água e coleta de lixo com peso menor (peso 1)

\section{Fase: Operacionalização dos indicadores}

Diante dos dados disponiveis pelo IBGE, nos grupos focais foi estabelecido um esquema de hierarquização das variáveis. Com relação ao Indicador de Inserção Social (IIS), foi sugerido que o peso maior recaisse sobre a variável escolaridade do chefe, pela sua importância na inserção no mercado de trabalho, bem como por configurar-se como condição mais permanente do que a renda. Com relação ao Indicador de Qualidade do Domicilio (IQD), que envolvia cinco diferentes variáveis, foi indicado que o peso maior deveria ser dado à variável aglomeração, retratada pelo número de pessoas por dormitório, que recebeu peso 3; seguido de condições sanitárias e tipo de construção, às quais foram atribuidos peso 2 e finalmente, acesso à água e coleta de lixo com peso 1 
Quanto à conformação do Índice de Potencial de Exposição Ambiental que representar a sintese dos dois indicadores, foi sugerido que o IIS tivesse peso 2 sobre o IQD.

Como resultado das discussões estabelecidas junto à população nas reuniões desenvolvidas, chegou-se ao seguinte esquema para compor os indicadores:

\section{Indicador de Inserção Social (IIS):}

$\frac{\text { Renda per capita }+2 \times \text { Escolaridade }+ \text { Condição de Ocupação do Domicilio }}{4}$

\section{Indicador de Qualidade do Domicilio (IQD): \\ Água $+2 \times$ Cond. Sanit $+3 \times$ Aglomeração $+2 \times$ Tipo de const + Lixo \\ 9}

Cabe esclarecer que o procedimento estatistico, utilizado para a comparação dos setores e seu posterior agrupamento, envolveu a pontuação das condições observadas nas tabelas, atribuindo-se a cada setor em estudo uma pontuação para as variáveis em função da condição encontrada mais freqüentemente, retratada pela média ponderada. A melhor condição possivel recebeu um valor positivo 1 e a pior condição recebeu um valor negativo de -1 , considerando-se os percentuais existentes em cada fração das variáveis, de forma análoga ao cálculo da média ponderada em termos absolutos.

Os cálculos foram efetuados utilizando-se o programa Excel. A seguir serão apresentados os valores numéricos representativos das condições encontradas em cada setor censitário, que permitiu a utilização da expressão matemática para se chegar aos indicadores. 
Quadro 3 Valores obtidos pelos setores censitánios nas variáveis relativas ao indicador de inserção social , Butantả. 1998

\begin{tabular}{|c|c|c|c|}
\hline $\begin{array}{c}\text { Setor } \\
\text { Censitário }\end{array}$ & $\begin{array}{l}\text { Indice de } \\
\text { escolaridade }\end{array}$ & $\begin{array}{c}\text { Indice de } \\
\text { Renda per Capita }\end{array}$ & $\begin{array}{l}\text { Indice de Condiçåo de } \\
\text { ocupaçăo do domicilio }\end{array}$ \\
\hline 1 & 0,8502 & 0,6781 & 0,9397 \\
\hline 2 & 0,9125 & 0,8372 & 0,9317 \\
\hline 3 & 0,6389 & $-0,2042$ & 1,0000 \\
\hline 4 & 0,8057 & 0,6658 & 0,9236 \\
\hline 5 & 0,6817 & $-0,1722$ & 0,9193 \\
\hline 6 & 0,6830 & 0,6748 & 0,9014 \\
\hline 7 & 0,6332 & $-0,2056$ & 0,9016 \\
\hline 8 & $-0,3275$ & $-0,2658$ & 0,8851 \\
\hline 9 & 0,6434 & $-0,2385$ & 0,8798 \\
\hline 10 & $-0,8746$ & $-0,8028$ & $-0,9980$ \\
\hline 11 & $-0,4184$ & $-0,3382$ & $-0,8286$ \\
\hline 18 & 0,8014 & 0,6033 & 0,9403 \\
\hline 19 & 0,6077 & $-0,2261$ & 0,8900 \\
\hline 29 & $-0,3199$ & $-0,2547$ & 0,8495 \\
\hline 30 & 0,7768 & $-0,1692$ & 0,8609 \\
\hline 31 & $-0,4601$ & $-0,4658$ & $-0,8456$ \\
\hline 32 & $-0,9637$ & $-0,8621$ & $-1,0000$ \\
\hline 33 & $-0,4621$ & $-0,5587$ & $-0,8331$ \\
\hline 34 & $-1,0000$ & $-0,9643$ & $-1,0000$ \\
\hline 35 & $-0,4092$ & $-0,3673$ & $-0,8149$ \\
\hline 36 & $-0,3842$ & $-0,4351$ & $-0,8233$ \\
\hline 37 & $-0,5877$ & $-0,7728$ & $-1,0000$ \\
\hline 38 & $-0,8398$ & $-0,7960$ & $-0,9862$ \\
\hline 39 & $-0,3817$ & $-0,3143$ & 0,8938 \\
\hline 43 & 0,6884 & $-0,2003$ & 0,9607 \\
\hline 44 & $-0,7060$ & $-0,7003$ & $-0,9958$ \\
\hline 45 & $-0,6892$ & $-0,7015$ & $-0,9933$ \\
\hline 46 & $-0,6788$ & $-0,5328$ & $-0,9851$ \\
\hline 83 & $-0,3563$ & $-0,3591$ & 0,8689 \\
\hline 84 & $-0,8150$ & $-0,8637$ & $-0,9964$ \\
\hline 85 & 0,6628 & 0,6011 & 0,8888 \\
\hline 144 & $-0,4293$ & $-0,4309$ & $-0,8507$ \\
\hline 147 & $-0,3387$ & $-0,2884$ & 0,8872 \\
\hline 148 & $-0,8164$ & $-1,0000$ & $-0,9668$ \\
\hline 160 & $-0,3192$ & $-0,2864$ & $-0,8264$ \\
\hline 161 & 0,7411 & $-0,1996$ & 0,8912 \\
\hline 162 & $-0,3415$ & $-0,3726$ & $-0,8406$ \\
\hline 165 & 0,8114 & 0,9591 & 0,8659 \\
\hline 236 & 0,9367 & 0,8686 & 0,8774 \\
\hline 237 & 0,8460 & 1,0000 & 0,8442 \\
\hline 238 & 0,7185 & 0,6500 & 0,8662 \\
\hline 296 & 1,0000 & 0,7898 & 0,9931 \\
\hline 297 & 0,9855 & 0,7892 & 0,9786 \\
\hline 298 & 0,8424 & 0,6906 & $-0,8339$ \\
\hline 393 & 0,7520 & 0,6062 & 0,8420 \\
\hline 395 & $-0,3908$ & $-0,3200$ & 0,8594 \\
\hline 397 & $-0,3633$ & $-0,2271$ & 0,8731 \\
\hline 406 & 0,8484 & 0,9670 & $-0,9701$ \\
\hline 415 & $-1,0000$ & $-0,6793$ & $-1,0000$ \\
\hline
\end{tabular}

104 
Quadro + Valores obtidos pelos setores censitários nas variáveis relativas ao indicador de qualidade do domicilio. 1998

\begin{tabular}{|c|c|c|c|c|c|}
\hline $\begin{array}{c}\text { Setor } \\
\text { censitário }\end{array}$ & $\begin{array}{l}\text { Indice de } \\
\text { acesso à } \\
\text { água }\end{array}$ & $\begin{array}{l}\text { Indice de } \\
\text { condições } \\
\text { sanitárias }\end{array}$ & $\begin{array}{l}\text { Indice de } \\
\text { aglomeração }\end{array}$ & $\begin{array}{c}\text { Indice de } \\
\text { condições } \\
\text { de coleta de } \\
\text { lixo }\end{array}$ & $\begin{array}{l}\text { Indice de } \\
\text { tipo de } \\
\text { construção }\end{array}$ \\
\hline 1 & 1.0000 & 0.9862 & 0.8867 & 1.0000 & 0.9948 \\
\hline 2 & 1.0000 & 0.9994 & 0,8867 & 0.9992 & 0,9985 \\
\hline 3 & 1.0000 & 0.9961 & 0.8867 & 0.9922 & 1,0000 \\
\hline 4 & 1.0000 & 1.0000 & 0.8867 & 1,0000 & 1,0000 \\
\hline 5 & 1.0000 & 1.0000 & 0,8867 & 1,0000 & 1,0000 \\
\hline 6 & 1.0000 & 0.9911 & 0.8867 & 1.0000 & 0.9980 \\
\hline 7 & 0.9981 & 0.9944 & 0.8867 & 0,9981 & 0.9963 \\
\hline 8 & 0.9983 & 0.9701 & -0.7500 & 0.9983 & 0.9913 \\
\hline 9 & 0.9976 & 0.9804 & 0.6650 & 0.9903 & 0,9793 \\
\hline 10 & 0.9318 & 0.7657 & -1.0000 & $-0,9985$ & $-0,9589$ \\
\hline 11 & 0.9951 & 0.9538 & -0.7500 & 1,0000 & 1,0000 \\
\hline 18 & 1.0000 & 0.9980 & 0.8867 & 1.0000 & 1,0000 \\
\hline 19 & 1.0000 & 0.9504 & 0.8867 & 1.0000 & 1,0000 \\
\hline 29 & 0.9973 & 0.9653 & -0.7500 & 0.9728 & 1.0000 \\
\hline 30 & 0.9964 & 0.9740 & -0.7500 & 0,9964 & 1,0000 \\
\hline 31 & 1.0000 & 0.9512 & -0.7500 & 1,0000 & 1,0000 \\
\hline 32 & 0.9137 & -0.7427 & $-1,0000$ & 1,0000 & $-0,9966$ \\
\hline 33 & 0,9990 & 0.8779 & $-1,0000$ & 0,9727 & 0,9854 \\
\hline 34 & 1,0000 & 0.9333 & $-1,0000$ & 1.0000 & $-0,9966$ \\
\hline 35 & 1.0000 & 0,9057 & $-0,7500$ & 1,0000 & 0,9762 \\
\hline 36 & 1,0000 & 0,9534 & -0.7500 & 1,0000 & 1,0000 \\
\hline 37 & 0.9896 & -0.7475 & -1.0000 & $-0,9878$ & $-0,9843$ \\
\hline 38 & 0.9580 & 0.8969 & $-1,0000$ & -1.0000 & $-0,9966$ \\
\hline 39 & 1,0000 & 0,9684 & $-0,7500$ & 1,0000 & 1,0000 \\
\hline 43 & 1,0000 & 0,9873 & -0.7500 & 0,9969 & 0,9939 \\
\hline 44 & 0.9776 & $-1,0000$ & -1.0000 & $-0,9966$ & -0.9966 \\
\hline 45 & $-1,0000$ & $-0,9559$ & $-1,0000$ & 0,9195 & $-1,0000$ \\
\hline 46 & -0.5955 & 0,7810 & -1.0000 & 0,9725 & $-0,8977$ \\
\hline 83 & 0.9977 & 0,9966 & -0.7500 & 0,9627 & 1,0000 \\
\hline 84 & 0,8575 & $-0,7063$ & $-1,0000$ & $-0,8922$ & $-0,9966$ \\
\hline 85 & 1,0000 & 1,0000 & 0,8867 & 1,0000 & 1,0000 \\
\hline 144 & 0.9891 & 0,9546 & $-0,7500$ & 0,9993 & 0,9748 \\
\hline 147 & 0,9982 & 0,9925 & $-0,7500$ & 1,0000 & 0,9946 \\
\hline 148 & -0.8809 & $-0,7370$ & -1.0000 & 1,0000 & $-0,9966$ \\
\hline 160 & 0.9946 & 0,9790 & $-0,7500$ & 1,0000 & 0,9729 \\
\hline 161 & 0,9971 & 0,9849 & 0,6650 & 1,0000 & 1,0000 \\
\hline 162 & 1.0000 & 0,9124 & -0.7500 & 1.0000 & 1,0000 \\
\hline 165 & 0.9982 & 0,9707 & 0,8867 & 1,0000 & 1,0000 \\
\hline 236 & 0,9912 & 0,9992 & 0,8867 & 0,9989 & 0,9956 \\
\hline 237 & 0.9982 & 0,9877 & 0,6650 & $-0,9233$ & 1,0000 \\
\hline 238 & 0,9972 & 0,9808 & 0.8867 & 0,9957 & 0,9872 \\
\hline 296 & 1,0000 & 0,9963 & 1,0000 & 1,0000 & 1,0000 \\
\hline 297 & 1.0000 & 1.0000 & 1,0000 & 1,0000 & 1,0000 \\
\hline 298 & 0,9912 & 0.9624 & 0.8867 & 0,9897 & 0,9985 \\
\hline 393 & 0.9963 & 0,9916 & 0,8867 & 0,9940 & 0,9544 \\
\hline 395 & 1.0000 & 1,0000 & $-0,7500$ & 0,9375 & 1,0000 \\
\hline 397 & 1,0000 & 1,0000 & $-0,7500$ & 1,0000 & 1,0000 \\
\hline 406 & 0.9918 & 0.9877 & 0,6650 & 0,9959 & 1,0000 \\
\hline 415 & 0,9898 & -0.6910 & $-1,0000$ & 0,9985 & -0.9880 \\
\hline
\end{tabular}


Com isso, pôde-se calcular os valores dos indicadores de inserção social e de qualidade do domicilio de cada setor censitário para posteriormente, efetuar o cálculo que expressou a situação dos setores em termos do Índice de Exposição Ambiental para as Condições de Risco para os Agravos Respiratórios, através da expressão:

Índice de Potencial de Exposição Ambiental: 2 x IIS + IQD

3

Em seguida, os setores foram ordenados de forma decrescente, segundo o valor final comparativo chegando-se a um "ranking" dos diferentes potenciais de exposição às condições de risco para o adoecimento por IRA, apresentados a seguir 
Quadro 5 Setores censitários segundo os diferentes potenciais de exposição às condiçōes de risco para as IRA e composição de grupos homogêneos a partir do Índice final, Butantã, 1998

\begin{tabular}{|c|c|c|c|c|c|}
\hline $\begin{array}{c}\text { Setor } \\
\text { censitário }\end{array}$ & $\begin{array}{c}\text { Indice de } \\
\text { Inserçäo } \\
\text { social } \\
\end{array}$ & $\begin{array}{c}\text { Setor } \\
\text { censitário }\end{array}$ & $\begin{array}{c}\text { Índice de } \\
\text { Qualidade do } \\
\text { domicilio }\end{array}$ & $\begin{array}{c}\text { Setor } \\
\text { censitário }\end{array}$ & $\begin{array}{c}\text { Indice } \\
\text { Final }\end{array}$ \\
\hline $\begin{array}{l}296 \\
297\end{array}$ & $\begin{array}{l}0,9457 \\
0,9347\end{array}$ & $\begin{array}{l}297 \\
296 \\
\end{array}$ & $\begin{array}{l}1,0000 \\
0,9992 \\
\end{array}$ & $\begin{array}{l}296 \\
297\end{array}$ & $\begin{array}{l}0,9635 \\
0,9565\end{array}$ \\
\hline 236 & 0,9048 & 4 & 0,9622 & 236 & 0.9232 \\
\hline 2 & 0,8985 & 5 & 0,9622 & 2 & 0,9196 \\
\hline 237 & 0,8840 & 85 & 0,9622 & 165 & 0,8931 \\
\hline 165 & 0,8619 & 18 & 0,9618 & 1 & 0,8724 \\
\hline 1 & 0,8296 & 2 & 0,9617 & 4 & 0,8542 \\
\hline 4 & 0,8002 & 3 & 0,9605 & 18 & 0,8450 \\
\hline 18 & 0,7866 & 236 & 0,9600 & 237 & 0,8133 \\
\hline 238 & 0.7383 & 6 & 0,9598 & 238 & 0,8103 \\
\hline 393 & 0,7381 & 7 & 0,9598 & 6 & 0,8103 \\
\hline 6 & 0,7355 & 1 & 0,9580 & 393 & 0,8084 \\
\hline 85 & 0,7039 & 165 & 0,9555 & 85 & 0,7900 \\
\hline 30 & 0,5613 & 238 & 0,9543 & 5 & 0,6725 \\
\hline 161 & 0,5434 & 298 & 0,9514 & 3 & 0,6658 \\
\hline 43 & 0,5343 & 19 & 0,9512 & 161 & 0,6572 \\
\hline 5 & 0,5276 & 393 & 0,9491 & 7 & 0,6470 \\
\hline 3 & 0,5184 & 161 & 0,8847 & 19 & 0,6303 \\
\hline 7 & 0,4906 & 406 & 0,8842 & 9 & 0,6140 \\
\hline 9 & 0,4820 & 9 & 0,8780 & 406 & 0,5770 \\
\hline 19 & 0,4698 & 237 & 0,6717 & 298 & 0,5741 \\
\hline 406 & 0,4234 & 397 & 0,4167 & 30 & 0,5109 \\
\hline 298 & 0,3854 & 147 & 0,4136 & 43 & 0,4936 \\
\hline 8 & $-0,0089$ & 43 & 0,4121 & 8 & 0,1299 \\
\hline 29 & $-0,0112$ & 83 & 0,4115 & 29 & 0,1277 \\
\hline 147 & $-0,0197$ & 30 & 0,4101 & 397 & 0,1255 \\
\hline 397 & $-0,0202$ & 395 & 0,4097 & 147 & 0,1248 \\
\hline 39 & $-0,0459$ & 39 & 0,4096 & 39 & 0,1059 \\
\hline 83 & $-0,0507$ & 8 & 0,4077 & 83 & 0,1034 \\
\hline 395 & $-0,0605$ & 36 & 0,4063 & 395 & 0,0962 \\
\hline 160 & $-0,4378$ & 11 & 0,4059 & 160 & $-0,1567$ \\
\hline 162 & $-0,4740$ & 31 & 0,4058 & 162 & $-0,1836$ \\
\hline 35 & $-0,5002$ & 29 & 0,4056 & 11 & $-0,1986$ \\
\hline 11 & $-0,5009$ & 160 & 0,4054 & 36 & $-0,2024$ \\
\hline 36 & $-0,5067$ & 144 & 0,3997 & 35 & $-0,2033$ \\
\hline 144 & $-0,5350$ & 162 & 0,3972 & 144 & $-0,2235$ \\
\hline 31 & $-0,5579$ & 35 & 0,3904 & 31 & $-0,2366$ \\
\hline 33 & $-0,5790$ & 33 & 0,2998 & 33 & $-0,2861$ \\
\hline 46 & $-0,7189$ & 34 & $-0,1252$ & 46 & $-0,5850$ \\
\hline 37 & $-0,7370$ & 46 & $-0,3174$ & 38 & $-0,6970$ \\
\hline 45 & $-0,7683$ & 38 & $-0,3602$ & 34 & $-0,7024$ \\
\hline 44 & $-0,7770$ & 10 & $-0,3837$ & 10 & $-0,7196$ \\
\hline 38 & $-0,8654$ & 415 & $-0,4855$ & 37 & $-0,7307$ \\
\hline 84 & $-0,8725$ & 32 & $-0,5072$ & 45 & $-0,7712$ \\
\hline 10 & $-0,8875$ & 148 & $-0,7054$ & 415 & $-0,7751$ \\
\hline 148 & $-0,8999$ & 84 & $-0,7156$ & 44 & $-0,7777$ \\
\hline 415 & $-0,9198$ & 37 & $-0,7180$ & 32 & $-0,8007$ \\
\hline 32 & $-0,9474$ & 45 & $-0,7769$ & 84 & $-0,8202$ \\
\hline 34 & $-0,9911$ & 44 & -0.7791 & 148 & $-0,8351$ \\
\hline
\end{tabular}




\subsection{O território a partir das desigualdades nas condições de vida}

Tomando-se por base o "ranking" citado, foi utilizada a técnica de análise de agrupamentos CLUSTER do pacote estatistico MINITAB para a identificação de quatro grupos homogêneos dos setores censitários, tendo em vista a perspectiva de reconhecimento das diferentes necessidades e a proposição de intervenções junto a estes grupos. Na coluna da direita do Quadro 5 pode-se identificar a composição de quatro grupos homogêneos em termos do potencial de exposição às condições de risco para as IRA, sendo que o grupo I reúne as melhores condições da área estudada; o grupo II reflete uma situação intermediária boa, na medida em que agrupa somente setores que obtiveram valores positivos e acima do valor médio de 0,5 ; o grupo homogêneo III apresenta uma situação regular e ruim na medida em que congrega setores com valores positivos baixos e negativos; e o grupo IV que reúne as piores condições de base para a população residente.

Com base na territorialização em saúde foram localizados os diversos grupos homogêneos, utilizando-se o programa Map Info. O mapa 4 apresenta a área de abrangência do Centro de Saúde destacando-se os grupos homogêneos em termos do potencial de exposição às condições de risco para as IRA. 


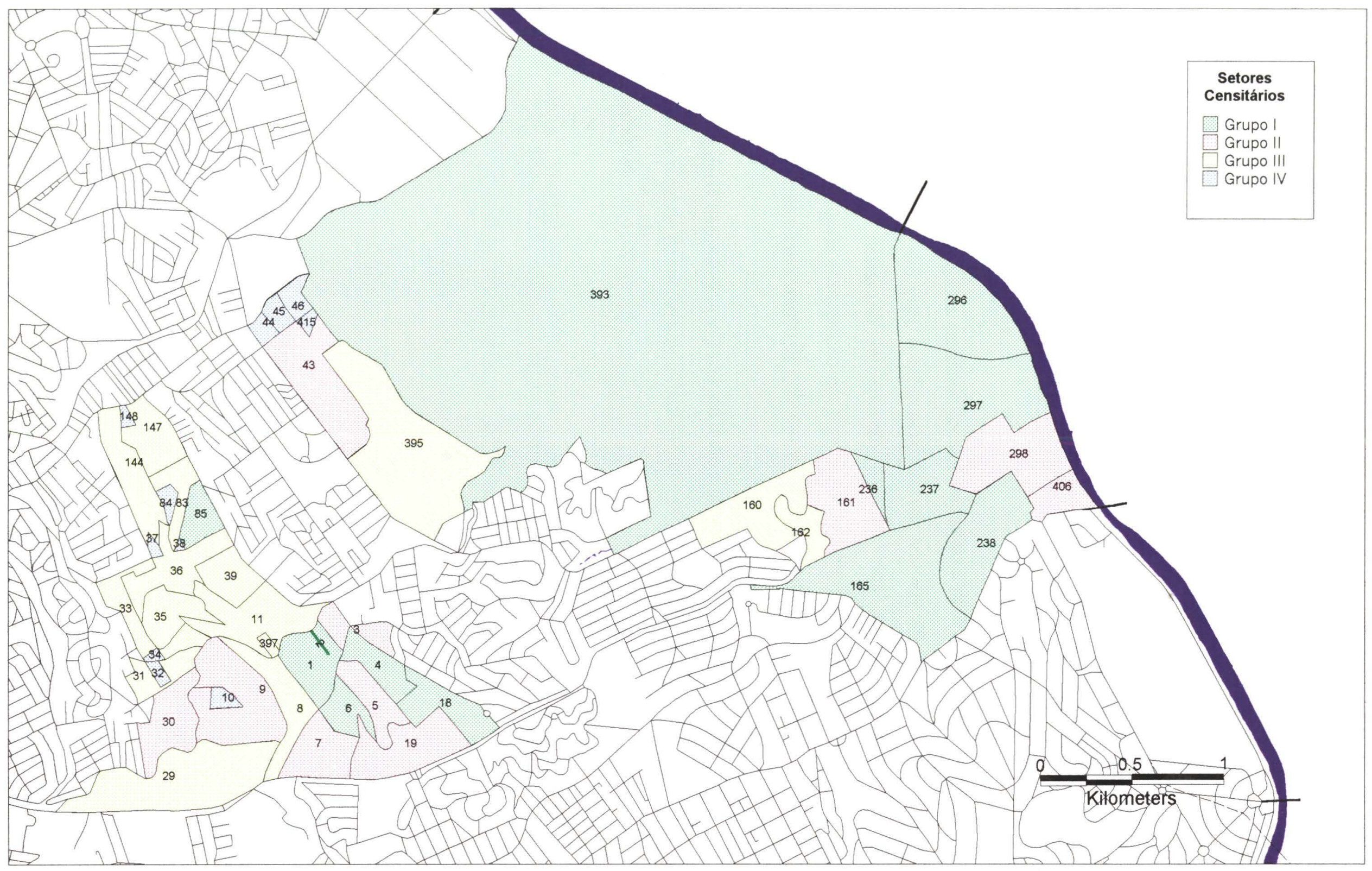

Mapa 4 - Distribuição dos Grupos Homogêneos na área de abrangência do Centro de Saúde Escola " Samuel B. Pessoa", Butantã, 1999. 
O mapa caracteriza as desigualdades sociais identificadas na microárea de estudo que se configura enquanto um espaço para atuação local na área da saúde. Configura-se também como um espaço de ação intersetorial considerando-se o leque de necessidades da população a ser contemplado pelos equipamentos públicos que atuam na mesma área. Neste sentido, acredita-se que este reconhecimento a partir das condições de vida pode contribuir para uma aproximação intersetorial proficua com vistas ao fortalecimento de uma nova postura ao assumir a tarefa de formulação e gestão nas políticas públicas.

Esse reconhecimento da realidade local é importante para a reorientação das ações propostas, tendo em vista o referencial teórico adotado no presente estudo Um aspecto a ser destacado inicialmente a partir dos grupos homogêneos identificados é a própria composição em termos de concentração dos domicilios, da população total e da concentração de crianças menores de cinco anos.

Os grupos encontrados a partir do Índice apresentam a seguinte composição em termos de total de domicilios, população total e população de crianças menores de 5 anos de idade. 
Gráfico 3 - Distribuição dos domicílios nos grupos homogêneos

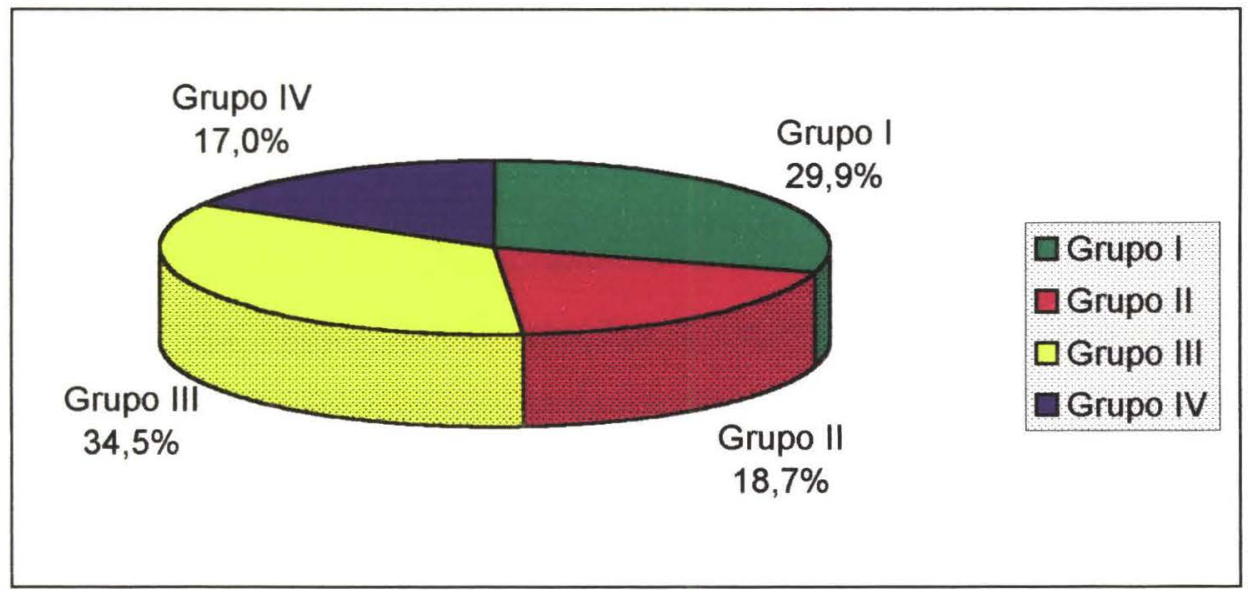

Gráfico 4 - Distribuição da população total nos grupos homogêneos

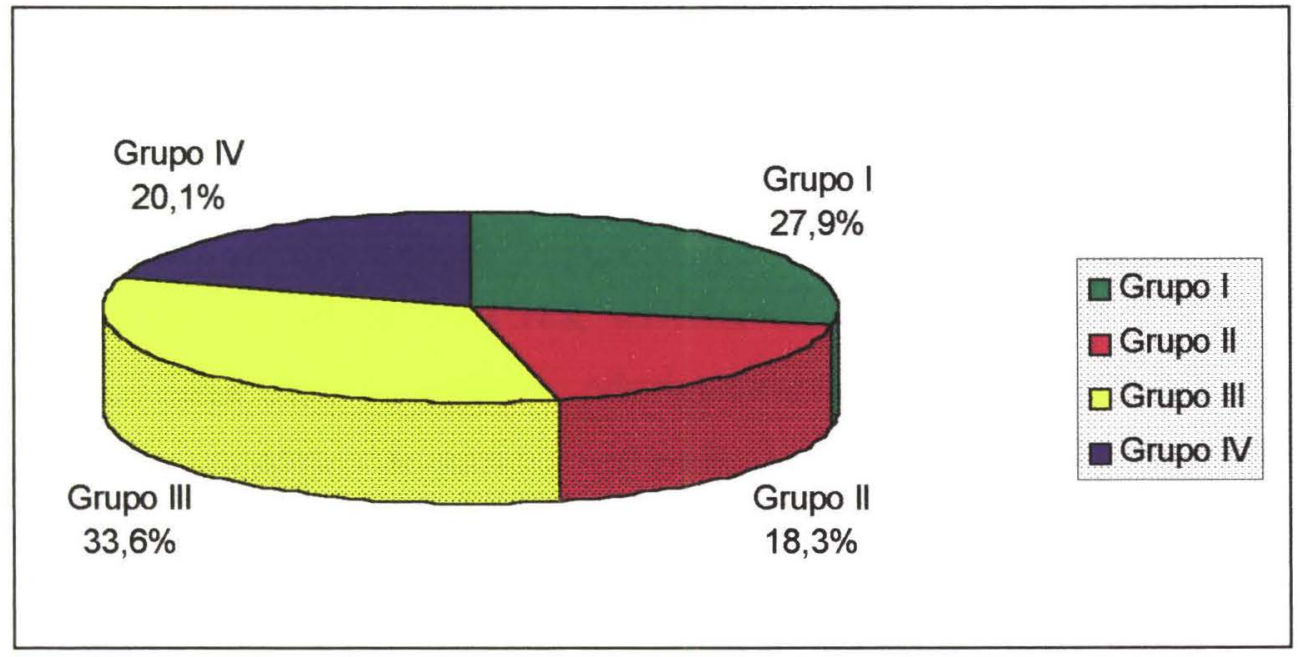

Gráfico 5 - Distribuição da população de menores de 5 anos nos grupos homogêneos

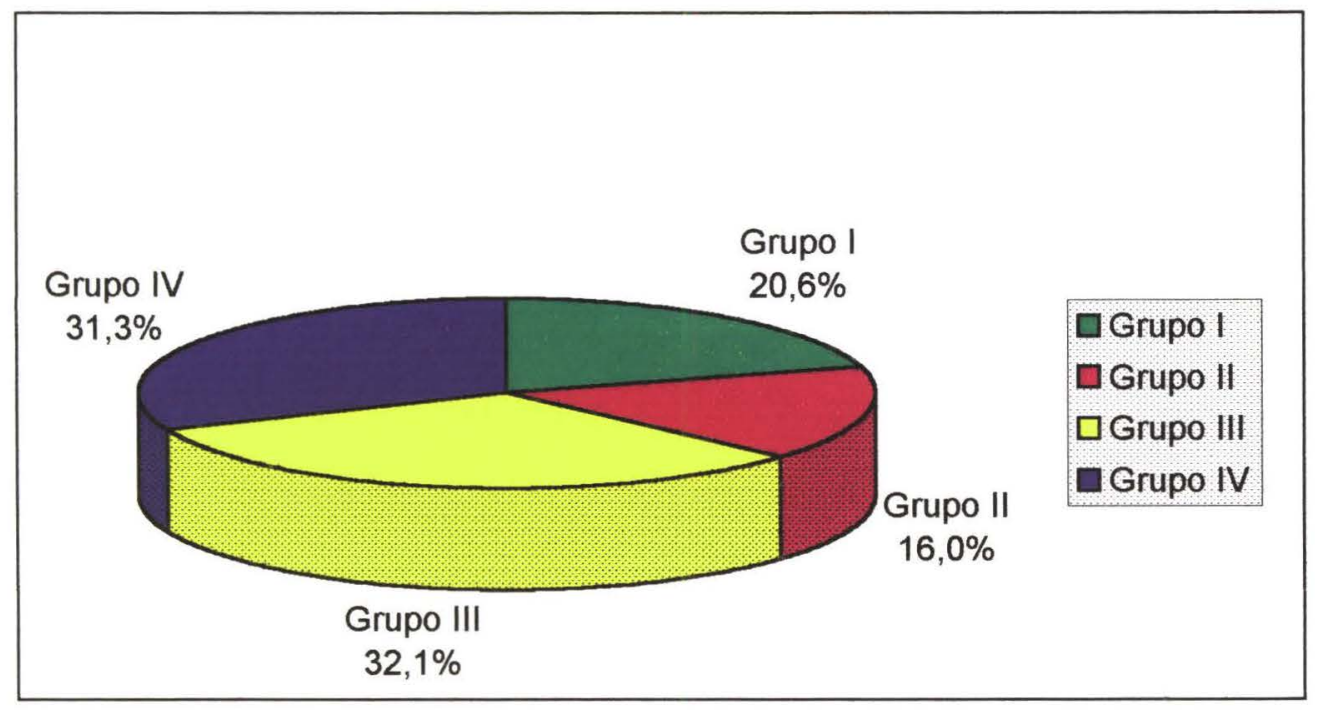


Vale destacar a importância que assumem os grupos homogêneos III e IV com relação à concentração de crianças menores de 5 anos

A partir desses dados foi possivel conhecer a ocorrência dos óbitos de menores de 5 anos desde 1991 até 1997, na região em questão. Para tal, foi solicitado ao PROAIM (Programa de Aprimoramento de Informações sobre Mortalidade no Município de São Paulo) as informações a respeito dessas mortes. A primeira dificuldade encontrada foi relativa aos dados do periodo de 1991 a 1993 porque não constava o sub-distrito em que residia a criança falecida. Além disso, somente a partir de abril de 1991 passaram a ser inseridos os endereços dos logradouros, tendo sido descartados os óbitos ocorridos em janeiro a março de 1991 devido à falta destes dados. Com isso, muitos dos endereços não puderam ser localizados. Este problema diminui a partir da listagem de 1994, que passou a incorporar este dado, fundamental para a localização geográfica dos eventos. Mesmo assim, vários endereços relativos às familias que ocupam o território de forma irregular, não puderam ser localizados. Foram excluidos do banco de dados 121 crianças por endereços incompletos, ou seja, aqueles que não mencionavam a rua, número, complemento e sub-distrito. Vale lembrar, que nesta etapa foi utilizado principalmente o programa Map-Info. Apesar deste recurso tecnológico de extrema importância para a visualização da ocorrência das mortes a área previamente classificada, foi necessário "redesenhar" algumas áreas do mapa, sobretudo aquelas onde concentravam-se as familias de pior Indice de Potencial de Exposição, dadas as caracteristicas de ocupação do território de forma irregular

O mapa 5 apresenta a distribuição dos 148 óbitos por todas as causas, em menores de 5 anos, ocorridos no periodo de 1993 a 1997 nas familias residentes na área estudada 


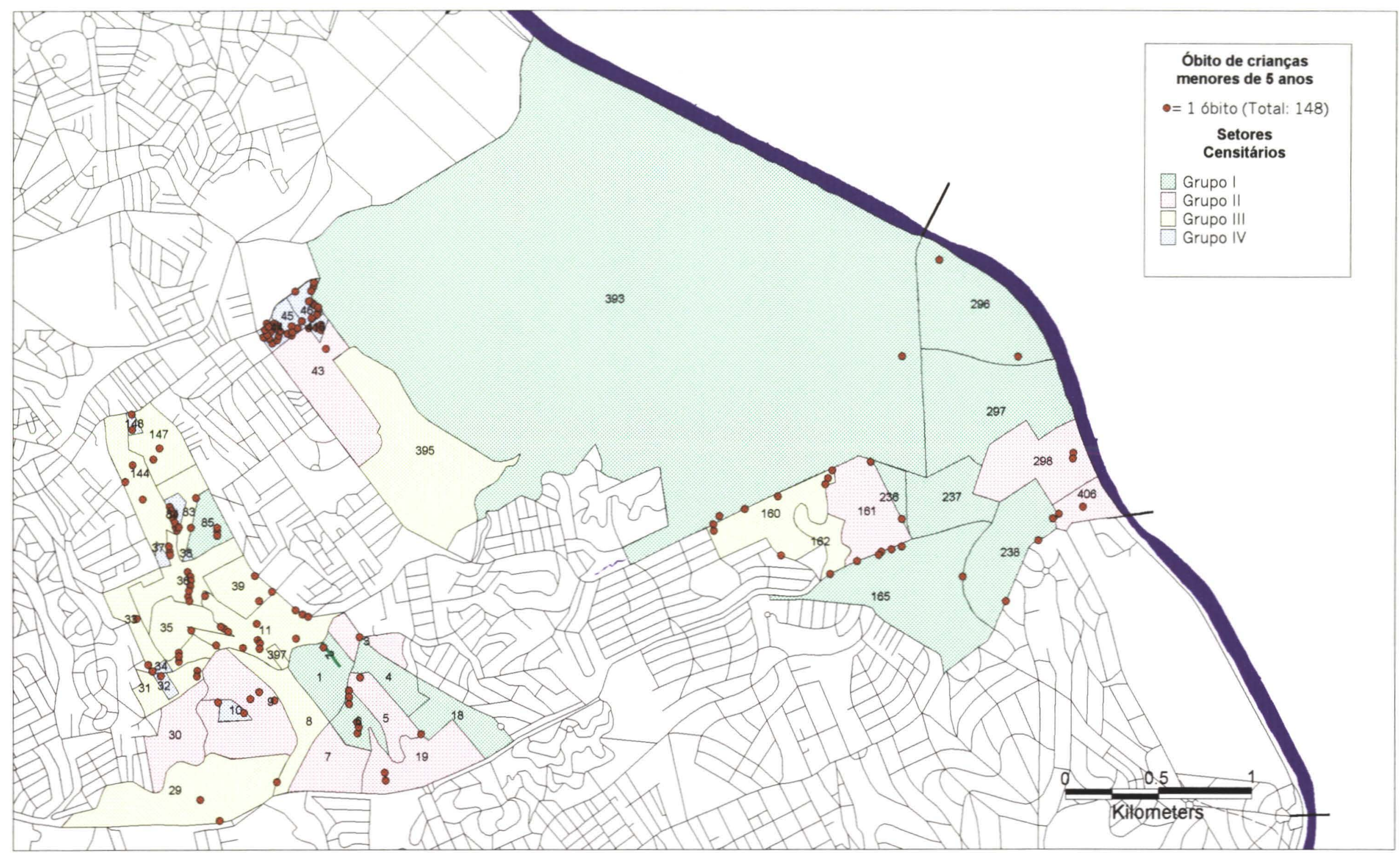

Mapa 5 - Distribuição dos óbitos de crianças menores de cinco anos na área de abrangência do Centro de Saúde Escola " Samuel B. Pessoa", Butantã, 1991-1997. 


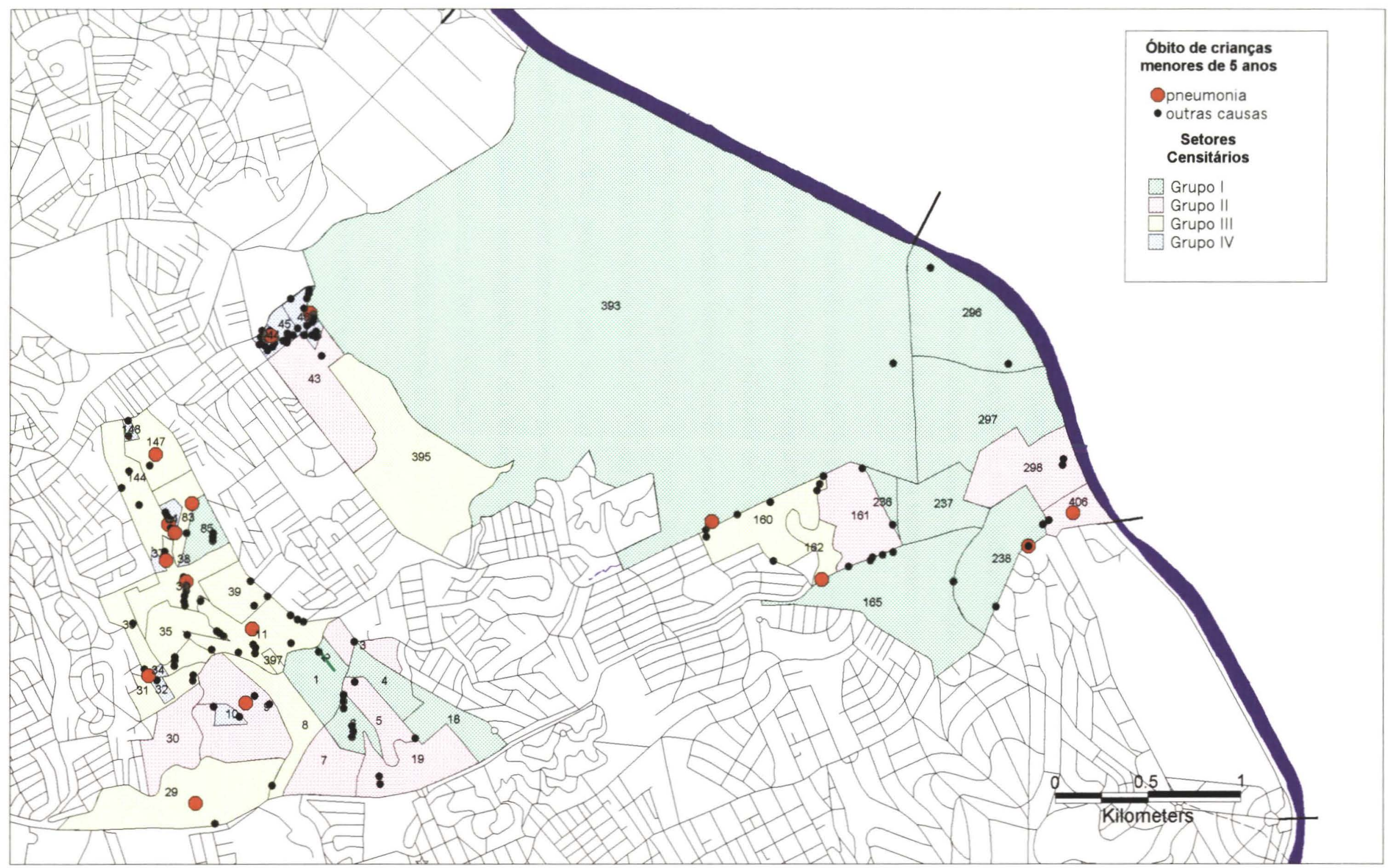

Mapa 6 - Distribuição de óbitos por pneumonia de crianças menores de cinco anos na área de abrangência do Centro de Saúde Escola " Samuel B. Pessoa", Butantã, 1991-1997. 
A relação entre pobreza e morte tem sido evidenciada em muitos trabalhos. principalmente quando se trata das mortes de crianças menores de cinco anos de idade Segundo ROCHA (1985), desde os primordios da formulaçào da Puericultura. em 1750 na França, proposta por Ballexserd. e posteriormente recuperado pelo médico francès Caron. em 1865. que a considerava a arte de criar fisiologica e higienicamente dos recem-nascidos, pode-se perceber a preocupaçâo em definir padrões de comportamento para o cuidado da criança. dada a sua condição de maior vulnerabilidade (ROCHA. 1985). Na Puericultura e na Saúde Pública, enquanto campo de conhecimentos especificos que buscam aprimorar os mecanismos de controle das doenças e reverter as situaçòes de altos indices de mortalidade infantil. essa questào tem assumido. historicamente. papel de destaque em termos das preocupaçòes dos profissionais de saúde e de toda a sociedade.

As discrepàncias dos de indices de mortalidade infantil em diversos paises. evidenciam que se trata de um fenòmeno relacionado à forma de organização social. constituindo, por isso, um excelente indicador de desenvolvimento social. A partir do momento em que a sociedade humana detém conhecimentos suficientes para intervir sobre os agravos capazes de provocar a morte nessa faixa etária de grande vulnerabilidade, os profissionais de saude passam a enfrentar um problema de ordem tecnica e de ordem politica, uma vez que o mesmo tem relação direta com a distribuição e acesso aos bens produzidos pelos diferentes segmentos da sociedac $\mathrm{Na}$ realidade brasileira este aspecto da distribuição mais eqüitativa configura-se c um dos grandes problemas a ser enfrentado, já que o Brasil vem apresentando uma situação de grande desigualdade interna ao longo dos últimos 30 anos.

Segundo COHN (1997), enquanto na década de 60 a parcela representada pelos $10 \%$ mais ricos da população apresentava uma concentração de renda 34 vezes mais do que os $10 \%$ mais pobres; esta relação em 1990, sobe para 78 vezes mais. Neste periodo de três décadas foi acentuado o processo que aumenta a discrepância social na realidade brasileira, repercutindo sobre a qualidade de vida. Ao mesmo tempo. observa-se a melhoria da expectativa de vida, indicando que a análise dos 
indicadores de forma isolada pode ocultar aspectos relevantes em termos das diferenças injustas

Segundo KUNST e MACKENBACH (1995) correlacionar os dados de mortalidade aos dados sócio-econômicos coletados nos censos é uma medida efetiva para mensurar desigualdades sociais e mortalidade que tem sido utilizada em vários paises

No presente estudo, o item da mortalidade foi utilizado como exercicio de operacionalização do mapeamento, não assumindo um caráter de estudo especifico sobre o problema, sobretudo para não se distanciar dos objetivos delineados inicialmente

Nesse sentido, o primeiro problema encontrado foi a dificuldade de utilizar somente o software Map-Info para proceder ao geoprocessamento dos dados obtidos. Tornou-se necessário complementar as informações registradas a partir do conhecimento das delimitações do território, incorporando novos elementos ao mapa Este trabalho está sendo feito pela equipe de técnicos do Setor de Vigilância Epidemiológica do Centro de Saúde Escola. Vale destacar que, só foi possível concretizar o mapeamento de cerca de $30 \%$ dos casos de mortes ocorridas pelas informações fornecidas pelos mesmos, principalmente em relação à área dos setores $43,44,45,46$ e 415 .

Outro aspecto que merece ser destacado é a dificuldade em se trabalhar com um evento raro numa pequena área de extensão territorial. Ainda assim, verificou-se que no decorrer no periodo compreendido entre os anos de 1991 a 1997, o maior número de mortes de menores de cinco anos ocorreu nos setores componentes do grupo homogêneo III, com 55 mortes (37,2\%); seguido do grupo IV, com 47 mortes (31,8\%); do grupo I, com 29 mortes (19,6\%)e finalmente do grupo II, com 17 mortes (11,5\%). Portanto, do total de 148 mortes, $69,0 \%$ ocorreram em familias dos grupos III e IV, no "ranking" de Potencial de Exposição às Condições de Risco para as IRA. 
Isso mostra a necessidade de intervenções especificas no âmbito da Promoção em Saúde, voltadas para esses seg̣mentos da população. De acordo com os dados apresentados no Gráfico 5 referentes à distribuição da população de menores de cinco anos nos diferentes grupos homogêneos, pode-se verificar que a ocorrência de óbitos pouco diferiu em função do numero de crianças incluídas nos grupos homogêneos Nos grupos I e II. o percentual de obitos ficou aquem da concentração de crianças e nos grupos III e IV, os obitos registrados superaram um pouco a concentração de crianças nos setores envolvidos

Tomando-se por base somente os dados relativos às mortes por pneumonia e excluindo-se a faixa etária que compreende o periodo neonatal. foram encontradas 16 obitos por pneumonia. num total de 69 mortes. representando $20.3 \%$. Tais mortes ocorreram quase que exclusivamente nos grupos III e IV e. dado que são mortes evitaveis, já que são amplas as possibilidades de detecção e tratamento precoce das mesmas. Esse fato por si so revela uma face das iniquidades com as quais se pretende trabalhar 
Qs percepções dos grupos sobre a vivência e a controle das doenças respiratórias na Infância 


\section{As percepções dos grupos sobre a vivência e o controle das doenças respiratórias na infância}

O objetivo central desta fase do trabalho consistia no conhecimento de diferentes dificuldades vivenciadas pelas famílias na vigência de episódios respiratórios, das causas atribuídas a tais problemas de saúde pela população e das sugestões de encaminhamentos vislumbradas pelos mesmos para a diminuição destes agravos. Vale destacar a importância de identificar necessidades específicas das familias em função da sua condição social, dada pela caracterização utilizada para conformar os diferentes grupos homogêneos. As questões centrais, portanto, diziam respeito à ocorrência dos agravos, aos encaminhamentos dados pela família frente aos problemas, às dificuldades percebidas $\mathrm{e}$ às sugestões de superação da problemática . Não se tratou, portanto, de um estudo centrado na morbidade e, em função disso, não foram utilizados procedimentos de confirmação de diagnóstico. Considerou-se a morbidade referida a partir do relato dos responsáveis visando identificar a morbidade percebida e expressa pela população a partir de entrevistas domiciliares, a exemplo da prática realizada nos inquéritos domiciliares de saúde (CESAR, et al. 1996). O período estabelecido para buscar a ocorrência de agravos ou problemas de IRA, foi de quinze dias anteriores à entrevista, para facilitar a lembrança dos participantes. Cabe ressaltar que alguns entrevistados mencionaram espontaneamente upisódios relativos a períodos anteriores à quinzena estabelecida, apresentados aqui como morbidade pregressa.

A seguir serão apresentados dados relativos à caracterização das famílias entrevistadas e, posteriormente, os temas relevantes a cada um dos aspectos estudados, segundo os grupos aos quais pertencem.

\subsection{Caracterização das famílias entrevistadas}

\section{Famílias do grupo homogêneo I}

Nos 13 setores que compunham este grupo homogêneo $(296,297,236,2$, $165,1,4,18,237,238,6,393,85)$ houve maior dificuldade em encontrar familias com crianças menores de 5 anos de idade, sobretudo nos setores mais próximos xo 
Centro de Saúde, porque havia um grande número de residências alugadas para fins comerciais. Mesmo assim, foram realizadas entrevistas junto a familias de 17 crianças.

Entre as 14 familias que compuseram a amostra do GH I, 9 eram extensas e 5 eram nucleares. Houve predominância de famílias chefiadas por homens, $12 \mathrm{e}$ somente 2 famílias chefiadas por mulheres. Os respondentes foram 9 mães, 2 pais e 3 outros familiares. Com relação à idade das crianças, houve uma distribuição entre todas as faixas etárias, destacando-se os pré-escolares, conforme a tabela 9.

\section{Familias do grupo homogêneo II}

Dos 10 setores que compunham o grupo homogêneo II $(5,3,161,7,19,9$, $406,298,30,43$ ) foram entrevistadas 8 familias, contando 13 crianças. Com relação à composição familiar, curiosamente, metade era do tipo nuclear e metade do tipo extensa. Predominaram as familias chefiadas por homens. Nesse grupo, os respondentes foram 6 mães; 1 pai e 1 casal. Conforme pode ser verificado na tabela 9 , houve uma distribuição eqüitativa entre os menores de 1 ano, os de $2 \vdash 3$ anos e $4 \vdash 5$ anos. Não houve crianças entre 1 e 2 anos e entre 3 e 4 anos.

\section{Famílias do grupo homogêneo III}

Dos 15 setores que compunham o referido grupo homogêneo $(8,11,29,31,33,35,36,39,83,144,147,160,162,395,397)$, foram selecionadas 19 familias, sendo que nos setores destacados em negrito, foram realizadas 2 entrevistas. As familias deste grupo homogêneo eram predominantemente nucleares e chefiadas por homens. Os respondentes foram representados por 16 mães e 3 outros familiares. Dentre as 19 familias, houve 26 crianças com a faixa etária apresentada na tabela 9 .

\section{Famílias do Grupo Homogêneo IV}

O referido grupo homogêneo engloba 11 setores censitários $(10,32,34,37,38,44,45,46,84,148$ e 415$)$ nos quais foram realizadas 23 entrevistas com duas familias por setor censitário. Houve predominância da composição nuclear e da chefia por homens. $\dot{E}$ interessante ressaltar que este grupo homogêneo que reúne 
as familias com as piores condições de vida, foi o que apresentou o maior número relativo (6) de famílias chefiadas por mulheres, ou seja $26,09 \%$. Tomando-se por base estes dois aspectos, pode-se observar que esse grupo concentra características que podem constituir maior dificuldade no cuidado $\mathrm{e}$ atenção às crianças. A concentração das familias chefiadas por mulheres neste grupo é superior aos índices encontrados nos trabalhos de identificação da exclusão social no Município de São Paulo, coordenados por SPOSATI (1996), no qual o Distrito do Butantã apresentava $21,14 \%$ das famílias nesta condição e o Distrito do Rio Pequeno, 18,95\%. Nesse grupo, os respondentes foram 17 mães, 1 pai e 4 outros familiares. Dentre as 23 familias entrevistadas, havia um total de 34 crianças, com idades predominantemente entre 3 e 5 anos incompletos, conforme pode ser observado na tabela 9.

TABELA 9 - Distribuição das crianças dos diferentes grupos homogêneos por idade, Butantã, SP, 1998.

\begin{tabular}{ccccccc}
\hline $\begin{array}{c}\text { GRUPO } \\
\text { HOMOGÊNEO }\end{array}$ & $\begin{array}{c}\text { FAIXA } \\
\text { ETÁRIA } \\
0<1\end{array}$ & $\begin{array}{c}\text { FAIXA } \\
\text { ETÁRIA } \\
1<2\end{array}$ & $\begin{array}{c}\text { FAIXA } \\
\text { ETÁRIA } \\
2<3\end{array}$ & $\begin{array}{c}\text { FAIXA } \\
\text { ETÁRIA } \\
3<4\end{array}$ & $\begin{array}{c}\text { FAIXA } \\
\text { ETÁRIA } \\
4<5\end{array}$ & TOTAL \\
\hline I & 2 & 3 & 3 & 4 & 5 & 17 \\
II & 4 & 0 & 4 & 0 & 5 & 13 \\
III & 6 & 5 & 3 & 5 & 6 & 26 \\
IV & 4 & 5 & 4 & 11 & 10 & 34 \\
\hline TOTAL & & & & & & 90 \\
\hline
\end{tabular}

\subsection{Os problemas de saúde mencionados}

Com relação à morbidade referida pelas famílias entrevistadas, um grande número de agravos foi mencionado por todos os grupos homogêneos. Os dados da tabela abaixo comparam a ocorrência de Infecções de Vias aéreas Superiores (IVAS) e de Infecções Respiratórias Agudas Baixas (IRAB), a partir da morbidade atual em todos os grupos homogêneos. 
TABELA 10 - Agravos relacionados às Infeç̧ões das Vias Aéreas Superiores e Infecções Respiratórias Agudas de Via Baixa como morbidade atual em menores de cinco anos na região do Butantã. São Paulo, 1998

\begin{tabular}{cccc}
\hline \multicolumn{4}{c}{ MORBIDADE ATUAL } \\
\hline GRUPO & NUMMERO TOTAL & EPISÓDIOS DE & EPISÓDIOS DE \\
HOMOGENNEO & DE CRIANÇAS & IVAS & IRAB \\
\hline I & 17 & 18 & 4 \\
II & 13 & 7 & 4 \\
III & 26 & 21 & 6 \\
IV & 34 & 23 & 12 \\
\hline
\end{tabular}

TABELA 11 - Agravos relacionados às Infecções de Vias Aéreas Superiores e Infecções Respiratórias Agudas de Via Baixa como morbidade pregressa referida em menores de 5 anos na região do Butantã. São Paulo. 1998

\begin{tabular}{cccc}
\hline \multicolumn{4}{c}{ MORBIDADE PREGRESSA } \\
\hline GRUPO & NUMERO TOTAL & EPISODIOS DE & EPISÓDIOS DE \\
HOMOGËNEO & DE CRIANÇAS & IVAS & IRAB \\
\hline I & 17 & 2 & 2 \\
II & 13 & 2 & 3 \\
III & 26 & 5 & 5 \\
IV & 34 & 2 & 7 \\
\hline
\end{tabular}

No GH I, em termos de morbidade respiratória atual, os responsáveis mencionaram a ocorrência de pelo menos um problema em 14 das 17 crianças, nos últimos quinze dias que antecederam a realização da entrevista, destacando-se os seguintes: Resfriado (5), Otite (4), Chiado (4), Amigdalite (3), Rinite (2), Sinusite (1), Adenóide (1), Gripe (1) e Obstrução nasal (1)

\section{A experiência vivida ao lidar com os episódios}

Ao relatarem o quadro atual ou ao comentarem problemas e dificuldades que perceberam no desenvolvimento do processo patológico, alguns entrevistados mencionaram outros problemas respiratórios constitutivos de morbidade pregressa como: Otites de repetição (2), Chiado (1) e Bronquite (1).

Em 13 situações foi referida a procura por assistência médica, prevalecendo o serviço conveniado ao serviço público. As situações em que foi mencionado o cuidado domiciliar, ao invés, ou antes mesmo da procura por atenção médica, incluiram os seguintes procedimentos: inalação; aumento da oferta de chás, sucos, mel ou mel com própolis; realização de vaporização no chuveiro; exposição da 
criança ao sol; evitar gelados e, ainda, evitar dar banho para não expor à friagem. Alguns entrevistados referiram o uso de medicamentos, tais como antinflamatório com vitamina $\mathrm{C}$, broncodilatador, solução fisiológica para uso nasal ou o seguimento de alguma prescrição médica anterior. As falas abaixo apresentam algumas situações em que se basearam os adultos, para levar a criança ao médico:

Uso da homeopatia

"A gente só trata com homeopatia, a não ser em casos, como houve, foi esse da otite que teve que ser uma coisa mais enérgica que teve que ir pro antibiótico..."

Uso de inalação em casa com broncodilatador

"A gente tenta fazer inalação, tem inalador em casa com remédio, mas eu não sei falar o nome do remédio. Damos também Bricanil até ele melhorar ....Se não melhora levo no Pronto Socorro. No atendimento médico eles geralmente dão antibiótico e inalação."

Identificação da febre ou respiração dificil como sinais de gravidade para procurar o médico

"... se for uma tosse que eu sei que através do mel ele vai melhorar eu trato em casa. Se eu tô vendo que ele tá muito resfriado eu levo no médico. Geralmente eu passo no Pronto Socorro quando começa a ter febre."

"Levo ele no médico particular. Ele fica cansado."

"Levei no médico. Tomou antibiótico." "Resfriado não, a gente vai tírando com chazinho, antitérmico. Na amigdalite eu tive que levar no médico, tomou Bactrim." "Geralmente primeiros socorros em casa eu sempre faço inalação com soro, eu dou mel, essas coisas bem natural, e quando tem febre eu levo no médico."

"Eu cuido em casa até que ela rejeite o medicamento com vômitos. Porque os problemas respiratórios dela que é ou tosse ou resfriado forte que dá, que a gente percebe que ela tá ficando cansada, eu faço inalação eu dou os remédios que ela está acostumada a tomar até ela rejeitar."

No GH II com relação à morbidade atual, houve menção de alg : tos 
episódios perguntados, em 11 das 13 crianças. As doenças ou problemas relatados foram os seguintes: amigdalite (2), bronquite (2), resfriado (2), otite (1), gripe (1), bronquiolite (1), rinite (1) e chiado (1).

A respeito da morbidade pregressa alguns mencionaram espontaneamente a ocorrência de chiado (2), otite (1), pneumonia (1) e resfriado (1). A procura por atenção médica foi relatada em 8 situações, aparecendo prioritariamente o serviço público (5), seguido do serviço conveniado (3). Os sinais de gravidade descritos pelos entrevistados, como motivos de preocupação com o estado da criança foram a febre (4), a tosse (3), crise forte (2) e chiado (1).

“...quando elas tão assim com febre, aí eu tenho medo, aí eu já levo pro prontosocorro ou, quando não levo pro pronto-socorro, eu levo pro postinho do Butantã, que é onde elas têm cartão."

"Logo que eu senti que ele estava com chiado no peito, porque eu fiquei tão traumatizada, não demorei não."

"Aquele resfriado que vem com febre, muita tosse."

Os cuidados domiciliares incluíram inalação, oferta de chás e outros líquidos, xaropes, mel e seguimento de prescrição médica anterior. Foram ainda citados medicamentos que têm propaganda veiculada através da TV

“A gente costuma usar mel. Não chega a ser assim, do meu ponto de vista, não e muito efetivo, não sei. Acho que é um pouco mais psicológico e que ele deve acalmar um pouco a garganta..."

No GH III foram referidos principalmente os seguintes problemas: resfriado (11); amigdalite (3); gripe (2); nariz obstruido (2); bronquite (2); otite (2); chiado (2); tosse (1); pneumonia (1) e laringite (1). Para 6 crianças, não houve relato de qualquer deles nos quinze dias que antecederam a entrevista. Em termos de morbidade pregressa mencionada espontaneamente pelos entrevistados, destacam-se: pneumonia (2); bronquite (2); amigdalite (2); otite (2); chiado (1) e gripe (1). 
A procura por assistência médica foi relatada em 19 situações, predominando o serviço público (10) em relação ao serviço conveniado (9). A percepção de sinais de gravidade pelos familiares aparece ligada à ocorrência de febre, tosse ou crise asmática.

"Eu tenho um convênio no Hospital Iguatemi, então assim que eu senti febre nele eu já levei."

"Eu já levei porque deu febre alta. Ela é super levada então quando ela cai (muda o comportamento) pode levar porque é sério."

"Ele começou com o olhinho vermelho. Depois queixou-se de dor de ouvido, aí eu levei lá em Cananéia, que eu tava lá. Me explicaram que o ouvido é conseqüência do resfriado."

"Quando eles têm falta de ar eu passo Vick no peito e Rinosoro no nariz." "Os gêmeos não podem ter febre porque eles têm convulsão. ... Aí eu já, eu corto já a febre deles."

Os cuidados domiciliares incluíram diversas ações que promovem desde hidratação, melhor alimentação no periodo da doença para compensar a inapetência da criança, inalação e vaporização em casa, além de auto medicação, seja com o uso de medicações propagandeadas na TV e rádio ou de xaropes e antinflamatório.

Entre os tratamentos caseiros recomendados, foram mencionados xaropes caseiros, mel com limão, mel com própolis, mel com leite e chás.

“...quando é resfriado muito forte assim é...se teve febre é remédio pra passar febre. Antibiótico só em último caso."

"Mas geralmente eu cuido em casa porque chega lá é uma canseira, então a gente vai acostumando com o procedimento, já essas coisas rotineiras..."

Procuram tratamento médico também

"O que eu faço, eu levo no médico e se eles passam algum remédio eu dou, se não passar eu também não dou por conta." 
"Levei-o ao médico e passaram antibiótico, fez bastante inalação, tomou bastante remédio."

Com relação à morbidade atual, das 34 crianças do GH IV foram destacados os seguintes problemas: resfriado (9); gripe (6); chiado (4); otite (3); bronquite (3); tosse (3); pneumonia (2); sinusite (2); amigdalite (1); rinite (1) e nariz obstruído (1). Das 34 crianças, 11 não tiveram nenhum problema respiratório no periodo de quinze dias que antecedeu a entrevista. Enquanto morbidade pregressa, os respondentes mencionaram pneumonia (4); chiado (3); amigdalite (1); otite (1). A procura por atendimento médico (21) foi mencionada como a providência tomada na vigência do problema respiratório, destacando-se o serviço público (20) e somente um caso de procura por serviço conveniado.

Antes de levar a criança ao médico ou nos casos em que a família não efetuou tal procura, foram destacados alguns cuidados domiciliares que incluíram, principalmente, a oferta de remédio caseiro, mel com limão, chás, inalação e mudança na alimentação.

"Ah, eu dou remédio pra tosse...eu tenho remédio pra resfriado, eu dou...Redoxon...assim, o que eu posso fazer em casa eu dou.... o que tá no meu alcance de fazer em casa eu faço. Agora quando eu vejo que não tá resolvendo, eu procuro o médico."

“...se eu tô dando o remédio pra ele, eu tô vendo que aquilo não tá cortando e o peito dele tá cheio e a cada dia que passa ele tá mais cheio ainda, aí eu procuro o médico."

"Eu levo no posto, dependendo do que o médico passa, quando não é uma gripe assim, agravada, os médicos sempre passam suco, que ajuda também...agora, quando é uma coisa assim, mais grave, o médico entra no antibiótico."

“....mas eu também em casa, gosto de pedir prá acompanhar porque quando a criança ela tá gripada ou com outros tipos de doença já perde toda a fome, né, perde o apetite, então eu gosto de basear o que? Eu começo a entrar na fruta, em coisas que ela aceita, elas....legumes que já não gosta eu faço de maneira, de outra, pra 
vê se, eu vejo o resultado porque é cortado mais rápido...pelas proteínas que dá tanto na verdura, no legume, como também nas frutas."

"Eu faço xarope com limão, quando tem mel eu faço com mel quando não tem eu faço com açúcar."

A procura por atenção médica se deu em serviços com acesso fácil, em termos de localização geográfica, para evitar a despesa com a locomoção. A falta de recursos para condução chega a ser impeditiva para o controle de saúde da criança, apesar da mãe reconhecer como importante para a manutenção da saúde.

"Eu levo ele mais ali no PAS...é mais fácil e um pouco mais perto pra mim que dá pra ir a pé..."

"Umas vezes a gente não tem dinheiro pra ir de ônibus, quando você vê : a criança tem que fazer um controle, não tem? É levar no médico de rotina pra ver como tá crescendo, se tá tudo bem, eu só levo meus filhos quando tá doente. Chego assim, não tá fácil, não levo pro médico de rotina."

Em alguns casos, apesar de terem convênio, houve relato de preferência por atendimento no serviço público.

"Eu levo no posto, no centro de saúde..., No HU só se for um, uma doença assim bem, eu não sei mesmo o que é. Aí eu levo, assim, num hospital. Agora, gripinha, febrinha, essas coisas, manchinha no corpo eu levo tudo no posto a pé."

“...olha, eu tenho plano de saúde mais ou menos...Vou no posto. Vou. Porque o posto lá eu acho bem melhor. Pra mim eu acho, é a consulta e tudo...eu não ligo muito de tá ali não, mas com os meus filhos... Eu, com qualquer coisinha já tô correndo com eles."

Para uma familia, a perspectiva de resolutividade do problema da criança seria contemplada a partir da assistência conveniada. Tratava-se de um problema de adenóide, com indicação cirúrgica, e a mãe aderiu a um plano de saúde exclusivamente para a criança, para o seguimento com especialista e posterior cirurgia. No entanto, no momento da entrevista, a mãe referiu que após a realização 
dos exames para esclarecer o diagnóstico, foi alegado que o problema consistia doença pré-existente e que, mesmo tendo transcorrido o periodo de carência para cirurgia, esta só seria realizada a cirurgia mediante pagamento complementar.

"Bom, eu procurei o médico, né. Ele eu tô...fazendo um tratamento com ele lá no Otorrino. É um convênio que eu pago pra ele...o caso dele precisa ser tratado freqüentemente, entendeu, com um médico acompanhando, porque eu já fiz vários tratamentos para ele só que nunca deu em nada..."

\section{Diferenças e semelhanças de episódios referidos entre os grupos homogêneos}

Apesar da alta incidência de agravos observada em todos os grupos, (GH I: 1,57; GH II: 1,0; GH III: 1,35; GH IV: 1,52) vale destacar que a ocorrência de problemas relativos ao trato inferior (IRAB) foi mais significativo no $\mathrm{GH}$ IV, tanto em termos da morbidade atual (12 ou $35,3 \%$ ) como em termos da morbidade pregressa ( 7 ou $20,6 \%$ ).

Com relação às pneumonias, estas foram mencionadas principalmente no $\mathrm{GH}$ IV, sendo quatro relativas à morbidade pregressa e duas relativas à atual; seguindo-se o GH III com duas situações relativas à morbidade pregressa e uma atual; no GH II, foi mencionado somente um caso relativo à morbidade pregressa, sendo que no GH I não houve nenhum relato de pneumonia.

Como foi mencionado anteriormente, apesar de não se tratar de um estudo sobre morbidade, os dados obtidos reiteram os dados de outros estudos específicos, que retratam maior número de ocorrências graves em crianças que vivem em condições desfavoráveis. Tendo em vista a finalidade do presente estudo, inicialmente apontada, acredita-se que os referidos achados possam contribuir para a construção de um panorama de iniqüidades em nivel local.

\subsection{As dificuldades no adoecimento da criança}

Em relação às dificuldades relatadas a partir da vivência dos problemas respiratórios, sejam eles recentes ou não, pode-se identificar que os aspectos relativos 
ao cuidado direto com a criança aparecem em todos os grupos, porém com maiores dificuldades e encaminhamentos diferentes dos problemas. Os dados a seguir foram obtidos a partir da análise temática, realizada sobre as fitas das entrevistas, após transcrição. Os temas mais significativos presentes nos discursos dos participantes foram organizados em categorias, a partir das entrevistas semi-estruturadas e serão comentados a seguir.

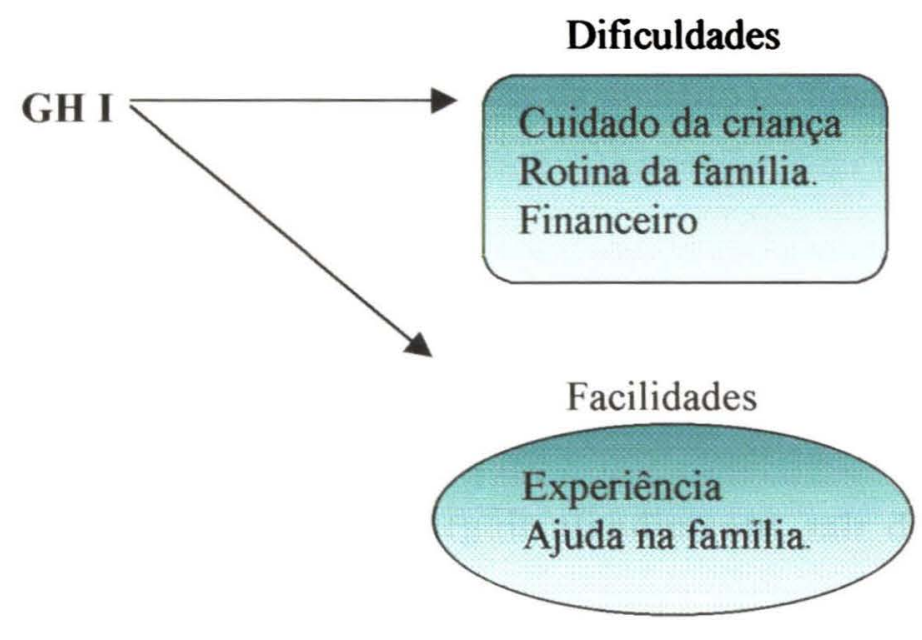

Para as familias do GH I, o aspecto mais relevante foi o cuidado direto da criança, destacando-se a dificuldade para administrar a medicação, sobretudo em casos de antibiótico, pela necessidade de observar rigidamente os horários.

Dificuldades para a criança tomar o remédio foram assim verbalizados pelos pais: "É difícil dar o remédio para ele. Ele não suporta tomar remédio."

"Dar o remédio, ele é difícil de tomar."

"O mais dificil é ela tomar o remédio. ... Tem que segurar, ela acaba vomitando." "Essa é a maior das dificuldades, porque dependendo do medicamento a gente tem que acordar durante a noite, como por exemplo antibiótico"

Mudanças na rotina da família devido ao estado geral alterado da criança que torna-se mais exigente, foi outro problema mencionado:

\footnotetext{
"a gente tem que acordar, tem que acordar a criança....muda a rotina."

"E depois você tem que tomar mais cuidado com a criança porque ela fica
} 
manhosa, não dorme de madrugada."

"Difícil é que a gente não dorme à noite, fica todo mundo cansado. A gente se estressa, se aborrece com a criança. Interfere na vida direto. Quando eu estou trabalhando, eu fico preocupada se ele está com febre. Quando dá eu venho."

Houve, também, relatos que apontavam como dificuldade, a necessidade de deslocamento para o hospital de forma repentina, exigindo um meio de transporte mais caro quando a urgência se dá na madrugada. Tal dificuldade torna-se, ainda maior, quando há problema financeiro como falta de dinheiro no final do mês.

Problema financeiro

"..quando cai final de mês para comprar o remédio é difícil "

Acesso ao serviço e locomoção

"O que é mais dificil para a gente é conseguir atendimento, sair de madrugada pra chegar no Hospital."

"Mais difícil é correr, levar ela no médico."

Por outro lado, algumas familias relataram que não tiveram dificuldades no cuidado com a criança durante a doença, pelo fato de já terem experiência anterior ou por serem famílias numerosas com mais adultos para ajudar no cuidado. Dentre esse foi possivel identificar como facilitadores: a experiência anterior da mãe em identificar sinais de gravidade na criança e facilidade em dar seguimento às orientações médicas por contar com a ajuda dos familiares ou de pessoa contratada para dividir trabalho de cuidar da criança.

Mãe não trabalha fora

"Não trabalho fora então não há problema para cuidar dela."

Família numerosa

"Ainda bem que aqui tem bastante gente pra cuidar dele."

"Não tive muitas dificuldades, eu não sou sozinha, pois tenho com quem dividir, 
você não sente muito os problemas, os cuidados com a criança."

Aprendem a lidar com o problema - aumentam o controle sobre o processo

"Nenhuma. Eu tô acostumada que o meu filho tem, ele teve otite a vida inteira..."

“Agora a gente já está acostumado, mas a primeira vez foi muito dificil. Agora logo a gente faz inalação, vê se tem febre...A aflição era da criança pequena quando não consegue respirar, fica sem fôlego. É pior quando tem febre e não consegue comer.... Depois de dois dias de antibiótico já melhora bem."

“...eu já percebi que quando tô fora de São Paulo ele dorme melhor." 


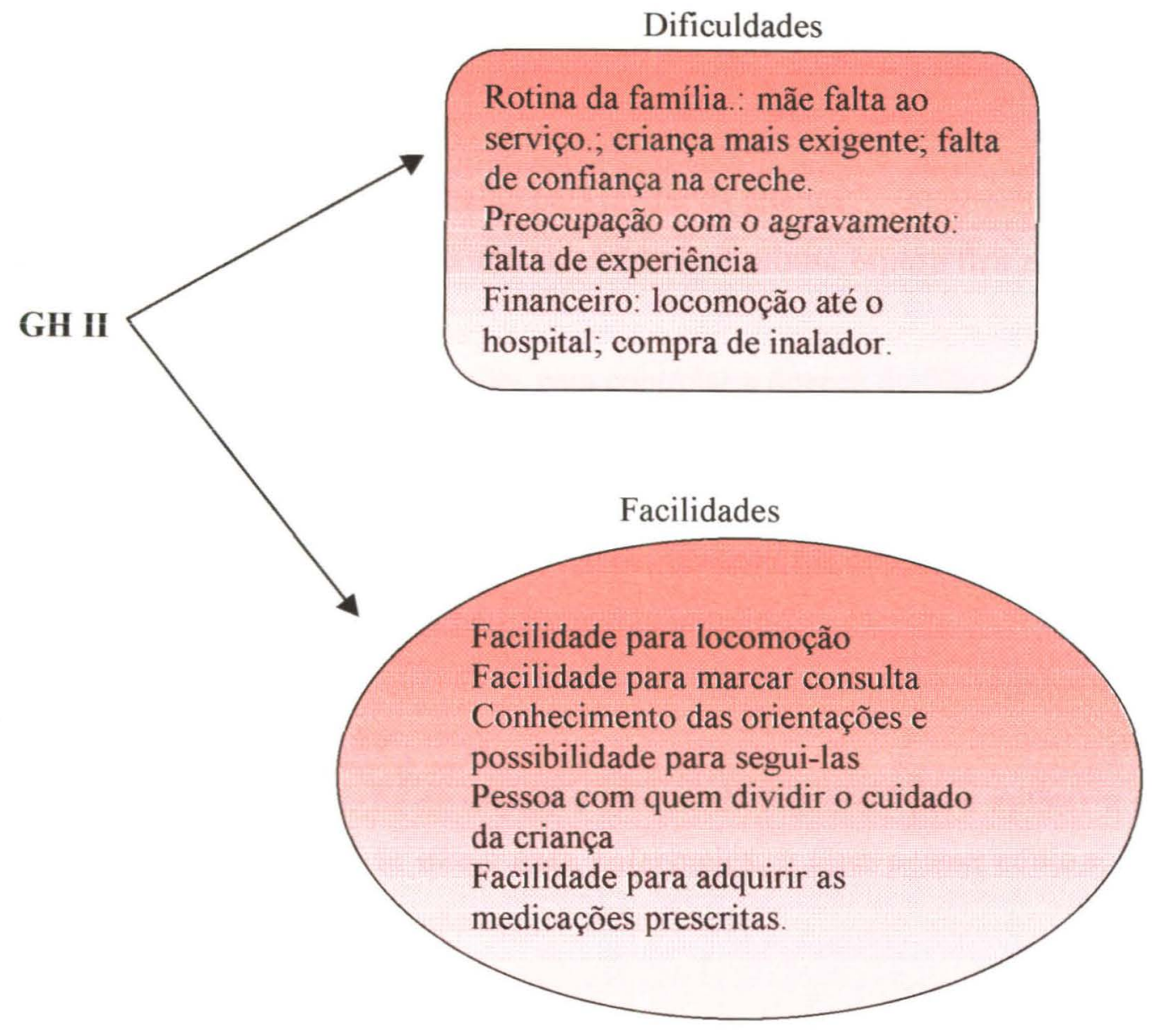

Com relação às dificuldades encontradas pelos responsáveis, no cuidado das crianças doentes, destacam-se, neste grupo, a interferência na rotina da família ou da criança, com a alteração do sono e do apetite por diversos dias exigindo mais cuidado e atenção por parte dos adultos. Outros problemas mencionados relacionam-se à necessidade da mãe faltar ao trabalho para cuidar melhor da criança, à inexperiência dos familiares para avaliar a gravidade do quadro e a falta de confiança no cuidado prestado pela creche.

Falta de apetite da criança e alteração do sono

“...às vezes elas não querem comer $\mathrm{e}$ a gente tem que dá uma fruta uma coisa $\mathrm{e}$ outra..."

\section{“Ele ficou muito enjoado, não comia bem, não mamava bem."}


"A hora de dormir, ela fica chata demais."

"Fica pior, porque aí não quer comer mesmo. Só quer tomar leite."

"E a alimentação, é difícil criança se alimentar neste caso..."

Necessidade da mãe faltar ao trabalho para cuidar da criança

“..dependo do estado que a criança tá, tá febril aí minha esposa fica em casa."

Não ter conhecimento ou informações para controlar a doença do filho

“...o hospital não me esclareceu nada..." "Eu fiquei resfriada logo que ele veio para casa, meu marido também, nós usávamos máscaras; eu tinha medo de passar a minha gripe para ele, foi meu primeiro filho." "A pneumonia foi difícil, foi um susto

A minha maior dificuldade foi a falta de prática mesmo."

Falta de confiança na creche

" $\dot{E}$ que ele vai para a creche de manhã e esse medicamento é para aplicar a cada quatro horas. Quem está lá não é uma enfermeira, é uma pessoa comum e não tem condições. Essa era a minha maior dificuldade."

Foi também mencionada a preocupação com o agravamento do problema, principalmente em duas situações, em que houve história anterior de hospitalização por pneumonia e em uma outra em que a criança apresentou reação alérgica ao antibiótico prescrito.

“...às vezes o próprio remédio é complicado. A gente tem experiência com antibiótico que dá alergia nela..."

Houve também referência de dificuldades financeiras da familia, inclusive para a locomoção para o Pronto Socorro e a possibilidade de compra de um aparelho inalador para cuidar da criança na própria casa.

"Além do problema financeiro, falta de socorro, de um carro pra levar na hora. Eu queria uma ajuda, um inalador." 
Vale destacar que das oito famílias entrevistadas somente uma não relatou dificuldades

"...eu não vejo porque eu tenho quem me leve na consulta, a consulta assim que eu ligo é marcada e eu faço tudo conforme ela (pediatra) pede porque eu sei os riscos que pode ter uma recaída, entendeu? ...eu tenho a menina prá me ajudá Não, por enquanto eu não encontrei dificuldade nenhuma, nem em procurar medicamento, nada. Os medicamentos que a gente não acha em farmácia por aqui, que nem eu, eu trabalho em hospital, o meu marido também trabalha na farmácia do Einstein, então qualquer coisa que a gente não acha por aqui a gente pega nos hospitais que a gente trabalha, entendeu?"

Destacou-se, a referència sobre ausência de dificuldades, denotando um melhor controle sobre a situação, apesar da doença. Notou-se também, uma insatisfação com a creche como serviço que não contempla totalmente as necessidades da criança, deixando de atender às expectativas das mães que trabalham fora de casa. Isso nos remete à forma como a sociedade está estruturada para lidar com os problemas relativos à esfera da reprodução social. De fato, não está bem estruturada, uma vez que continua recaindo sobre a familia, mais especificamente sobre a mulher, a responsabilidade de encontrar alternativas de superação das dificuldades. Não basta à família uma inserção social mais estável que permita atender a todas as suas necessidades no cuidado das crianças, pois, nos momentos em que há uma maior exigência para cuidar das mesmas, evidencia-se o conflito.

Em uma das familias pertencentes a este $\mathrm{GH}$, foi interessante o depoimento de um pai entrevistado, que enfatizou na sua resposta que todas as vezes que a criança adoecera, quem havia faltado do trabalho para cuidar da criança, que freqüentava regularmente uma creche, foi a esposa, sem que ele tivesse faltado uma vez sequer

Segundo o próprio entrevistado, isso se dava em função da facilidade que a mãe encontrava para faltar e compensar em outro momento, já que a mesma trabalhava em uma instituição pública próximo da moradia. A questão do trabalho 
materno passa a compor uma das categorias fundamentais para a identificação das necessidades e encaminhamentos possíveis nos grupos estudados. $\mathrm{O}$ trabalho em si pode não se configurar em problema dependendo da flexibilidade encontrada para conciliar as exigências de cuidado para com a criança.

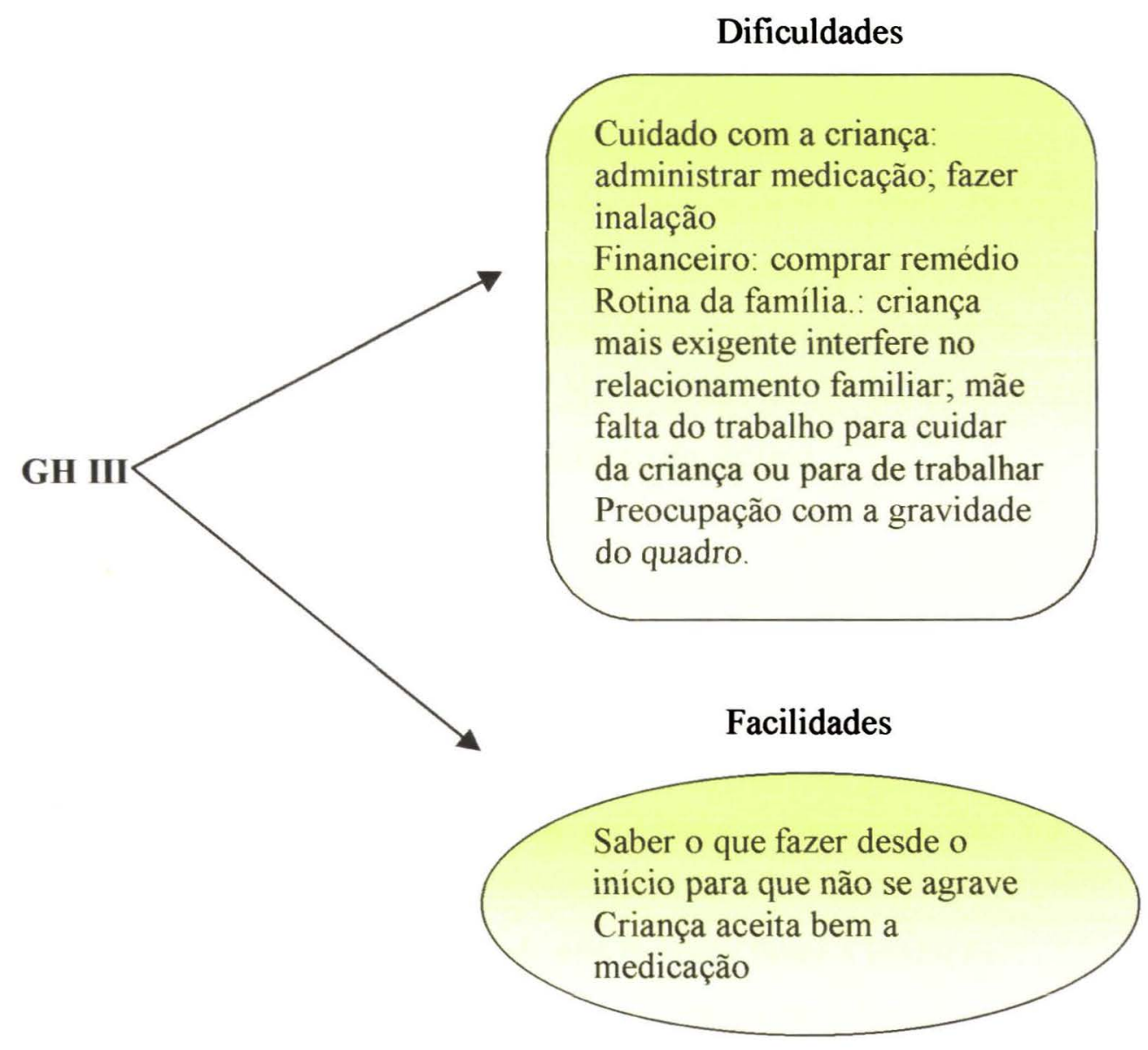

No GH III foram identificados os mesmos aspectos apontados anteriormente no GH I e GH II, porém em grau mais acentuado, podendo comprometer a própria inserção da mãe no mercado de trabalho e levando a uma deterioração das relações familiares, em decorrência das freqüentes alterações no cotidiano. A interferência no relacionamento familiar foi destacada principalmente numa situação em que as crianças eram gêmeas e tinham problema renal detectado desde o nascimento, além de história anterior de quadro convulsivo. Pelo relato materno, havia uma expectativa de sua parte no sentido de começar a trabalhar para contribuir para o orçamento familiar. Essa expectativa nunca se concretizava por causa das freqüentes 
intercorrências doentias dos filhos. Apesar de recentemente ter conseguido matriculá-los na creche faltava conseguir vaga para o filho menor. A situação tornava-se ainda mais complicada, segundo ela, pois o marido não compreendia e, além do mais, cobrava dela para que contornasse a situação e não permitisse que as crianças acordassem à noite. A preocupação com o agravamento do quadro foi mais evidente nesse grupo, cujas histórias de doenças eram comparativamente mais graves.

As dificuldades apresentadas pelos responsáveis pelas crianças estão relacionadas principalmente ao seguimento das orientações médicas, às alterações na rotina da familia decorrentes do adoecimento freqüente ou mais grave da criança e à preocupação com a evolução da doença. Nesse grupo de 19 famílias, somente três disseram que não haviam tido dificuldades de qualquer tipo.

A seguir destacamos algumas falas que retratam os temas apontados acima.

Dificuldade em administrar a medicação ou seguir orientações

"Eu acho que é dar o remédio... Porque ele às vezes não quer tomar, a gente tem que forçar...Que quando é antibiótico aí é fogo... Tem que dar no horário certinho.'

"E em casa ficou sendo dificil porque ele não deixava fazer a inalação."

“...pra dar o remédio é muita tristeza, ele não toma de jeito nenhum, então eu tenho muito dificuldade quanto a isso."

" Só encontrei assim para tomar o remédio. Ela não queria nada. Ela ficou pior só nos dois primeiros dias. Ela é dificil de ficar doente porque eu amamentei bastante, até um ano e oito meses. Normalmente ela só espirra. Eu só levo no médico quando dá febre alta."

"É ruim dele tomar remédio, mas aí eu dou uma enganada, dou na mamadeira." "Foi complicado porque ela não gosta de fazer inalação, fica chorando, aí demora mais para melhorar, e tem falta de apetite, ela só queria mamar no peito."

Dificuldade financeira para comprar o remédio 
"Mas a minha maior dificuldade mesmo é o dinheiro, é horrivel."

"Mas eu fico preocupada assim de não ter condições de comprar o remédio

"Se eu disser pra você que é o remédio, na hora de comprar, porque o remédio, a gente tendo o remédio a gente dá na hora certa Não tem...dificil mais é pra comprar, às vezes também a gente não tem as coisas urgentes"

Alteração na rotina da criança ou da familia, influenciando as relações familiares e a possibilidade da mãe continuar trabalhando

Preocupação com a dificuldade respiratória

"A maior dificuldade é na respiração, que é no nariz parece que tem uma coisa que não deixa tomar mamadeira, ficam com falta de ar, não tomam mamadeira, respiram só pela boca."

Falta de apetite e alteração do sono

"A alimentação é um problema, os maiores já não querem comer."

"É que ela não dorme... Não deixa os outros dormir...fica irritada, chora demais, nariz entupido

"Ah, o problema é que ela não dorme direito ela não gosta de comer, só isso."

Pai fica impaciente com a doença e não cuida dos filhos

"O pai deles é muito nervoso, não entende quando as crianças estão doentes, em vez de dar carinho o pai vem com ignorância."

Acesso dificil ao serviço de saúde

"Porque a gente vai se deslocar daqui, faltar no serviço tudo pra poder ir lá pra poder marcar" 
Impossibilidade de cuidar em casa

"Ter que dar inalação, levar até o posto."

Mãe precisou parar de trabalhar

"Eu estava trabalhando, ele ficava na creche, ele tinha muita febre, tomava muito remédio, tive que tirar da creche, que sair do serviço. Foi muito difícil para mim."

Preocupação com a evolução da doença

“...pneumonia eu tenho mais medo, e o resto sossegada."

"Ela estava com falta de ar, em casa não dá para curar, tive que levá-la no médico."

"A pneumonia, aquela dificuldade para respirar, muito catarro no peito, muita preocupação."

A ausência de dificuldades também aparece nos discursos, destacando-se o conhecimento da mãe para avaliar a criança, detectando sinais de gravidade ou quando a criança aceita a medicação

"Eu nem sei explicar qual é o problema. É, não é difícil cuidar."

"Nenhuma, eu trato logo e ela sara rápido."

"Eu já estou acostumada porque ele já teve outros resfriados, agora eu medico com esse remédio, cuido desde o início, ele se alimenta bem, assim não se torna um resfriado muito forte. Ela adora os remedinhos." 


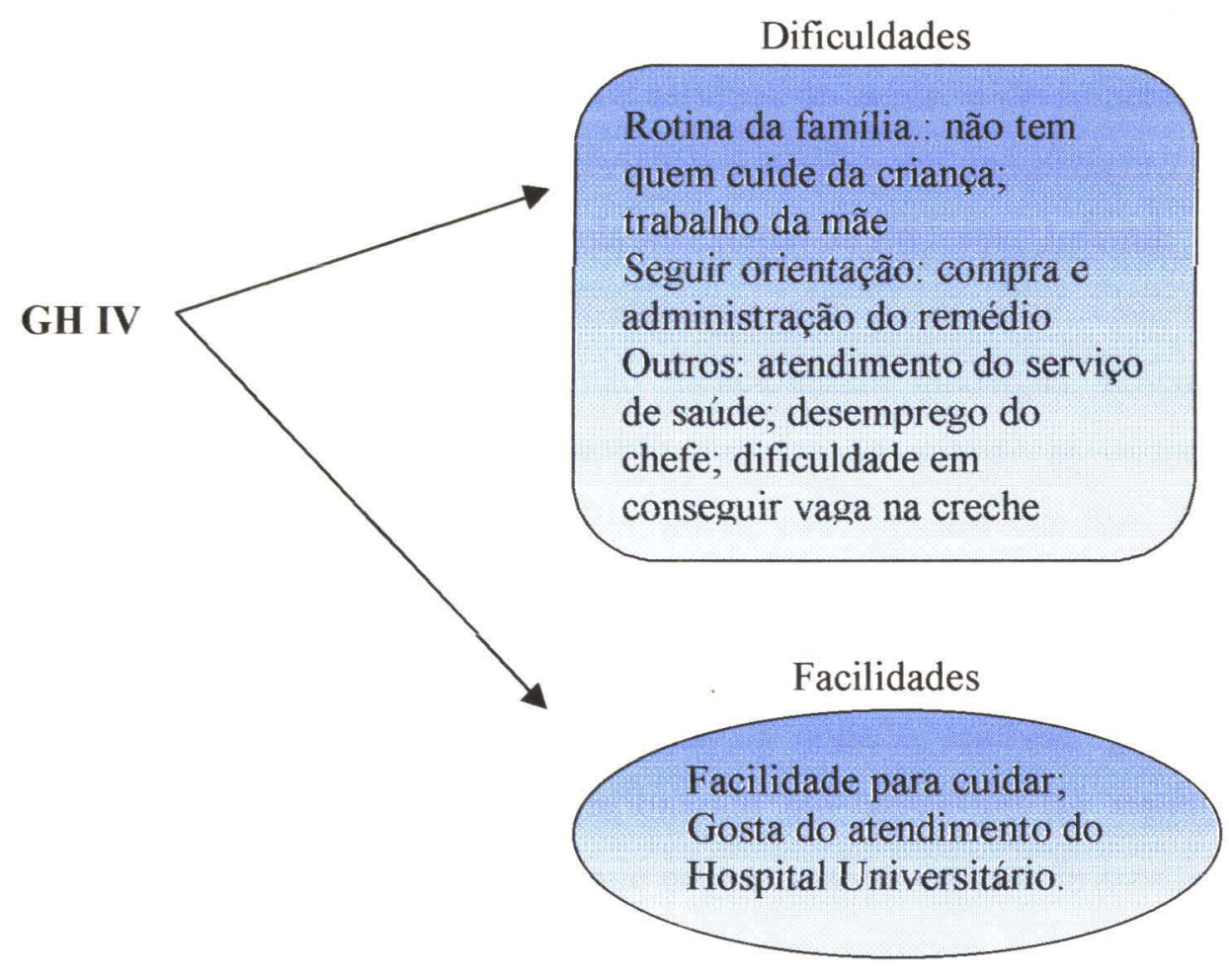

No quadro síntese dos temas significativos identificados nos discursos dos entrevistados desse $\mathrm{GH}$, pode-se perceber que as dificuldades sentidas decorrem dos aspectos anteriormente detectados, como alteração da rotina da família para cuidar da criança doente e seguimento das orientações médicas. Percebe-se nessas famílias as dificuldades que têm para cuidar das crianças, para levá-las ao serviço de saúde, ou para cuidar das mesmas já que não podem freqüentar a creche ou escola de educação infantil durante a doença.

Ainda no tocante à rotina da familia também apareceram relatos de abandono do trabalho por parte da mãe, assim como faltas ao trabalho para possibilitar o tratamento dos filhos. A maior influência da baixa renda, pode ser verificada de forma mais contundente neste GH, constatada através da dificuldade para comprar a medicação prescrita, presente na maior parte das falas, além da falta de dinheiro para locomoção. Nesse aspecto, chama a atenção o depoimento de uma entrevistada, mãe de cinco filhos, que mencionou saber da importância de levar as crianças ao Centro de Saúde para uma avaliação periódica; contudo, por falta de dinheiro para condução, só as levava quando apresentavam alguma doença. Outro aspecto a 
destacar, foi a maior presença de outros temas relativos a dificuldades encontradas pela demora para conseguir atendimento nos serviços de saúde, o desemprego do pai ná mais de um ano e dificuldades para matricular a criança em equipamento público de atenção à criança como creche ou Escola Municipal de Educação Infantil.

Alguns entrevistados deste GH não mencionaram quaisquer dificuldades, principalmente nos casos em que a mãe não trabalha ou quando as crianças são cuidadas por outra pessoa da familia. Em geral, nas famílias em que as mães trabalham fora de casa, cabe às mesmas a tarefa de levar os filhos ao serviço de saúde, sendo o Hospital Universitário o local de escolha, pelo amplo horário de atendimento que permite a consulta no periodo da noite e, também, pela própria qualidade do hospital. Entre os que mencionaram que gostavam do atendimento recebido nesse hospital a menção a qualidade centrava-se na certeza de atendimento, na confiança nas prescrições e nas orientações que auxiliam a recuperação da criança.

A seguir, apresentam-se alguns trechos de falas que ilustram os temas descritos destacando-se a dificuldade em encontrar alguém que cuide dos outros filhos enquanto leva o filho doente à consulta médica, a necessidade de faltar ao serviço para levar à consulta médica ou a impossibilidade da criança freqüentar a creche representam alguns dos problemas mais mencionados pelos entrevistados nesse $\mathrm{GH}$.

Dificuldade para levar o filho doente à consulta médica

"É que eu tenho três ...Então para deixar quando a minha mãe não dá, eu deixar com alguém, meu marido tá trabalhando não dá para deixar sozinhos."

A mãe menciona como dificuldade o fato do marido ter que faltar do serviço, porque não tem com quem deixar as crianças que não estão doentes, enquanto leva o doente ao médico

“Às vezes eu até levo todos. Ele chega lá já não pode ficar com os outros, eu sei que é para levar o que tả doente, então aí é difícil." 
Dificuldade financeira

"Quando não dão o remédio aí fica difícil de comprar"

"O difícil também é comprar os remédios, pior quando é antibiótico caro."

"Às vezes a gente não tem dinheiro pra comprar o mel..."

Ter que faltar no trabalho para levar à consulta médica

"Eu trabalho de faxina, trabalhava até as $10 \mathrm{~h}$, então às vezes não dava pra levar. Às vezes tem que faltar. $E$ só mais isso mesmo."

Ter que parar de trabalhar

"Quando ele teve pneumonia pela terceira vez, minha mãe tava trabalhando....ela teve que parar de trabalhar para ficar com ele."

Atendimento demorado

"Porque às vezes eles demoram a atender a gente."

Insatisfação com o atendimento recebido

"...eles examinaram assim, por cima, e falam - 'Ah, que gripinha, a senhora dá um remédio caseiro e pronto '- então eu já cheguei a levar essa menina com $40^{\circ} \mathrm{C}$ de febre pra USP e eles... e infecção brava mesmo. E eles passaram remedinho caseiro : Chazinho, melzinho, essas coisas. Então...não resolveu nada."

Seguir as orientações

“É ter que cuidar bem cuidado...dar banho, dar remédio na hora certa."

Neste grupo de famílias com as piores condições de vida, pode-se perceber que o adoecimento das crianças torna-se um elemento negativo que acaba por comprometer outras instâncias da vida da familia, como o trabalho dos pais. 


\subsection{As percepções dos entrevistados sobre possiveis causas relacionadas às}

IRA

A seguir é apresentada a compreensão dos familiares sobre as causas dos agravos respiratórios. Este aspecto é de fundamental importância, pois configura o quadro de referência dos sujeitos para a definição das ações necessárias. Como salientado anteriormente no Marco Conceitual, há um distanciamento entre a ótica do profissional de saúde e a ótica da clientela para explicar os problemas de saúde encontrados. Muitas vezes essas diferenças sobre as causas dos problemas de saúde alimentam barreiras que prejudicam a comunicação e o diálogo entre ambos.

BOLTANSKI, (1984) em pesquisa realizada na França acerca das concepções de saude-doença presentes nos diferentes segmentos da população afirma que um dos fatores desse distanciamento centra-se na condição de subalternidade de classe da clientela em relação ao profissional de saúde

No GH I, predominam referências aos fatores de ordem genérica relacionados à degradação do meio ambiente decorrente da poluição do ar, ao clima instável da cidade e a estação do ano. Em seguida, surgiram os aspectos ligados ao ambiente doméstico, destacando-se a preocupação com os fatores alergênicos em cortinas, tapetes. excesso de poeira ou o uso de produtos de limpeza com componente tóxico. Foram ainda lembrados dois aspectos relativos ao cotidiano das crianças como a alimentação inadequada das crianças maiores que, com maior autonomia para se alimentar, acabam ingerindo menos frutas e verduras, diminuindo a resistência contra resfriados e gripes, alem do contato com outras crianças na escola ou na rua.

Os entrevistados do GH I mencionaram principalmente os fatores genéricos como a poluição

“...problemas de rinite essas coisas, eu acho que é um pouco em função de poluição."

"Eu acho que é o ar terrivel da nossa cidade"

"Ah! Com certeza poluição, isso ai afeta" 
"Sem dúvida a poluição...é escapamento de carro, de caminhão"

"Muita poluição, fumaça de caminhão..."

"Eu acho que é o ar, poluição."

"Acho que a poluição. Com o ar poluído você está mais propenso a pegar outras doenças. Qualquer tipo de virose."

"Eu acho que é a poluição, porque tá calor então não dá para colocar a culpa no frio."

O clima instável da cidade :

"...e mudança de tempo muito brusca."

"A mudança de temperatura, de manhã tá frio, quente."

"Eu associo com o tempo frio, ela sempre fica assim quando esfria."

\author{
A friagem \\ "No caso dele mesmo foi friagem. Eu viajava muito de caminhão com meu \\ marido, à noite...dele já foi friagem." [referindo-se à história de otites de repetição \\ do filho mais velho] \\ "Ele sempre anda descalço, mexe em água o dia inteiro." \\ O outono como estação em que se adoece mais \\ “...mas é muito também da estação, não é? Todo ano no outono todo mundo fica \\ doente." \\ "O próprio tempo. Outono é a época que mais dá doença em criança".
}

Presença de tapetes, cortinas e excesso de poeira na casa que propiciam o contato com alérgenos domésticos:

“...pó, cortina e tapetes da casa e poluição."

“Geralmente a pessoa quer a casa mais bonita e não vê o lado, por exemplo das plantas. Se for plantada do lado de fora tudo bem, mas dentro é prejudicial, fica boa mas tudo isso, tapete, cortina é prejudicial."

Suspeita de atividade poluidora clandestina nas proximidades da moradia :

....tem algum depósito de lixo, alguma indústria, alguma coisa que chega de 
noite eles soltam uma fumaça e a chaminé, fica aquele cheiro típico de lixo queimado...."

Alimentação inadequada da criança :

“...acho que alimentação, quer dizer, essa idade que a L. tá, por exemplo, é uma idade que já acha que é capaz de escolher o cardápio...acaba comendo porcaria...Eu acho que alimentação é fundamental no caso."

"Ele é meio difícil para se alimentar, mas é uma criança saudável, não é gordo nem magro. Agora ele perdeu peso por causa da doença."

Presença de substâncias irritantes nos produtos de limpeza de uso doméstico "Os produtos de limpeza por causa do cheiro. Eu tenho certeza que estes produtos tem muita química, muita substância que provoca essas coisas, essas irritações."

O contato com outras crianças na escola ou na própria rua :

"Na escolinha também teve caso."

"E contato, ela se tiver contato com gripe com certeza vai ficar doente."

No GH II os fatores de ordem genérica como o clima instável e a poluição, e os relacionados ao cotidiano das crianças, como o contato com outras crianças na creche e a inexperiência da mãe, apareceram com a mesma importância, seguidos dos aspectos ligados ao ambiente doméstico (umidade, reforma da casa e presença de animais domésticos). A qualidade da assistência ao parto $\mathrm{e}$ a imaturidade imunológica da criança também foram mencionadas em duas entrevistas.

Enquanto fatores de ordem mais genérica, destacaram-se:

- A poluição

"Poluição da Raposo..."

"Pode ser a poluição"

- O clima instável da cidade

"Também tem a mudança de temperatura." 


\section{"Mudança de tempo." \\ “...a mudança de tempo."}

- A friagem

"A friagem."

"Foi um pouco de abuso porque o I. ele é teimoso...ele tá à vontade em casa ele sai com tudo, prá fora você entendeu? Então o I. foi o abuso e, o resfriado ocasionou a bronquiolite,

Relativos ao cotidiano da criança, foram mencionados

- O contato com outras crianças na creche

"...ela está numa creche, na creche o contato..

"Enquanto ele está em casa não tem problema nenhum. Quando ele vai para a escola ele tem."

- O contato com o irmão doente

“...ele dormindo no mesmo quarto que o B., o B. por ser pequeno não tem defesa ainda, pegou a gripe e também ocasionou uma bronquiolite."

- O contato com substância alérgica na creche

"Eu fiquei imaginando que era contato com alguma substância alérgica. Todo dia ele voltava com o nariz entupido."

- A inexperiência da mãe superprotegendo a criança

“...ela não pode pegar muito vento, porque quando ela nasceu eu não deixava ela sair no vento... ela não acostumou e foi culpa minha."

Em relação ao ambiente doméstico foi mencionada a umidade da casa

“...o bercário era num, numa região de várzea, era úmido e frio."

"...e a umidade da casa." 
A má qualidade da assistência no serviço de saúde em que a criança nasceu

"Eu acho que o que causou mesmo a pneumonia foi descuido do hospital..."

Imaturidade imunológica da criança :

“...o sistema imunológico dela não está preparado prá responder"

No GH III os aspectos mais mencionados diziam respeito aos fatores de ordem genérica como a instabilidade climática e a poluição ambiental. Em seguida, encontraram-se os fatores ligados ao ambiente doméstico ou à creche, com inadequações como exposição à friagem, falta de ventilação adequada, excesso de poeira e contato com pais fumantes. Apareceram, ainda, de forma isolada, fatores biológicos da própria criança, como a predisposição hereditária e maior suscetibilidade decorrente de outra patologia crônica.

Dentre os fatores de ordem mais genérica foram mencionados:

- A instabilidade climática :

"O próprio, o próprio meio ambiente também é fogo...Você vê, mudança de tempo a gente não pode prever e isso eu acho que ajuda muito a ter problemas." "Mudança de tempo, de repente tá quente, de repente esfria."

"O resfriado, a mudança de tempo."

"Basta mudar o tempo que eles ficam bem ruinzinhos."

- A poluição ambiental

“A poluição e esse tempo ruim judia muito da criança... ... Ar, poluição, passa muito carro. Fumaça que sai do carro prejudica a respiração.”

“O tempo, a poluição."

"...a poluição, o ar."

Os problemas relativos à casa ou à creche incluíram a exposição à friagem :

"No dia antes de ele ter febre, uns dois dias antes eu fui na Liberdade, de metrô, e estava muito quente e quando nós saímos do metrô teve assim um vento não frio, mas um vento meio forte....mas eu achei que teve esse choque do quente, 
que estava muito quente embaixo do metrô e quando a gente saiu estava esse vento

“..ele acordava cedo, tomava banho, vitrô aberto, a creche não podia ficar fechada, ele não se adaptou."

Creche que não atende bem

"Falta de alimentação, se a criança não quer comer elas (referindo-se às funcionárias da creche) não insistem, muita criança, falta de carinho, então ele foi adoecendo, adoecendo, foi por causa disso."

A falta de ventilação adequada

"Aqui dentro da minha casa particularmente o ar é meio abafado."

O contato com pais fumantes

“...e eu sou fumante e ele (marido) também, então deve provocar também... Às vezes a gente nem percebe e fuma do lado dele."

Em relação à própria criança, foram destacadas a hereditariedade

"Porque eu tenho também bronquite, já é genético..."

Maior suscetibilidade por serem crianças nervosas

"Eu acho que eles são muito nervosos os dois. $E$ eles vivem doentes, vivem gripados."

Gripe mal curada

"A bronquite foi a gripe mal curada né, que vai acumulando, acumulando e foi causando a febre, a pneumonia e a bronquite, deu muito catarro, remedinho que não dava certo. Então foi uma gripe mal curada."

Assistência ao parto inadequada

“...e ela já nasceu com problema de respiração ..ela passou da hora de naseer." 
No GH IV também, destacaram-se os fatores de ordem genérica como o clima instável, a poluição ambiental e a sujeira nas vias públicas. Em seguida, surgiram os fatores ligados à casa, com referências principalmente, à moradia inadequada, ao excesso de poeira e à presença de umidade. Outros temas foram a falta de cuidado com a criança, a ingestão de gelado e a frequêencia à creche. A inexperiência da mãe e a maior susceptibilidade hereditária também apareceram como fatores prejudiciais.

Os fatores de ordem genérica mencionados foram principalmente

- O clima instável

“...por causa do tempo.. Esse tempo muda : um dia tá quente, um dia tá calor."

“...a mudança de tempo, hora calor, depois de repente fica frio, daí ele...fica assim. ...É, fica cansadinho. É só mudar o tempo."

"Eu acho que foi a mudança de temperatura. Tava muito quente."

“Eu não sei. É por causa do clima daqui, porque lá no Norte eles não têm esses problemas. Aqui tem hora que tá garoando."

“Que nem eu falei pra você. É só mudar o tempo e ele fica ruim. É o pó e quando muda o tempo."

- A poluição

"A poluição, a sujeira que fica no ar e ataca as crianças."

"A poluição também."

"Ah...acho que, negócio dessa poluição que tem... Essa poluição que faz isso também"

"Tem também a poluição, porque qualquer coisa vem aquele mau cheiro pra cá,"

- Sujeira pública e ambiente externo deteriorados

"Olha aqui também, como é que anda isso aqui, sempre tá limpando, é um monte de rato, às vezes tem rato aqui dentro. $E$ olha que eu limpo sempre. Mas tem as pessoas aí que jogam a sujeira prá cá." 
“Tem também esse mau cheiro do lixo, e o esgoto aí fora. Tem momentos que dá um cheiro horrível, eu nem gosto de ficar aqui na frente. Eu acho que deve contribuir Esgoto estourado que não está concertado."

“...sei lá num tem um lugar mais suficiente prá morar, sei lá se pode ser isso. Se é o rio que é, é muito perto"

Em seguida, apareceram os fatores ligados à casa, como moradia inadequada :

- Insolação inadequada

"Eu não sei se é assim se é o frio. Porque quem morava aqui era a minha avó, e ela falava ainda no calor o sol bate um pouco, mas no frio não pega sol de jeito nenhum. Então é muito frio, mas é isso, a umidade. O córrego influi um pouco, as casas que ficam mais embaixo é mais frio."

- Falta de ventilação

"Ai às vezes, eu moro aqui fechou essa porta, abafou, ai começa "

- Isolamento térmico insatisfatório

“Aqui é muito frio. No calor você não agüenta aqui dentro, no frio você...fica muito frio. Fica, e também quando chove entra água aqui dentro. É muita água aqui dentro, eu ando assim descalça, mas fico... e qualquer chuvinha, entra água: é por cima, é por baixo. O médico mesmo já falou que é o frio."

- Umidade e enchente

“...deixa úmido, é de repente ... às vezes passa água também aí na porta, quando dali solta os vizinhos, fica aquela coisa,"

- Vazamentos, enchentes e contato com esgotos :

"Eu te falo : é aqui, quando, na minha casa, enche de água, de esgoto daí de cima, e as crianças não pára no sofá quieto, qué brincá, então o dedinho que ele passa na coisa pega na bactéria, então não dá, fica dificil." 
- Desobediência

"Olha eu acho que facilita esses probleminhas também, devido o abuso deles...eles fazem muito escondido, sabe....Mesmo a gente tando em cima, mas sempre apronta por trás."

- Ingestão de gelado

“....Então se eles vêem alguém chupando alguma coisa gelado, sempre um de fora dá escondidinho a gente nem percebe. Porque eu não tenho costume de dar nada gelado pra ela..."

"O resfriado, coisa gelada ela não pode tomar também. E ela, danadinha pra tomar coisa gelada."

- Falta de agasalho e calçado adequados :

“Olha, sinceramente eu penso não vou dizer pra você porque, a criança ela precisa de todo cuidado... tipo assim, que nem tá esse tempo como tá, ficar calçada, agasalhada, ter mais um conforto"

\section{- Higiene}

"Eu acho que, também, a higiene é muito importante nas crianças. $O$ cuidado que a mãe deve ter com o filho sobre as roupas, sobre o que a criança ela vai comer, o que ela pega pra pôr na boca, acho que vem de, também de tudo isso aí....Eu presto muita atenção nos lugares que eu vou, tem mãe que deixa a criança de tudo quanto é jeito, como é que é, é alimentação mal cozida, até mesmo o leite quando vai fazer, então isso aí prejudica ajuda a que, os vermes a tomar conta do organismo da criança principalmente quando é uma criança que tá com o organismo fraco."

- Alimentação inadequada :

“...acho que a alimentação também tem um tipo de alimentação que ajuda, eles não ficar doente, tem tudo isso" 
Algumas características individuais das crianças também foram destacadas:

"Eu penso assim que além da poluição, além da umidade, do lugar que a gente mora tem também acho que é, é da criança."

Frequêencia à creche

“...ele era muito novinho, acho que elas deixavam ele no tapete, no chão. Ela saía cedo assim, 6 horas, foi no tempo do inverno. Depois de 2 meses ele já teve pneumonia."

"Acho que foi a creche, porque quando a irmã cuidava dele, ele não tinha isso."

Hereditariedade :

"É, porque quando ele nasceu, já nasceu com aquilo lá. O médico disse que já veio da geração, sabe, ele nasceu com bronquite, já com três dias já era cansadinho....Aí deve ser alguma coisa assim, né, porque não vai dar assim, ele tá dentro da barriga da gente e já nasce com aquilo, né, aquelas doenças, aquelas coisas."

Sintetizando os achados foi constatado que os fatores de ordem genérica apareceram em primeiro lugar em todos os grupos sendo que no GH IV, além da poluição e do clima instável, surgiu mais uma característica relativa ao bairro que foi a sujeira nas vias públicas, indicando a percepção de um ambiente mais deteriorado

Em geral os temas ligados ao ambiente doméstico também estiveram muito presentes nos discursos dos entrevistados, adquirindo nuances diferentes em cada grupo. No GH I o aspecto negativo da moradia, esteve relacionado à presença de fatores alérgenos ligados a utensílios e à decoração, como cortinas e tapetes. Nos GHs II e III puderam ser identificados outros problemas como a umidade, a exposição à friagem ou a falta de ventilação adequada, além dos fatores alérgenos ou irritantes como excesso de poeira por reforma da casa, contato com animais e contato com pais fumantes. 
No GH IV que reunia as piores condições, os problemas foram decorrentes das precárias condições de moradia. Alguns depoimentos revelam a percepção de isolamento térmico insatisfatório, a exposição às inundações, a falta de insolação e a ventilaçào inadequada, além do excesso de poeira e umidade.

Com relação ao cotidiano das crianças, o aspecto mais destacado como prejudicial foi o contato com outras crianças na creche, aparecendo com maior destaque no GH II, seguido dos GH I e GH IV. No GH I, ainda, vale destacar a alimentação com menos frutas e verduras das crianças maiores, como fator predisponente.

O quarto agrupamento temático mais presente nos discursos dos entrevistados foi a falta de cuidados adequados com a criança. Neste tema, foi relevante o papel do adulto na vigilância da criança, para evitar a exposição à friagem ou às alterações decorrentes da instabilidade climática. No GH II apareceu como tema central a falta de experiência anterior da mãe, incorrendo numa atitude superprotetora prejudicial. No GH IV a ênfase dada às causas de adoecimento apareceram ligadas às roupas e calçados inadequados, ao clima e à ingestão de gelado.

Fatores de ordem individual da criança também foram mencionados no GH II, ligados à imaturidade imunológica da criança; no GH III, como predisposição hereditária e maior susceptibilidade pela vigência de problema crônico e no GH IV, como predisposição hereditária

A assistência ao parto de má qualidade também apareceu como causa de adoecimento por IRA, no GH II, por condições insatisfatórias do Hospital, e no GH IV, porque a criança nasceu com problema respiratório em decorrência de demora para a realização do parto.

\subsection{Os encaminhamentos apontados}

O último agrupamento temático de interesse desta investigação para a identificação das diferentes necessidades em função das iniqüidades presentes no 
território, dizia respeito às sugestões propostas pelos participantes para melhorar o controle dos agravos respiratórios. A partir daí pode-se conhecer também o cenário eleito pelos sujeitos para focalizar as ações necessárias para a mudança, configurando um aspecto de extrema importância para o planejamento local de saúde, bem como para a aproximação intersetorial

No GH I, pode-se perceber uma convergência entre os fatores causais apontados e os encaminhamentos possiveis, pois o principal aspecto destacado para a superação dos problemas foi a diminuição da poluição. $O$ encaminhamento apresentado por esse grupo para a diminuição da poluição, centra-se no controle de emissão de poluentes. No âmbito individual, inclusive, pode-se perceber um movimento de se ausentar da cidade. sempre que possivel, para usufruir de um ambiente mais saudável, distante da poluição.

Em relação à poluição as sugestões revelam a preocupação com a emissão de poluentes decorrentes do grande fluxo de veículos, agravado pela existência de veiculos mal regulados.

Sair de São Paulo

“...porque eu viajo muito para a casa da minha mãe que é em Minas."

Percepção da poluição

“O ar daqui, quando a gente entra em Atibaia a gente já percebe que é poluído."

"Uma coisa que faz muito mal, é a fumaça dos caminhões. ... Aquela fumaça preta que sai , aquilo acaba com a gente."

Um dos encaminhamentos apontados foi a diminuição da poluição, porém com dificuldade em indicar a alternativa de como fazer

"Nada que esteja ao meu alcance, por exemplo para sugerir."

"Tirar todos os carros da rua, principalmente esses caminhões enormes que passam." 
A poluição sonora decorrente do grande fluxo de veiculos também apareceu como fator gerador de stress, dificultando o sono e piorando as relações familiares. "A questão é a poluição sonora da Eliseu de Almeida....e não é só sonora ...a minha casa tá, é novinha, bonitinha, muito bem construída, ela tem uma rachadura assim, e a casa vibra, vibra tudo.... Ninguém dormia direito, não conseguia respirar direito...então ficava nervoso ....quando eu comprei a casa não tinha nada disso."

No caso acima. a pessoa entrevistada relatou que a poluição sonora e do ar motivou a mudança para um local mais tranqüilo, dentro da região do Butantã mesmo.

Houve um destaque também para o cuidado mais direto com a criança, sendo reforçada a necessidade de evitar friagem, ingestão de gelado ou alimentação incorreta. A superaçào foi vista no âmbito da própria casa e das pessoas que cuidam da criança

Ainda com relação a este tema, foram sugeridos maior informação ou "conscientização" da população para assumir atitudes mais saudáveis. Tais sugestões incluiam

- Evitar levar a criança à escola na vigência de um episódio doentio

"Eu acho que os pais, quando os filhos estão doentes devem evitar levar as criancas na escolinha."

- Estimular o controle individual dos automóveis regulando melhor os motores dos carros em circulação, ou estimular o maior plantio de árvores para aumentar as áreas verdes.

"O único jeito é conscientizar a própria populacão a plantar mais, verificar seu carro, parar de queimar."

- Desenvolver novos produtos de limpeza

"Outros problemas na casa é pó, cortina, tapete, ácaro. Deveria ter um produto de limpeza que acabasse com o ácaro." 
Foi sugerida a ampliação do acesso às vacinas contra gripe, talvez pela influência da propaganda veiculada na TV sobre a vacinação de idosos na época da realização das entrevistas. Uma das mães entrevistadas manifestou estar insatisfeita pelo fato da assistência conveniada não oferecer esse tipo de atendimento

"Não sei. Eu acho que já tem vacina para isso, não tem."

"Fixar bem esse negócio da gripe, meus filhos pegam direto, meu convênio não cobre a vacina da gripe. Se é uma coisa que vale a pena deveria ter na Saúde Infantil."

“Estão fazendo uma divulgação boa da vacina para idosos, devia ter para crianças também. Porque é caro e toda hora eles estão tendo. Deveria fazer essa campanha de vacinação."

Para a assistência à saúde, a população procurava o serviço de pronto atendimento do Hospital Universitário, apesar de algumas pessoas terem planos de assistência conveniada. Foi interessante observar numa das falas a diversidade dos serviços procurados para a atenção à saúde do filho: o Hospital Universitário para pronto atendimento, o convênio para o seguimento sistemático e o Centro de Saúde para a vacinação

No GH II não houve destaques especiais apontando de forma equivalente as mudanças relacionadas à poluição, à moradia adequada, ao cuidado direto da criança, à melhoria da assistência médica e ao desenvolvimento de tecnologia apropriada para aperfeiçoar a prevenção dos agravos.

As sugestões relativas à poluição passam pela diminuição de circulação de veículos nas vias de maior tráfego da região; destacando-se, além do papel de fiscalização por parte do Estado no controle deste problema, a necessidade de envolvimento de toda a população para mudança de comportamento no sentido de se modificar práticas incorretas

“... a quem compete fazer alguma coisa eles fazem, que é a fiscalização em 
termos de poluição....não cabe somente à eles, falta um pouco de conscientização da população.... ". . .o pessoal joga lixo aonde acha que tem que jogar e pronto." "Acabar com a Raposo, diminuir mais, os caminhões soltam muita fumaça preta."

A referència à moradia adequada apareceu ligada à manutenção da limpeza no interior da casa

".. morar num lugar bom ...tambem ajuda bastante.

“Eu limpo a casa...procuro deixar a janela aberta para desabafar...evito animal."

O cuidado com a criança centrou-se nas praticas de aumentar a hidratação e proteger da friagem. recomendadas no inicio dos problemas, evidenciando a preocupação em evitar a evoluçào para um processo mais grave.

As ações necessárias para se obter a diminuição dos agravos diretamente relacionadas às crianças, incluiram alguns cuidados domiciliares

"Não posso fazer nada, não sou médica. Dar mais líquido para ela, sopa, chà."

“.. faço chá e xarope...protejo da friagem."

A vacinação especifica para os quadros respiratórios, também apareceu nos discursos deste $\mathrm{GH}$, enquanto uma medida capaz de diminuir a incidencia dos episódios

O desenvolvimento tecnológico também apareceu nas sugestões dos entrevistados, através da referência à ação protetora de uma vacina contra gripe.

"Eu acharia que deveria ter assim, uma vacina prá fazê elas não pegá gripe fácil, porque assim elas pega sempre gripe."

"Deveria existir uma vacina, alguma coisa que proteja as crianças. Porque a maioria dos recém nascidos não têm anticorpos e pegam qualquer coisa." 
A assistência à saúde prestada pelos serviços também foi mencionada enquanto um fator de superação

"Poderia ter evitado se tivesse caído no hospital certo. Coloquei no hospital errado, deu tudo errado."

Possibilidade de escolha do profissional médico

"Depois da pneumonia eu troquei de pediatra, ele tinha o pulmão muito frágil. Ele estava tomando seis remédios. Quando voltei para São Paulo levei em um terceiro pediatra e ele mandou jogar tudo no lixo, falou que meu filho não tinha nada e estava vomitando por causa de tanto remédio. Hoje em dia está ótimo."

No GH III a ênfase para os enfrentamentos foi dada aos cuidados com a criança. destacando-se a preocupação com a exposição à friagem e a necessidade de atuar no início do processo doentio para evitar agravamento.

Cuidar melhor da criança apareceu como uma atribuição da mãe ou do adulto responsável, que deveria protegê-la dos riscos do ambiente.

"Eu acho que é mais friagem, falta de cuidado.. Cuidá melhor e agasalhar melhor.....Cuidado da mãe"

"Para que não fique (doente) eu acho que tem que agasalhar na época de frio, não deixar ficar na rua, não mexer com água. Ela tem loucura para andar descalça, toda hora ela tira. É gelado o piso."

"Agasalho bem e alimentação eu acho importante e sempre xarope caseiro ou mel ajuda bastante. Eu já fiz e realmente corta."

"Ter cuidado (com a criança)."

Para alguns, era dificil entender o adoecimento por acreditar tomar os cuidados necessários.

"Eu tenho bastante cuidado e não adiantou, não deixo eles ficarem molhados, mas não adiantou." 
O principal meio de controle seria a vigilância sobre a criança, tarefa esta reputada à mãe como ator principal. Foram também sugeridas mudanças com relação à poluição destacando-se o rodizio de veículos enquanto medida satisfatória para minimizar o problema.

A poluição foi lembrada através do rodizio de veículos, da necessidade de melhorar a arborização da cidade e maior controle sobre todos os aspectos ambientais

“...Poluição, muita poluição...É eles já estavam fazendo isso.. Estavam fazendo o rodízio dos carros, tudo. Acho que melhorou um pouco."

"Bom a poluição é, eu acho que é o fator principal $E$ o que a gente não pode fazer muito..."

"Ah, eu não sei dizer, talvez os carros... Diminuir...como tá tendo o rodízio tá diminuindo um pouco."

“.... problema é a cidade inteira.. A poluição que é muito grande e esse clima que também...eu acho"

"Aí, aí eu não sei, sei lá tem que fazer alguma coisa Negócio de rio, vê poluição..., um monte de coisa que a gente tem ...caminhão..., fábrica."

A assistência prestada pelos serviços de saúde também compôs o panorama de mudanças necessárias para a diminuição dos agravos respiratórios. Particularmente sobre este aspecto, os discursos revelaram uma adesão aos serviços, com referência de que sempre foram bem atendidos, com destaque às orientações recebidas para a prática do aleitamento materno, lembrado como um elemento de promoção da saúde e de controle dos agravos respiratórios nas crianças.

Atuar no inicio do processo para impedir que o quadro se agrave, destacando a importância de orientações médicas adequadas, também foi um dos aspectos mencionados como alternativa possivel.

"Pra criança uma boa alimentação também "

"Fazer inalação nele. Depois que eu fiz inalação ficou bem. Ele nunca fica doente." "Eu já conheço a medicação que a pediatra passou. Eu ligo pra ela, ela fala a quantidade. Eu trato logo no início para não dar uma gripe forte." 
Outros temas que surgiram nas entrevistas deste GH III evidenciaram uma adesão aos serviços de saúde e confiança nos profissionais. O médico foi lembrado por ter "acertado" na prescrição

"acompanhamento com um bom pediatra tudo, você consegue prevenir ou se tiver algum probleminha até resolver rápido"

"Nunca o médico prescreveu uma medicação que não surtiu o efeito desejado

"...tudo que eu já passei eu tive resposta."

"Eu acho que quando dá esses problemas o melhor mesmo é procurar um médico para saber o que está acontecendo."

"Eu acho que em primeiro lugar deve logo procurar um médico, não se deve dar qualquer remédio em casa. Ligar logo para marcar consulta. Ela manda também fazer inalação."

A prática do aleitamento materno foi lembrada por duas mães entrevistadas tanto pelo fator protetor do leite, como pelo sucesso obtido a partir de orientações recebidas no Centro de Saúde

"Porque eu amamentei ele bastante. Eu tenho só que agradecer vocês terem instruído. Tem gente que fala que não vai amamentar porque não quer cair o peito, mas a gente que é mãe, a gente não vive mais para nós. Ser mãe começa desde quando já gerou."

"É, todo mundo fala. Eu peguei gripe, meu marido pegou uma horrorosa, minha mãe e ele (filho que ainda estava sendo amamentado somente pela mãe) não pegou."

No GH IV, assim como no grupo anterior, a ênfase dada aos encaminhamentos centrou-se no cuidado com a criança, incluindo a não exposição à friagem e o seguimento das orientações médicas.

"Não tem como a gente tomar cuidado, porque é da natureza. Acho que a gente tem que cuidar quando o negócio está feio mesmo, agora evitar eu acho assim : evitar a gente não pode evitar, agora cuidar sim, cuidar a gente já pode." 
"Ah! Depende de tanta coisa, eu acho, no caso ele por exemplo : se ele fosse uma criança mais obediente, entendeu, não ficasse tomando muito gelo..."

“É, tem que andar agasalhado evitar tomar vento...é evitar tomar friagem. Dá banho nele sempre quando tiver quente e quando tá frio assim eu não dou banho nele."

“...Cuidado, Cuidados."

“...mais atenção, na criança, ...deixar a criança agasalhada, não deixar relaxada na rua, agasalhar a criança, tá entendendo? Aí não acontece isso....”

Apesar das piores condições de moradia desse grupo, as sugestões da população encaminhavam para uma ação individual no cuidado com a criança, como se o adulto pudesse impedir a ação destrutiva do ambiente precário de moradia para evitar o adoecimento

O segundo aspecto mencionado como importante para a diminuição dos agravos, dizia respeito ao atendimento médico recebido e aos tratamentos utilizados.

- Atendimento médico, expectativa de melhoria

"Acho que melhor atendimento no posto."

- Expectativa de novos medicamentos :

"Eu, acho que tem, tem um tipo de remédio, deve ter, um ter um tipo de remédio, mais..., algum...tratamento assim...pra combater, assim, o cansaço que a gente tem, não tem.?.."

- Atendimento medico, experiência positiva :

“...dar inalação. Em casa mesmo. Eu aprendi no postinho mesmo, elas me ensinaram."

"Dou inalação em casa...Eu uso inalador e se eu vejo que não melhora aí eu corro para o HU." 
Houve relato de uma situação de atendimento na qual a avaliação da mâe não foi contemplada pelo profissional que avaliou a criança, levando-a a crer que as recomendações gerais orientadas não se aplicavam.

"Olha, geralmente eu costumo levá-la na USP mesmo. Eu costumo levá-la mas eles nunca passam remédio pra esse problema de garganta....eles examinaram assim, por cima, e falam Ah, é gripinha, a senhora dá um remédio caseiro e pronto.então eu já cheguei a levar essa menina com $40^{\circ} \mathrm{C}$ de febre pra USP e eles... e infecção brava mesmo. E eles passaram remedinho caseiro : chazinho, melzinho, essas coisas. Então...não resolveu nada."

Nos discursos em que esta questão esteve presente, pode-se perceber que quando a mãe avaliava que a criança estava grave, acreditava que deveria ser prescrito um antibiótico; desconsiderando as orientaçôes gerais para os processos virais e considerando que o profissional não está dando a devida importância ao episódio mórbido

“....eu não vou falar que o médico não tem capacidade, tem, eu sei que eles têm bastante...pacientes e, e...não é fácil pra eles. Mas só que a minha filha, eles ...eu senti que eles não tavam se importando muito, sabe, eles achavam que tinham muitos casos mais importantes que o dela."

Sem dúvida, trata-se de um problema relativo à comunicação no momento do atendimento e a insatisfação leva a mãe a procurar atendimento em outro serviço. (.oficinas..)

Com menor destaque, apareceram sugestões relativas ao controle da poluição, sendo lembrado mais uma vez o rodizio de veículos

"Acho que o governo deveria, sei lá, porque tem muitas fábricas por aqui que soltam muita poluição, acho que deveria tomar uma providência sobre isso."

"...e isso tem o problema também da poluição."

"Sabe por que? Aqui é muito poluído. Então, antes eles tavam fazendo aquele rodizio ali que eu acho que tava até melhorando" 
"Eu acho que no mais é a poluição, dá muitos problemas para as crianças. São Paulo anda muito poluido, eu acho que deveria ter alguma coisa para diminuir essa poluição."

A melhoria da moradia também foi lembrada, sem que tenham sido apontados para ações especificas. Vala lembrar que algumas moradias eram extremamente insalubres e, mesmo assim, os familiares apontaram poucas formas para superação disso

Numa entrevista foi mencionada a religião como alternativa para a cura definitiva das doenças 
$Q P_{\text {romoçãa à Saúde e o }}$ enfrentamento das $I_{n i q u ̈ i d a d e s}$ 


\section{A Promoção à Saúde e as iniqüidades: propostas para superação}

A abordagem do conceito de iniqüidade é mais complexa que o de desigualdade. Assim, é importante ressaltar que o planejamento de ações centradas no princípio da eqüidade deve ampliar os poderes dos individuos e grupos para atuar nos processos geradores da saúde-doença. $O$ conjunto das iniqüidades observadas no território estudado baseia-se na possibilidade dos diferentes grupos homogêneos controlarem as situações de risco.

O desafio da Promoção à Saúde, sobretudo nos paises em que as desigualdades sociais são mais expressivas, está centrado na transformação das relaçōes excludentes, através de estratégias de trabalho intersetorial que conciliem interesses para ampliar o desenvolvimento e a garantia do bem estar social, como condição indispensável para a melhor qualidade de vida.

Os campos de ação destacados para o encaminhamento dessa proposta de Promoção à Saúde, desde a Carta de Ottawa, implicam na elaboração de políticas públicas saudáveis, na criação de ambientes favoráveis à saúde, no reforço da ação comunitária, no desenvolvimento de habilidades pessoais e grupais, assim como na reorientação dos sistemas e serviços de saúde. Trata-se, portanto, de uma área de atuação pública com objeto de ação ampliado, principalmente para o setor saúde. Nessa perspectiva, a saúde deve ser entendida não como uma finalidade em si e sim como um meio para a garantia da qualidade de vida.

Segundo NWOKEDI (1998) não tem sido fácil a tarefa de promover eqüidade. Um elemento necessário, porém não suficiente, para contemplar essa tarefa está relacionado à obtenção de dados da realidade que devem revelar a magnitude do problema e as causas das disparidades encontradas. $\mathrm{O}$ autor analisa que ainda faltam medidas concretas para avaliar o impacto das ações voltadas para a promoção da eqüidade, bem como para mensurar as iniqüidades por classe, sexo e níveis de saúde por área geográfica. 
O presente estudo busca apresentar uma alternativa metodologica para identificação das iniqüidades no âmbito do nivel local de assistència à saúde, a partir de determinada área geográfica.

\subsection{A Identificação das iniqüidades}

As categorias empíricas delineadas evidenciam as condições objetivas de vida das familias residentes no território, a percepção dos familiares sobre a vivência do problema respiratório das crianças no cotidiano e as iniqüidades das condições de vida e saude

Recuperando-se os objetivos do presente estudo, pode-se considerar que os resultados da primeira etapa possibilitaram a localização geográfica de maior e menor concentração das carências relativas às condições de vida. Os métodos utilizados possibilitaram, ruma primeira instância, identificar os aspectos quantificáveis, permitindo a comparação entre os setores censitários constitutivos da área. Pôde-se, portanto, conhecer as desigualdades sociais no âmbito da micro área, identificando-se quatro grupos homogêneos com relação ao potencial de exposição às condições de risco para as doenças respiratórias das crianças menores de cinco anos de idade.

A segunda etapa, de cunho qualitativo, contribuiu para revelar o universo das percepções dos moradores da área, acerca da vivência de episódios de IRA nas crianças, possibilitando uma maior aproximação com as necessidades expressas relativas ao controle desses agravos. A percepção dos sujeitos foi obtida nas entrevistas domiciliares com os responsáveis pelas crianças, destacando-se principalmente as seguintes situações: morbidade respiratória na época em que foi desenvolvido o estudo, dificuldades observadas na vivência da doença, causas presumiveis dos problemas em pauta, assim como as possibilidades de enfrentamento dos referidos agravos. 
E importante mencionar que cada etapa não identifica isoladamente as iniqüidades em saúde, entendidas como as situações comumente vistas como inaceitáveis e passiveis de controle, cuja ocorrência acomete principalmente os grupos com inserção social menos favorecida. DAHLGREN e WHITEHEAD (1992) apresentam uma estrutura para análise dos determinantes dos diferenciais de saúde para identificar a presença dessas duas condições na qual destacam quatro aspectos que configuram as iniqüidades, quais sejam: os comportamentos prejudiciais decorrentes da escolha limitada por fatores socioeconômicos, a exposição excessiva aos riscos à saúde no ambiente físico e social, o acesso restrito à assistência essencial à saúde e o declinio social decorrente do adoecimento.

No presente estudo utilizou-se como estratégia para evidenciar as iniquidades a relação estabelecida entre os agrupamentos tematicos relativos às necessidades identificadas pelos diferentes grupos homogêneos e os agrupamentos temáticos dos encaminhamentos vislumbrados pelos mesmos grupos.

A análise baseou-se na identificação das contradições existentes entre o conjunto de necessidades apontadas pelos mesmos e os encaminhamentos vislumbrados, em relação à sua inserção social. Por outro lado, conforme será apresentado adiante, a superação das contradições apoia-se na possibilidade de estruturação de propostas de ação a partir da perspectiva de fortalecimento ou "empowerment", na dimensão individual e coletiva. Nessa perspectiva está implícito o conceito de autonomia dos sujeitos, enquanto possibilidade (poderes/habilidades) de superar as necessidades que se configuram no cotidiano

Segundo BERTOLOZZI (1998) "O sujeito particular constrói as suas representações acerca da realidade a partir de seu locus social e este, por sua vez, também define o conjunto de necessidades desse sujeito nessa determinada sociedade. Dessa forma, tanto as necessidades como as suas formas de satisfação variam segundo a inserção do indivíduo na sociedade". (p.43) 
Tal questão é central no campo da Promoção à Saúde, a partir da qual as ações devem visar o maior controle dos indivíduos, grupos ou comunidades sobre os processos ou condições que interferem negativamente sobre a saúde.

Outro conceito agregado para a identificação das iniqüidades, foi o de vulnerabilidade buscando apoiar a compreensão da inter-relação entre as necessidades e as possibilidades de superação.

A vulnerabilidade pode ser utilizada como um instrumental que associa a avaliação objetiva da exposição a determinado agravo e a análise das alternativas existentes para a proteção do mesmo (AYRES; FRANÇA JÚNIOR; CALAZANS 1997). O referido conceito teve origem na decada de 90 , no âmbito do direito, relativo a grupos ou indivíduos fragilizados juridica ou politicamente na promoção, proteção ou garantia dos seus direitos. Em 1992, teve início sua incorporação no campo da saúde, sobretudo na prevenção da AIDS, no contexto dos países do hemisfério Norte, expandindo-se recentemente para outras áreas da saúde, como nas reflexões de gênero em saúde reprodutiva (AYRES; FRANÇA JÚNIOR; CALAZANS 1997).

Além disso, o conceito de vulnerabilidade foi fundamental para explicar a trajetória da epidemia da AIDS, permitindo a superação da idéia inicial e segregatória da identificação de "grupos de risco", reorientando a questão para a população como um todo. A mudança se deu na superação do conceito de risco individual pelo de vulnerabilidade social, ou seja, no sentido de que os originariamente chamados "grupos de risco" foram capazes de assimilar estratégias de proteção, denotando um grande poder ou habilidade para enfrentar a situação de exposição. A expansão da epidemia para os grupos sociais inseridos mais precariamente na produção ou dela alijados materializou o processo de pauperização da epidemia, que teve início nos anos 90, explicitando a associação entre a falta de poder e a maior exposição ao problema. Assim, o conceito de "empowerment" também auxiliou para a construção do conceito de vulnerabilidade, traduzida pela noção de suscetibilidade e condições para enfrentar as condições adversas. 
Análogo ao conceito de "empowerment", o de vulnerabilidade também está centrado na identificação das fragilidades dos indivíduos ou grupos buscando a sua superação através de medidas que tenham impacto no plano individual, por meio do aprimoramento do seu comportamento em decorrência do maior poder ou habilidade para controlar as diferentes situações; sobre o plano programático, relativo à organização dos serviços de saúde responsáveis pela estruturação de ações voltadas para minimizar tais fragilidades; e sobre o plano social, ou seja, a estrutura social que determina as políticas de saúde e a organização social que determina os diferentes perfis epidemiológicos.

A partir desses conceitos foi estruturado um quadro para identificar as contradições existentes entre as necessidades e possíveis encaminhamentos, conforme segue:

\section{GRUPOS TEMÁTICOS}

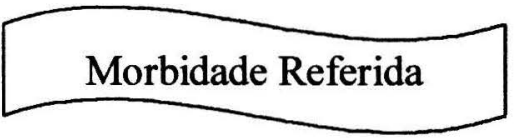

Reconhecimento dos problemas expressos na dimensão biológica.
Determinantes Percebidos

Quadro de referência dos sujeitos sobre causas atribuídas ao adoecimento.

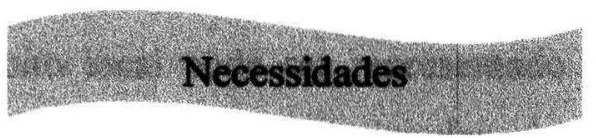

\begin{tabular}{|lr|}
\hline Interpretação da & vivência \\
dos sujeitos & para \\
identificação & das \\
dificuldades & $\mathrm{e}$ \\
possibilidades. & \\
\hline
\end{tabular}

\section{Encaminhamentos Possiveis}

\begin{tabular}{|lr|}
\hline Cenário para $\quad$ o \\
exercício das \\
habilidades ou poderes \\
para a superação das \\
necessidades.
\end{tabular}


As necessidades emergiram do reconhecimento dos problemas expressos na dimensão biológica, constituídos pelos agravos identificados como morbidade referida no grupo de crianças menores de cinco anos pelos membros das famílias entrevistadas, pela explicitação dos serviços de saúde procurados nos episódios doentios, bem como a interpretação das vivências dos sujeitos para a identificação das dificuldades e possibilidades percebidas como aspectos facilitadores apontados. Esta dimensão constituiu o conjunto de agravos e a forma como eles foram vividos pelas famílias dos diferentes grupos homogêneos.

Os encaminhamentos possiveis foram formulados a partir do quadro de referência dos sujeitos sobre as causas relacionadas ao adoecimento por IRA, bem como pelo cenário apontado para indicar as ações necessárias reveladoras das habilidades ou poderes para a superação das necessidades.

Para a discussão dos encaminhamentos propostos face ao referencial teórico que embasa o presente estudo, julgamos oportuno sistematizar o quadro das proposições para a diminuição dos agravos, utilizando as seguintes dimensões para interpretar o foco das ações propostas: estrutural, particular e singular.

Segundo EGRY (1996), essas dimensões auxiliam na identificação da interrelação das diferentes totalidades dos fenômenos permitindo a compreensão da relação dialética entre as partes e o todo. A dimensão estrutural engloba os aspectos macro-estruturais da sociedade, incluindo a base econômica e as instâncias jurídicopolítico e ideológicas. A dimensão particular refere-se aos processos de reprodução social, mais especificamente aos perfis epidemiológicos dos grupos homogêneos e ao acesso aos bens de consumo e serviços para a satisfação de suas necessidades que no âmbito local pode ser representado pelas organizações comunitárias e instituições públicas. A dimensão singular abarca os processos especificos relacionados aos indivíduos e suas famílias, inclusive os significados por eles atribuídos a tais processos. 
As dimensões acima mencionadas visam sistematizar os núcleos significativos apontados pelos entrevistados para o maior controle dos agravos respiratórios. Devem ser entendidas como partes do todo, não podendo ser consideradas isoladamente, ressaltando-se a interface existente entre as mesmas. Trata-se de uin recurso importante para analisar o foco que os grupos homogêneos elegem como prioritário no controle das doenças respiratórias, o que poderá subsidiar a formulação de ações de Promoção à Saúde,

Dando seguimento à análise e interpretação dos resultados obtidos e a partir do quadro anteriormente citado, pôde-se recuperar de forma sintética os agrupamentos temáticos que emergiram em cada grupo homogêneo, identificando as contradições existentes. Com isso. nos diferentes GHs pôde-se obter um panorama para a identificação das condições geradoras de vulnerabilidade, tomando-se esta como expressão das iniqüidades. 


\section{GRUPOS TEMÁTICOS - GH I}

\section{MORBIDADE REFERIDA}

\begin{tabular}{|l|l|}
\hline \multicolumn{1}{|c|}{ Morbidade } & \multicolumn{1}{c|}{ Serviços } \\
\hline Resfriado & Serviço conveniado (08) \\
Otite & Serviço público (06) \\
Chiado & \\
Amigdalite & \\
Rinite & \\
Sinusite & \\
Adenóide & \\
Gripe & \\
Nariz obstruído & \\
\hline
\end{tabular}

\section{NECESSIDADES}

\begin{tabular}{|c|c|}
\hline Dificuldades & Possibilidades \\
\hline $\begin{array}{l}\text { Administrar } \\
\text { medicamentos : } \\
\text { horário rígido de } \\
\text { algumas medicações } \\
\text { altera rotina da } \\
\text { criança; criança } \\
\text { resiste a tomar o } \\
\text { remédio. } \\
\text { Rotina da família : } \\
\text { pior quando a mãe } \\
\text { trabalha fora; mãe } \\
\text { trabalha preocupada } \\
\text { com a criança. } \\
\text { Financeira : comprar } \\
\text { remédio no final do } \\
\text { mês. }\end{array}$ & $\begin{array}{l}\text { Possibilidade de } \\
\text { controlar o processo } \\
\text { : mãe não trabalha } \\
\text { fora; mãe tem } \\
\text { experiência anterior } \\
\text { com a doença; sabe } \\
\text { reconhecer a doença } \\
\text { no início; pode } \\
\text { intervir no } \\
\text { domicílio; a família } \\
\text { é grande e tem com } \\
\text { quem dividir o } \\
\text { cuidado da criança; } \\
\text { costuma sair de São } \\
\text { Paulo nos finais de } \\
\text { semana para } \\
\text { melhorar o ambiente }\end{array}$ \\
\hline
\end{tabular}

\section{DETERMINANTES PERCEBIDOS}

\begin{tabular}{|l|}
\hline \multicolumn{1}{|c|}{ Causas atribuídas } \\
\hline Poluição \\
Clima / Estação \\
Ambiente doméstico : contato com \\
substâncias alérgenas, produtos de limpeza \\
Alimentação inadequada da criança (poucas \\
frutas e verduras); contato com outras \\
crianças
\end{tabular}

\section{ENCAMINHAMENTOS POSSÍVEIS}

Proposta para diminuição dos agravos

Diminuir a poluição : restringir a circulação,

Principalmente dos caminhões;

Incentivar/fiscalizar a regulagem dos

veículos. (estrutural)

Cuidado direto com a criança: evitar friagem, gelado; alimentação correta; não levar à escola quando doente.(singular)

Campanhas de conscientização: ampliar áreas verdes para crianças

brincarem.(estrutural/particular)

Ampliar o acesso à vacinação extra-oficial da população que tem convênio de

saúde.(particular)

Desenvolver produtos de limpeza menos

tóxicos e específicos para

ácaros.(particular/estrutural) 


\section{GRUPOS TEMÁTICOS - GH II}

\section{MORBIDADE REFERIDA}

\begin{tabular}{|l|l|}
\hline \multicolumn{1}{|c|}{ Morbidade } & \multicolumn{1}{c|}{ Serviços } \\
\hline Amigdalite & Serviço conveniado (05) \\
Bronquite & Serviço público (03) \\
Resfriado & \\
Otite & \\
Gripe & \\
Bronquiolite & \\
Rinite & \\
Chiado & \\
\hline
\end{tabular}

\section{NECESSIDADES}

\begin{tabular}{|c|c|}
\hline ades & Possibilidades \\
\hline $\begin{array}{l}\text { Rotina da família : } \\
\text { mãe tem que faltar } \\
\text { ao trabalho para } \\
\text { controlar o } \\
\text { problema. } \\
\text { Rotina da criança : } \\
\text { alteração do sono e } \\
\text { apetite por diversos } \\
\text { dias exigindo maior } \\
\text { cuidado por parte } \\
\text { dos adultos. } \\
\text { Falta de confiança } \\
\text { na creche. } \\
\text { Preocupação com } \\
\text { gravidade/evolução. } \\
\text { Financeira : para } \\
\text { locomoção ao } \\
\text { Pronto Socorro e } \\
\text { para cempғa de } \\
\text { inalador. }\end{array}$ & $\begin{array}{l}\text { Ter quem leve à } \\
\text { consulta; poder } \\
\text { marcar a consulta } \\
\text { médica por telefone; } \\
\text { conhecer os riscos; } \\
\text { seguir as } \\
\text { orientações; ter } \\
\text { quem ajude no } \\
\text { cuidado; ter onde } \\
\text { buscar } \\
\text { medicamentos que } \\
\text { porventura não } \\
\text { encontre na } \\
\text { farmácia; } \\
\text { flexibilidade no } \\
\text { trabalho da mãe : } \\
\text { possibilidade de } \\
\text { faltar ao trabalho } \\
\text { Quando a filha } \\
\text { adoece e compensar } \\
\text { em outro momento. }\end{array}$ \\
\hline
\end{tabular}

\section{DETERMINANTES PERCEBIDOS}

\begin{tabular}{|l|}
\hline \multicolumn{1}{|c|}{ Causas atribuídas } \\
\hline Clima instável \\
Contato com outras crianças \\
Poluição \\
Falta de experiência da mãe \\
Ambiente doméstico: umidade \\
Imaturidade imunológica da criança \\
Assistência ao parto inadequada: má \\
assistência no berçário por ocasião do \\
nascimento da criança.
\end{tabular}

\section{ENCAMINHAMENTOS POSSIVEIS}

\section{Proposta para diminuição dos agravos}

Diminuir a poluição : já existe fiscalização, há que aumentar a "conscientização"; acabar com a rodovia Raposo; diminuir os caminhões. (estrutural)

Cuidado com a criança : além de proteger da friagem, dar mais líquidos e xarope.(singular) Moradia : morar num lugar bom; limpar a casa; arejar o ambiente.(singular)

Desenvolvimento tecnológico: vacina contra a gripe.(estrutural)

Assistência à saúde : procurar atendimento onde os profissionais sejam mais preparados. (particular) 


\section{GRUPOS TEMÁTICOS - GH III}

\section{MORBIDADE REFERIDA}

\begin{tabular}{|l|l|}
\hline \multicolumn{1}{|c|}{ Morbidade } & \multicolumn{1}{|c|}{ Serviços } \\
\hline Resfriado & Serviço conveniado (10) \\
Amigdalite & Serviço público (09) \\
Gripe & \\
Bronquite & \\
Otite & \\
Chiado & \\
Tosse & \\
Nariz obstruído & \\
Pneumonia & \\
Laringite & \\
\hline
\end{tabular}

\section{NECESSIDADES}

\begin{tabular}{|c|c|}
\hline Dificuldades & Possibilidades \\
\hline $\begin{array}{l}\text { Dificuldades para } \\
\text { administrar a } \\
\text { medicação : criança não } \\
\text { aceita bem; seguir } \\
\text { horários rígidos; fazer } \\
\text { inalação. } \\
\text { Financeira : comprar o } \\
\text { remédio. } \\
\text { Rotina da família : } \\
\text { alteração do sono; falta } \\
\text { de compreensão por } \\
\text { parte do pai; dificuldade } \\
\text { para marcar consulta ou } \\
\text { exames; ter que faltar } \\
\text { ao trabalho para marcar } \\
\text { exames ou para levar a } \\
\text { criança ao médico; mãe } \\
\text { ter que parar de } \\
\text { trabalhar. } \\
\text { Preocupação com a } \\
\text { gravidade : medo de ter } \\
\text { pneumonia; dificuldade } \\
\text { para respirar devido à } \\
\text { grande quantidade de } \\
\text { secrecão }\end{array}$ & $\begin{array}{l}\text { Iniciar o } \\
\text { tratamento no } \\
\text { início evitando } \\
\text { que se agrave; } \\
\text { quando a mãe já } \\
\text { sabe o que deve } \\
\text { fazer; quando a } \\
\text { criança aceita } \\
\text { bem o remédio. }\end{array}$ \\
\hline
\end{tabular}

\section{DETERMINANTES PERCEBIDOS}

\begin{tabular}{|l|}
\hline \multicolumn{1}{|c|}{ Causas atribuídas } \\
\hline Clima instável \\
Poluição \\
Ambiente doméstico / Creches: exposição à \\
friagem, poeira, má ventilação, contato com \\
pais fumantes. \\
Assistência ao parto: "criança passou da hora \\
de nascer". \\
Características individuais : hereditariedade; \\
maior suscetibilidade em decorrência de \\
doença crônica; "crianças nervosas". \\
\hline
\end{tabular}

\section{ENCAMINHAMENTOS POSSÍVEIS}

\section{Proposta para diminuição dos agravos}

Cuidado com a criança : agasalhar; mãe deve cuidar melhor; não deixar "mexer" com água; prover alimentação adequada; xarope caseiro e mel no início do problema.(singular)

Controle da poluição: rodízio dos carros melhora.(estrutural)

Moradia : lugar deveria ser mais arborizado.(particular)

Assistência médica : seguir as prescrições; fazer acompanhamento com bom pediatra; poder resolver por telefone; mãe poder reconhecer o problema e poder intervir no início. Aleitamento materno como fator protetor.(particular/singular) 
GRUPOS TEMÁTICOS - GH IV

MORBIDADE REFERIDA

\begin{tabular}{|l|l|}
\hline \multicolumn{1}{|c|}{ Morbidade } & \multicolumn{1}{|c|}{ Serviços } \\
\hline Resfriado & \\
Gripe & Serviço público (20) \\
Chiado & Serviço conveniado (01) \\
Otite & \\
Bronquite & \\
Tosse & \\
Pneumonia & \\
Sinusite & \\
Amigdalite & \\
Rinite & \\
Nariz obstruído & \\
\hline
\end{tabular}

\section{NECESSIDADES}

\begin{tabular}{|l|l|}
\hline \multicolumn{1}{|c|}{ Dificuldades } & \multicolumn{1}{c|}{ Possibilidades } \\
\hline Rotina da família : mãe & $\begin{array}{l}\text { Poder praticar as } \\
\text { orientações } \\
\text { tem que faltar no } \\
\text { trabalho ou parar de } \\
\text { trabalhar; não tem com } \\
\text { recebidas no } \\
\text { serviço de saúde. } \\
\text { filhos para procurar } \\
\text { assistência médica. } \\
\text { Financeira : falta de } \\
\text { dinheiro para comprar } \\
\text { mel; falta de dinheiro } \\
\text { para locomoção ao } \\
\text { serviço de saúde; não } \\
\text { consegue fazer } \\
\text { acompanhamento de } \\
\text { saúde, procurando só } \\
\text { quando a criança está } \\
\text { doente; falta de dinheiro } \\
\text { para comprar remédio. } \\
\text { Atendimento médico: } \\
\text { demorado, ineficiente }\end{array}$ \\
\hline
\end{tabular}

\section{DETERMINANTES PERCEBIDOS}

\begin{tabular}{|l|}
\hline \multicolumn{1}{|c|}{ Causas atribuídas } \\
\hline Clima instável \\
Poluição \\
Ambiente deteriorado: presença de lixo; \\
cheiro de esgoto. \\
Ambiente doméstico: presença de umidade; \\
falta de isolamento térmico; inundação; falta \\
de ventilação. \\
Cuidado com a criança: criança desobediente; \\
agasalho e calçados inadequados; ingestão de \\
gelado; falta de higiene com a criança. \\
Exposição à friagem. \\
\hline
\end{tabular}

\section{ENCAMINHAMENTOS POSSÍVEIS}


É necessário esclarecer que as propostas foram agrupadas segundo a magnitude de freqüência com que apareceram nos diferentes grupos.

Como pode ser verificado a melhor inserção social e a melhor da qualidade dos domicilios. encontrada nas famílias do GH I, determinam um maior grau de controle das pessoas sobre as condições favorecedoras do adoecimento. Esse maior grau de controle se expressa na maior possibilidade de cuidar das crianças, quando doentes. $O$ fato da mãe não trabalhar fora de casa. a experiência anterior com outros problemas de saúde. a possibilidade de identificar o agravo no inicio e intervir no próprio domicílio: assim como o fato de ter com quem dividir a responsabilidade do cuidado da criança ao lado da possibilidade de deixar a cidade nos finais de semana. são exemplos de alternativas que justificavam às dificuldades no cotidiano. As mudanças sugeridas para a diminuição dos agravos. também apareceram como desdobramentos das causas apontadas. Neste âmbito, foram interessantes as sugestões dirigidas à ampliação dos direitos do consumidor, ou ao indicarem a cobertura de vacinação específica pelos planos de saúde e o desenvolvimento de produtos menos tóxicos ou específicos para o combate ao ácaro. As propostas formuladas destacaram sobretudo ações no âmbito das dimensões estrutural e particular para a diminuição dos problemas respiratórios.

A possibilidade de melhor controlar o adoecimento também foi apontada no GH II. A doença em si, não se evidencia como problema, quando há com quem dividir as ações necessárias que envolvem a consulta, o tratamento e os cuidados. Além disso, a flexibilização do trabalho da mãe também foi apontada como fator facilitador. por permitir um maior controle sobre a situação. Entre as mudanças sugeridas para a diminuição dos agravos respiratórios, destacaram-se o uso da vacina contra a gripe, que foi agrupada segundo o tema do desenvolvimento tecnológico. de cunho estrutural, além das ações para fortalecer o controle da poluição no nível local, de âmbito particular. Foram ainda apontadas ações dirigidas às causas presumíveis. destacando-se aquelas que projetam a possibilidade de escolha do serviço de saúde. quando não há confiança na capacitação técnica dos profissionais. Também nestı grupo. destacaram-se propostas centradas na dimensão singular. 
No GH III, puderam ser observados comprometimentos mais importantes na rotina da família devido ao adoecimento, destacando-se o prejuízo no trabalho da mãe, seja pela necessidade de faltar ou até ao extremo do desligamento do trabalho para garantir o cuidado da criança. Este foi um aspecto importante que revela a vulnerabilidade do grupo, o qual, alem disso mostra uma situação regular ou ruim em termos de escolaridade e renda e ademais com maior risco de abandonar o trabalho Segundo os componentes deste grupo, a creche aparece como um fator relacionado ao conjunto de causas dos agravos. Contribui também para este cenário, a fragilidade das instituições que prestam cuidados às crianças, por não atenderem as necessidades em todos os momentos. Os elementos apontados como facilitadores recuperam a informação e o conhecimento do adulto (mãe) no sentido de tomar as providências necessárias no inicio do processo de adoecimento, evitando que se agrave. Neste grupo, chama ainda a atenção o fato de que ao sugerirem as modificações para encaminhar o problema, as prioridades não coincidem com as causas apontadas. Apesar de mencionarem problemas relativos ao clima e à poluição como maiores responsáveis pelo adoecimento, destacaram o cuidado com a criança como a principal ação para a diminuição desses agravos. O discurso revelou, ainda, um elevado grau de adesão às orientações normalmente veiculadas nos serviços de saúde, sobretudo da rede pública, apontadas como outras alternativas para o controle dos agravos.

Parece que a preocupação em seguir as orientações e cuidados recomendados assume importância no cotidiano, que coloca em segundo plano a própria percepção do ambiente em que vivem. Isso possivelmente decorre da forma como a assistência tem sido estruturada, na medida em que não leva em conta as condições de vida dos clientes no momento do atendimento à saúde. Como afirmou JACOBI (1990), os profissionais de saúde sabem da importância das condições de vida e do ambiente na incidência das doenças e a população também associa o adoecimento às condições ambientais. Porém, no momento do atendimento, o foco é a alteração biológica e o cenário em que se vive é desconsiderado. A ênfase passa a ser o cuidado padronizado sem que as causas principais sejam mencionadas. Talvez isso contribua para compreender o motivo pelo qual os grupos mais desprivilegiados tendem a assumir 
para si a dificil tarefa de evitar que as crianças adoeçam, concentrando portanto, as proposições na dimensão singular.

Com relação aos agrupamentos temáticos do GH IV, houve a intensificação dos aspectos relativos às dificuldades na rotina da família, ao trabalho materno e à dificuldade financeira que restringiam a possibilidade de exercer controle sobre as necessidades identificadas. A vivência da doença assumiu um contorno de maior comprometimento do cotidiano e a instabilidade econômica que permeia a vida dificultando, até mesmo, a adesão aos programas de controle periódico de saúde das crianças, reconhecidos como necessários pela população. A autonomia deste grupo encontrava-se muito mais comprometida, por ser um grupo de maior vulnerabilidade. As contradições entre as causas presumíveis e as superações apontadas, também contribuiram para conformar este cenário, onde as possibilidades de encaminhamento centraram-se nas ações da própria família, denotando um menor grau de engajamento para ações coletivas para a superação do problema.

Além disso, é importante destacar que os grupos III e IV evidenciaram problemas relativos à maior exposição aos riscos na saúde em decorrência da deterioração ambiental sendo que os integrantes do grupo IV relataram, também problemas econômicos que restringem o acesso à assistência à saúde.

Conforme foi verificado anteriormente, o panorama das iniqüidades no âmbito local foi construido a partir da maior concentração de mortes por pneumonia nos grupos III e IV (apresentadas no mapa 6) e pelo maior comprometimento do cotidiano das famílias desses grupos, em decorrência do adoecimento das crianças. Dado que são agravos freqüentes, ressalta-se a importância de se focalizar intervenções que minimizem os problemas mencionados.

Os resultados encontrados reiteram a importância de se estruturar um sistema de informações para delimitar as condições sociais geradoras dos problemas de saúde e de monitorá-las a partir da implantação de ações específicas. Evidenciou-se, 
também, a importância de se revelar a percepção dos sujeitos para atender às suas necessidades.

Retomando-se o exposto no capitulo referente à Metodologia acerca do conceito de necessidades como fenômenos intrínsecos aos individuos, porém estabelecidos na relação destes com a sociedade, visualiza-se que a organização familiar assumiu neste estudo um papel relevante. Sem aprofundar a discussão acerca da historicidade da familia, vale recuperar alguns aspectos relativos à constituição familiar relacionados ao cuidado da criança.

\subsection{A determinação das iniqüidades}

Vale retomar o processo histórico de constituição do padrão de família que se encontra atualmente para buscar compreender as origens desses problemas. Segundo BADINTER (1985) data do final do século XVIII a preocupação de que a família assumisse o cuidado da criança desde o seu nascimento. Até então, era prática comum na Europa entregar a criança, logo após o seu nascimento, aos cuidados de outras pessoas ou famílias, onde viveriam até por volta dos 7 anos de idade, sem que fosse estabelecido qualquer contato entre os familiares e a criança durante este período. Através de análise documental em obras literárias, filosóficas e teológicas dos séculos XVII, XVII e XIX, a autora relata

"No século XVII, a sociedade monarquista ainda não reconheceu o reinado do Menino-Rei, centro do universo familiar(....)Foi Rousseau, com a publicação de Émile, em 1762, que cristalizou as novas idéias e deu um verdadeiro impulso inicial à família moderna, isto é, a familia fundada no amor materno(....)A acreditar não só na literatura, na filosofia e na teologia da época, mas também nas práticas educativas e nas estatísticas de que hoje dispomos, constatamos que, na realidade, a criança tem pouca importância na familia, constituindo muitas vezes para ela um verdadeiro transtorno" (BADINTER, 1985, p. 54) 
A importância do cuidado com a criança, semelhante ao modelo de família que encontramos nos dias de hoje, foi resultado de muitos investimentos centrados basicamente em três discursos. O discurso econômico, voltado para as autoridades representativas do poder estatal, baseado em pesquisas demográficas que registravam altíssimos índices de mortalidade infantil. Esse valorizava o cuidado dos futuros cidadãos e a necessidade de melhor cuidar da criança, na medida em que esta passava a adquirir um valor mercantil. O discurso denominado dos intermediários, médicos, filantropos, pedagogos, administradores, voltado às mulheres, enaltecia a sua tarefa de zelar pelo bem social, incentivando a amamentação pela própria mãe e os cuidados na infância. Por último, o discurso moralizador que tratava da educação feminina para atender às novas exigências do papel de esposa e mãe (BADINTER, 1985)

REZENDE (1998), em seu trabalho de investigação acerca da prática da amamentação em um grupo de trabalhadoras da Escola de Enfermagem da Universidade de São Paulo, questiona a necessidade de que o adulto cuidador do bebê seja a mãe, indicando a possibilidade da criação de vínculos afetivos com o pai ou outro adulto que se disponibilize a construir essa relação. A autora destaca também a omissão no cumprimento da legislação que obriga as empresas públicas e privadas a manterem berçários nos locais de trabalho para possibilitar o aleitamento. A enorme dificuldade em fazer valer os direitos relativos à mãe trabalhadora podem ser evidenciados no levantamento realizado pelo Conselho Estadual da Condição Feminina em 1984, segundo o qual havia somente 38 berçários em locais de trabalho no Estado de São Paulo, quando a estimativa para atender às necessidades seria de aproximadamente 60.000 berçários

A discussão desse problema requer a revisão da estrutura de atendimento oferecido pelas creches, na região do estudo. No trabalho coordenado por SPOSATI (1996), o distrito do Butantã contava com um déficit de 1574 vagas em creches e o distrito do Rio Pequeno tinha um déficit de 5198 vagas em 1991, evidenciando a necessidade de ampliação desse serviço para contemplar minimamente o aspecto quantitativo relativo à demanda reprimida. 
Outro aspecto diz respeito à necessidade de se inovar a estrutura das creches, pois existe hoje uma situação complexa acerca do cuidado da criança. Apesar da necessidade desse tipo de atendimento, em alguns grupos (III e IV) a creche é apontada como local que propicia o adoecimento, deixando portanto, de ser valorizada pela população que dela necessita. Como foi apontado no capítulo introdutório, vários estudos destacam o fator prejudicial referente à permanência da criança em ambientes coletivos para o desenvolvimento de doenças respiratórias de origem infecciosa (AMARAL et al. 1997; FONSECA et al. 1997)

A discussão, no entanto, deve focalizar a superação dos aspectos prejudiciais da estrutura atual, na perspectiva de chegar a outras alternativas nas quais a responsabilidade pelo cuidado da criança não recaia exclusivamente sobre a família Tais questões deveriam ser objeto de estudos para formular alternativas locais, com custo racional, as quais poderiam contar com o apnio de organizações não governamentais e com trabalhadores residentes na própria área. Um aspecto importante a ser mencionado referente à capacidade do serviço na medida em que grandes concentrações de crianças são prejudiciais

Outro aspecto extremamente importante é que chamavam atenção, nos grupos III e IV, as dificuldades relativas à interrupção ou permanência da mãe no trabalho Mas, problema observado na região do Butantã reflete o que se encontra no cenário maior da realidade brasileira. Segundo BRUSCHINI (1996), apesar do mundo moderno apresentar diversas transformações, sobretudo no âmbito do trabalho, ainda cabem às mulheres as atividades reprodutivas e as ligadas ao ambiente doméstico, como se esses aspectos fossem inerentes à condição feminina. A necessidade de conciliar papéis profissionais e familiares interfere na disponibilidade das mulheres no ingresso e permanência no processo de produção

\footnotetext{
"Se a família for tão pobre que os rendimentos obtidos pela trabalhadora são vitais para a sobrevivência do grupo, será acionado qualquer arranjo improvisado para o cuidado das crianças, como a rede de parentesco, a
} 
vizinhança ou os filhos um pouco mais velhos. Por outro lado, a situação sócioeconòmica mais favorável da família, assim como a escolaridade mais elevada da trabalhadora, propiciam a obtenção de trabalhos mais rentáveis e gratificantes, que compensam a saida do lar e o pagamento de apoio doméstico substituto" (BRUSCHINI, 1996, p. 88)

Em última instância o que ocorre é que a sociedade não assume a tarefa da reprodução social, sobretudo o cuidado da criança, que se torna um problema circunscrito à família e, dentro desta, cabe à mãe assumir as situações de conflito, mesmo que isto represente para a mulher a necessidade de abdicar de um projeto autònomo.

Essa situação acaba por influenciar as oportunidades de trabalho para as mulheres, traduzindo-se em barreiras ao acesso e às promoções além de desigualdades salariais em relação aos homens. Isso também compromete em última instância, a autonomia das mulheres no que diz respeito ao seu projeto profissional.

Segundo CAPPELIN (1996), a inserção e a permanência das mulheres no mercado de trabalho criam diferentes exigências, necessidades, interesses e expectativas que acabam por condicionar a sua disponibilidade. Isto, em função do conjunto de atividades diversas desempenhadas pelas mulheres na realização de serviços e práticas vinculadas à reprodução social no âmbito da família. O cotidiano de homens e mulheres é marcado por diferentes desafios, preocupações e responsabilidades decorrentes dessa demanda que, para as mulheres, configura-se como sobrecarga. A autora relata a importância do desenvolvimento das ações afirmativas, operacionalizadas em projetos que atuem no controle e proibindo as discriminações no acesso ao trabalho, no aprimoramento profissional, na remuneração, projetos esses que evidenciem as medidas que resultam no afastamento definitivo ou temporário do trabalho ou, ainda, nos pedidos de transferências, permitindo tais discriminações. Algumas dessas ações têm sido implementadas em muitos paises com a finalidade de corrigir as iniquidades no campo do trabalho feminino 
Com relação à reestruturação dos serviços de saúde, esta não é uma discussão recente nem tampouco esgotada. Desde a criação do SUS está colocado o desafio de se rever a atençãc à saúde e, sem dúvida, muitos avanços já ocorreram resguardando as suas diretrizes e principios. A descentralização gerencial e administrativa talvez seja um dos aspectos que mais contribuiu para as modificações observadas. O que se propõe aqui é a necessidade de se repensar os serviços oferecidos no que se refere às priorização e adequação das ações para resultar em maior impacto sobre dada realidade

Tal proposição está respaldada na forma como os serviços de saúde apareceram na opinião dos entrevistados. Foi interessante observar que os grupos III e IV reportavam-se a estes na tematica das dificuldades, destacando-se a marcação de consultas e exames complementares, a demora no atendimento e a insatisfação em decorrència de comunicação pouco efetiva entre usuários e serviços de saúde. Os grupos II e III mencionaram os serviços de saúde como causadores de agravos ao relatarem situações de má assistência ao parto e presença de profissionais despreparados para realizar os atendimentos. Os quatro grupos também mencionaram aspectos relativos à estruturação dos serviços de saúde na proposição de modificações para a diminuição dos problemas. No GH III foram encontrados a ampliação da oferta de vacinas especificas para as IRA, facilitando o acesso ao setor público ou conveniado, a necessidade de melhorar a formação ou capacitação dos profissionais que atuam na área e a importância das orientações para o reconhecimento dos problemas, além da intervenção no início do processo de adoecimento

BERTOLOZZI (1998) ao analisar os aspectos significativos da adesão de pacientes ao Programa de Controle da Tuberculose na região do Butantã, destaca entre outros, que o sucesso do tratamento está principalmente relacionado à organização dos serviços de saúde no que se refere ao acesso e atendimento às demandas dos doentes, ao lado da a assistência prestada e do respaldo oferecido nos âmbitos da família e do trabalho, para o desenvolvimento do tratamento. 
No tocante à assistência destaca-se a importância de se atender o conjunto das necessidades dos sujeitos, as quais extrapolam a suposta normalidade biológica mas incorporam os problemas centrados no cotidiano, na esfera da vida e do trabalho. Recuperando-se este aspecto mencionado no conjunto das iniqüidades, relativas às informações e orientações recebidas nos serviços de saúde, destaca-se o componente comunicativo da prática para identificar as possibilidades de superação.

Possivelmente a comunicação se constitui de fato, o foco principal para operar as mudanças necessárias no âmbito do atendimento à saúde.

FREIRE (1988), ao analisar as características do trabalho de agrônomos junto a camponeses com a finalidade de ensinar-lhes novas técnicas agricolas, discute as limitações do termo extensão, utilizado para denominar tais atividades, propondo que se utilize o conceito de comunicação enquanto abordagem mais adequada na perspectiva de uma verdadeira relação de intercâmbio entre o trabalhador com formação técnica e o trabalhador com formação profissional construída empiricamente

Se por um lado o conceito de extensão implica na transmissão de um conteúdo pré-determinado a alguém que não detém tal domínio, o processo comunicativo só pode acontecer a partir de uma relação de reciprocidade entre os sujeitos que dele participam. Nas palavras do próprio autor:

"Comunicar é comunicar-se em torno do significado significante (...). É então indispensável ao ato comunicativo, para que este seja eficiente, o acordo entre os sujeitos, reciprocamente comunicantes. Isto é, a expressão verbal de um dos sujeitos tem que ser percebida dentro de um quadro significativo comum ao outro sujeito" (FREIRE, 1988, p. 67).

$\mathrm{Na}$ estratégia de controle das doenças prevalentes da infância (AIDPI), podese observar a preocupação com o componente educativo através da incorporação nos 
processos de capacitação de recursos humanos, de conteúdos sobre habilidades de comunicação interpessoal.

Este aspecto centrado na comunicaçãc tem inclusive fomentado o desenvolvimento de estudos etnográficos, sobretudo nos paises da América Latina que contam com diferentes dialetos regionais e culturais, visando a maior aproximação do técnico à clientela para que o atendimento possa se configurar num momento comunicativo, onde haja efetivamente o diálogo entre ambos (CHARALY, 1998).

Nesse sentido, verificou-se no presente estudo que as práticas mencionadas pelos entrevistados, em geral, são compativeis com aquelas preconizadas por técnicos, que incluem: aumento da oferta de liquidos, de xaropes caseiros com mel para amenizar a irritação na garganta bem como o uso de vaporização. Porém, alguns relatos, indicam a necessidade de se realizar outros estudos centrados especificamente na questão das práticas, principalmente buscando o aprimoramento do conhecimento da exposição à friagem. Pode-se perceber uma hipervalorização deste risco ambiental, sendo que inclusive alguns entrevistados relataram, até mesmo, que evitam banhar as crianças para protegê-las da friagem.

WESTPHAL (1982), ao analisar a percepção de mães de crianças com crises asmáticas, também encontrou muitas referências à exposição à friagem com explicações incorretas e centradas nas categorias seco/úmido e quente/frio. A autora comenta os aspectos negativos da incorporação desses conceitos, levando a restrições infundadas no dia a dia das crianças que podem prejudicam o desenvolvimento psicomotor além da própria socialização da criança.

Os sinais de gravidade apontados pelos entrevistados nos quatro grupos homogêneos centraram-se principalmente na febre, chiado, tosse e respiração dificil Este aspecto, também, merece mais cuidado nas orientações prestadas pelos serviços, no sentido de relativizar a febre e tosse pois estas são respostas benéficas do organismo e não necessitam sofrer intervenções imediatas. Vale também, difundir os 
parâmetros mais objetivos para a avaliação da respiração dificil, valorizando a frequêencia respiratória aumentada ou a presença de ruidos, sendo este um marcador importante na classificação da gravidade da doença respiratória infantil, segundo a Organização Mundial da Saúde.

Ainda é interessante destacar que, tanto os cuidados domiciliares praticados pelos adultos antes de procurarem a consulta médica, como os sinais de gravidade apresentaram-se de forma muito semelhante entre os diferentes grupos.

Apesar dos esforços mencionados, em relação à melhora do componente comunicativo na assistência à saúde, avaliação recente sobre a implementação da estratégia AIDPI em alguns paises da América Latina, evidenciou o pequeno avanço no sentido de reverter a deficiência dos profissionais nas habilidades comunicativas As possiveis causas levantadas para explicar a situação encontrada foram a falta de motivação do trabalhador em saúde para realizar esta interação, bem como a própria ênfase dos serviços, os quais muitas vezes avaliam os trabalhadores muito sob a perspectiva da produção do que pela qualidade da assistência prestada (OPAS, 1998).

Talvez uma questão tenha sido negligenciada na análise acima, por reduzir a comunicação desejada a algumas técnicas ou habilidades a serem incorporadas pelos profissionais. Mais do que isso é necessário corresponder à dimensão dialógica proposta por FREIRE (1988), para a qual seria necessário o desencadeamento de uma discussão mais aprofundada sobre as dificuldades na interação do profissional e clientela, sobretudo acerca das causas estruturais geradoras dos agravos e das diferenças culturais encontradas no cotidiano da prática, para não se criar a expectativa de que se tratam de barreiras superáveis apenas através de recursos técnicos isolados. As orientações devem ser estruturadas enfatizando-se conceitoschave e evitando-se centralizar as discussões sobre condutas corretas ou incorretas Emergindo os conceitos-chave é possivel estabelecer a troca de conhecimentos, garantindo-se uma relação de respeito mútuo no atendimento. Nessa perspectiva, esse enfoque seria ampliado para não se utilizar a comunicação para operacionalizar a subordinação ou o condicionamento. 
Conforme foi verificado o panorama das iniqüidades na região estudada se conformou a partir das fragilidades expressas pelas famílias no cotidiano, revelando que os grupos mais expostos às condições de risco para as IRA, concentravam as proposições de mudanças sobretudo na dimensão singular o que revela a dificuldade para a superação das iniqüidades.

\subsection{Encaminhamentos para a superação das iniqüidades}

O Brasil é um pais com grandes desigualdades sociais decorrentes do modelo econômico excludente. Segundo WESTPHAL (1998), nos últimos quatro anos, além do controle da inflação, nenhuma outra medida efetiva tem sido comprovada para diminuir as iniqüidades sociais. Neste cenário a Promoção à Saúde, a exemplo de outros países que também albergam problemas estruturais semelhantes, tem à frente o desafio de transformar as relações sociais excludentes

No contexto brasileiro o campo da Promoção à Saúde é recente, ainda em expansão, porém com enorme potencial, dadas as demandas emergentes na década de 90 decorrentes da descentralização preconizada pelo SUS na Constituição de 1988, que favoreceram o desenvolvimento de um movimento municipalista da Saúde e o fortalecimento da participação popular e o controle social da população nas questões de saúde (WESTPHAL, 1998)

O Ministério da Saúde recentemente inseriu a Promoção à Saúde na Secretaria de Politicas Públicas entendendo-se que, além da sua institucionalização no âmbito ministerial, há que investir em formação de profissionais para lidar com esse objeto ampliado, para aprimorar os instrumentos de reconhecimento da realidade local e buscar a aproximação intersetorial. Também destaca-se a necessidade do desenvolvimento de processos educativos emancipatórios os quais constituir-se-ão como ações prioritárias do campo da Promoção à Saúde para lidar com as iniqüidades evidenciadas. 
A análise do conjunto das necessidades e encaminhamentos apontados pelos quatro grupos homogêneos, à luz da vulnerabilidade, como categoria que alia a realidade objetiva e a capacidade de enfrentamento dos problemas observados, destaca a necessidade de estruturar ações fundanientadas no conceito de "empowerment", privilegiando-se para tal os grupos III e IV, através do envolvimento de entidades e instituições atuantes nos territórios. A perspectiva que ora se coloca, baseia-se no conceito de "empowerment" comunitário proposto por ROBERTSON e MINKLER (1994), que reconhecem na comunidade, ou espaço local, a existência de um nivel intermediário entre a dimensão estrutural e a dimensão singular, que estabelece a mediação entre ambos, configurando o espaço da reprodução social constituido pelas igrejas, organizações comunitárias, escolas e outras instituições locais. WALLESRTEIN e BERNSTEIN (1994) também destacam a importância dessa dimensão na prática em saúde que possibilita um processo de ação social em que indivíduos e grupos atuam para ampliar o domínio sobre suas vidas no contexto das mudanças no seu ambiente politico e social.

Neste sentido, o mapa apresentado a seguir, contém algumas das instituições importantes que podem apoiar a discussão das ações necessárias para a superação das iniqüidades encontradas 


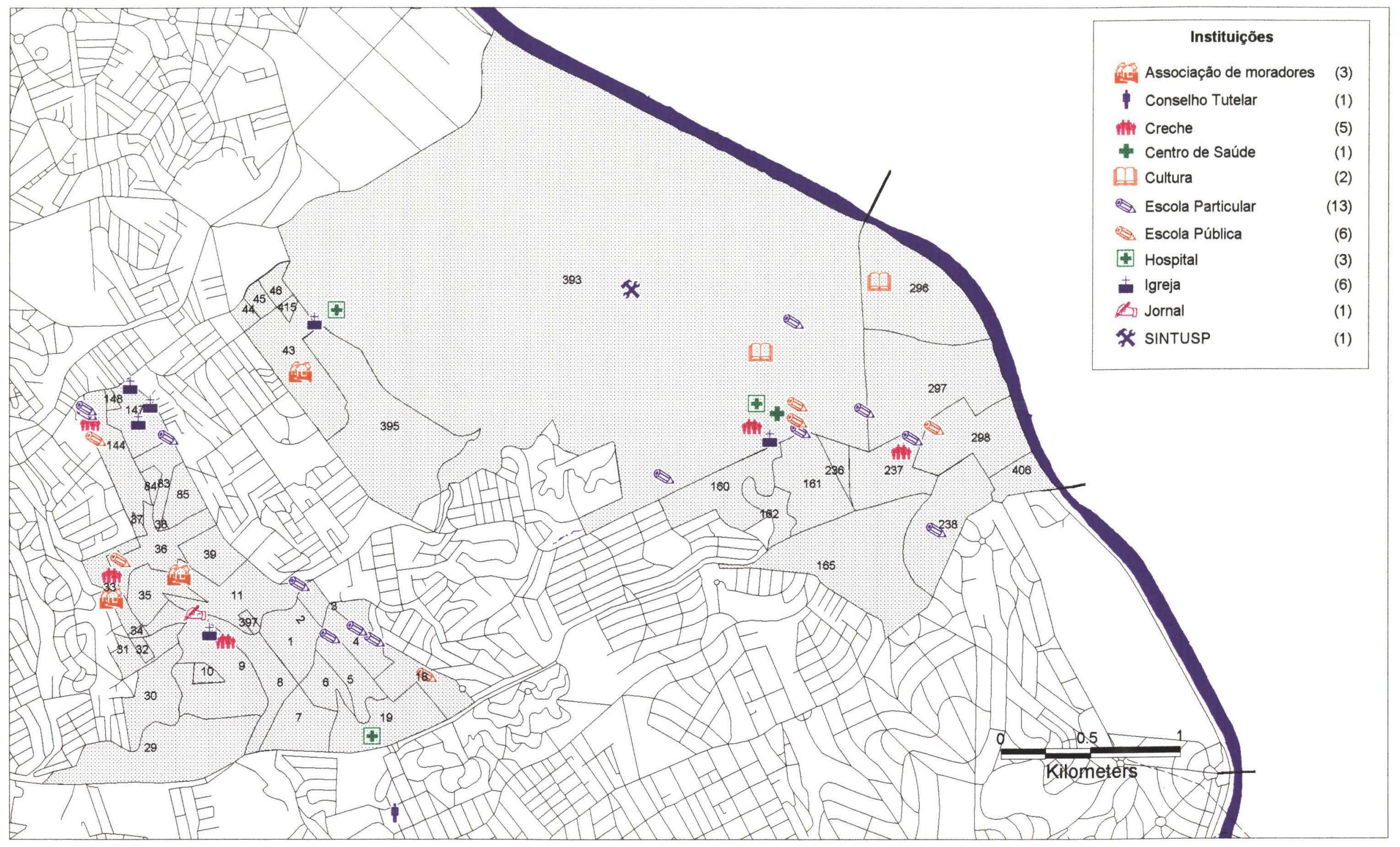

Mapa 7 - Principais instituições da área de abrangência do Centro de Saúde Escola " Samuel B. Pessoa", Butantã, 1999. Fnnte: PROIFTn RITTANTÃ 199 ? 
Conforme pode ser observado. a região onde se desenvolveu o presente estudo engloba parcialmente os distritos do Butantã e do Rio Pequeno. e conta com diversas instituiçòes e orgarizações locais, que constituem um cenário favorável para a implementação de estratégias de Promoção a Saúde. A proposição de escolas promotoras de saúde pode ser ampliada para as creches saudáveis. envolvendo tecnicos. associações de moradores e a população como um todo em processos de discussão e elaboração de alternativas. Trata-se de uma instância privilegiada para o desenvolvimento de processos educativos que recuperem as condiçòes de risco analisadas, promovendo espaços de reflexão. inclusive para desmistificar algumas práticas que acabam prejudicando o desenvolvimento da criança.

Outra instância de extrema importància no desencadeamento deste processo é o jornal do bairro, que circula quinzenalmente. Neste já existe um espaço reservado para a divulgação de temas sobre saúde, atualmente assumido por profissionais do Centro de Saúde Escola Prof. Samuel B. Pessoa. O envolvimento desse veículo de comunicação pode significar uma possibilidade de incrementar as discussões sobre as ações de Promoção à Saúde.

Outra alternativa importante para o enfrentamento das IRA relaciona-se ao controle das condições ambientais na região, principalmente através de ações que enfoquem o controle da poluição ambiental decorrente do alto fluxo de veículos, além da reorganização dos serviços de saúde para ampliar os espaços de discussão sobre as causas dos problemas encontrados, aliada à melhor capacitação do conjunto de profissionais para deteç̧ão e tratamento precoce das crianças, a reorganização dos serviços prestados pelas creches para que possam melhor atender o conjunto de necessidades da população que se constitui na sua demanda.

O diagnóstico local do Municipio de São Paulo com relação aos problemas ambientais, revela que a região do Butantã integra uma das três áreas críticas de poluição do ar, além de possuir áreas inundáveis. A percepção da população revelou uma grande preocupação com esse fenômeno indicando quase sempre a diminuição 
da circulação de veículos para o controle do problema. Pode-se considerar que ja existe uma proximidade muito positiva entre o olhar dos técnicos e dos moradores sobre a existència deste problema. sendo desejável uma maior articulação local para dar seguimento aos prog̣ramas permanentes de controle da emissão de poluentes que ja existem Com exceçào do rodizio de veiculos que foi mencionado pelos entrevistados. não foram destacados outros programas de controle da qualidade do ar. tais como politicas de transporte coletivo e anel viário. indicando a necessidade de maior divulgação para ampliar a informação e. até mesmo, para envolver um maior numero de pessoas e instituições

Um outro ponto que merece destaque e a atenção à Saude da Criança, que apesar de se configurar em modalidade de atendimento ja consolidada pelos serviços de saude. carece atualmente de novas propostas de atenção para enfrentar os "velhos" e os "novos" problemas de saude que acometem a população infantil. Nesse sentido. a intersetorialidade é apropriada, pois busca aproximar os diversos outros setores da sociedade com vistas a aprimorar as ações voltadas para as condiçōes geradoras dos problemas (SUCUPIRA, 1998)

Segundo JUNQUEIRA (1998). o conceito de intersetorialidade surgiu como uma perspectiva de solução integrada dos problemas vividos pela população, decorrentes da incapacidade de superação pelas politicas setoriais fragmentadas. As mudanças necessárias incluem a aproximação dos responsáveis pelas diferentes instituiçōes e a leitura das necessidades do coletivo

"Nessa lógica, a escola não se limita ao ensino. O serviço de saúde não se limita ao atendimento das intercorrências ou ações preventivas. $\mathrm{O}$ ginásio de esponte não se limita a oferecer seu espaço e equipamentos Cada serviço sediado numa dada comunidade compõe uma rede de ação social. Essa rede deve articular-se para identificar os problemas e encaminhar soluções integradas" (JUNQUEIRA, 1998 p. 19)

O fortalecimento da ação intersetorial, no entanto, esbarra em condições politicas propicias pois é fundamental a revisão do papel das instituições promotoras 
de politicas públicas tendo em vista a promoçào da eqüidade e a integralidade no atendimento ao cidadào

Verificou-se ainda que as ações de Promoçào à Saúde c'everiam contemplar a flexibilizaçào do trabalho feminino para que seja possivel compatibilizar a permanència no trabalho e a maternidade, bem como a ampliação e estrutura da rede de creches e a revisâo do seu funcionamento. no sentido de criar espaços que permitam cuidar da criança de forma mais permanente. E necessário ainda fomentar o aspecto da comunicação e o diálogo no atendimento nas instituições de saúde e nas creches. A flexibilizaçào das instituiçòes requer açôes integradas e o reconhecimento das diferentes necessidades da clientela.

Ja no àmbito do setor saude. entende-se que as mudanças incluem a revisão do modelo assistencial dentre outras já mencionadas na discussão deste estudo. Há necessidade de maior valorização da estrategia da atenção primária, cujo foco de atuação deve ser voltado predominantemente para o coletivo. As açôes oferecidas pelos serviços deveriam incorporar espaços voltados para a orientação, de forma rotineira Nesse sentido, coloca-se a estratégia de controle das doenças prevalentes na infância. AIDPI, primeiramente pelo enfoque integral da criança ao invés da doença, e tambem. pelo destaque dado à capacitaçâo dos profissionais para assumirem as orientações no cotidiano do seu trabalho buscando dar conta das necessidades da clientela. Outro aspecto, também relevante no àmbito do setor saúde, é o desenvolvimento de ações extra-muros às Unidades Básicas de Saúde, principalmente para os segmentos identificados como vulneráveis, os quais evidentemente são os que carecem de maior prioridade

Outro aspecto igualmente importante para viabilizar as mudanças necessárias diz respeito a participação comunitária. WESTPHAL (1997) propõe que esta seja entendida como um processo que leve a parceria, no sentido da aproximação entre as autoridades públicas e a coletividade organizada. 
Segundo FREIRE (1996), a participação comunitária só pode ocorrer a partir da descentralização do poder das instituições públicas. Essas devem flexibilizar as estruturas administrativas para permitir a maior participaçào da população que se utiliza dos serviços prestados. Mais uma vez, portanto, depara-se com a questão do poder institucional que precisa ser revisto para incorporar as mudanças com vistas à promoçào da equidade 
Conchusão 


\section{CONCLUSÃO}

A opção metodológica adotada neste estudo atendeu à finalidade anteriormente delimitada, possibilitando o conhecimento das necessidades da população residente na área de abrangência do centro de Saúde Escola Prof. Samuel B. Pessoa, relativas ao controle dos agravos respiratórios na infância. Foi também possivel obter elementos que instrumentalizam o planejamento das ações de Promoção e Educação à Saúde em nivel local. Os objetivos previstos foram atendidos, destacando-se a seguir cada etapa realizada

Com relação ao primeiro objetivo, entende-se que o uso de indicadores compostos e a construção do Índice de Potencial de Exposição às Condições de Risco para os Agravos Respiratórios permitiram a visualização geográfica das áreas de maior e menor privação no território, evidenciando grupos homogêneos prioritarios para a formulação de ações específicas. Entende-se que a presente investigação poderá auxiliar a realização de outros estudos sobre morbidade dos diferentes grupos homogêneos, semelhante à investigação realizada por ISSLER et al. (1996), aprimorando-se os indicadores construidos neste processo, para que o método descrito possa ser reproduzido em outros contextos subsidiando o planejamento local.

Neste sentido, destaca-se que as técnicas de geo processamento abriram um proficuo campo para o desenvolvimento de outras pesquisas, não somente no âmbito da saúde infantil, nem tampouco circunscrito à área da saúde, constituindo um excelente instrumento para a aproximação de diferentes setores responsáveis por políticas públicas em dada realidade. A esse respeito destaca-se a importância da participação de outros atores sociais no processo investigativo, o que efetivamente pode incentivar futuras articulações intersetoriais, contribuindo para envolver outros setores no debate sobre os determinantes das condições de saúde.

No tocante ao segundo objetivo, relativo ao conhecimento das mediações simbólicas dos diferentes grupos homogêneos a respeito da vivência do adoecimento 
por IRA, considera-se que a realização das entrevistas domiciliares permitiram uma conhecimento bastante abrangente acerca da temática em foco. Pôde-se identificar sobretudo, as percepções sobre os determinantes dos agravos, as dificuldades e facilidades encontradas no decorrer do adcecimento bem como os encaminhamentos possíveis sugeridos para a diminuição do problema estudado; apontados pelos diferentes grupos homogêneos. Nesta fase, puderam ser evidenciados os aspectos relativos à menor capacidade dos grupos mais vulneráveis, de controlar os processos doentios que acometem as crianças.

Em relação ao terceiro objetivo, relativo à identificação das iniqüidades, foi construído um esquema referencial que auxiliou a sistematização dos dados obtidos nas etapas anteriores, baseando-se principalmente no conceito de vulnerabilidade e nas dimensões da realidade. Com isso, pôde-se evidenciar as diferenças entre os grupos que configuram as iniqüidades, destacando-se os aspectos os aspectos evitáveis e socialmente injustos dessas diferenças

Dado que o campo da Promoção à Saúde deve priorizar o enfrentamento das iniqüidades com vistas a melhorar a qualidade de vida, considera-se que o presente estudo contribuiu para a operacionalização do referido conceito com a proposição metodológica adotada.

A superação das iniqüidades identificadas reforça as estratégias delineadas no âmbito da Promoção à Saúde, destacando-se o fortalecimento da ação intersetorial, o desenvolvimento de trabalhos junto aos individuos ou grupos, estruturados a partir da perspectiva de "empowerment", e a incrementação de políticas públicas saudáveis relativas ao meio ambiente. A concretização dessas estratégias, no âmbito local, envolve a flexibilização das instituições promotoras de politicas públicas, o engajamento dos setores organizados da população, a maior utilização dos meios de comunicação local para estimular esse processo bem como a formulação de ações afirmativas voltadas para a correção das discriminações percebidas. 
Em sintese. considera-se que o estudo realizado contribuiu para evidenciar que o alcance da eqüidade e possivel, reiterando-se o potencial de fortalecimento do nivel local enquanto espaço de resistència aos processos destrutivos decorrentes da subordinação cultural e econòmica. Com isso. a Promoção à Saúde. assumindo o seu desafio crucial de promover a equidade, podera contribuir para a melhoria da qualidade de vida almejada para o próximo seculo. 
Referências Bibliográficas 


\section{REFERÊNCIAS BIBLIOGRÁFICAS}

Adorno RC, Castro AL. O exercício da sensibilidade: pesquisa qualitativa e a saúde como qualidade. Saúde e Sociedade 1994; 3 (2): 172-85.

Akerman M, Campanário P, Maia PB. Saúde e meio ambiente: análise de diferenciais intra-urbanos. Município de São Paulo. Brasil. Rev. Saúde Pública. 1996; $30(4): 373-82$.

Akerman M, Massei W, Cabral S, Broch A. Premonesi A. Alves TS, Srichenbruder MT. A concepção de um projeto de observatório de qualidade de vida: relato de uma experiência realizada em Campinas SP. Saúde e Sociedade. 1997; 6 (2): 83-99.

Akerman M. Metodologia de construção de indicadores compostos: um exercício de negociação intersetorial In: Barata RB, organizador. Condições de Vida e Situação de Saúde. Rio de Janeiro: ABRASCO. 1997 p. 95-113.

Amaral JJF. Menezes AMB. Halpern R. Victora CG, Barros FC. Prevalência e fatores de risco para infecção respiratória aguda em crianças aos seis meses de vida em Pelotas. RS. In: Benguigui Y. editor. Investigações Operacionais sobre o Controle das Infecções Respiratórias Agudas (IRA). Washington (DC): Organização Panamericana da Saúde/Organização Mundial da Saúde (Série HCT/AIEPI-2); 1997. p. 85-97.

Ammann SB. Ideologia do desenvolvimento de comunidade no Brasil. São Paulo: Cortez. 1985.

Arroyo M. Território. Cidadania e produção social de saúde na cidade. [encarte]. Rede IDA.. $1995: 18$. 
Ayres JRCM, França Júnior I, Calazans GJ. AIDS, vulnerabilidade e prevenção. In: II Seminário Saúde Reprodutiva em tempos de AIDS; 1997 mar 13-15; Rio de Janeiro, Brasil. Rio de Janeiro: Associação Brasileira Interdisciplinar de AIDS, Programa de Estudos e Pesquisa em Gênero, Sexualidade e Saúde-IMS/UERJ; 1997, p.20-37.

Badinter E. Um amor conquistado: o mito do amor materno. Rio de Janeiro: Nova Fronteira, 1985.

Barata RCB, Waldman EA, Moraes JC, Guibu IA. Rossov T Takimoto S. Gastroenterites e infecções respiratórias agudas em crianças menores de 5 anos em área da região Sudeste do Brasil. 1986-1987. I - Infecções Respiratórias Agudas. Rev. Saúde Pública. 1996; 30 (6): 553-63.

Bardin L. Análise de conteúdo. Lisboa: Persona. 1988.

Basch CE. Focus group interview: an underutilized technique for improving theory and practice in health education. Health Educ. Q. 1987; 14 (4): 411-48.

Benguigui Y. Controle das Infeç̧ões Respiratórias Agudas nos Sistemas Locais de Saúde (SILOS). Washington (DC): Organização Panamericana da Saúde: 1995.

Benguigui $Y$. Antuñano FJL. Schmunis G. Yunes J. Infecções respiratórias em Crianças. Washington (DC) : Origanização Panamericana da Saúde / Organização Mundial da Saúde: 1998 (Série HCT / AIEPI - 1.P)

Bertolozzi MR. Gomes MF. Chiesa AM, Veríssimo MDLOR. Sigaud CHS et al. Identificação de marcadores que definem situações de risco para infecções respiratórias agudas em crianças. Projeto de Pesquisa. São Paulo: 1998. 
Bertolozzi MR. A Adesão ao Programa de Controle da Tuberculose no Distrito Sanitário do Butantã, São Paulo. São Paulo; 1998. [Tese de Doutorado Faculdade de Saúde Pública da USP].

Boltanski l. As classes sociais e o corpo. 2 ed. Rio de Janeiro: Graal. 1984.

Borrel C. Métodos utilizados no estudo das desigualdades sociais em saúde. In: Barata RB, organizador. Condições de Vida e Situação de Saúde, Rio de Janeiro: ABRASCO; 1997. p.167-95.

Borrero I . Fajardo L. Infecciones Agudas del aparato respiratorio en una cohorte natal de niños hasta 17 meses de vida: Cali, Colombia. In: Organización Panamericana de la Salud/ Organizacion Mundial de la Salud. Neumonía y otras infecciones respiratorias en niños: una bibliografia sectiva anotada. Washington (DC): OPAS: 1993. p.4, v.I.

Brasil. Ministério da Saúde. Coordenação Materno - Infantil. Assistência e Controle das Infecções Respiratórias Agudas: Manual de Normas. Brasília (DF); 1994.

Bruschini C. Desigualdades de Gênero no mercado de trabalho brasileiro: o trabalho da mulher no Brasil e nas regiões Nordeste e Sudeste na década de oitenta. In: Ligogcki MSL. Libardoni M. Discriminação positiva Ações afirmativas: em busca da igualdade. São Paulo: CFEMEA/ELAS: 1996. p. 87-118.

Buss PM. Ignara RM. Promoção de Saúde: um novo paradigma mundial para Saúde [Introdução]. In: Ministério da Saúde. Promoção da Saúde: Carta de Otawa, Declaração de Adelaide, Sundsvall e Santa Fé de Bogotá. Tradução de LE Fonseca. Brasilia: 1996.

Campos GWS. Merhy EE. Nunes ED. Planejamento sem normas. São Paulo: HUCITEC. 1994. 
Cappelin P. Ações afirmativas: uma estratégia para corrigir as desigualdades entre homens e mulheres. In: Ligogcki MSL, Libardoni M. Discriminação positiva Ações afirmativas: em busca da igualdade. São Paulo: CFEMEA/ELAS; 1996. P.13-31.

Cardoso MR. A Indoor environmental risk factors for lower respiratory diseases in young children in São Paulo, Brazil. Londres; 1997. [Tese de Doutorado University of London].

Carneiro-Sampaio MMS, Grumach, AS, D’Agostini M, Kaihami HN, Jorge IMGM, Camargo MMA et al. Tratamento global da criança asmática no período intercrítico. Jornal de Pediatria. 1984; 58 (3):115-31.

Castellanos PL. Sistemas Nacionales de Vigilancia de Salud segun condiciones de vida y del impacto de las acciones de salud y bienestar. Proyecto OPAS, 1991.

Castellanos PL. Epidemiologia. Saúde Pública. Situação de Saúde e Condições de Vida: considerações conceituais. In: Barata RB. organizador. Condições de Vida e Situação de Saúde. Rio de Janeiro: ABRASCO, 1997a. p.31-75.

Castellanos PL. Perfis de Mortalidade. Nível de Desenvolvimento e Iniqüidades Sociais na Região das Américas. In: Barata RB et al.. organizadores. Eqüidade e Saúde: Contribuições da Epidemiologia. Rio de Janeiro: FIOCRUZ/ ABRASCO. Série Epidemiológica I. 1997b. p.137-60.

Centers for Disease Control. World Health Organization. Epilnfo 6 [Programa de computador]. Versão 6.02. Atlanta: WHO: 1994.

Cesar CLG. Westphal MF. Cardoso MRA. Costa MZA, Gattas VL.. Morbidade referida e utilização de serviços de saúde em localidades urbanas brasileiras: metodologia. Rev. Saúde Pública.1996: 30(2):153-60. 
Charaly MD. Resultados de Estudos Etonográficos em relação ao controle das IRA na Bolívia. In: Benguigui Y, Antunãno FJL, Schmunis G, Yunes J. Infecções Respiratórias em crianças. Washington (DC): Organización Panamericana de la Salud (Série HCT/AIEPI- 1.P); 1998. p.383-408.

Chatkin JM , Molinari JF. Estudo de óbitos infantis por pneumonias através de inquérito domiciliar. In: Benguigui $\mathrm{Y}$, editor. Investigações Operacionais sobre o Controle das Infecçōes Respiratórias Agudas (IRA). Washington (DC): Organização Panamericana da Saúde/Organização Mundial da Saúde (Série HCT/AIEPI-2); 1997. p. 41-59.

Chiesa AM. Bertolozzi MR. Estudo epidemiológico da mortalidade por infecções do aparelho respiratório em menores de cinco anos da região do Butantã - São Paulo. Brasil. In: Benguigui Y, editor. Investigações Operacionais sobre o Controle das Infeçẽes Respiratórias Agudas (IRA). Washington (DC): Organização Panamericana da Saúde/Organização Mundial da Saúde (Série HCT/AIEPI-2); 1997. p. 19-29.

Cocco MIM. A ideologia da enfermeira: prática educativa em saúde. Campinas, 1991. [Dissertação de Mestrado - Faculdade de Educação da Universidade Estadual de Campinas].

Cohn A. Nunes E. Jacobi PR. Karsch US. A saúde como direito e como serviço. São Paulo: Cortez CEDEC. 1991.

Cohn A. Desenvolvimento Social e Impactos na Saúde. In: Barata RB. organizador. Condições de Vida e Situação de Saúde.Rio de Janeiro:ABRASCO. 1997. p. 77 93.

Companhia de Tecnologia de Saneamento Ambiental. Relatório de Qualidade do Ar no Estado de São Paulo. 1995 : 1996. São Paulo: 1996. 
Costa NP, Campos SO. Infecções recorrentes das vias aéreas superiores. Pediatria Moderna. 1993; XXIX(6):779-90.

Dalmaso ASW, Sala A. Senna. DM. Adscrição da população e recepção da clientela. In: Scraiber LB, Nemes, MIB; Mendes-Gonçalves, RB, organizadores. Saúde do Adulto: programas e ações na unidade básica. São Paulo:HUCITEC, 1996. p. 194-208.

Di Nicola P. Las dimensiones socioculturales en las prácticas relativas a la salud. In: Donati P. Manual de Sociologia De La Salud. Madrid, Diaz de Santos; 1994. p.3347.

Dahlgren G, Whitehead M. Policies and strategies to promote equity in health Copenhagen: World Health Organization/ Regional Office for Europe; 1992.

Dowbor L. Da globalização ao poder local: a nova hierarquia dos espaços. In: Freitas MC., organizador. A reinvenção do futuro. São Paulo:Cortez/ USF, 1996. p. 55-75.

Egry EY. Saúde Coletiva: construindo um novo método em Enfermagem. São Paulo: Ícone: 1996.

Ejzenberg B. Considerações sobre a Etiologia da Pneumonia Infantil [ensaio], Rev. Paul. Pediatria.1995; 13(1):20-3.

Flecha R. As novas desigualdades educativas. In: Castells M. Flecha R. Freire P. Giroux H. Macedo D. Willis P. Novas perspectivas críticas em Educação. Porto Alegre: Artes Médicas: 1996. p. 33-52.

Freire P. Extensão ou comunicação. 9"ed., São Paulo: Paz e Terra: 1988. 
Freire P. Educação e Participação Comunitária. In: Castells M, Flecha R, Freire P, Giroux H, Macedo D, Willis P. Novas perspectivas críticas em Educação. Porto Alegre: Artes Médicas; 1996. p. 53-61.

Freitag B. Habermas e a Filosofia da Modernidade. Perspectivas. 1993; 16: 23-45.

Fonseca W, Kirkwood BR, Victora CG, Fuchs SR, Flores JÁ, Misago C. Fatores de risco para pneumonia em menores de dois anos de idade em Fortaleza, Brasil: um estudo de casos e controles. In Benguigui $\mathrm{Y}$, editor. Investigações Operacionais sobre o Controle das Infeç̧ões Respiratórias Agudas (IRA). Washington (DC): Organização Panamericana da Saúde/Organização Mundial da Saúde (Série HCT/AIEPI-2); 1997. p. 71-84.

Fundação SEADE. Pesquisa de condições de vida na região Metropolitana de São Paulo, São Paulo; 1992.

Fundo das Nações Unidas para a Infầncia/Fundação Instituto Brasileiro de Geografia e Estatística (UNICEF/IBGE). Municípios brasileiros: crianças e suas condições de sobrevivência. Brasilia: UNICEF; 1994

Fundo das Nações Unidas para a Infầncia/Fundação Instituto Brasileiro de Geografia e Estatística (UNICEF/IBGE). Comemorando os avanços na área da saúde infantil no Brasil. Brasilia: UNICEF; 1998. p. 42-43.

Giroux H. Pedagogia Radical. São Paulo: Autores Associados/ Cortez; 1983.

Glik D, Gordon A. Ward W. Kouame K, Guessan M. Focus group methods for formative research in child survival: an Ivorian example. Int. Quarterly of Community Health Education. 1987-88; 8 (4):297- 316. 
Goldbaun M. A epidemiologia em busca da eqüidade em saúde. In : Barata RB, Barreto ML, Almeida Filho N, Veras RP. Eqüidade e saúde. Contribuições da epidemiologia. Rio de Janeiro : FIOCRUZ/ABRASCO; 1997. P. 63-80.

Gomes FMS, Valente MH, Margarida Filho H, Paes EC, Tanaka CM, Passos LD et al. Incidência de Infecções Respiratórias Agudas em Crianças do Centro de Saúde Escola "Professor Samel B. Pessoa", São Paulo, Brasil. In: Benguigui Y, editor. Investigações Operacionais sobre o Controle das Infecções Respiratórias Agudas (IRA). Washington (DC): Organização Panamericana da Saúde/Organização Mundial da Saúde (Série HCT/AIEPI-2); 1997. p. 9-17.

Green LW, Kreuter MW. Health Promotion Planning: an educational and environmental approach. Mountain View: Mayfield Publishing Company; 1991.

Hansen EJ. Explanations of social inequality: an approach to the problem. (mimeografado)

Issler RMS, Giugliani ERJ. Kreutz GT. Meneses CF. Justo EB. Kreutz VM e Pires M. Poverty levels and children`s health status: study risck factors in an urban population of low socioeconomic level Rev. Saúde Pública. 1996; 30 (6): 506-11

Jacobi P. Habitat e Saúde na Periferia. São Paulo em Perspectiva. 1990; 4(3/4): $121-30$

Junqueira LAP. Descentralização e intersetorialidade : a construção de um modelo de gestão municipal. RAP. 1998: 32(2) : 11-22

Kadt E. Tasca R. Promovendo a equidade: um novo enfoque com base no setor da saúde. São Paulo/Salvador: HUCITEC/Cooperativa Italiana em Saúde. 1993.

Kawachi I et al. Social Capital. Income Inequality and Mortality. Am. Journal of Public Health. 1997; 87(9):1491-98. 
Kishi HS, Saldiva PHN. Associação entre poluição atmosférica e internações pediátricas por causas respiratórias na cidade de São Paulo. Rev. Med. 1998; 77 (1): 2-10.

Kunst AE, Mackenbach JP. Measuring socioeconomic inequalities in health. Copenhagen. WHO/Regional Office for Europe, 1995.

Leowski J. Mortalidad por infecciones respiratorias agudas en niños menores de 5 años de edad: estimaciones globales. In: Organización Panamericana de la Salud/ Organizacion Mundial de la Salud. Neumonía y otras infecciones respiratorias en niños: una bibliografia sectiva anotada. Washington (DC): OPAS; 1993. p. 13, v.I.

Map Info Professional [Programa de computador]. Versão 4.1. New York: MapInfo Corporation; 1985-1996.

Martins MG. coordenador. Primórdios e Atualidades da Região do Butantã. Pesquisa destinada à realização do documentário “Os caminhos do Butantã”. São Paulo, 1995-1996.(mimeo)

Mendes EV.. Importância de los sistemas locales de salud en la transformacion de los sistemas nacionales de salud. In: Paganini JM. Capote Mir R. Los Sistemas Locales de Salud: conceptos, métodos, experiencias. Washington (DC): OPS (Publicacion Cientifica 519); 1990, p.21-8.

Mendes EV. organizador. Distrito Sanitário : o processo social de mudança das práticas sanitárias no Sistema Único de Saúde. São Paulo/Rio de Janeiro : HUCITEC/ABRASCO; 1995. p. 221-235

Mendes. EV. Aula proferida no curso de pós graduação de Enfermagem em Saúde Coletiva da EEUSP. São Paulo. 21/08/96 
Mendes-Gonçalves RB. Práticas de Saúde: processos de trabalho e necessidades. São Paulo: CEFOR; 1992.

Mendes-Gonçalves RB. Tecnologia e organização social das práticas de saúde: características tecnológicas do processo de trabalho na rede estadual de centros de saúde de São Paulo. São Paulo: HUCITEC; 1994.

Minayo MCS. O desafio do conhecimento: pesquisa qualitativa em saúde. $2^{\mathrm{a}} \mathrm{ed}$. São Paulo/Rio de Janeiro: Hucitec/ABRASCO;1993; p. 269.

Ministério da Saúde. Coordenação Materno-Infantil. Assistência à criança com Infecção Respiratória Aguda : Módulo I. Brasília (DF); 1997.

Ministério da Saúde. Promoção da Saúde: Carta de Otawa, Declaração de Adelaide, Sundsvall e Santa Fé de Bogotá. Tradução de LE Fonseca. Brasília; 1996.

Monteiro CA. Rea M. O aleitamento materno. In: Monteiro CA, Saúde e Nutrição das crianças de São Paulo. São Paulo:HUCITEC/EDUSP, 1988. p.55-70.

Monteiro CA. Benício MHD'A. Estudo das Condições de Saúde das Crianças do Município de São Paulo, SP (Brasil), 1984-1985. VI Doença Respiratória. Rev. Saúde Pública. 1987; 21(5):380-86.

Monto AS. Ullman BM. Enfermedad respiratoria aguda en una comunidad americana: el estudio Tecumesh. In: Organización Panamericana de la Salud/ Organizacion Mundial de la Salud. Neumonía y otras infecciones respiratorias en niños: una bibliografia sectiva anotada. Washington (DC): OPAS; 1993. p. 9, v.I.

Motta RS. Mendes APF. Custos de saúde associados à poluição do ar no Brasil. Pes.Plan.Econ. 1995: 25 (1):165-98. 
Musgrove P. Mesurement of Equity in Health. Wld HIth Statist. Quart. 1986; 39: $325-35$

Niobey FML, Duchiade MP, Vasconcelos AGG, Carvalho ML, Leal MC, Valente JG. Fatores de risco para morte por pneumonia em menores de um ano em uma região metropoliatana do sudeste do Brasil. Um estudo tipo caso-controle. Rev. Saúde públ. 1992; 26 (4) : 229-38.

Nwokedi J. Equity in health. Promotion \& Education. 1998; V (3/4): 13-17.

Organización Panamericana de la Salud/Organización Mundial de la Salud. Programa Especial de Salud materno-Infantil y Población. Control de las Infecciones Respiratórias Agudas: Bases Técnicas para las Recomendaciones de la OPS/OMS. Equador-Quito:OPAS/OMS; 1993.

Organización Panamericana de la Salud. Diálogo sobre Atención Infantil. Primera reunión global de AIEPI. 1997. OPAS; Cidade: 2. p. 4.

Organización Panamericana de la Salud. Reunión de evaluación y planificación del prjecto USAID/LCAC - OPS - BASICS: La atención integrada a las enfermedades prevalentes de la infancia (AIEPI) en paises de America Latina. Washington (DC): OPAS (Série HCT/AIEPI-12). 1998.

Oshiro JH. Educação para a saúde nas instituições de saúde. São Paulo; 1988. [Dissertação de Mestrado - Pontificia Universidade Católica de São Paulo].

Paganini JM. Capote Mir R. Los Sistemas Locales de Salud: conceptos, métodos, experiencias. Washington (DC): Editora (Publicacion Científica 519); 1990.

Paim. JNA. A reorganização das práticas de saúde em Distritos Sanitários. In: Mendes EV, organizador. Distrito Sanitário processo social de mudança das 
práticas sanitárias do SUS. São Paulo - Rio de Janeiro:HUCITEC/ABRASCO; 1995. p.187-220.

Paim, JS. Abordagens teórico-conceituais em estudos de condições de vida e saúde: notas para reflexão e ação. In: Barata RB, organizador. Condições de Vida e Situação de Saúde. Rio de Janeiro: ABRASCO, 1997. p. 7-30.

Queiroz VM, Salum MJL. Operacionalizando a Heterogeneidade do Coletivo na Releitura da Categoria Reprodução Social. 1997. (mimeografado)

Rezende MA. Amamentação e trabalho na Escola de Enfermagem da USP - um estudo sobre representações sociais. São Paulo; 1998. [ Tese de Doutorado Escola de Enfermagem da USP].

Ribeiro HP et al. Estudo das correlações entre infecções das vias aéreas superiores, bronquites asmatiformes e poluição do ar em menores de 12 anos em Santo André. Pediat Prat.1971;42(9).

Robertson A. Minkler M. New Health Promotion Movement: a critical examination. Health Education Quarterly. 1994; 21 (3):295-312.

Rocha SMM. A puericultura e a enfermagem no estado de São Paulo. Ribeirão Preto. 1985. [Tese de doutorado - Escola de Enfermagem de Ribeirão Preto da USP].

Rolnik R. A cidade e a Lei : legislação, política urbana e territórios na cidade de São Paulo. São Paulo: FAPESP/Studio Nobel: 1997.

Saldiva PHN. Lichtenfels AJFC. Paiva PSO. Barrone IA. Martins MA. Massad E et al. Association between Air Pollution and Mortality Due to Respiratory Diseases in Children in São Paulo. Brazil: a preliminary report. Environmental Research. 1994; 65:218-25. 
São Paulo (Estado). Lei 9358 de 13 de junho de 1996. Autoriza o Poder Executivo implantar o Programa de restrição à circulação de veículos automotores na Região Metropolitana de São Paulo. Diário Oficial do Estado, São Paulo, 27 julho 1996, Seção 1, p.2.

São Paulo (Prefeitura). Agenda 21 Local, compromisso do Município de São Paulo. Resolução 17/96 do Conselho Municipal de Meio Ambiente e Desenvolvimento Sustentável (CADE). Diário Oficial do Município de São Paulo, São Paulo, 6 ago 1996.

São Paulo (Prefeitura). Projeto Butantã. São Paulo, 1992.

Santos M. Técnica, Espaço, Tempo: globalização e meio técnico-científico informacional. São Paulo:HUCITEC;1994.

Santos M. Souza MAA, Silveira ML, organizadores. Território: globalização e fragmentação. São Paulo:HUCITEC/ANPUR; 1994.

Schraiber LB. Mendes-Gonçalves, RB. Necessidades de Saúde e Atenção Primária. In: Schraiber LB. Nemes MIB, Mendes-Gonçalves RB, organizadores. Saúde do Adulto: programas e ações na unidade básica. São Paulo:HUCITEC. 1996. p.2947.

Silva MAF. Situação do Controle e Assistência das Infecções Respiratórias Agudas (IRA) no Brasil. Brasília (DF): Comissão Materno Infantil do Ministério da Saúde. 1996. (Mimeografado).

Souza MFM. Kalichman AO. Vigilância à saúde: epidemiologia. serviços e qualidade de vida. In: Souza MFM. Vigilância à Saúde : Textos. São Paulo: Cadernos do CEFOR (série textos) 2. 1992. 
Sposati A, coordenadora. Mapa da Exclusão/Inclusão Social da Cidade de São Paulo. São Paulo:Educ; 1996.

Sucupira ACSL. Repensando a atenção à saúde da criança e do adolescente na perspectiva intersetorial. R.A.P. 1998; 32 (2): 61-78.

Teixeira CF. Planejamento e programação situacional em distritos sanitários: metodologia e organização. In: Mendes EV, organizador. Distrito Sanitário: o processo social de mudança das práticas sanitárias no Sistema Único de Saúde. São Paulo/ Rio de Janeiro:HUCITEC/ABRASCO, 1995. p.237-65.

Tones K. Health promotion, empowerment and action competence. In: Jensen BB, Schnack K. Action and Action Competence. Didaktiske studier, 1994, p. 163-183.

Triviños ANS. Introdução à pesquisa em ciências sociais: a pesquisa qualitativa em educação. São Paulo:Atlas;1995. p.175 .

Unglert CVS. Territorialização em sistemas de saúde. In: Mendes EV, organizador. Distrito Sanitário: o processo social de mudança das práticas sanitárias no Sistema Único de Saúde. São Paulo/ Rio de Janeiro:HUCITEC/ABRASCO, 1995. p.221-35.

Unglert CVS. Territorialização em Saúde: a conquista do espaço local enquanto prática do planejamento ascendente. São Paulo; 1995. [Tese de Livre-Docência Faculdade de Saúde Pública da USP].

Universidade de São Paulo. Fique por dentro da USP : informações gerais para os novos funcionários da USP. 1997

Victora CG, Fuchs S; Flores JAC. Fonseca W. Kirkwood B, Risk factors for Pneumonia among children in a Brazilian area. Pediatrics. 1994; 93 (6): 977-85. 
Victora CG. Fatores de Risco nas IRA baixa In In: Benguigui Y, Antunãno FJ, Schmunis G, Yunes J. Infecções Respiratórias em crianças. Washington (DC): Organización Panamericana de la Salud (Série HCT/AIEPI- 1.P); 1998. p.43-61.

Wallerstein N, Bernstein E. Introduction to Community Empowerment, Participatory Education and Health. Health Education Quarterly. 1994; 21(2) : 141-148.

Wallerstein N, Bernstein E. Empowerment education: Feire's ideas adapted to health education. Health Education Quarterly, 1998; 15 (4): 379-94.

Wallerstein N. Empowerment Education Applied to Youth. In : Matiella MA, Editor. The Multicultural Challenge in Health Education. California. ETR Associates. Publishers. 1994; p. 153-176.

Wandalsen NF, Alterthum M. DeAgostinho J. Crises de asma brônquica em crianças: influência dos fatores meteorológicos e de alguns poluentes sobre sua ocorrência em Santo André nos anos 73 e 74. J. Pediat. 1976; 41 (15-16): p.17-26.

Westphal MF. Participação da mãe no cuidado da criança com asma brônquica. São Paulo; 1982. [Tese de Doutorado - Faculdade de Saúde Pública da USP].

Westphal MF. Carneiro-Sampaio MMS. O valor do tratamento intercrítico da criança asmática e seus aspectos educativos. Pediat . 1984; 6: 116-23.

Westphal MF. Participação popular e políticas municipais de saúde: Cotia e Vargem Grande Paulista. São Paulo: 1992. [Tese de Livre-Docência - Faculdade de Saúde Pública da USP].

Westphal MF. Bógus CM. Faria MM. Grupos focais: experiências precursoras em programas educativos em saúde no Brasil. Bol. Of. Sanit. Panam. 1996; 120 (6): $472-82$. 
Westphal MF. Recursos educativos e métodos de Avaliação e Promoção da saúde. (mimeografado); 1997.

Westphal MF. A promoção à saúde no Brasil. (mimeografado); 1998.

Whitehead M. The concepts and principles of equity and health. Copenhagen: WHO/Regional Office for Europe, 1990. 
Qnexas 


\title{
ANEXO 1
}

Definições sumárias dos agravos que constituem as Infecções Respiratórias Agudas

\begin{abstract}
Asma: é uma doença pulmonar inflamatória crônica persistente, que se caracteriza pela obstrução ou estreitamento das vias aéreas. É reversivel total ou parcialmente, sob tratamento ou espontaneamente. Além da inflamação das vias aéreas apresenta uma hiper-reatividade brônquica de diferentes graus, desencadeada por vários estímulos irritantes das vias aéreas - combustão nos motores dos automóveis, pó, fumaça de cigarro, vírus, aerossóis ou hiperventilação nos exercícios (BENGUIGUI et al., 1998).
\end{abstract}

Bronquiolite: é uma inflamação dos bronquíolos. É uma síndrome infecciosa que se apresenta inicialmente no trato respiratório superior sob a forma de coriza, rinorréia e obstrução nasal e que progride com manifestações do trato respiratório inferior, como tosse, dificuldade respiratória, retração costal, estertores grossos difusos ou roncos e sibilos (BENGUIGUI et al., 1998).

Bronquite: é uma infecção dos brônquios e em crianças de pouca idade é geralmente causada por vírus (MINISTÉRIO DA SAÚDE, 1997).

Crupe: estreitamento da laringe, da traquéia ou da epiglote que dificulta a entrada de ar nos pulmões. Pode ser causada por infecção bacteriana ou viral (MINISTÉRIO DA SAÚDE, 1997).

Epiglotite: infecção bacteriana da epiglote que pode causar crupe grave. (MINISTÉRIO DA SAÚDE, 1997)

Espasmo bronquial: contração (espasmo) dos músculos em torno das passagens de ar, estreitando-as e causando sibilância. (MINISTÉRIO DA SAÚDE, 1997)

Faringite: infecção da garganta. (MINISTÉRIO DA SAÚDE, 1997)

Faringoamigdalite bacteriana: caracterizada por dor de garganta, febre alta, hiperemia da orofaringe, hipertrofia das amígdalas com pontos purulentos, petéquias no palato mole e adenopatia cervical anterior(GOMES et al., 1997).

Laringite: infecção da laringe que causa rouquidão ou crupe. (MINISTÉRIO DA SAÚDE, 1997). 
Otite média aguda: hiperemia/opacificação e/ou abaulamento da membrana timpânica, que pode aparecer com sintomas respiratórios persistentes por mais de uma semana, irritabilidade, choro intenso, anorexia e otalgia (GOMES et al., 1997).

Pneumonia: caracterizada por febre, tosse e dispnéia, acompanhadas ou não por batimento das asas do nariz, freqüência respiratória elevada, vômitos, dor abdominal ou torácica (GOMES et al., 1997).

Resfriado comum: também chamado por gripe ou catarro comum, é a doença contagiosa viral que mais acomete o ser humano. Caracteriza-se por sintomas nasais (rinorréia, obstrução nasal, espirros) e algumas vezes por sintomas faringoamigdalianos (dor e inflamação) acompanhados de mal-estar geral e algumas vezes febre (BENGUIGUI et al., 1998).

Rinofaringite aguda: caracterizada por congestão nasal e/ou coriza hialina, espirros, tosse, anorexia e febre baixa com duração de 6 a 10 dias (GOMES et al., 1997).

Sinusite: caracterizada por sintomas intensos de rinorréia purulenta e febre elevada ou sintomas persistentes por mais de 10 dias, incluindo rinorréia, tosse seca ou com expectoração mais freqüente à noite (GOMES et al., 1997). 


\begin{abstract}
ANEXO 2
Roteiro para entrevistas do projeto : A Equidade como principio norteador da identificação de necessidades relativas ao controle dos agravos respiratórios na infầncia.

Setor:

Grupo

Rapport

Meu nome é

estou fazendo uma pesquisa aqui neste bairro, com famílias que tem crianças menores de 5 anos de idade. A responsável pela pesquisa é a professora Anna Maria Chiesa, da Escola de Enfermagem da USP e está sendo feita para podermos conhecer as dificuldades enfrentadas pelas famílias quando alguma criança está com problema respiratório como, resfriado, rinite, otite, bronquite, pneumonia, chiado. Para isto precisarei fazer algumas perguntas e gravar as suas respostas. Gostaria também de esclarecer que não serão divulgados os nomes dos participantes, garantindo o sigilo das suas informações. Levará cerca de 30 minutos. Os senhores concordam em participar?
\end{abstract}

Se não: Por quê?

Obrigada.

Se sim: Obrigada

1. Qual a composição da sua familia?

\begin{tabular}{|l|l|l|}
\hline NOME & PARENTESCO & IDADE \\
\hline & & \\
\hline & & \\
\hline & & \\
\hline & & \\
\hline & & \\
\hline & & \\
\hline & & \\
\hline & & \\
\hline
\end{tabular}


2. Há quanto tempo vocês moram neste local?

3. As crianças (citar os nomes) tiveram algumas das doenças citadas depois do Carnaval até agora ? (resfriado, rinite, otite, bronquite, pneumonia, chiado, bronquiolite, amigdalite?)

Sim. Quais?

Não

4. Na sua opinião, há alguma coisa que possa ser feita para diminuírem os problemas encontrados? Por quê?

5. O que a senhora/senhor fizeram quando isto aconteceu? Por quê?

6. Qual foi o tratamento utilizado? 
7. Quais foram as maiores dificuldades encontradas por vocês no cuidado da criança quando teve o problema? Por quê?

8. O que a Senhora/senhor acha que provocou esses problemas?

9. Vocês gostariam de mencionar mais alguma coisa que eu deixei de perguntar? 


\begin{abstract}
ANEXO 3
Procedimentos metodológicos para composição da amostra aleatória de famílias para realização
\end{abstract}

\title{
$\left.1^{\circ}\right)$ Confecção dos croquis correspondentes aos 49 setores censitários
}

- Xerocópias ampliadas dos mapas do guia da cidade de São Paulo, das páginas correspondentes a área de abrangência do Centro de Saúde Escola.

- Delimitou-se os setores censitários nestes mapas, que foram colados em folhas de papel A-4, um a um, e numerados de acordo com a numeração fornecida pelo IBGE.

\section{$\left.2^{\circ}\right)$ Sorteio dos endereços}

- Sorteio aleatório com registro das vias identificadas de um ponto qualquer da região delimitada

- Para o setor 395, o sorteio foi realizado através de papéis com os nomes das respectivas ruas que o compunham, pelo fato de que neste setor encontra-se a Cidade Universitária Armando Sales de Oliveira que foi excluída do estudo e que ocupava quase a totalidade da área deste setor, restando um número muito reduzido de ruas e, procedendo-se ao sorteio como estava sendo feito, poderia-se comprometer a aleatoriedade.

- O logradouro sorteado era então anotado nos croquis correspondentes os quais foram separados de acordo com a composição dos grupos homogêneos

- Chegando ao endereço sorteado, partia-se do início da rua, seguindo primeiro pelo lado direito, verificando em todas as casas a presença de criança de menores de cinco anos. Caso não conseguisse encontrar uma família com o perfil procurado, passavase para o lado esquerdo e depois para a próxima rua que pertencesse ao mesmo setor censitário, no sentido horário do ponto inicialmente definido. 